\title{
Annotated bibliography of peer-reviewed literature related to the sexual and reproductive health of young people in Nigeria (2000-2014)
}

Population Council

Follow this and additional works at: https://knowledgecommons.popcouncil.org/departments_sbsr-hiv

Part of the Demography, Population, and Ecology Commons, Family, Life Course, and Society Commons, Gender and Sexuality Commons, and the International Public Health Commons How does access to this work benefit you? Let us know!

\section{Recommended Citation}

Population Council. 2015. "Annotated bibliography of peer-reviewed literature related to the sexual and reproductive health of young people in Nigeria (2000-2014)." Abuja: Population Council. 
ANNOTATED BIBLIOGRAPHY OF PEER-REVIEWED LITERATURE RELATED TO THE SEXUALAND REPRODUCTIVE HEALTH OF YOUNG PEOPLE IN NIGERIA (2000-2014) COUNCIL 


\section{Popuration \\ Ideas. Evidence. Impact.}

The Population Council confronts critical health and development issues-from stopping the spread of HIV to improving reproductive health and ensuring that young people lead full and productive lives. Through biomedical, social science, and public health research in 50 countries, we work with our partners to deliver solutions that lead to more effective policies, programs, and technologies that improve lives around the world. Established in 1952 and headquartered in New York, the Council is a nongovernmental, nonprofit organization governed by an international board of trustees.

Population Council

No. 16 Mafemi Crescent

Abuja

Nigeria

Tel: +234 $98706071 ;+23498706057 ;+2348067787750$

email: info.nigeria@popcouncil.org

popcouncil.org

Suggested citation: Population Council. 2015. "Annotated bibliography of peer-reviewed literature related to the sexual and reproductive health of young people in Nigeria (2000-2014)." Abuja:

Population Council.

(C)2015 Population Council, Inc. 


\section{Table of Contents}

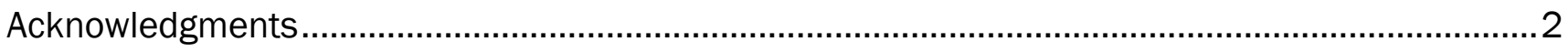

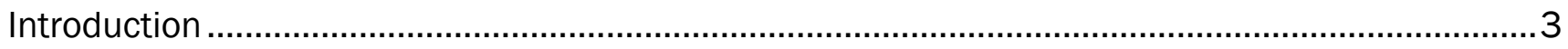

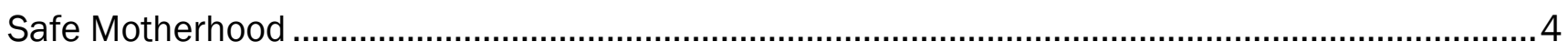

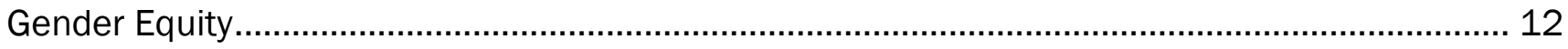

Family Planning Information and Services.................................................................. 17

Prevention and Treatment of Reproductive Tract and Sexually Transmitted Infections .............. 25

Prevention and Management of the Complications of Abortion .............................................. 83

Elimination of Harmful Customary Practices ....................................................................... 88

Screening for Reproductive Tract Cancers-Prostate, Breast and Cervix .................................. 102

Sexual Abuse, Coercion, and Violence ............................................................................ 107

Other Sexual and Reproductive Health and Rights Related Topics ....................................... 114

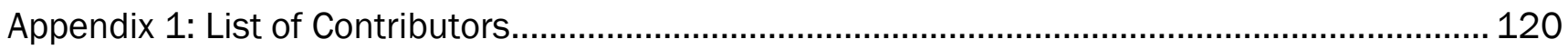




\section{Acknowledgments}

This publication was developed by the Population Council with the financial support of the Ford Foundation. Our Youth Programme Assistants, Adline Chiamaka Uzomba, and Akinola Olusegun Alalade, were instrumental to the drafting of this publication. This work is dedicated to the goal of preventing and mitigating the impact of sexual and reproductive health morbidity and mortality among youth in Nigeria and beyond. 


\section{Introduction}

The 1994 International Conference on Population and Development's Programme of Action identified eight components (safe motherhood, gender equity, family planning information and services, prevention and treatment of infertility and sexual dysfunction in both men and women, prevention and management of the complications of abortion, prevention and treatment of reproductive tract infections and sexually transmitted infections including HIV, elimination of harmful customary practices, and screening for reproductive tract cancers-prostate, breast and cervix) of sexual and reproductive health (SRH) for all persons including young people aged 10-24.

This annotated bibliography is organized with the eight components as its guiding framework with several other sections (sexual abuse, coercion, and violence; other sexual and reproductive health and rights related topics) included to provide a more comprehensive classification of published peer-reviewed literature related to the SRH of young Nigerians aged 10-24 from the time period 2000 to 2014. Literature searches utilizing PubMed, JSTOR, and Google Scholar were conducted to find the relevant publications. Of note, no articles were found pertaining to the prevention and treatment of infertility and sexual dysfunction in the desired age group. 


\section{Safe Motherhood}

Okafor, U.H., Nwobodo, M.U., \& Ezeugwu, F.O. (2013). Pregnancy in a 24 year old Nigerian woman with chronic kidney disease: challenges and outcome. Nigerian Journal of Medicine, 22(1):68-71. Article available at: http://www.ncbi.nlm.nih.gov/pubmed/23441525

This report highlights the challenges of pregnancy in women with chronic kidney disease and the possible outcome. Investigators reported the case of a 24-year-old Nigerian woman diagnosed with chronic kidney disease who presented with 10 weeks gestation and deteriorating kidney function. Her management was associated with various challenges including non-adherence to medications and irregular attendance of follow up visits. She later developed eclampsia and had intra uterine foetal death. She had various interventional measures including haemodialysis. She recovered kidney function appreciably but defaulted in her follow up after discharge.

Ago, B.U., Abeshi, S., Njoku, C., Agan, T.U., \& Ekabua, J. (2012). Obstetric outcomes of booked teenage pregnancies at University of Calabar Teaching Hospital, Nigeria.

Adolescent Health Medicine and Therapeutics, 3:105-9. Article available at: http://www.ncbi.nlm.nih.gov/pmc/articles/PMC3915793/

The purpose of this study was to determine the patterns and obstetric outcomes of booked (teenage mother had received antenatal care prior to delivery) teenage pregnancies at the University of Calabar Teaching Hospital (UCTH) in South-south Nigeria. A retrospective comparative analysis of teenage pregnancies and mature mothers at UCTH was carried out from January to December 2011. A total of 82 teenage pregnancies and 72 mature pregnancies were compared. There were 145 teenage deliveries from a total of 2,313 deliveries which was 6.3 percent of total deliveries. There was no statistically significant difference in the mode of delivery (caesarean section, spontaneous vaginal delivery, instrumental delivery) between the groups of mothers. There was also no difference in risk of complications, including obstructed labour, retained placenta, uterine atony, pre-eclampsia/eclampsia, and antepartum haemorrhage. However, teenage mothers had more perineal lacerations $(p=0.02)$ and more preterm labour $(p=0.05)$, and delivered more low-birth-weight babies $(p=0.02)$.

Amoran, O.E. (2012). A comparative analysis of predictors of teenage pregnancy and its prevention in a rural town in Western Nigeria. International Journal for Equity in Health, 11, 37. Article available at http://www.equityhealthj.com/content/11/1/37

This analytical comparative cross-sectional study was designed to determine the recent prevalence and identify factors associated with teenage pregnancy in a rural town in Nigeria. A total sample of 225 pregnant women attending the primary health care in Sagamu local government area, Ogun State, Southwest, Nigeria within a 2-month period were recruited into the study. The prevalence of teenage pregnancy was 22.9 percent $(n=56)$. Teenagers reported more unwanted pregnancy when compared with the older age group [48.2 percent vs. 13.6 percent, respectively, $\mathrm{OR}=5.91, \mathrm{C} . \mathrm{I}=2.83-12.43$ ]. About half [ 41.1 percent] of the teenage pregnant women and 28.6 percent of the older pregnant women did not know how to correctly use a condom to prevent pregnancy $[O R=0.57, C . I=0.29-1.13]$. Predictors of teenage pregnancy were low social class $(\mathrm{OR}=2.25, \mathrm{C} . \mathrm{I}=1.31-3.85]$, religion $(\mathrm{OR}=0.44, \mathrm{C} . \mathrm{I}=0.21-0.91]$, being a student $(\mathrm{OR}=3.27$, C.I $=1.02-10.46)$ and having a white collar job $(\mathrm{OR}=0.09, \mathrm{C} . \mathrm{I}=0.01-0.81)$. 
Ayuba, I.I., \& Gani 0. (2012). Outcome of teenage pregnancy in the Niger delta of Nigeria. Ethiopian Journal of Health Sciences, 22(1):45-50. Article available at: http://www.ncbi.nlm.nih.gov/pmc/articles/PMC3437979/pdf/EJHS2201-0045.pdf

This is a retrospective study performed over a period of 4 years (1 January 2007 to 31 December 2010) in Niger Delta University Teaching Hospital Bayelsa State, South-south Nigeria where data was retrieved from the hospital records. All teenage mothers (aged 13-19) who had delivery within the period were compared with 180 randomly selected deliveries in the older age group (20-32 years) over the same period. Variables of interest were the demographic characteristics of the women, their obstetric complications and the outcome. There were a total of 1,341 deliveries during the study period, out of which 83 (6.2 percent) were teenagers. Teenage mothers were significantly more likely to be unbooked (did not receive antenatal care prior to presenting for delivery) $(p=0.000)$ and unmarried; $\left(x^{2}=26.2 ; p=0.000\right)$ had significantly more preterm labour $(p=0.000)$ and caesarean sections $(p=0.014)$. However, there was no difference in both the perinatal and maternal mortality rates between the two groups.

\section{Ezegwui, H.U., Ikeako, L.C., \& Ogbuefi F. (2012). Obstetric outcome of teenage pregnancies at a tertiary hospital in Enugu, Nigeria. Nigerian Journal of Clinical Practice, 15(2):147-50. \\ Article available at: http://www.ajol.info/index.php/njcp/article/view/78818/69142 OR http://goo.gl/6hKrR3}

The objective of this study was to determine the incidence of all teenage pregnancies and their obstetric outcomes at the University of Nigeria Teaching Hospital (UNTH), Enugu, Southeast, Nigeria. A retrospective review of all teenage pregnancies at UNTH over a 6-year period (2000--2005) was undertaken. A total of 74 teenage pregnancies were analysed and compared with 105 controls (adult mothers). Records of 74 teenage pregnancies were identified within the study period which constitutes 1.67 percent of 4,422 deliveries within the period. Majority of the teenagers (78.3 percent) were nulliparous. There was statistically significant differences between the teenage mothers and older mothers in the rate of unemployment $(75.7$ percent vs. 24.8 percent, $p=0.000$ ), booking status (41.9 percent vs. 100 percent, $p=0.000$ ), anaemia (32.4 percent vs. 24.8 percent, $p=0.001$ ), unsure of last menstrual period (32.4 percent vs. 15.2 percent, $p$ $=0.007$ ), caesarean section (18.9 percent vs. 10.5 percent, $p=0.000$ ), cephalopelvic disproportion as an indication for caesarean section (9.4 percent vs. 3.8 percent, $p=0.001)$, preterm delivery (18.9 percent vs. 11.4 percent, $p=0.001)$, low birth weight (23.0 percent vs. 10.5 percent, $p=0.005)$, episiotomy (61.7 percent vs. 28.7 percent, $p=0.001)$, instrumental delivery (6.8 percent vs. 2.9 percent, $p=0.001)$, Apgar score at 1 minute (35.1 percent vs. 19.1 percent, $p=0.005$ ), and perinatal mortality (16.2 percent vs. 12.4 percent). There were no maternal deaths.

Iklaki, C.U., Inaku, J.U., Ekabua, J.E., Ekanem, E.I., \& Udo, A.E. (2012). Perinatal outcome in unbooked teenage pregnancies in the University of Calabar Teaching Hospital, Calabar, Nigeria. ISRN Obstetrics and Gynecology, 2012:246983.

Article available at:

\section{http://www.ncbi.nIm.nih.gov/pmc/articles/PMC3316960/\#!po=3.84615}

To determine the influence of antenatal care on perinatal outcome in teenage pregnancies in Calabar, South-south, Nigeria, a review of patient records from the University of Calabar Teaching Hospital was conducted between 1st January, 2006 and 31st December, 2010. Teenage pregnancy accounted for 644 (6.5 percent) of the total deliveries with 245 (38.0 percent) booked while 399 (62.0 percent) were unbooked. Teenage mothers contributed significantly to the proportion of women who were delivered without prior antenatal care $\left(x^{2}=6.360 ; p<0.05\right)$. The mean duration of labour in booked teenagers was $10.85 \pm$ 4.2 hours, while unbooked teenagers was $23.31 \pm 3.6$ hours (t-value $=77.1039 ; p<0.05$ ). There was statistically more caesarean sections among unbooked teenage pregnancies than booked $\left(x^{2}=36.75 ; p<\right.$ 0.05). Stillbirth was statistically significant $\left(x^{2}=27.096 ; p<0.05\right)$ among unbooked teenagers than booked. 
However, early neonatal death was not significantly different between booked and unbooked teenage pregnancies $\left(X^{2}=0.512 ; p<0.05\right)$.

Lane, C., Joof, Y.M., Hassan, A.A., \& Pryor, S. (2012). Promoting healthy timing and spacing of pregnancy with young married women in Northern Nigeria: a short report. African Journal of Reproductive Health, 16(2):263-9.

Article available at: http://www.bioline.org.br/pdf?rh12035

The Extending Service Delivery Project (ESD) partnered with the Federation of Muslim Women Association of Nigeria and religious leaders to educate communities about the benefits of using family planning to practice healthy timing and spacing of pregnancy (HTSP) in five local government areas in Kano State, Northwest, Nigeria. Informal discussions with 148 women and 28 men found high recall of the HTSP recommendations and favourable attitudes towards spacing and family planning although many remained concerned about the side effects of contraceptive methods.

Melvin, A.O., \& Uzoma U.V. (2012). Adolescent mothers' subjective well-being and mothering challenges in a Yoruba community, southwest Nigeria. Social Work in Health Care, 51(6):552-67. Article available at: http://www.tandfonline.com/doi/full/10.1080/00981389.2012.679020\#abstract

This study explored adolescent mothers' (13-20 years) subjective well-being by focusing on their childbirth, mothering experiences, and available network of supports. Thirty face-to-face in-depth interviews were conducted through the support of four informants and peer referrals. Content analysis was used to identify salient themes and patterns. Findings showed that a high proportion of the adolescent mothers had stigmatizing experiences among which included dropping out of school, and lack of support from families, friends, and the society. Where available, support was perceived as inadequate in contributing to their wellbeing and that of their children. Some of the adolescent mothers were apprehensive of losing their children to ill health while emphasizing that their present challenges could affect their children's future. However, the adolescent mothers invoked their agency by subtly using strategies such as petty trading and apprenticeship to reduce the social consequences of unintended pregnancy and earn a living.

\section{Nwobodo, E.I., \& Panti, A. (2012). Adolescent maternal mortality in North-west Nigeria. West African Journal of Medicine, 31(4):224-6. Article available at: http://www.ncbi.nlm.nih.gov/pubmed/23468022}

The objective of this descriptive study was to determine the institutional maternal mortality ratio among adolescents, its risk factors/causes and suggest ways of preventing or reducing the deaths. Investigators reviewed hospital case records of all adolescent maternal deaths at Usmanu Danfodiyo University Teaching Hospital (UDUTH) Sokoto between January 2000 and December 2009. There were 165 maternal deaths and 3,047 live births among the adolescent mothers within the period giving an adolescent maternal mortality ratio of $5415 / 100,000$ live births. The main causes of death were eclampsia (53.9 percent), prolonged obstructed labour (15.3 percent), anaemia (14.5 percent) and haemorrhage (9.1 percent). Abortion (2.4 percent) was an uncommon cause of adolescent maternal mortality in this study. Identified risk factors included lack of prenatal care/labour supervision and illiteracy. 
Olusanya, B. O., \& Ebuehi, O. M. (2012). Addressing the needs of adolescent mothers and their offspring in Nigeria: a community-based study. International Journal of Adolescent Medicine and Health, 24(4):307-313.

Article available at: http://www.degruyter.com/view/i/ijamh.2012.24.issue 4/ijamh.2012.044/ijamh.2012.044.xml

The purpose of this study was to determine the perinatal profile of adolescent mothers with surviving offspring against the backdrop of limited community-based data on the outcomes of adolescent pregnancy in low-income countries. A case-control study of adolescent mothers (13-19 years) attending four communitybased clinics for routine childhood immunization was conducted from July 2005 to March 2008 in Lagos, South-West, Nigeria. A total of 241 adolescent mothers (mean age, 18.2 \pm 1.2 years) were consecutively recruited over the study period and matched (for infant age and sex) with 1,205 controls (mean age, $27.3 \pm 3.9$ years). Adolescent mothers in this population were significantly more likely to be unmarried, of the Hausa ethnic tribe, without postsecondary education, unemployed, and primiparous. Although all received antenatal care, they were also more likely to deliver outside hospital without skilled attendants, and their offspring were likely to be undernourished.

Onyeka, I.N., Miettola, J., Ilika, A.L., \& Vaskilampi, T. (2012). Becoming pregnant during secondary school: findings from concurrent mixed methods research in Anambra State, Nigeria. East African Journal of Public Health, 9(1):19-25. Article available at: http://www.pubfacts.com/detail/23120944/Becoming-pregnantduring-secondary-school:-findings-from-concurrent-mixed-methods-research-in-Anambr

This study assessed reported cases of unintended pregnancy among students and perceptions of these pregnancies by members of the community. The study took place in a rural community in Anambra state, southeastern Nigeria. A cross-sectional survey of 1,234 students and 46 teachers in five secondary schools was carried out using self-administered questionnaires. In addition, focus group discussions (FGDs) involving 10 parents and an in-depth interview (IDI) with a student who became pregnant were conducted. Reports of pregnancy were more common during second and third years of junior secondary school than other school years or level. According to teachers, ignorance was the main reason given by students who became pregnant. Students who became pregnant were reported to have performed poorly academically and lived with both parents, who were either subsistence farmers or petty traders. In the IDI, the ex-student opined that pregnant students faced shame, marital limitations and lack of respect from community members. Participants in the FGDs suggested that teenagers should be provided with sex education in schools and in churches; parents should communicate with teenagers about sexual matters and make adequate financial provision; and the male partners should be held more accountable for the pregnancies.

Rai, R.K., Singh, P.K., \& Singh L. (2012). Utilization of maternal health care services among married adolescent women: insights from the Nigeria Demographic and Health Survey, 2008. Women's Health Issues, 22(4):407-14. Article available at: $w w w$. raiseinitiative.org/library/download.php?id $=577$

This study examined the factors associated with selected maternity services-married adolescent women who have had at least four antenatal care (ANC) visits, those who have undergone safe delivery care, and those who received postnatal care within 42 days of delivery. Data from the Nigeria Demographic and Health Survey, 2008, were used. An eligible sample of 2,434 married adolescent (aged 15-19 years) women was included in the analysis. Pearson chi-square test and binary logistic regression were performed to fulfil the study objective. It was found that about 35 percent of adolescent women had at least four ANC visits, a little over 25 percent had undergone safe delivery care, and nearly 32 percent received postnatal care within 42 days of delivery. Women's education, husband's education, wealth quintile, and region of residence were documented as the most important factors associated with maternal healthcare service utilization. 
Fadupin, G.T., \& Pikuda Y.C. (2011). Maternal weight gain and pregnancy outcome in adolescent girls in Ibadan, Nigeria. African Journal of Medicine and Medical Sciences, 40(3):197-205.

\section{Article available at: http://www.ncbi.nlm.nih.gov/pubmed/22428513}

Investigators sought to determine the influence of maternal weight gain on the pregnancy outcome of adolescent mothers in Ibadan, Oyo state, Southwest Nigeria. A retrospective review of case notes of 785 adolescents $<$ or $=19$ years and 1300 adult mothers who delivered at Adeoyo and Oluyoro maternity hospitals from January 2003 to December 2006 was carried out. Anthropometric information such as weight at second and third trimester, and infant birth weight and length were collected using a record review proforma. The data were analysed using chi-square, ANOVA, Pearson's and Spearman's correlation. Adolescent mothers had a significantly lower weight gain $(6.1+/-2.9 \mathrm{~kg})$ compared to the control whose mean weight gain was $6.7+/-3.6 \mathrm{~kg}(\mathrm{p}<0.05)$. There was also a significant difference in the proportion of the adolescent mothers ( 77.3 percent) and the adult mothers ( 57.6 percent) with packed cell volume below normal levels $(p<0.05)$. The mean infant birth weight and length among adolescents $(2.8+/-0.5 \mathrm{~kg}$ and $46.6+/-4.0 \mathrm{~cm}$ ) were significantly lower than $3.1+/-0.5 \mathrm{~kg}$ and $47.9+/-3.5 \mathrm{~cm}$ of adult mothers respectively $(p<0.05)$. The prevalence of low birth weight was significantly higher among the adolescent mothers (12.2 percent) than in the adult mothers $(7.9$ percent) $(p<0.05)$. A significant positive relationship was found between infant birth weight and maternal weight gain in pregnancy $(r(s)=0.18, p<0.05)$. Caesarean section was significantly higher among adolescent mothers (21.0 percent) than adult mothers (10.7 percent) $(p<0.05)$. Complications of pregnancy were more common among adolescent mothers (35.8 percent) than adult mothers (15.5 percent).

Ogelle, O.M., Eke, A.C., Okafor, C.I., Mbamara, S.U., \& Obiechina, N.J. (2011). Teenage pregnancies: a lingering obstetric problem in Nigeria. Nigerian Journal of Medicine, 20(4):414-20.

Article available at: http://www.ncbi.nlm.nih.gov/pubmed/22288314

To determine the teenage pregnancy rate, associated epidemiological factors, outcome and complications in a Nigerian tertiary hospital, a 5 year retrospective study of women presenting with teenage pregnancies, between 1 January 2004 and 31 December 2008 was done. The obstetric variables from 72 cases of teenage pregnancies and 89 selected controls aged 20-24 years were compared. The prevalence of teenage pregnancy was 2.7 percent. The age range was from $14-19$ years with a mean age of $17.8+/-1.2$ years. 33 (45.8 percent) women among the study group were single while 39 (54.2 percent) were married. There was a statistically significant difference in the marital status between the study and control groups ( $X^{2}$ $=41.80, \mathrm{p}=0.001$ ). Interestingly, the teenage group were mainly primiparous women (63.9 percent) compared to the adults who were mostly nulliparous. Ante-partum complications such as anaemia, malpresentations and ante-partum haemorrhage were more common in the teenage pregnancy group. Prolonged labour, preterm labour, intra-uterine growth restriction, premature rupture of foetal membranes, and caesarean deliveries were commoner in the teenage group, but not to a significant level.

Adeyinka, D.A., Oladimeji, O., Adekanbi, T.I., Adeyinka, F.E., Falope, Y., \& Aimakhu, C. (2010). Outcome of adolescent pregnancies in southwestern Nigeria: a case-control study. Journal of Maternal-Fetal and Neonatal Medicine, 23(8):785-9.

Article available at: http://informahealthcare.com/doi/abs/10.3109/14767050903572166

To evaluate the risk factors of adolescent pregnancy, assess and explore the occurrence of specific complications and compare pregnancy complications among adolescent parturients to older controls in a tertiary health centre in order to design appropriate policies and interventions. A retrospective study was conducted in a population of adolescents (age <18 years) delivered at the University College Hospital, 
Ibadan, Nigeria from January 2007 to November 2008. The birth register for the study-period was reviewed and socio-demographic data and labour records were extracted for both cases and controls. The proportion of adolescent pregnancy between January 2007 and November 2008 was between 1.5 percent and 2.2 percent. Overall, almost half ( 44.44 percent) of adolescent pregnancies had one form of complication or the other. The corresponding figure among the control was 22.22 percent. Adolescents had statistically more significant complication rates in pregnancy $(p=0.002)$. In terms of the individual complications, the incidence of eclampsia and pre-eclampsia among adolescents was 20 percent which was only 3.33 percent among the controls $(p=0.001)$.

\title{
Omole-Ohonsi, A., \& Attah R.A. (2010). Obstetric outcome of teenage pregnancy in Kano, North-Western Nigeria. West African Journal of Medicine, 29(5):318-22. Article available at: http://www.ajol.info/index.php/wajm/article/viewFile/68252/56338
}

Investigators conducted a retrospective case-control study of 500 booked teenage primigravidae, who delivered at the Aminu Kano Teaching Hospital labour ward in Kano, Northwest Nigeria from January 2002 to December 2005. Their obstetric outcome was compared with that of an equal number of booked primigravidae aged 20-34 years, who met the recruitment criteria and delivered immediately after a selected teenage mother (control group). The study variables of interest were the demographic characteristics of the women in the two groups, antenatal/intrapartum complications, and neonatal outcome. There were no significant differences in the mean birth weight, mean gestational age at delivery, mean height, and perinatal mortality between the two groups, but mean maternal weight and body mass index (BMI) were higher among the older women. The teenage mothers had increased incidence of preterm labour and low birth weight infants $(p<0.05)$. The incidence of caesarean section and instrumental deliveries were lower among the teenage mothers.

\section{Ebeigbe, P.N., \& Gharoro E.P. (2007). Obstetric complications, intervention rates and maternofetal outcome in teenage nullipara in Benin City, Nigeria. Tropical Doctor, 37(2):79-83.}

\author{
Abstract available at: http://www.ncbi.nlm.nih.gov/pubmed/17540084 \\ Full article available at: http://tdo.sagepub.com/content/37/2/79.long
}

An audit to determine the incidence of births to teenage nullipara, pregnancy complications, obstetric intervention rates, maternal and foetal outcomes in 114 teenage nullipara compared with 700 randomly selected older nullipara (age 20-29 years), was undertaken in a tertiary institution in Benin City, Southsouth, Nigeria. Births to teenage nullipara contributed 1.7 percent of all deliveries. Teenagers were significantly more likely to be unbooked for antenatal care $(p<0.0001)$, book late $(p<0.0001)$ and be single mothers $(p<0.0001)$. Teenagers were also significantly more likely to have primary education $(p<$ $0.0001)$, secondary education ( $<0.001)$ or be apprentices $(p<0.0001)$. Teenagers had a significantly higher incidence of caesarean sections $(p=0.0002)$. There were no significant differences in the incidence of pregnancy complications, induction or augmentation of labour, preterm delivery, instrumental deliveries, and foetal outcome. The maternal mortality ratio for teenagers was 1,835 per 100,000 live births. There were no deaths among the older nullipara.

Ujah, I.A., Aisien, O.A., Mutihir, J.T., Vanderjagt, D.J., Glew, R.H., \& Uguru, V.E. (2005). Maternal mortality among adolescent women in Jos, north-central, Nigeria. Journal of Obstetrics and Gynaecology, 25(1):3-6.

\section{Article available at:}

\section{http://informahealthcare.com/doi/abs/10.1080/01443610400023395}

Between January 1991 and December 2001, the case files of all adolescent women aged 10-19 years dying in pregnancy and childbirth in the maternity unit of Jos University Teaching Hospital, Jos, North Central Nigeria were retrieved as soon as a death occurred. A comprehensive record of all deliveries, including 
complications and maternal deaths in this age group was also kept. The case file was reviewed and any doubtful or incomplete information provided in the file was crosschecked with close relatives of the deceased. A total of 25 maternal deaths occurred among 4,564 deliveries in adolescent women aged 1019 years. The maternal mortality ratio (MMR) recorded was 547/100,000 deliveries. During the same period, of the 25,357 total deliveries, 211 were maternal deaths. Adolescent maternal deaths accounted for 11.8 percent of all deaths and maternal mortality ratio of $98.6 / 100,000$ deliveries in the general population. The mean age of maternal death was 17.6 (SD 1.2) years with age range of 15-19 years. An important finding in this study was the high incidence of complicated induced abortion, which was the leading direct cause of adolescent maternal deaths (37 percent), followed by eclampsia and sepsis with each accounting for 26.3 percent. The main causes of maternal deaths among the adolescents were unsafe abortion, eclampsia and sepsis. The Hausa/Fulani ethnic group constituted the largest ethnic group of adolescent maternal deaths. The risk factors for adolescent maternal mortality were illiteracy, non-utilisation of antenatal services and Hausa/Fulani ethnic group.

\section{Loto, O.M., Ezechi, O.C., Kalu, B.K., Loto, A., Ezechi, L., \& Ogunniyi, S.O. (2004). Poor obstetric performance of teenagers: is it age- or quality of care-related? Journal of Obstetrics and Gynaecology, 24(4):395-8. \\ Article available at: http://informahealthcare.com/doi/abs/10.1080/01443610410001685529}

We studied prospectively the effect of antenatal care on the obstetric performance of teenagers seen at a university teaching hospital over a 14-month period. This comparative study was carried out at the Obafemi Awolowo University Teaching Hospitals Complex, Ile-lfe, Southwest Nigeria over a period of 14 months (1 November 1998-31 December 1999). All teenagers (less than 20 years of age) seen at the obstetric unit of the above hospital during the study period were recruited into the study. The next two women aged 23-29 years of the same booking status and parity seen after each teenage mother acted as controls. When the obstetric complications among the teenagers were compared to their older counterpart, there were significantly higher complication rates, especially anaemia, preterm delivery, low birth weight and neonatal admission. After controlling for utilisation of antenatal care, significant differences were observed only in the incidence of low birth weight babies.

\section{Airede, L.R., \& Ekele, B.A. (2003). Adolescent maternal mortality in Sokoto, Nigeria. Journal of Obstetrics and Gynaecology, 23(2):163-5. Article available at: http://informahealthcare.com/doi/abs/10.1080/0144361031000074709}

The aim of this study was to determine the magnitude of adolescent maternal deaths at the Usmanu Danfodiyo University Teaching Hospital (UDUTH), Sokoto, Northwest Nigeria. Investigators also studied the associated and causative factors, and recommended strategies for their prevention. They conducted a retrospective, cross-sectional study of adolescent maternal deaths that occurred at UDUTH, Sokoto from January 1990 to December 1999. There were 946 live births (LB) from adolescents and 46 maternal deaths during the study period. The maternal mortality ratio (MMR) in adolescents was 4,863/100,000 LB and $2,151 / 100,000$ LB in the general hospital population. The mean age of the adolescents who died was 17 years. Risk factors included absence of routine antepartum, intrapartum and postpartum care, illiteracy and poverty. Eclampsia and prolonged obstructed labour were responsible for 76 percent of deaths. Abortion was an uncommon cause of maternal death in adolescents. 
Oboro, V.O., Tabowei, T.O., Jemikalajah, J.J., Bosah, J.O., \& Agu, D. (2003). Pregnancy

outcomes among nulliparous teenagers in suburban Nigeria. Journal of Obstetrics and

Gynaecology, 23(2):166-9.

Article available at:

http://informahealthcare.com/doi/abs/10.1080/0144361031000074718

Researchers' objective was to study the pregnancy outcomes among teenagers in a rural Nigerian setting. Single births to 1,394 nulliparous mothers aged $\leq 19$ during 1996-2001 at three district general hospitals were studied retrospectively. The outcome of pregnancy was compared with that of 1,488 older nulliparae aged 20-24 years who delivered during the study period. Compared with women aged 20-24 years, patients of 15 years or less were at higher risk for anaemia, premature labour, low birth weight, and operative deliveries. However, the older teenagers (16-19 years) were less at risk. When women with inadequate prenatal care were removed from analysis, the risks in younger teenagers were not significantly different from those of older mothers.

Oguntona, C.R., \& Akinyele, I.O. (2002). Food and nutrient intakes by pregnant Nigerian adolescents during the third trimester. Nutrition, 18(7-8):673-9. Article available at: http://www.nutritionjrnl.com/article/S0899-9007\%2802\%29007475/abstract

Investigators assessed the food and nutrient intakes of pregnant adolescent Nigerians during their third trimester of pregnancy. The subjects consisted of 101 adolescents ( 47 urban and 54 rural) and 20 controls (primigravidae, 20 to 25 years old) who attended antenatal clinics. The 3-d weighed-intake technique was used to obtain information on food intake. For all cohorts, the results showed that the bulk of the foods derived from three main food groups, namely roots or tubers, cereals, and legumes. Older adolescents (17.5 to $19 \mathrm{y}$ ) in urban areas had the highest energy intake $(5.9 \mathrm{MJ} / \mathrm{d}$ ), and the younger urban adolescents (15 to $17 \mathrm{y})$ had the lowest $(5.2 \mathrm{MJ} / \mathrm{d}$ ) energy intake. Mean protein intake levels for urban adolescents $(37.7 \mathrm{~g} / \mathrm{d})$ did not differ significantly $(p>0.05)$ from mean intake levels $(35.3 \mathrm{~g} / \mathrm{d})$ for rural subjects. Dietary iron intake was similar in all cohorts including controls, and only 32.3 percent to 39.3 percent of the recommended daily allowance for iron was met by the subjects. Approximately 30 percent of subjects individually achieved 100 percent of the recommended levels of zinc. Mean intakes as percentages of the recommended daily allowance by adolescent subjects were 50.7 percent for calcium, 29.2 percent for copper, and 28.5 percent for folate.

Igwegbe, A. O., \& Udigwe, G. O. (2001). Teenage pregnancy: still an obstetric risk. Journal of Obstetrics and Gynaecology, 21(5):478-481.

Article available at http://informahealthcare.com/doi/abs/10.1080/01443610120072027

A 30-month retrospective and comparative study of the obstetric performance of teenagers between 12 and 19 years old, and females between 20 and 24 years old was performed at Nnamdi Azikiwe University Teaching Hospital, Nnewi, South-East, Nigeria. The prevalence of teenage birth was 21.8 per 1,000 deliveries. Females aged 20-24 years performed better than teenagers with respect to booking status, marital status, preterm delivery, low birth weight, and perinatal morbidity. 35.71 percent teenage deliveries were preterm but there was no preterm delivery among the older age group. There was no difference with respect to pre-eclampsia, caesarean section and perinatal mortality. 


\section{Gender Equity}

Rogow, D., Haberland, N., Del Valle, A., Lee, N., Osakue, G., Sa, Z., \& Skaer, M. (2013). Integrating gender and rights into sexuality education: field reports on using It's All One. Reproductive Health Matters, 21(41):154-166. Article available at: http://www.rhm-elsevier.com/article/S0968-8080\%2813\%29416993/pdf

This paper reports on an effort to gather and analyse practitioners' experiences using It's All One (a sexuality education curriculum) in diverse contexts, as a way to explore the acceptability, feasibility, and challenges faced by programmes implementing empowerment sexuality education. It also explored whether programmes using this approach are seeking to affect non-health outcomes. To gain a sense of practitioners' experience with this tool, a two-part exercise was conducted. First, responses from an on-line survey of It's All One users were synthesized. Additionally, five programmes were selected for documentation, including two school-based programmes (Nigeria, China), two reaching extremely vulnerable youth (Haiti, Guatemala), and one reaching adolescents from a polygamous Mormon community (United States). Findings suggest the shift to an empowerment approach was indeed taking place in diverse geographic and programmatic contexts, and that It's All One had strengthened the ways their programmes addressed gender, fostered young people's critical thinking skills, and used interactive teaching methods. A common challenge across many programmes was strengthening teacher capacity. Recommendations for further implementation and research were presented.

\section{Barnett, J. P., Maticka-Tyndale, E. \& HP4RY Team. (2011). The gift of agency: sexual exchange scripts among Nigerian youth. Journal of Sex Research, 48(4):349-359. Article available at: http://www.tandfonline.com/doi/full/10.1080/00224499.2010.499523\#abstract}

This article examined the practice of directly exchanging goods for sexual intercourse using data from 36 focus group discussions with youth living in rural Edo State, South-South, Nigeria. Conceptualizing this practice as a sexual script, the authors conducted a deductive thematic analysis framed by the broader context in which sexual exchange occurs. Combining scripting theory with an analysis of the form of the payment, it was found that the cultural script of exchange supports girls' agency. However, at the interpersonal level of practice, this script often lost out in conflict with the cultural scripting of male control. The shape of this practice was influenced by intrapsychic scripts (e.g., sexual violence is an option), interpersonal resources (e.g., family money), and cultural scripts (e.g., stuff and status bring friends). In the final analysis, sexual exchange was found to be a script that both enabled and restricted agency. It was a power niche for those with limited social and economic power, enabling them to seek and access material goods, social status, and sexual experience. It was also a means of coercing unwanted sex via peer and parental pressure, poverty, and a context of gender inequality. Implications for HIV prevention were discussed.

Salihu, H. M., Abubakar, I. S., Iliyasu, Z., Galadanci, H. S., \& Aliyu M. H. (2011). Prevalence and correlates of gender-based violence among female university students in northern Nigeria. African Journal of Reproductive Health, 15(3):111-119.

Article available at: http://www.jstor.org/stable/pdf/41762351.pdf

Using self-administered questionnaires, investigators determined the prevalence and risk factors for genderbased violence (GBV) among 300 female university students in Kano, Northwestern Nigeria. Respondents' age ranged from 18 to 42 years (Mean $\pm \mathrm{SD}=22.5 \pm 3.2$ years). The overall prevalence of GBV was 58.8 percent [95 percent $\mathrm{Cl}=52.9$ percent to 64.5 percent]. Specifically, 22.8 percent, 22.2 percent, and 50.8 
percent of students experienced physical, sexual, or emotional violence, respectively. Religious affiliation, ethnicity, indigeneship, marital status, campus residence, and faculty affiliation were significant predictors of GBV.

\title{
Mmari, K. N., Oseni, O., Fatusi, A. 0. (2010). STI treatment-seeking behaviours among youth in Nigeria: are there gender differences? International Perspective on Sex and Reproductive Health, 36(2):72-79. \\ Article available at: http://www.guttmacher.org/pubs/journals/3607210.html
}

\begin{abstract}
Bivariate and multivariate analyses were conducted on data drawn from the 2003 and 2005 National HIV/AIDS and Reproductive Health Surveys to determine gender differences among those who had sought treatment for their sexually transmitted infection (STI) symptoms, and the factors related to seeking treatment from formal health care sources versus informal sources. Data from 538 males and females aged 15-24 with at least one STI symptom were utilized for the analyses. A greater proportion of males than of females had sought treatment for their STIs (64 percent vs. 48 percent). Among those who had sought treatment, 60 percent of females had gone to formal sources, most commonly a government clinic; 54 percent of males had sought care from informal sources, most commonly a traditional healer. Females had lower odds than males of having sought STI treatment (odds ratio, 0.6). Among both males and females, economic status was positively associated with seeking treatment from a formal source rather than an informal source (2.4-4.2); among females aged 22-24 were more likely than those aged 15-18 to have sought treatment from a formal source (2.5).
\end{abstract}

\section{Smith, D. J. (2010). Promiscuous girls, good wives, and cheating husbands: gender inequality, transitions to marriage and infidelity in southeastern Nigeria. Anthropological Quarterly, 83(1):123-152.}

Article available at: http://www.ncbi.nlm.nih.gov/pmc/articles/PMC3831578/pdf/nihms513234.pdf

This paper examines the adjustments of young women in southeastern Nigeria during the transition from premarital sexual relationships and courtship to marriage and parenthood and, specifically, how young married women's lives are affected by the reality of male infidelity and a persistent gender double standard regarding the acceptability of extramarital sex. The study was carried out in two settings, Owerri-the capital of Imo state, and Ubalaka-a semi-rural community in Abia state. The author concluded that "Few young wives acknowledged the seeming irony that the premarital sexual culture they participated in as single women conflicted with their marital ideals. Marriage and childbearing completely transform a woman's social position and status in southeastern Nigeria, and with it much of her orientation towards Nigeria's contemporary sexual landscape. Married women routinely condemn the very behaviour they engaged in when they were single."

\section{Izugbara, C. 0. (2008). Representation of sexual abstinence among rural Nigerian adolescent males. Sexuality Research \& Social Policy, 4(2) 74-87. Article available at: http://link.springer.com/article/10.1525\%2Fsrsp.2007.4.2.74}

This article reports on a study of representations and narratives of sexual abstinence among adolescent males in rural Nigeria. Study results showed that abstinence occupied a variable position in the lives and minds of these youth. Beliefs about sexual abstinence being moral and healthy and signifying decency, propriety, and decorum existed alongside narratives depicting it as dangerous, unhealthy, and as an imposition and a sign of disempowerment and powerlessness. These variations in views about sexual abstinence constituted a vibrant critique of conventional public health messages and discourses casting abstinence as beneficial and doable for all youth and also raised important questions regarding young males' constructions of sexuality, gender, health, risk, danger, and pleasure. 
Izugbara, C. 0. (2008). Masculinity scripts and abstinence-related beliefs of rural Nigerian male youth. Journal of Sex Research, 45(3):262-276.

Article available at: http://www.tandfonline.com/doi/pdf/10.1080/00224490802204472\#.VP7RneH3hwg

This study examined the direct perspectives of unmarried rural adolescent males aged 11-21 regarding the preventive practice of "abstinence until marriage." These participants, numbering 120, were recruited from eight rural Ngwa communities in Obi-Ngwa Local Government Area of Abia State, South-East, Nigeria. The study revealed that norms of masculinity suffuse Nigerian male youth narratives surrounding the benefits and hazards of abstinence. Key gender norms that frame male youth views of the consequences of abstention included those that cast men as strong-willed and resolute, represent sexual activity as a central marker of malehood, depict male sexuality as naturally dominant and aggressive, emphasize male sexual potency, associate maleness with power and leadership, and portray sexual activity as normal, proper, and permissible for males.

Fawole, O. I., Ajuwon, A. J., \& Osungbade, K. O. (2005). Evaluation of interventions to prevent gender-based violence among young female apprentices in Ibadan, Nigeria. Health Education, 105(3):186-203. Article available at: http://www.emeraldinsight.com/doi/abs/10.1108/09654280510595254

This intervention project targeted one vulnerable group, female apprentices in Ibadan, Nigeria, to evaluate the effectiveness of multiple interventions aimed at preventing violence against women (VAW). A baseline survey was conducted through face-to-face interviews with 350 young women recruited from apprenticeship workshops in Ibadan, Southwest Nigeria. The interventions consisted of skills training workshops for apprentices (323); sensitization training for the instructors of apprentices (54), police (30), and judicial officers (25); and the development/distribution of educational materials to reduce the incidence of violence. The apprentices' ages ranged from 9 to 32 years with a mean of 21 years. A follow-up survey was conducted with 203 apprentices after five months of interventions. Improvements were found at follow-up with respect to knowledge of types and sexual forms of violence (up from 89.4 to 97 percent) ( $p<0.05$ ), and appreciation of vulnerability to VAW increased (from 77 to 95 percent) $(p<0.05)$. The prevalence of beating dropped from 65.4 to 23 percent. A significantly greater proportion ( $p<0.05$ ) of the apprentices reported payment for vocation-related work (8.9 percent compared with 16.4 percent). Only a slight decline was reported in rape (5.7 to 5.4 percent) and sexual harassment ( 22.9 and 22.7 percent). The proportion of victims of violence who sought redress increased from 40.2 to 72.7 percent.

Fawole, O. I., Ajuwon, A. J., \& Osungbade, K. O. (2004). Violence and HIV/AIDS prevention among female out-of-school youths in southwestern Nigeria: lessons learnt from interventions targeted at hawkers and apprentices. African Journal of Medicine and Medical Sciences, 33(4):347-353.

Article available at: http://www.ncbi.nlm.nih.gov/pubmed/15977443

Between 1997 and 2003, four studies on hawkers and apprentices in motor parks and workshops in south west, Nigeria were carried out to evaluate the effectiveness of interventions aimed at preventing HIV infection and gender-based violence (GBV). The studies were in three phases namely baseline, intervention, and endline. Interventions consisted of development and distribution of education materials; and training programmes for the police, judiciary, instructors, drivers, traders and apprentices/hawkers, including microcredit facilities were implemented in some of the studies. The major lessons learnt were that: young girls working in the informal sector of the Nigerian economy face dual risks of HIV infection and GBV and yet they are seldom targets of intervention; many had been victims of GBV and did not seek redress either because they accept it is their lot, are afraid of being stigmatized, or are put off the prolonged legal system; 
perpetrators tend to deny their involvement in violence; despite the challenges involved, interventions implemented among female apprentices and hawkers, especially those that involve multiple stakeholders, made a difference in protecting this group from dual risks of GBV and HIV infection.

Fawole, O. I., Ajuwon, A. J., Osungbade, K. O., \& Faweya, O. C. (2003). Interventions for violence prevention among young female hawkers in motor parks in south -western Nigeria: a review of effectiveness. African Journal of Reproductive Health, 7(1):71-82. Article available at: http://www.bioline.org.br/request?rh03010

An intervention study was carried out among hawkers, drivers, instructors, police, and judicial officers to reduce the incidence of violence against young female hawkers in three cities of south-western NigeriaAbeokuta (Ogun State), Ibadan (Oyo State), and Osogbo (Osun State). Knowledge and experience of violence among the hawkers before and after the interventions were then compared. The mean age of the hawkers was 23.5 years. Findings show that they had greater knowledge of the different types of violence $(p<0.05)$, were more aware of their vulnerability to violence (99.4 percent after compared to 82.7 percent before intervention) and sought help or redress ( 76.3 percent after compared to 45.8 percent before intervention) following violent acts. Sexual violence was the commonest type experienced (30.4 percent and 15.7 percent at base line and end line respectively). The rate of violence also decreased.

Odutolu, O., Adedimeji, A., Odutolu, O., Baruwa, O., \& Olatidoye, F. (2003). Economic empowerment and reproductive behaviour of young women in Osun state, Nigeria. African Journal of Reproductive Health, 7(3):92-100. Article available at: http://www.bioline.org.br/pdf?rh03043

This paper examined the relationship between empowerment (defined in terms of increased access to reproductive health information and economic resources) and reproductive behaviour among women aged 19-25. The study utilised qualitative data collected as part of an intervention programme designed to increase access to reproductive health information/services and economic resources among young women in South-West, Nigeria. The aim of the intervention was to provide reproductive health information, training in basic business skills, and micro-credit facilities to enable beneficiaries to establish private businesses. Focus group discussion (FGD) guides were designed and used to conduct interviews with groups of young women who had benefited from the first and second components of programme implementation. FGDs were also held with their opinion leaders in the selected communities within Osogbo, Ife, and Iree towns of Osun State. Findings from the study highlight the importance of the relationship between education of females, and access to economic resources as a means of furthering empowerment of women especially in terms of their reproductive behaviour.

Rotimi, O. J. \& Olley, B. O. (2003). Gender differences in condom use behaviour among students in a Nigerian university. African Journal of Reproductive Health, 7(1):83-91. Article available at: http://www.jstor.org/stable/pdf/3583348.pdf?acceptTC=true

The study evaluated condom use behaviour in a sample of students at the Faculties of Social Sciences and Arts, University of Ibadan, Nigeria. The study population comprised 262 (62.1 percent) males and 160 (37.9 percent) females with a mean age of 24.1 years $(S D=4.5)$ and mean educational level of 17.36 years $(S D=$ 5.8). Results show that 422 students (representing 55.2 percent) were sexually active within three months before the study. Seventy-seven percent of students reported ever using a condom, 89 percent of females reported condom use by a partner, while 70 percent of males had used condoms during sex with a partner. Regarding the frequency of use, more males (30 percent) than females (11 percent) had never used condom. 
Fawole, O. I., Ajuwon, A. J., Osungbade, K. O., \& Faweya, O. C. (2002). Prevalence and nature of violence among young female hawkers in motor-parks in south-western Nigeria. Health Education, 102(5):230-238.

Article available at http://www.emeraldinsight.com/doi/abs/10.1108/09654280210444100 OR http://goo.gl/yHCLXC

A total of 345 young female hawkers from six motor parks in south-western Nigeria were interviewed to determine the nature and extent of violent acts against them-particularly sexual harassment, economic violence, forced marriage, and involuntary withdrawal from school. The hawkers' ages ranged from 8 to 32 years with a mean of 23.5 years. Beatings or batterings and being sexually abused in childhood were reported. The most common perpetrators were drivers or bus conductors and neighbours and these acts mostly occurred in the motor-parks and at home. About a quarter had experienced attempted rape, while about one in twenty had actually been raped. The rapists were spouses and boyfriends. Most of the victims did not seek care or redress. 


\section{Family Planning Information and Services}

Ojiyi, E., Anolue, F., Ejekunle, S., Nzewuihe, A., Okeudo, C., Dike, E., \& Ejikem, C. (2014).

Emergency contraception: awareness, perception and practice among female undergraduates in Imo State University, southeastern Nigeria. Annals of Medical and Health Sciences Research, 4(6):904-9.

Article available at: http://www.ncbi.nIm.nih.gov/pmc/articles/PMC4250989/

The aim of was to assess the awareness, perception and practice of emergency contraception among female undergraduates in Imo State University, southeastern Nigeria. A questionnaire-based cross-sectional survey using randomly selected female undergraduates was utilized. A total of 700 students participated in the study. Awareness of emergency contraception was very high (85.1 percent) (596/700). The awareness was significantly higher amongst students in health related faculties than in the non-health related faculties $(p=$ $0.01)$. The main sources of information were through friends (43.1 percent) (317/700) and lectures (22.1 percent) (192/700). High dose progestogen (postinor-2) was the most commonly known type of emergency contraception (70.8 percent) (422/596). Only 58.1 percent $(346 / 596)$ of those who were aware of emergency contraception approved of their use. The major reasons given by the 41.9 percent $(250 / 596)$ who disapproved of their use were religious reasons (50.4 percent) $(126 / 250)$ and that they were harmful to health (49.2 percent) $(123 / 250)$. Two-thirds (67 percent) $(469 / 700)$ of the students were sexually active and only 39.9 percent (187/469) of them used emergency contraception. The most common situation in which emergency contraception was used was following unprotected sexual intercourse (45.5 percent) (85/144). Only 34.6 percent $(206 / 596)$ of those who were aware of emergency contraception identified correctly the appropriate time interval for its effectiveness.

Eke, A. C., \& Alabi-Isama, L. (2011). Long-acting reversible contraception (LARC) use among adolescent females in secondary institutions in Nnewi, Nigeria. Journal of Obstetrics and Gynaecology, 31(2):164-168.

Article available at: http://informahealthcare.com/doi/abs/10.3109/01443615.2010.539720

The aim of this study was to determine knowledge, attitude and usage of LARCs among female secondary school adolescents of Nnewi, Anambra State, South-East, Nigeria. It wasconducted among 243 adolescent girls aged 10-19 in 12 secondary schools. Of these, 81 (34.5 percent) were sexually active; 42 (17.9 percent) had heard of LARC and 25 (10.6 percent) have used LARC. The most common source of information about contraception was from friends (47.6 percent), while religious (25.7 percent) and cultural (21.4 percent) beliefs were the most common reasons for non-use of LARC. The acceptability rate for LARCs was high (95.8 percent).

Okanlawon, K., Reeves, M., \& Agbaje, O. F. (2010). Contraceptive use: knowledge, perceptions and attitudes of refugee youths in Oru Refugee Camp, Nigeria. African Journal of Reproductive Health, 14(4):16-25.

Article available at: http://www.ajrh.info/vol14_no4/14_4_article_2a.pdf

This study examined the perceptions, beliefs, knowledge and attitudes of 208 refugee youths (aged 10-24 years old) in Oru refugee camp, South-west, Nigeria, toward contraceptive use. The study also examined their access to and use of condoms and other contraceptives. Findings revealed that respondents experienced difficulty gaining access to family planning services, which were not available in the camp. Most respondents 
had little correct information about contraceptives; 42.9 percent had misperceptions about its safety, believing that contraceptives are dangerous and that chemicals in contraceptives can damage their reproductive system. Such beliefs have resulted in the low use of contraceptives (31.6 percent use last sex) and many unintended pregnancies, which caused some refugee girls to drop out of school.

\section{Okereke, C. I. (2010). Unmet reproductive health needs and health-seeking behaviour of adolescents in Owerri, Nigeria. African Journal of Reproductive Health, 14(1):43-54. Article available at: http://www.jstor.org/stable/pdf/25766338.pdf}

This study examined unmet reproductive health needs and health-seeking behaviour of in- and out-of-school adolescents in Owerri, Imo State, Nigeria. Primary information was obtained through a questionnaire, focus group discussions (FGDs) and in-depth interviews. The mean age of the adolescents was 15.7 years. A majority (74.9 percent) were aged 15-19 years, with 25.1 percent aged 10-14 years. The adolescents were mostly Christians (99.6 percent) and Catholics (78.6 percent), with 66.4 percent living with their parents. Half (50.8 percent) of the adolescents have had sex. Contraceptive use was low, due to culture. Data showed that 27.2 percent of those who had ever had sex have had sexually transmitted infections, mostly gonorrhoea and syphilis; 30.2 percent of the female adolescents have had unintended pregnancies, amongst whom 73.3 percent had recurrent pregnancies, and 19.6 percent of all the females have had an abortion. The primary contact for health care was patent medicine operators.

\section{Olugbenga-Bello, A. I., Adekanle, D. A., Ojofeitimi, E. O., \& Adeomi, A. A. (2010). Barrier} contraception among adolescents and young adults in a tertiary institution in South-western Nigeria: a cross-sectional descriptive study. International Journal of Adolescent Medicine and Health, 22(2):321-329.

Article available at: http://www.degruyter.com/view/j/ijamh.2010.22.2/ijamh.2010.22.2.321/ijamh.2010.2 2.2.321.xml

This descriptive cross-sectional study was carried out among first year students of Osun State University, Osogbo, South-Western Nigeria. Four hundred respondents were studied using pre-tested semi-structured questionnaires. The respondents were selected by balloting. Most of the respondents were within the age range of 19 years or less (53.5 percent) to 20-24 years (38.9 percent) with the mean age 19.6 +/- 2.6 years. Most respondents (93 percent) had heard about the male condom as a method of barrier contraception. Most respondents (79.1 percent) supported the use of barrier contraceptives, but many (62.5 percent) thought it would promote sexual promiscuity, 33.4 percent believed that the use of barrier contraception reflected a lack of trust from the partner, and 38.7 percent felt barrier contraception is not necessary with a stable partner. One hundred and sixty one ( 40.5 percent) had used a form of barrier contraception before, but only 130 (32.7 percent) are currently using BC. The male condom was the most commonly used method (88.2 percent), followed by the female condom, and diaphragm (5.6 percent for both respectively). The prevention of sexually transmitted infections and unwanted pregnancies were the main reasons (59 percent) given by respondents for using birth control, while religion was the main reason given by non-users.

\section{Abiodun, O. M., \& Balogun, O. R. (2009). Sexual activity and contraceptive use among young female students of tertiary educational institutions in llorin, Nigeria._Contraception, 79(2):146-149.}

\section{Article available at: https://www.unilorin.edu.ng/publications/balogunro/a6.pdf}

This study evaluated the pattern of sexual behaviour and contraceptive practices among young students between the ages of 15 and 24 years in tertiary institutions within Ilorin metropolis, Kwara State, South West Nigeria. Of the 600 students, 562 (93.7 percent) completed the questionnaire. Most (98.6 percent) of the respondents were unmarried, 77.6 percent have had sexual intercourse, 67.8 percent have had an 
unwanted pregnancy, while 63.5 percent have had an induced abortion. All the respondents were aware of contraceptives, but only 25.4 percent have ever used any contraceptive method. The most common sources of information about contraception among the respondents were friends/relatives (73.7 percent), while the fear of side effects of modern contraceptives was the most common reason ( 77.5 percent) for non-use.

Adeyinka, D. A, Oladimeji, O., Adeyinka, E. F., Adekanbi, I. T., Falope, Y., \& Aimakhu, C. (2009). Contraceptive knowledge and practice: a survey of undergraduates in Ibadan, Nigeria. International Journal of Adolescent Medicine and Health, 21(3):405-411 Article available at: http://www.degruyter.com/view/j/ijamh.2009.21.3/ijamh.2009.21.3.405/ijamh.2009.2 1.3.405.xml?format $=$ INT

A descriptive cross-sectional study which sought to determine the knowledge, attitude of undergraduates to contraception and their practice of the various contraceptive options. The study was done among undergraduates of the Polytechnic of Ibadan and the University of Ibadan, South-West, Nigeria $(n=600)$. A majority, 382 (70.6 percent) of the respondents were between 15 and 24 years. A large percent (65.1 percent) of the undergraduates were sexually experienced. Approximately, 90.2 percent of the respondents who had sex did so before the age of 19 years, 31.8 percent had more than one sexual partner, and 21.8 percent had clandestine abortions. All respondents were quite knowledgeable about HIV/AIDS but fewer (30.2 percent) of the sexually active took precautions to prevent HIV transmission. The majority (65.4 percent) were not knowledgeable about contraception, and 10.5 percent heard about contraception from parents. About half (52.3 percent) of the latter mentioned pharmacy shops as their source of contraceptives.

\section{Babayaro, H., Folda, L., \& Babalola, S. (2008). The effects of a communication program on contraceptive ideation and use among young women in northern Nigeria. Studies in Family Planning, 39(3):211-220. \\ Article available at: http://www.jstor.org/stable/pdf/20454464.pdf}

This study assessed the effects of a communication campaign designed to encourage young people in northern Nigeria to use modern family planning methods to avoid unwanted pregnancies. The respondents were young men and women aged 15 to 24 living in two northern states; Bauchi and Kano (in the North East and North West geopolitical zones respectively) who were selected for interview through a multistage random process. A total of 3,844 individuals (1,924 males and 1,920 females) were interviewed successfully. The average age of female respondents was 18.8 years and 819 were sexually experienced. Findings revealed that the direct effect of campaign exposure on the probability of contraceptive use was only marginally significant, but the effect of exposure on contraceptive ideation was robust, as was the effect of contraceptive ideation on contraceptive use.

lyaniwura, C. A. (2006). Its perspective of adolescent reproductive health behaviour in a suburban town in Nigeria. Nigerian Journal of Medicine, 15(3):255-259.

Article available at: http://www.ncbi.nlm.nih.gov/pubmed/17111754 http://www.pubfacts.com/detail/17111754/Its-perspective-of-adolescent-reproductivehealth-behaviour-in-a-suburban-town-in-Nigeria

The objective of this study was to assess the attitude of parents to adolescent reproductive health behaviour in a suburban Nigerian town. This cross-sectional descriptive study was carried out in Ikenne, Ogun State, South-West, Nigeria. A semi-structured questionnaire was used to gather information from 370 adults who were chosen by multi-staged sampling method. About two-thirds of the adults surveyed (62.2 percent) were against premarital sex among adolescents. Although 46.8 percent said it was permissible for adolescents to use contraceptives, 87.1 percent will react negatively if they found contraceptives with their children. The condom was the most commonly approved contraceptive method for adolescents by 60.7 percent of those who approved of adolescents use of contraception, consisting of 14.6 percent of all the parents in the study. 
The major reasons against contraceptive use by adolescent were the promotion of promiscuity (41.5 percent) and infertility in the future (24.9 percent). Although gender difference was not statistically significant, the females expressed a more conservative attitude to adolescent sexuality and contraception than males; they were less likely to approve of sexual activity among young people (17.8 percent versus 23.6 percent) or contraceptive use by them (44.6 percent versus 49.2 percent). Eighty-seven percent of those that had children/ward above 12 years had discussed sexuality issues with them. The major form of advice was sexual abstinence and the possibility of unplanned pregnancy. Only 8.5 percent had advised them about contraception. While 74.1 percent had approved of sex education in schools, only 31.9 percent approved of teaching about condom in schools.

\section{Oye-Adeniran, B. A., Adewole, I. F., Umoh, A. V., Oladokun, A., Ghadegsin, A., Ekanem, E. E., \& Mahmoud, P. (2006). Community-based study of contraceptive behaviour in Nigeria. African Journal of Reproductive Health, 10(2):90-104. Article available at: http://www.bioline.org.br/pdf?rh06030}

This was a cross-sectional, community-based, descriptive study among women of reproductive age group (15-49 years) in Nigeria to explore the possible reasons for contraceptive non-use despite reported high awareness. Data were obtained using a standard questionnaire instrument and applied on 2,001 respondents recruited from four randomly selected States (Anambra in the Southeast, Oyo in the Southwest, Kaduna in the Northwest, and Bauchi in the Northeast). Contraceptive prevalence among sexually active respondents was 14.8 percent for all methods, 10.1 percent for modern methods, and only 0.8 percent for emergency contraceptives. The most frequently stated reasons for non-use of contraceptives, among those who had never used any contraceptives, but who did not want more children were: "did not think about it," "against religious belief," and "fear of side effects." Prior counselling significantly improved the continuation rate of contraception. Multivariate analysis showed that older, married, and more educated women tended to use contraceptives more.

\section{Salako, A. A., Iyaniwura, C. A., Jeminusi, O. A., \& Sofowora, R. (2006). Sexual behaviour, contraception and fertility among in-school adolescents in Ikenne Local Government, south-western Nigeria. Nigerian Journal of Clinical Practice, 9(1):26-36. Article available at: http://www.ajol.info/index.php/njcp/article/view/11265/63489}

A cross-sectional study was conducted among in-school adolescents in six secondary schools in the health districts of Ikenne Local Government, South West, Nigeria to assess the sexual behaviour, contraception and fertility experiences of the adolescents between the months of May and November 2002. Secondary school students in the age group of 13-18 years constituted the bulk, 71.1 percent (810) of the respondents, students in age group 10-12 years were 15.0 percent (171), while those aged 19-24 years were 13.9 percent (159). The mean ages at first intercourse were $13.9+/-2.8$ years and $14.8+/-2.4$ years for males and females, respectively. Boys initiated sex earlier than girls. This difference was found to be statistically significant $(p<0.05)$. Sexual intercourse had been experienced by 28.5 percent of the adolescent students, significantly more (37.6 percent) males than females (20.4 percent). The school adolescents that responded as being married were.4.5 percent (26males, 23 females) of the respondents. Knowledge on contraception was 36.9 percent and 22.1 percent for male and female students, respectively, more males than females had knowledge of contraception in a significant proportion, apparently due to increased awareness of the male condom among males. Current use of contraception was equally low, and was found to be 10.9 percent and 6.0 percent for males and females, respectively. The reasons for non-use were mainly that of nonavailability (22.3 percent), cost (11.8 percent), negative attitude towards contraception due to societal disapproval (33.2 percent), and lack of knowledge of how to use them (21.3 percent). The proportion of adolescents that had ever experienced symptoms associated with sexually transmitted infections was 26.8 percent. 
Bassey, E. A., Abasiattai, A. M., Asuquo, E. E., Udoma, E. J., \& Oyo-lta, A. (2005). Awareness, attitude and practice of contraception among secondary school girls in Calabar, Nigeria. Nigerian Journal of Medicine, 14(2):146-150. Abstract available at: http://www.ncbi.nlm.nih.gov/pubmed/16083236 Article available at: http://www.ajol.info/index.php/njm/article/view/37171

This study was carried out to assess the awareness, attitude, and use of contraceptives among secondary school girls in Calabar, Cross River State, South-South, Nigeria and to determine how attitude affects its use. Data was obtained using self-administered, semi-structured questionnaires distributed to 480 secondary school girls out of whom 450 properly filled and returned them. The study revealed that contraceptive awareness was high. The main sources of contraceptive information were books/magazines (37 percent) and friends (26 percent). Three hundred and thirty-three (74 percent) girls had a negative attitude (misconceptions) towards contraceptives, while 117 (26 percent) girls said contraceptives were essential/useful. Sixty-six girls (14.7 percent) admitted that they were currently sexually active and 42 (9.3 percent) of them used contraceptives. There was a statistically significant association between positive attitude/beliefs and use of contraceptives.

Ikeme, A. C., Ezegwui, H. U., \& Uzodimma, A. C. (2005). Knowledge, attitude and use of emergency contraception among female undergraduates in eastern Nigeria. Journal of Obstetrics and Gynaecology, 25(5):491-493. Article available at: http://informahealthcare.com/doi/abs/10.1080/01443610500176291

The objective of the study was to investigate the knowledge, use, and attitude towards emergency contraceptive pills among female undergraduates. This was done using a randomly selected sample of female undergraduate students at three tertiary institutions in Enugu, South-East, Nigeria. A total of 500 questionnaires were administered. The overall response rate was 84 percent and 420 questionnaires were analysed. Almost three-quarters (73.8 percent) were aged between 15 and 24 years. The majority of the respondents (95 percent) were aware of contraception. However, 61 percent of the female undergraduates had heard of emergency contraception but only 31 percent had actually used it. The most common source of information about emergency contraceptive pills was from friends and teachers. Most respondents (19 percent) used Postinor rather than other types. While using emergency contraception, 16 percent got pregnant, of whom 9 percent carried the pregnancy to term and delivered the baby while 10 percent procured an illegal abortion. Increased utilization of emergency contraception is plagued with fear of infertility, anovulation, ill health, and sexually transmitted infections. Though 40 percent of the female undergraduates accepted it when informed and would recommend it to other female students, more information dissemination is required to further create awareness and enhance wider acceptance. Awareness programmes should address the barriers to effective use of emergency contraception preferably using peer educators and the media.

\section{Ozumba, B.C., Obi, S.N., \& ljioma, N.N. (2005). Knowledge, attitude and practice of modern contraception among single women in a rural and urban community in southeast Nigeria. Journal of Obstetrics and Gynaecology, 25(3):292-5. Article available at: http://informahealthcare.com/doi/abs/10.1080/01443610500105498}

This study was to ascertain the knowledge, attitude and practice of contraception among single women in a rural and urban community in southeast Nigeria, using a cross-sectional survey of 279 and 295 single women in Ngwo (rural) and Enugu (urban) community. The mean age of the population was 21.3 years. Contraceptive awareness was more among the urban than rural respondents (90.2 percent vs 34.1 percent). The major sources of contraceptive knowledge were mass media (68 percent) and peer groups (86.3 percent) for the urban and rural respondents, respectively. Most respondents in both groups had positive attitude towards contraception. More urban than rural respondents (68.3 percent vs 12.5 percent) began sexual activity during adolescence and the level of contraceptive use during first coitus were 48.4 percent and 13.7 percent, respectively. Of the currently sexually active respondents, 32.5 percent (rural) and 59.7 
percent (urban) were using a form of modern contraception. Condoms, followed by oral pills were the most popular contraceptive method because they can easily procure them over the counter. Poor contraceptive information, highly critical behaviour of family planning providers towards unmarried women seeking contraception and attitude of male partners militate against contraceptive practice.

\section{Olaseha, I. O., Ajuwon A. J., \& Onyejekwe, O. C. (2004). Reproductive health knowledge and use of contraceptives among adolescent mothers in a sub-urban community in Oyo State, Nigeria. African Journal of Medicine and Medical Science, 33(2):139-143. Article available at: http://www.ncbi.nlm.nih.gov/pubmed/15565932/}

This survey explored the reproductive health knowledge and use of contraceptives among 316 young mothers in Ogbere, a sub-urban community in Oyo State, South-West Nigeria. A cluster sampling technique was used to recruit the respondents and data were collected from them through face-to-face interviews using questionnaires. The ages of the respondents ranged from 17 to 20 with a mean of 18.9. The majority (76.9 percent) of the respondents were married and had primary school education (72.8 percent). Five percent had lost a pregnancy due to abortion, miscarriage, or still birth. Forty-three percent had fair, poor (34.5 percent), and good knowledge of contraceptives (22.5 percent); 53 percent did not know any of the routes for HIV transmission. A large majority (70 percent) had never used any contraceptives, 29 percent had done so. Eighty percent of those who had ever used any contraceptive were using one at the time of the survey. The most popular contraceptives used were condoms (44.4 percent) and pills (16.1 percent).

\section{Anochie, l., \& Ikpeme, E. (2003). The knowledge, attitude and use of contraception among secondary school girls in Port Harcourt. Nigerian Journal of Medicine, 12(4):217-220. Article available at: http://www.ncbi.nlm.nih.gov/pubmed/14768197}

This study sought to describe the knowledge, attitude and use of contraception among female students in Port Harcourt, Rivers State, South-South, Nigeria. A self-administered questionnaire was used for the study. Five hundred and thirty four students selected from a female only secondary school in Port Harcourt Local Government Area of Rivers State were studied. The students were aged 8-23 years (mean 15.6 years). Two hundred and sixty four (49.4 percent) were in junior classes (JSS1-3) and 270 (50.6 percent) in senior classes (SS1-SS3). Two hundred ninety-five (55.2 percent) of the respondents had heard of at least one contraceptive method. Age and not the academic level significantly influenced knowledge. Condom was the commonest method known by the students. Few students ( $<10$ percent) had knowledge of the modern contraceptive methods. One hundred thirty-five (25.3 percent) students believed that contraceptives could be harmful. Among the sexually active girls, only 45.3 percent had ever used any method of contraception. The use of contraception was more among junior students than senior students (64.5 percent vs 35.5 percent).

Aziken, M. E., Okonta, P. I., \& Ande, A. B. (2003). Knowledge and perception of emergency contraception among female Nigerian undergraduates. International Family Planning Perspectives, 29(2):84-87. Article available at: http://www.jstor.org/stable/pdf/3181062.pdf

Between September and October 2001, a randomly selected sample of female undergraduate students at the University of Benin, Edo State, South-South, Nigeria, were surveyed about their demographic information, sexual history and contraceptive use, and their awareness and knowledge of emergency contraception. Of the 880 respondents, 69 percent were between ages 20 and 24 years, 43 percent were sexually active, 39 percent had ever practiced contraception, and 34 percent had ever had an induced abortion. Overall, 58 percent of respondents reported knowing about emergency contraception; sexually active respondents were significantly more likely than those who were not, and those who had ever practiced contraception were more likely than those who had not to be aware of emergency contraceptives. However, only 18 percent of respondents who reported knowing about emergency contraception knew the correct time frame in which emergency contraceptives must be used to be effective. 
Arowojolu, A.O., Ilesanmi, A. O., Roberts, O. A., \& Okunola, M. A. (2002). Sexuality, contraceptive choice and AIDS awareness among Nigerian undergraduates. African Journal of Reproductive Health, 6(2):60-70. Article available at: https://www.researchgate.net/publication/10995097 Sexuality contraceptive choice a nd_AIDS_awareness_among_Nigerian_undergraduates

This survey of 2388 Nigerian undergraduates was performed to understand the sexual behaviour and contraceptive practice among them as related to their awareness of HIV infections. This survey was carried out among students in the University of Ibadan; University of Lagos; Ogun State University; Lagos State University; The Polytechnic, Ibadan; Lagos State Polytechnic and Ogun State Polytechnic, all of which are located in South-western Nigeria. Of the 2,388 respondents, 52.4 percent were males and 47.6 percent were females. The sex of the respondents was about evenly distributed but there were more females than males among the polytechnic students. Majority (74.1 percent) were aged between 16 and 25 years. Findings revealed that 87 percent were sexually active and 66 percent had more than one sexual partner, while 17.5 percent have had clandestine abortions. All respondents were quite knowledgeable about HIV/AIDS but few sexually active ones took precautions to prevent HIV transmission. Majority (87.5 percent), were knowledgeable about contraception and approved of its use, but only 34.2 percent were current users of contraceptives. About 58 percent of these cited pharmacy shops as their source of contraceptives.

\section{Briggs, I. L. (2002). Comparative analysis of parents' and teachers' view points on contraceptive practice among adolescents in Port Harcourt, Nigeria. West African Journal of Medicine, 21(2):95-98. Article available at: http://www.pubfacts.com/detail/12403026/Comparative-analysis-of-parents-and- teachers-view-points-on-contraceptive-practice-among-adolescents}

This study compared the viewpoints of parents and teachers on contraceptive practice by sexually active adolescents in the study environment. The instrument for the study was a structured and pre-tested questionnaire. Findings showed that there was significant difference in opinion between parents and teachers on the use of contraceptives by adolescent girls. Most (79.1 percent) parents will not encourage girls to use contraceptives. However, a substantial number (45.8 percent) of teachers would similarly not encourage adolescents to use contraceptives. Various reasons were given by both respondents for discouraging adolescents from using contraceptives although there was significant difference in the reasons given.

Adekunle, A.O., Arowojolu, A.O., Adedimeji, A.A., \& Roberts, O.A. (2000). Adolescent contraception: survey of attitudes and practice of health professionals. African Journal of Medicine and Medical Sciences, 29(3-4):247-52. Article available: http://www.ncbi.nlm.nih.gov/pubmed/11714000\#

This study compared the viewpoints of parents and teachers on contraceptive practice by sexually active adolescents in the study environment. The instrument for the study was a structured and pre-tested questionnaire. Findings showed that there was significant difference in opinion between parents and teachers on the use of contraceptives by adolescent girls. Most (79.1 percent) parents will not encourage girls to use contraceptives. However, a substantial number (45.8 percent) of teachers would similarly not encourage adolescents to use contraceptives. Various reasons were given by both respondents for discouraging adolescents from using contraceptives although there was significant difference in the reasons given. 


\section{Adekunle, A.O., Arowojolu, A.O., Adedimeji, A.A., \& Roberts, O.A. (2000). Adolescent contraception: survey of attitudes and practice of health professionals. African Journal of Medicine and Medical Sciences, 29(3-4):247-52. Article available: http://www.ncbi.nlm.nih.gov/pubmed/11714000\#}

The aim of this study was to assess the attitudes and practice of health workers in Ibadan, Southwest Nigeria, regarding adolescent contraception. A structured questionnaire was administered to 735 health workers in selected hospitals and health facilities in Ibadan. Information relating to their practice and attitudes towards adolescent contraception was sought. The results revealed that while 58.9 percent of the respondents had counselled adolescents, only 30.7 percent had ever prescribed contraceptives for them. Among health workers that approved of family planning, 52.6 percent were favourably disposed to adolescent contraception while 23.9 percent were not. We observed that 40.2 percent of health workers that did not approve of family planning were not favourably disposed to adolescent contraception. Health workers who counselled adolescents on the use of contraceptives were more likely than those who did not to approve of its use. In addition, those who approved of family planning were 12 times more than those who did not, to have a favourable disposition to adolescent contraception.

\section{Arowojolu, A. 0., \& Adekunle A. 0. (2000). Perception and practice of emergency contraception by post-secondary school students in southwest Nigeria. African Journal of Reproductive Health, 4(1):56-65. Article available at: http://www.jstor.org/stable/pdf/3583243.pdf}

This study was designed to assess the perception and practice of emergency contraception (EC) by female students in post-secondary institutions in the south-western part of Nigeria (University of Ibadan; University of Lagos; Ogun State University and Ibadan Polytechnic, Schools of Nursing and Midwifery at the University College Hospital, Ibadan; Oyo State Schools of Nursing and Midwifery and the Civil Service Training School, Ibadan, Oyo State). Most respondents were aged 16-25 (75.1 percent), single (86.3 percent), Christians from Pentecostal churches (49.9 percent), and university students (50.5 percent). Among the married respondents, 89.7 percent had monogamous union while 11.3 percent were in polygamous unions. Respectively, 32.4 percent, 20.4 percent and 19.8 percent knew that combined pills, progesterone only pills and intrauterine contraceptive device (IUCD) were usable for EC, while 56.7 percent mentioned the use of traditional methods. Only 11.8 percent had ever used either pills or IUCD and 10.7 percent had used a traditional method. Few students (11.5 percent and 2.3 percent respectively) knew the correct timing of EC pills and IUCD. The respondents reported varying circumstances under which EC was indicated but the majority cited condom breakage and sexual assault. The popular media represent the commonest source of information while hospitals/clinics were the commonest sources of procurement. About 37 percent of the respondents planned to use EC in future while 58 percent would not and 4.7 percent were uncertain. Reasons for these responses were explored.

\section{Okpani, A. O. U., \& Okpani, J. U. (2000). Sexual activity and contraceptive use among female adolescents: a report from Port Harcourt, Nigeria. African Journal of Reproductive Health, 4(1):40-47. Article available at: http://www.jstor.org/stable/pdf/3583241.pdf}

Seven hundred sixty-eight randomly selected single senior secondary school girls from Port Harcourt (mean age 16.32 years) were surveyed on aspects of sexual activity and contraceptive use. Two hundred ten (210) pregnancies (24 deliveries and 186 induced abortions) had occurred in 142 out of 605 girls (78.8 percent) who admitted being sexually exposed. The mean, modal, and youngest ages of initiation into sexual activity were 15.04, 15, and 12 years, respectively. At the time of the survey, 190 girls (24.7 percent) were sexually active and 74.2 percent of their male partners were older working men. Other findings were high awareness (72.4 percent) of the relationship between sexual activity and sexually transmitted infections; a rather low level (56 percent) of knowledge of effective contraceptive methods, and limitation of contraceptive method use by sexually active girls, largely to the rhythm and withdrawal methods. Exposure to multiple sexual partners and a high level of parental approval of subjects' use of contraception were also present. 


\section{Prevention and Treatment of Reproductive Tract and Sexually Transmitted Infections}

Amaugo, L. G., Papadopoulos, C., Ochieng, B. M., \& Ali, N. (2014). The effectiveness of HIV/AIDS school-based sexual health education programmes in Nigeria: a systematic review. Health Education Research, 29(4):633-648. Abstract available at: http://www.ncbi.nlm.nih.gov/pubmed/24572458 Article available at: http://her.oxfordjournals.org/content/29/4/633.long

This systematic review assessed the efficacy of sexual health educational programmes and examined how future programmes and their evaluations can improve. Primary literature published between January 2002 and May 2012, which measured sexual health outcomes among school-based Nigerians before and after a sexual health education programme was delivered, were identified. All seven studies that met the inclusion and exclusion criteria showed there had been positive changes in outcomes following these educational programmes. These included increased knowledge, healthier attitudes, and safer sexual health behaviour. However, these studies each had methodological flaws which highlighted a range of important design, implementation, and evaluation challenges that future programmes need to meet.

Asubiaro, O.Y., \& Fatusi, A.O. (2014). Differential effects of religiosity on sexual initiation among Nigerian in-school adolescents. International Journal of Adolescents Medicine and Health, 26(1):93-100. Article available at: http://www.degruyter.com/view/j/ijamh.2014.26.issue-1/ijamh-2012-0118/ijamh-20120118.xml

This cross-sectional study examined the influence of religiosity on sexual debut among in-school adolescents (aged 10-19) in Lagos State, South-West, Nigeria. Data was obtained from 1,350 randomly selected inschool adolescents using a self-administered questionnaire. Internal and external religiosity, defined based on the extant literature, were the independent variables. Of the participants, 19.8 percent of the females and 26.6 percent of the males have had sex $(p<0.004)$. Internal religiosity was protective against sexual debut among females ( $\mathrm{HR}=0.63,95$ percent $\mathrm{Cl}=0.44-0.91)$, whereas external religiosity was protective among the males $(\mathrm{HR}=0.70,95$ percent $\mathrm{Cl}=0.51-0.71)$. Age was positively associated with sexual debut among both male $(\mathrm{HR}=1.11,95$ percent $\mathrm{Cl}=1.001-1.24)$ and female adolescents $(\mathrm{HR}=1.26,95$ percent $\mathrm{Cl}=1.11-1.42)$. Early pubertal development $(\mathrm{HR}=1.11$; 95 percent $\mathrm{Cl}=1.001-1.24)$ was also a risk factor for male adolescent sexual initiation. In addition, knowledge of HIV/AIDS risk $(\mathrm{HR}=0.47 ; 95$ percent $\mathrm{Cl}=$ $0.30-0.72$ ) was a protective factor against sexual debut among adolescent females, whereas the positive perspective of friends' involvement in sex $(\mathrm{HR}=1.014 ; 95$ percent $\mathrm{Cl}=1.21-2.58)$ was a risk factor.

Emelumadu, O. F., Ezeama, N. N., Ifeadike, C. O., Ubajaka, C. F., Adogu, P. O., Umeh, U., Onyeonoro, U. U. (2014). Parents' perceptions of timing of initiation of sexuality discussion with adolescents in Anambra State, South Eastern Nigeria. Journal of Paediatric and Adolescent Gynaecology, 27(5):294-300. Article available at: http://www.jpagonline.org/article/S1083-3188\%2813\%2900378-1/abstract

This study aimed to determine the perception of the timing and practice of sexuality discussion among parents in South Eastern Nigeria. The study was carried out in three randomly selected Local Government Areas in Anambra State, South Eastern Nigeria. The study participants were parents with adolescent children 
who had been residents in the study areas for at least two years. Most parents opined that the sexuality discussion should be initiated after puberty. Only 20 percent of them discussed reproductive health issues often with their adolescents, while another 20 percent never discussed such issues with their adolescent children. Topics most commonly discussed bordered on the adverse consequences of sex rather than measures for preventing them. About half of parents were willing to discuss contraception with their adolescent child. Predictors of parent-child communication were age, gender, and educational status. Common reasons for low parental involvement in sexuality discussions were due to their lack of capacity and the perception that discussing such issues before puberty is ill timed.

\section{Ezeanochie, M.C., \& Olagbuji, B.N. (2014). Human papilloma virus vaccine: determinants of acceptability by mothers for adolescents in Nigeria. African Journal of Reproductive Health, 18(3):154-158. Article available at: http://www.bioline.org.br/pdf?rh14053}

This was a cross-sectional survey of 201 mothers attending the gynaecology clinic at the University Of Benin Teaching Hospital in South-south Nigeria on acceptability of the HPV vaccines and its determinants. Although 70 percent accepted vaccination of their daughters, 30 percent were unwilling with the most common reason being that it may encourage sexual promiscuity (62.3 percent). Mothers with poor knowledge of sexually transmitted infections were significantly more unwilling to accept HPV vaccines compared to those with average or good knowledge $(p=0.002)$. Furthermore, perception of susceptibility to HPV infection by daughters was significantly associated with acceptance of the vaccines $(p=0.0001)$.

\section{Kunnuji, M. (2014). Basic deprivation and involvement in risky sexual behaviour among out-of-school young people in a Lagos slum. Culture, Health, \& Sexuality, 16(7):727-40. Article available at: http://www.tandfonline.com/doi/pdf/10.1080/13691058.2014.894206}

This study set out to examine the association between forms of basic deprivation-such as food deprivation, high occupancy ratio as a form of shelter deprivation, and inadequate clothing-and two sexual outcomestiming of onset of penetrative sex and involvement in multiple sexual partnerships. The study used survey data from a sample of 480 girls (aged 10-19 years) resident in Iwaya community (Lagos, South-West Nigeria). A survival analysis of the timing of onset of sex and a regression model for involvement in multiple sexual partnerships revealed that among the forms of deprivation explored, food deprivation is the only significant predictor of the timing of onset of sex and involvement in multiple sexual partnerships.

Odeyemi, K. A., Onajole, A. T., Ogunowo, B. E., Olufunlayo, T., \& Segun, B. (2014). The effect of a sexuality education programme among out- of- school adolescents in Lagos, Nigeria. Nigerian Postgraduate Medical Journal, 21(2):122-127. Abstract available at: http://www.ncbi.nIm.nih.gov/pubmed/25126865 Article available at: https://www.researchgate.net/publication/264831220_The_effect_of_a_sexuality_educa tion_programme_among_out-_of-_school_adolescents_in_Lagos_Nigeria

This intervention study was conducted to assess the effect of a community-based sexuality education programme on the sexual health knowledge and practices of out-of-school female adolescents. The study was conducted in two markets within Lagos, Nigeria. Representative samples of adolescents were interviewed on their sexual health knowledge and practices. An education-entertainment programme provided sexuality education to adolescents in the Mushin market only (intervention group) followed by post intervention surveys six months later in the Mushin market and Sangrouse market (control group). The pre and post intervention surveys were compared to detect any changes. Sexual health knowledge and behaviour was similar among respondents in both markets pre intervention. Post intervention, the sexual health knowledge of the respondents in the intervention site improved significantly $(p<0.05)$. Fewer adolescents initiated sex in the intervention site than in the control site and contraceptive use increased. However among the sexually active, there was no significant change in their condom use and number of sexual partners. 
Ojikutu, B., Higgins-Biddle, M., Greeson, D., Phelps, B. R., Amzel, A., Okechukwu, E., \& Hirschhorn, L. R. (2014). The association between quality of HIV care, loss to follow-up and mortality in pediatric and adolescent patients receiving antiretroviral therapy in Nigeria. PLoS One, 9(7). Article available at: http://journals.plos.org/plosone/article?id=10.1371/journal.pone.0100039

A retrospective cohort study was conducted with patients aged 18 and under enrolled in care between November 2002 and December 2011 to explore the quality of HIV care and treatment in Nigeria and to determine the association between quality of care, loss to follow-up, and mortality. This was carried out in 23 sites across 10 states which included 1,516 patients. A quality score comprised of six process indicators was calculated for each patient. More than half of the patients (55.5 percent) were found to have a high quality score, using the median score as the cut-off. Most patients were screened for tuberculosis at entry into care (81.3 percent), had adherence measurement and counselling at their last visit (88.7 percent and 89.7 percent, respectively), and were prescribed co-trimoxazole at some point during enrolment in care (98.8 percent). Thirty-seven percent received a CD4 count in the six months prior to chart review. Mortality within 90 days of ART initiation was 1.9 percent. A total of 4.2 percent of patients died during the period of follow-up (mean: 27 months) with 19.0 percent lost to follow-up. In multivariate regression analyses, weight for age z-score (Adjusted Hazard Ratio (AHR): 0.90; 95 percent $\mathrm{Cl}$ : 0.85, 0.95) and high quality indicator score (compared a low score, AHR: 0.43; 95 percent $\mathrm{Cl}$ : 0.26, 0.73) had a protective effect on mortality. Patients with a high quality score were less likely to be lost to follow-up (Adjusted Odds Ratio (AOR): 0.42; 95 percent Cl: 0.32, 0.56), compared to those with low scores.

Olugbenga-Bello, A.I., Adebimpe, W.O., Akande, R.O., \& Oke, O.S. (2014).Health risk behaviours and sexual initiation among in-school adolescents in rural communities in south-western Nigeria. International Journal of Adolescent Medicine and Health. 26(4):503-10. Article available at: http://www.degruyter.com/view/j/ijamh.2014.26.issue-4/ijamh-2013-0326/ijamh-20130326.xml;jsessionid

This was a school-based descriptive cross-sectional study among 377 in-school adolescents, who were selected using multistage sampling methods. Research instruments were semi-structured self-administered questionnaires. The mean age of respondents was $15.7(+1.8)$ years. Most of the respondents claimed to have heard about sex education at one time or another. About 53 (14.1 percent) had their first sexual experience before or at the age of 15 years. The mean age of the first sexual experience for males was 14 years 3 months and 15 years 3 months for females. Fourteen (3.7 percent) had no fixed sexual partner; most of the sexually active respondents did not use a condom during their last intercourse. Only 7.7 percent of the respondents reported to have had a sexually transmitted infection. Most of the 207 female respondents (85.5 percent) had never been pregnant while 88.9 percent of those who had been pregnant had an abortion. Females were about 1.5 times more likely to have had first sexual intercourse before the age of 15 years, though the observed likelihood was not statistically significant [odd ratio $(\mathrm{OR})=0.7,95$ percent; confidence interval $(\mathrm{Cl})=0.3-1.5 ; \mathrm{p}=0.642$ ]. Likewise, males were 1.7 times more likely to have used condoms at the last sexual intercourse, and the observed likelihood was not statistically significant (OR $=1.7 ; 95$ percent $\mathrm{Cl}=0.8-3.4 ; \mathrm{p}=0.079$ ). 
Tobin-West, C. I., Maduka, O., Onyekwere, V. N., \& Tella, A. O. (2014). Awareness, acceptability, and use of female condoms among university students in Nigeria: implications for STI/HIV prevention. International Journal of Adolescent Medicine and Health, 26(2):259-262. Article available at: http://www.degruyter.com/view/j/ijamh.2014.26.issue-2/ijamh-2013-0300/ijamh-20130300.xml;jsessionid=4C923A3E4F91E6900B26B2332685E6BB

The study assessed the acceptability and use of female condoms in the context of HIV prevention in order to provide basic information that can stimulate female condom programming to promote sexually transmitted infection and HIV prevention among youth in tertiary institutions. The study was carried out among 810 undergraduate students of the University of Port Harcourt (South-south, Nigeria) from October to November 2011, using a stratified sampling method and self-administered questionnaires. The study revealed that most of the students, 589 (72.7 percent) were sexually active; 352 (59.7 percent) reported having just one sexual partner, while 237 ( 40.3 percent) had multiple partners. The mean number of sexual partners in the past six months was $2.2 \pm 0$. Consistent condom use was reported among 388 (79.2 percent) students, 102 (20.8 percent) reported occasional usage, while 99 (16.8 percent) did not use condoms at all. Only 384 (65.2 percent) of the students had ever been screened for HIV. Although 723 (89.3 percent) were aware of female condoms, only 64 (8.9 percent) had ever used one due to unavailability, high cost, and difficulty with its insertion. Nevertheless, 389 (53.8 percent) of the students expressed willingness to use them if offered, while 502 (69.4 percent) would recommend it to friends/peers.

\section{Abu-Saeed, M. B., \& Abu-Saeed, K. (2013). Attitudinal changes using peer education training in the prevention of HIV/AIDS: a case study of youths in North Central Nigeria. Advanced Pharmaceutical Bulletin, 3(1):45-50._Article available at: http://www.ncbi.nlm.nih.gov/pmc/articles/PMC3846034/pdf/apb-3-45.pdf}

This experimental study was aimed at assessing the impact of peer education in terms of attitudinal changes and practices on issues related to HIV/AIDS among youth in North Central Nigeria. The study was carried out in Ilorin West Local Government Area (LGA) of Kwara State, North Central, Nigeria. Participants included male and female students of Government High School between the ages of 15 and 24 years who had never had previous peer education training on HIV/AIDS with a control group of similar composition as the study group. The sample size was 80 students each for study and control groups. There was no significant difference before the intervention when respondents in both study and control groups were asked if they thought they were at risk at contracting HIV $(p=0.642)$. The reverse was the case after intervention $(p=0.015)$. More respondents (about 52.5 percent) in the study group thought that they were at risk of acquiring HIV after the intervention. All the study group participants were willing to take an HIV test after the intervention and when compared to those willing in the control group (there was no change before and after the intervention), the difference was found to be statistically significant $(0.000)$. The results revealed that peer education training among youth can be used to provide HIV/AIDS education and bring about attitudinal changes.

Adebowale, S. A., Ajiboye, B. V., \& Arulogun, O. (2013). Patterns and correlates of condom use among unmarried male youths in Nigeria: NDHS 2008. African Journal of Reproductive Health, 17(3):149-159. Article available at: http://www.bioline.org.br/pdf?rh13048

This retrospective, cross-sectional study utilized the 2008 Nigerian Demographic and Health Survey dataset to improve existing knowledge on condom use and its associated factors among male youth in Nigeria. The study focused on unmarried male youth in Nigeria, who had ever had sexual intercourse (vaginal, oral, and anal). Mean age of the respondents was $20.5 \pm 2.4,62.0$ percent ever used a condom and 49.5 percent were currently using a condom. Among the sexually active, age, region, residence, education, wealth index, ever undergone an HIV test, and total life-time number of sexual partners were significantly associated with the current use of a condom. Living in the South West $(\mathrm{OR}=2.47 ; \mathrm{C} . \mathrm{I}=1.72-3.55 ; \mathrm{p}<0.001)$ and South East 
$(\mathrm{OR}=2.11 ; \mathrm{C} . \mathrm{I}=1.38-3.22 ; \mathrm{p}=0.001)$ was a determinant factor for having ever used a condom than living in the north central. The odds of ever having used a condom was higher among male youth who were in the middle, richer, and richest wealth quintiles than the poorest. Having ever undergone HIV testing increased the likelihood of using a condom.

\section{Aderemi, T. J., Pillay, B. J., \& Esterhuizen, T. M. (2013). Differences in HIV knowledge and sexual practices of learners with intellectual disabilities and non-disabled learners in Nigeria. Journal of the International AIDS Society, 16(1):17331. Article available at: http://www.ncbi.nlm.nih.gov/pmc/articles/PMC3568677/pdf/JIAS-16-17331.pdf}

This cross-sectional, comparative study utilized a survey to investigate HIV knowledge and sexual practices among learners with mild/moderate intellectual disabilities and non-disabled learners (NDL) in Nigeria. Learners with mild/moderate intellectual disabilities $(n=300)$ and NDL $(n=300)$ within the age range of 12 to 19 years drawn from schools across Oyo State, South-West, Nigeria, completed a structured questionnaire to assess their knowledge of HIV transmission and sexual practices. Significantly more learners with mild/moderate intellectual disabilities (62.2 percent) than NDL 48 (37.8 percent) reported having sexual experience ( $p=0.002)$. Of the sexually experienced female learners with mild/moderate intellectual disabilities, 28 (68.3 percent) reported history of rape compared with 9 (2.9 percent) of female NDL ( $p=$ 0.053). Intellectual impairment was significantly associated with lower HIV transmission knowledge scores ( $p$ $<0.001$ ). Learners with mild/moderate intellectual disabilities were less likely than NDL to have heard about HIV from most of the common sources of HIV information ( $p<0.001)$. In addition, when compared with nondisabled learners, learners with mild/moderate intellectual disabilities were significantly more likely to have reported inconsistent condom use with boyfriends/girlfriends ( $p<0.001$ ), with casual sexual partners ( $<<$ $0.001)$ and non-use of condom during last sexual activity $(p<0.001)$. Findings suggest that adolescents with intellectual impairments are at higher risk of HIV infection than their nondisabled peers. This gap could be addressed through interventions that target Nigerians with intellectual impairments with accessible HIV information and services.

Aransiola, J. O., Asa, S., Obinjuwa, P., Olarewaju, O., Ojo, 0. O., \& Fatusi, A. O. (2013). Teachers' perspectives on sexual and reproductive health interventions for in-school adolescents in Nigeria. African Journal of Reproductive Health, 17(4):84-92. Article available at: http://www.ajol.info/index.php/ajrh/article/view/98378/87662

This qualitative study involved conducting 16 focus group discussions among teachers from 8 secondary schools in Ile-Ife and Ilesa, Osun State, South-West, Nigeria. The aim of the study was to examine the perception and the level of involvement that teachers would prefer in school-based adolescent reproductive health education. In this study, the teachers favoured school-based reproductive health education (RHE), but have diverse opinions on what should be included in such RHE. A majority of the teachers were not willing or comfortable with being involved in personal counselling of students but could teach RHE in a classroom environment. They supported the current approach of expelling pregnant school girls.

Arulogun, O. S., Titiloye, M. A., Afolabi, N. B., Oyewole, O. E., \& Nwaorgu, O. G. (2013). Experiences of girls with hearing impairment in accessing reproductive health care services in Ibadan, Nigeria. African Journal of Reproductive Health, 17(1):85-93. Article available at: http://www.bioline.org.br/pdf?rh13008

This study described experiences of 167 girls with hearing impairment in accessing reproductive health services in Ibadan, Oyo State, South-West, Nigeria, using a validated questionnaire. The scope of this study was delimited to communication/interactive experiences between service providers and hearing impaired clients as well as the factors influencing access to services. A total of 167 hearing impaired girls comprising 140(83.8 percent) in-school and 27 (16.2 percent) out-of-school were interviewed. The age range of the hearing impaired girls surveyed was 11-25 years with an overall mean age as at their last birthday being $17.5 \pm 3.4$ years. Almost 95.0 percent of respondents had ever visited a health facility for reproductive health 
issues. Of these 6.2 percent and 4.6 percent went for treatment of STIs and pregnancy termination, respectively; 36.7 percent were embarrassed to ask questions in the presence of an interpreter. Communication (40.5 percent) and cost (10.8 percent) were key barriers to access and 85.6 percent would use a facility if hearing impairment-friendly services were provided. Respondents who were currently working were 20 times more likely to receive services they wanted ( $O R=20.29, \mathrm{Cl}=1.05-392.16)$.

\section{Ezenwa, B.N., Balogun, M.R., \& Okafor I.P. (2013). Mothers' human papilloma virus knowledge and willingness to vaccinate their adolescent daughters in Lagos, Nigeria. International Journal of Women's Health, 5,371-7. Article available at: http://www.ncbi.nIm.nih.gov/pmc/articles/PMC3711756/pdf/ijwh-5-371.pdf}

The objective of this study was to assess mothers' human papillomavirus (HPV) knowledge and their willingness to vaccinate their adolescent daughters in Lagos, Southwest Nigeria. This study was a community-based, descriptive cross-sectional study carried out in July 2012 in Shomolu Local Government Area (LGA). A multistage sampling method was employed to select the 290 respondents who participated in the study. Structured, pretested, interviewer-administered questionnaires were used for data collection. The study revealed low awareness of HPV (27.9 percent) and HPV vaccines (19.7 percent) among the mothers that participated. There was a high awareness for cervical cancer but little knowledge of its link to HPV. Awareness and utilization of HPV vaccines increased with increasing educational level $(p<0.05)$. There was a high willingness and intention among the mothers to vaccinate their girls ( 88.9 percent) and to recommend the vaccine to others (91.0 percent). Accessibility and affordability of the HPV vaccines were found to be possible barriers to future utilization of the vaccines.

Iliyasu, Z., Abubakar, I. S., Sani, I. H., Jibo, A. M., Karaye, I. M., Salihu, H. M., \& Aliyu, M. H. (2013). Male circumcision and HIV risk behaviour among university students in northern Nigeria. American Journal of Men's Health, 7(2):94-101. Article available at: http://imh.sagepub.com/content/7/2/94.long

A cross-sectional study design was employed to explore knowledge and attitudes to male circumcision (MC) among university students in Kano, North-West, Nigeria $(n=375)$. Respondents' age ranged from 16 to 42 years (mean $\pm S D=23.2 \pm 3.54$ years). Almost all respondents (98.1 percent) reported being circumcised ( $n$ $=368$; 95 percent confidence interval $=96.2$ percent to 99.2 percent). There was no variation in circumcision status by age, ethnicity, religion, or marital status. Majority of the respondents were circumcised by a health worker (51.2 percent). Most circumcisions were performed between the ages of 5 and 10 years (57.9 percent) and for religious reasons (79.2 percent). Only 38 percent of the respondents $(n$ $=104$ ) were aware of the role of male circumcision in reducing HIV acquisition in heterosexual males. Three quarters of the respondents agreed that circumcised men still need to use condoms.

Mbamara, S. U., \& Obiechina, N. J. (2013). Awareness and attitudes toward voluntary counselling and testing for HIV/AIDS among law undergraduates in tertiary institutions in southeast Nigeria. Journal of Reproductive Medicine, 58(1-2):55-60. Abstract available at: http://www.ncbi.nlm.nih.gov/pubmed/23447920 Article available at: http://www.reproductivemedicine.com/toc/auto_abstract.php?id=24040

The objective of this cross-sectional questionnaire-based survey was to determine the knowledge of and attitudes towards voluntary counselling and testing (VCT) for HIV/AIDS among law undergraduates at tertiary institutions, Anambra State in southeast Nigeria. The respondents were all full-time law students and were aged from 15 to 42 years with a mean of 21.06 +/- 3.0 years and a modal age of 20-24 years. In all, 210 (71.4 percent) of the students were aware of VCT for HIV/AIDS, while 84 (28.6 percent) of the respondents had no knowledge of it. The most common sources of information about VCT for HIV/AIDS were electronic media (114 [38.8 percent]) followed by churches (67 [22.8 percent]) and print media (44 [15.0 percent). Although a majority of respondents had a positive attitude towards VCT for HIV/AIDS, 20 percent of them disapproved of VCT. 


\section{Sangowawa, A. O., \& Adebiyi, A. O. (2013).Factors associated with sexual abstinence among out-of-school females in a transitional town in Oyo State, South-Western Nigeria. Health Care Women International, 34(10):917-932. Article available at: http://www.tandfonline.com/doi/pdf/10.1080/07399332.2013.769998\#.VP 53-EYPLM}

The cross-sectional study was conducted in Ilero, which is a transitional (semirural) town in Kajola Local Government Area of Oyo State, South-western Nigeria. One hundred and forty-three unmarried out-of-school female respondents aged 15-24 years participated and 42 (29.4 percent) of them had never had sex. About 92 percent engaged in at least one leisure activity. Factors significantly associated with abstinence included: living arrangement, type of occupation, mode of earning, self-esteem, alcohol use, and some leisure activities $(p<.05)$. Factors predictive of abstinence were living with parents or other relatives, earning weekly and monthly wages as opposed to daily wages, high self-esteem, and reading of novels during leisure time.

Speizer, I. S., Fotso, J. C., Davis, J. T., Saad, A., \& Otai, J. (2013).Timing and circumstances of first sex among female and male youth from select urban areas of Nigeria, Kenya, and Senegal._Journal of Adolescent Health, 53(5):609-616. Article available at: http://www.ncbi.nIm.nih.gov/pmc/articles/PMC3805698/

This study examined the timing and circumstances of first sex among urban female and male youth in Kenya, Nigeria, and Senegal. In each country, a large, representative sample of women (aged 15-49) and men (aged 15-59) was collected from multiple cities. Data from youth (aged 15-24) were used for the analyses of age at sexual initiation, whether first sex was premarital, and modern family planning use at first sex. Cox proportional hazard models and logistic regression analyses were performed to determine factors associated with these outcomes. Across all three countries, a greater percentage of male youth than female youth reported initiating sex with a non-marital partner. More educated youth were less likely to have initiated sex at each age. In Nigeria and Senegal, poor female youth reported earlier first sex than wealthier female youth. In Kenya, richer female youth were more likely to have premarital first sex and to use contraception/condom at first sex than their poorer counterparts. Older age at first sex and youth who reported that first sex was premarital were significantly more likely to use a method of contraception (including condom) at first sex. City-specific distinctions were found and discussed for each outcome.

\section{Wusu, O. (2013). Exposure to media content and sexual health behaviour among adolescents in Lagos metropolis, Nigeria. African Journal of Reproductive Health,17(2):157-68. Article Available at: http://www.ajrh.info/vol17_no2/17_2_article15.pdf}

Data were gathered through a survey conducted among adolescents aged 12-19 years in the Lagos metropolis between November 2009 and February 2010. A multistage sampling strategy was adopted in selecting respondents. Logistic regression technique was utilised in the analysis. The results indicated that the respondents were most frequently exposed to television (male $=92.2$; female $=94.9$ ) and radio (male $=$ 88.2 ; female $=91.7$ ) media. The odds ratios indicated that sexual health content of mass media significantly predicted condom use, multiple sexual relationship, sexual intercourse, and self-reported occurrence of abortion in the study sample. 
Akinfaderin-Agarau, F., Chirtau, M., Ekponimo, S., \& Power, S. (2012). Opportunities and limitations for using new media and mobile phones to expand access to sexual and reproductive health information and services for adolescent girls and young women in six Nigerian states. African Journal of Reproductive Health, 16(2):219-230. Article available at: http://www.bioline.org.br/request?rh12031

This study aimed to gain insight into the context surrounding the use of mobile phones to provide sexual and reproductive health $(\mathrm{SRH})$ information and services. Focus group discussions were held with 726 females (aged 12-30 years; mean = 19.92 years) from Adamawa, Akwa Ibom, Cross River, Gombe, Kaduna, and Taraba states to assess their access to mobile phones, as well as the barriers and limitations to the use of their phones to seek SRH information and services. Results demonstrate high mobile phone access but limited use of phones to access SRH information and services. Barriers to use of these services included cost of service for young female clients, request for socio-demographic information that could break anonymity, poor marketing and publicity, socio-cultural beliefs and expectations of young girls, individual personality and beliefs, as well as infrastructural/network quality.

Arnold, R., Maticka-Tyndale, E., Tenkorang, E., Holland, D., Gaspard, A., Luginaah, I., \& HP4RY Team. (2012). Evaluation of school- and community-based HIV prevention interventions with junior secondary school students in Edo State, Nigeria. African Journal of Reproductive Health, 16(2):103-125. Article available at: http://www.bioline.org.br/pdf?rh12024

This study examined the impact of two interventions delivered in rural communities and junior secondary schools (JSS) in Edo State, South-South, Nigeria designed to decrease youth vulnerability to HIV infection. Analyses for this study used survey and focus group data collected from students in JSS grades 1-3 attending 30 public schools in Edo State, Nigeria. The Ministry of Education approved Family Life and HIV Education (FLHE) programme delivered in JSS and a community-based initiative to raise AIDS competency of rural communities were evaluated using a clustered randomized control trial and mixed qualitativequantitative methods. Ten schools were assigned to each of three research arms: FLHE programme only, FLHE and community programme, and control. Results demonstrated positive effects on rejection of myths, attitudes related to abstinence and use of condoms, and sexual activity. Confidence in these results is supported by both levels of statistical significance and consistency in patterns of results across different levels of schooling.

Berg, K., Sun, C. J., \& Babalola, S. (2012). Predictors of parent-child communication among a nationally representative sample in Nigeria. Journal of Social Aspects of HIV/AIDS Research Alliance, 9(2):95-103. Article available at: http://www.tandfonline.com/doi/pdf/10.1080/17290376.2012.683583

This study analysed data from the 2007 National HIV/AIDS and Reproductive Health Survey to explore what constructs were associated with parent-adolescent communication about AIDS/sexually transmitted infections (STIs) and sexual relationships in Nigeria. The analysis focused on the 2,593 men and women who had at least one child over the age of 12 years. The respondents were classified as low, medium, or high communicators. Low communicators were parents who did not talk to their child about either AIDS/STIs or sexual relationships. Medium communicators were parents who discussed only one topic with at least one child. High communicators were parents who discussed both topics with at least one child. Logistic regression was used to compare high communicators with low/medium communicators. There were commonalities and differences among men and women in the factors associated with parent-adolescent communication. Age, religion, and knowing where to obtain information about HIV/AIDS were associated with the extent of communication, regardless of the parent's gender. Perceived social support was an important correlate for fathers, while knowledge of female STI symptoms showed a significant association only for mothers. 
Dlamini, S. N, Maticka-Tyndale, E., Omorodion, F., Anucha, U., Lowik, A. J. \& HP4RY Team. (2012). What does a decolonizing/decentralizing methodology in examining sexual lives entail? African Journal of Reproductive Health, 16(2):55-70. Article available at: http://www.ajrh.info/vol16 no2/16 2 article5.pdf

This paper is based on an international study, HIV Prevention for Rural Youth (HP4RY) 2008-2012, designed to examine the state of, and teach about, sexual health and HIV/AIDS in Edo State, South-South, Nigeria. The paper focused on the mixed methods used in this study, paying attention to the meaning of collaboration and participation in research in a cross-continental setting. Additionally, the paper considered the complexities of engaging in decolonizing and respectful methodological approaches in these settings. Drawing on specifics from the mixed methods and details from the relevant literature, this paper demonstrates the continued need for cross-continental decolonization and decentralized engagements, specifically when dealing with sensitive topics like sexuality and HIV/AIDS.

Dlamini, N., Okoro, F., Ekhosuehi, U. O, Esiet, A., Lowik, A. J., \& Metcalfe, K. (2012). Empowering teachers to change youth practices: evaluating teacher delivery and responses to the FLHE programme in Edo State, Nigeria. African Journal of Reproductive Health, 16(2):87-102. Article available at: http://www.academia.edu/10255826/Empowering_Teachers_to_Change_Youth_Practice s_Evaluating_Teacher_Delivery_and_Responses_to_the_FLHE_Programme_in_Edo_State Nigeria

School-based programming is one of the most common approaches to HIV prevention among youth. This paper presents the history and development of the Family Life and HIV Education (FLHE) programme in Edo State, South-South, Nigeria and evaluation results of teacher actions and responses to training in its delivery. The setting of the project was 30 junior secondary schools in Edo State. Results indicate that teachers benefited from the training, were aware of new and/or existing teaching resources, and began to teach about HIV/AIDS. Teachers expressed that the programme facilitated open dialogue about HIV/AIDS. However, given limited human resources, FLHE was viewed as additional work to already overloaded teaching schedules.

Gilliam, M., Orzalli, S., Heathcock, S., Sutherland, E., Jagoda, P., Menendez, A., \& Ojengbede, O. (2012). From intervention to invitation: reshaping adolescent sexual health through storytelling and games. African Journal of Reproductive Health, 16(2):189-196. Article available at: http://www.bioline.org.br/pdf?rh12028

This article describes the Game Changer Chicago, an initiative that incorporates digital storytelling, new media, and game design to conduct workshops with youth around issues of sexuality and emotional health, and discusses its possible cross-cultural applications. The project sought to reframe and retool adolescent sexual health education through focusing on inviting rather than intervening with youth, which encourages self-empowerment. Based on the success of storytelling and digital media programs in Nigeria and the success of Game Changer Chicago, the investigators believe this model holds promise for implementation in Nigeria and other sub-Saharan African countries.

Godswill, J. (2012). Education and sexuality: towards addressing adolescents' reproductive health needs in Nigeria. Current Research Journal of Social Sciences, 4(4): 285-293. Article available at: http://maxwellsci.com/print/crjss/v4-285-293.pdf

In this article, the author assesses the role of sexuality education in addressing adolescents' reproductive health needs within the backdrop of immense challenges in Nigerian environment. 
Iliyasu, Z., Abubakar, I. S., Galadanci, H. S., Babam Maryam, A., \& Aliyu, M. H. (2012). Premarital sexual experience and preferred sources of reproductive health information among young men in Kumbotso, northern Nigeria. Nigerian Journal of Medicine, 21(3):343-349. Article available at: http://www.ncbi.nlm.nih.gov/pubmed/23304934 http://www.pubfacts.com/detail/23304934/Premarital-sexual-experience-and-preferredsources-of-reproductive-health-information-among-young-me

This study explored the predictors of premarital sex and preferred sources of sexual and reproductive health information among young unmarried men in Kumbotso Local Governemt Area in Kano state, North-West, Nigeria. A cross section of 400 young men was interviewed using structured questionnaires with mostly closed-ended questions. The age range of the respondents was 15-24 years with a mean age of 19.2 ( \pm 2.7) years. Of the 385 respondents, 39 (10.1 percent) were sexually experienced. Less than half of respondents (48.7 percent) used a condom at sexual debut, and an equal proportion reported having multiple sex partners. Only 41.0 percent of sexually experienced respondents reported subsequent consistent condom use. Age (adjusted odds ratio $[A O R]=4.12$; 95 percent confidence interval $(\mathrm{Cl})$ : 2.245.20 and educational attainment $[A O R=3.57$; 95 percent $\mathrm{Cl}(1.49-9.10)]$ were significant predictors of sexual experience. The current versus preferred sources of sexual and reproductive health information included friends (51.3 percent vs. 93.3 percent), Islamic school teachers (41.0 percent vs. 72.7 percent), and school teachers (8.8 percent vs. 15.1 percent).

Iliyasu, Z., Aliyu, M. H., Abubakar, I. S., \& Galadanci, H. S. (2012). Sexual and reproductive health communication between mothers and their adolescent daughters in northern Nigeria. Health Care Women International, 33(2):138-152. Article available at: http://www.pubfacts.com/detail/23304934/Premarital-sexual-experience-and-preferredsources-of-reproductive-health-information-among-young-me

In this study, investigators utilized structured interviews and focus groups to examine reproductive health $(\mathrm{RH})$ communication practices among 184 mother-daughter pairs in Ungogo town, Kano State, North-East, Nigeria. Transcripts were analysed using the grounded theory approach. The age of the daughters ranged from 11 to 19 years while the parents' age ranged from 26 to 54 years. A total of 136 mothers reported discussing $\mathrm{RH}$ issues with their daughters. The majority of daughters acquired $\mathrm{RH}$ education from their mothers. Parents were more likely to discuss marriage, menstruation, courtship, premarital sex, and sexually transmitted infections than other sex education topics.

Isiugo-Abanihe, U. C., Erinosho, O., Ushie, B., Aderinto, A., Sunmola, G., \& Joseph, R. (2012). Age of sexual debut and patterns of sexual behaviour in two local government areas in southern Nigeria. African Journal Reproductive Health, 16(4):81-94. Article available at: http://www.ajrh.info/vol16_no4/16_4_article9.pdf

The study examines the age of sexual debut and patterns of sexual behaviour in Ugep, Cross River State, South South Nigeria, and Badeku and Olunloyo in Oyo State, South West, Nigeria. A survey of households and individuals was conducted in the three communities; a multi-stage sampling scheme was used to select households with at least one person between the ages of 15 and 59 years. Qualitative data were also collected through in-depth interviews and focus group discussions. Slightly more than one-fifth of the respondents were adolescents and young adults aged 15-24. The median age of first sex among nevermarried males and females were 17 years and 18 years, respectively; more than one in five adolescents have had sex before age 16. Never-married males and females initiated sex earlier than ever-married, older respondents. That 14 percent of married men keep other sexual partners besides their wives is indicative of substantial extramarital relationship; also 12 percent of never-married male respondents with regular sex partners have other sexual partners. Condom use is fairly high, especially in sexual relations involving nonregular partners. About 77 percent of never-married males who have had sex with a non-regular partner used the condom in the last encounter and about 64 percent of married men who had sex with a non-regular 
partner used the condom. The corresponding figures for never married and married females are 25 percent and 75 percent, respectively.

\section{Maticka-Tyndale, E. \& HP4RY Team. (2012). Bridging theory and practice in HIV prevention for rural youth, Nigeria. African Journal of Reproductive Health, 16(2):39-53. Article available at: http://www.bioline.org.br/pdf?rh12020}

This article reviews the dominant theoretical approaches used to develop behaviour change interventions and strategies and presents the theoretical frameworks guiding the multi-level strategy to reduce youth vulnerability in Edo State, South-South, Nigeria known as HIV Prevention for Rural Youth (HP4RY). HP4RY is set within the multi-level Ecological Framework and specifically uses Sexual Scripting Theory and the AIDS Competent Community Theoretical Framework to guide an action research project that uses research to enhance the Family Life and HIV Education (FLHE) programme delivered in junior secondary schools and a community mobilization programme led by members of the National Youth Service Corps. The benefits to using these theories and their fit with contemporary thinking in the field of HIV prevention through behaviour change are reviewed by the article.

\section{Omorodion, F., Akpede, E., Maticka-Tyndale, E., Agbontean-Eghafona, K., Onokerhoraye, A. \& HP4RY Team. (2012). The use of National Youth Service Corp members to build AIDS competent communities in rural Edo State Nigeria. African Journal of Reproductive Health, 16(2):71-85. Article available at: \\ http://www.ajrh.info/vol16_no2/16_2_6_download.html}

This paper describes the community component of a larger action research project on HIV Prevention for Rural Youth (HP4RY), funded by the Global Health Research Initiative (Canada). The project began with ethnographic research in 10 communities selected using geographic representative sampling and random assignment to one of three research arms. Using the AIDS Competent Community (ACC) model developed by Catherine Campbell, the ethnographic research identified factors in six domains that contributed to youth vulnerability to HIV infection. This was followed by recruitment, training, and deployment of three overlapping cohorts of young adults $(n=40)$ serving in Nigeria's National Youth Service Corp (NYSC), to mobilize youth and adults in the communities to increase communities' AIDS competence over a nearly two year period. Monthly reports, field coordinator observations, and community feedback supported the conclusion that communities moved towards greater AIDS competence and reduction in youth vulnerability to HIV infection.

\section{Onokerhoraye, A. G., Maticka-Tyndale, E., \& HP4RY Team.(2012). HIV prevention for rural} youth in Nigeria: background overview. African Journal of Reproductive Health, 16(2):25-

\section{Article available at: http://www.bioline.org.br/pdf?rh12019}

This paper provides the background to the outcomes of Action Research-HIV prevention for rural youth project, reported in this special edition of this journal by reviewing the HIV/AIDS situation in sub-Saharan Africa and the nature of the associated response; discussing the rationale for Action Research which focuses on Nigeria; and outlining the key components of the research. The first section reviews the HIV/AIDS situation in sub-Saharan Africa and the associated response. The second section examines the challenge and experiences of HIV prevention among young people in sub-Saharan Africa while the third section discusses the rationale for the Action Research on HIV prevention for rural youth in Edo State, Nigeria. The fourth section outlines the components of the Action Research while the final section concludes the paper. 
Onokerhoraye, A. G., Maticka-Tyndale, E., \& HP4RY Team. (2012). Meeting the challenges of North-South collaboration: the case of HIV prevention for rural youth, Edo State, Nigeria. African Journal of Reproductive Health, 16(2):127-146. Article available at: http://www.jstor.org/stable/23318024?seq=1\#page scan tab contents

The paper reviewed the context of contemporary North-South research collaboration which provided the framework for the implementation of the HIV Prevention for Rural Youth, Edo State, South-south, Nigeria. It then examined the benefits which the implementation of the programme stimulated as well as the various challenges which confronted the partnership and how they were handled. The implications of the project's implementation experiences for future North-South collaborative research programmes were highlighted. The first section reviewed the context of contemporary North-South research collaboration which provided the framework for the implementation of the HIV Prevention for Rural Youth.

Opara, P.I., Eke, G.K., \& Tabansi, P.N. (2012). Perception of sexuality education amongst secondary school students in Port Harcourt, Nigeria. West African Journal of Medicine, 31(2):109-13. Article available at: http://www.ajol.info/index.php/wajm/article/view/98984

The objective of this study was to determine perceptions and knowledge of sexuality education amongst secondary school students in Port Harcourt, South-south Nigeria. A structured, anonymous, and selfadministered questionnaire was distributed amongst a convenience sample of 1,050 secondary school students attending a series of school debates in Port Harcourt Metropolis. The students were aged 10-20 years, with a median age of 15 . There were 486 males and 564 females giving a M:F ratio of 1:1.2. Almost three-quarters (73.4 percent, 414) of the females had attained menarche. Nine hundred and fifty (90.5 percent) of the respondents had heard of sexuality education but only 422 (40.1 percent) discussed relevant topics on the subject. A little over half (52.8 percent) believed that sexuality education should be given at home by both parents. However, only 164 (31.2 percent) and 19 (3.6 percent) got such information from their mothers and fathers, respectively. Only 7.6 percent acknowledged the school teacher as a source of information.

Oyeyemi, A., \& Oyeyemi, B. (2012). Young adults and AIDS epidemics: their perception awareness information sources and sexual practices. East African Journal of Public Health, 9(1):13-18. Article available at: http://www.ncbi.nlm.nih.gov/pubmed/23310935

This study aimed to investigate a group of Nigerian student teachers' awareness and perception on AIDS, and their adherence to safe sex practices. Nigerian students in a College of Education $(\mathrm{N}=382)$ were surveyed using a 52-item questionnaire that solicited information on socio-demographics, knowledge on AIDS, and on how serious and concerned are the students about AIDS epidemic. It also elicited information on their information sources and needs, AIDS testing, sexual activity, and condom use. The students showed satisfactory knowledge and that the AIDS epidemic was a serious issue and of concern to them, but many of the sexually active students seldom used condoms on a consistent basis. Level of perceived seriousness and feeling of concern about AIDS epidemics influenced condom use consistency, while male gender and knowledge level influenced the students' appreciation of the seriousness of the AIDS epidemic. Male students reported experience with sexual intercourse and condom use more frequently than their female counterparts.

Ankomah, A., Mamman-Daura F., Omoregie, G., \& Anyanti, J. (2011). Reasons for delaying or engaging in early sexual initiation among adolescents in Nigeria. Adolescent Health, Medicine and Therapeutics, 2, 75-84. Article available at: http://www.ncbi.nlm.nih.gov/pmc/articles/PMC3926781/pdf/ahmt-2-075.pdf

This qualitative study explored both the key factors that motivate some unmarried young people to engage in early sex and reasons some delay. It was based on data from 30 focus group discussions held with 
unmarried 14- to 19-year-olds in 4 geographically and culturally dispersed Nigerian states (Lagos and Oyo in the South-west, Kano in the North-West, and Enugu in the South-East. Focus groups were stratified by sexual experience and age (14-16;17-19) to capture variations among different subgroups. Several reasons for early premarital sex were identified. The "push" factors included situations where parents exposed young female adolescents to street trading. "Pull" factors, particularly for males, included the pervasive viewing of locally produced movies, peer pressure, and for females, transactional sex (where adolescent girls exchange sex for gifts, cash, or other favours). Also noted were overtly coercive factors, including rape. There were also myths and misconceptions that "justified" early sexual initiation. Reasons cited for delay included religious injunction against premarital sex; disease prevention (especially HIV/AIDS); fear of pregnancy, and linked to this, the fear of dropping out of school; and, for females, the fear of bringing shame to the family, which could lead to their inability to get a "good" husband in the future. The differences observed between sexually active and abstinent adolescents were that the latter were more confident, had greater determination, and, most importantly, deployed refusal skills to delay first sex.

\section{Asekun-Olarinmoye, E. O., Dairo, M. D., Abodurin, O. L., \& Asekun-Olarinmoye, I. O. (2011- 2012).Practice and content of sex education among adolescents in a family setting in rural southwest Nigeria. International Quarterly of Community Health Education, 32(1):57-71. Article available at: http://qch.sagepub.com/content/32/1/57.long}

A descriptive cross-sectional study to assess adolescents' view of the practice and content of sex education within the family setting in a rural Nigerian community (in Olorunda local government area, Osun State, South-West Nigeria) and explore whether there was any association between parental communication on sex and adolescents' sexual debut and habits. Simple random sampling was utilized, while a semi-structured questionnaire was used to collect data from 350 respondents. The study population consisted of adolescents aged 10-19 years that resided in the community. Majority of the respondents (48.8 percent) were late adolescents (15-19 years), 291 (85.1 percent) had had sex education, most (45.7 percent) of whom were exposed between ages 10 and 14 years. The main content of parental sex education was HIV prevention (51.9 percent), avoidance of pregnancy (40.9 percent), abstinence (38.1 percent), and basic information about reproduction and biology (35.4 percent). Poor attitude to parental communication on sex was associated with a higher likelihood of pre-marital sex. Curiosity was the most common major reason for sexual debut.

\section{Bamise, O. F., Bamise, C. T., Adedigba, M. A. (2011). Knowledge of HIV/AIDS among secondary school adolescents in Osun state, Nigeria. Nigerian Journal of Clinical Practice, 14(3):338-344. Article available at: http://www.njcponline.com/temp/NigerJClinPract143338-3176875_084928.pdf}

This study aimed to assess the knowledge of secondary school students in Osun State about HIV/AIDS and the sources of their information. A multistage random sampling technique was used to select 592 secondary school students from 5 local government areas of Osun State, South-West, Nigeria. Of the 581 questionnaires used for the analysis, 277 (47.7 percent) were males and 304(52.3 percent) were females. Their ages ranged from 11 to 25 years [mean 14.15 (SD \pm 2.447 ) years]. About half believed that HIV can be contracted via mosquito bites and 53.7 percent believed via kissing. Half of the respondents agreed that a person who looks healthy can be infected and possess the ability to describe the look of an infected person. Majority (92.6 percent) claimed to have heard about HIV/AIDS prior to the study. More than half (67.8 percent) agreed that HIV/AIDS is a life-threatening disease, 29.4 percent said there is a cure for AIDS, and 77.6 percent thought that the government is doing enough to deal with the disease. The most important source of HIV/AIDS information among the respondents was the media and the least important source were traditional healers (35.3 percent). 
Doskoch, P. (2011). In Nigeria, migrant youth are more likely than others to have had sex. International Perspectives on Sexual and Reproductive Health, 37(3):161-162. Article available at: http://www.jstor.org/stable/pdf/41309598.pdf?acceptTC=true

To explore the relationship between migration and sexual behaviour, researchers analysed data from the nationally representative 2008 Nigeria Demographic and Health Survey. The investigators focused on responses from 10,865 unmarried males and females aged 15-24, as these youth were more likely than their married peers to experience undesirable outcomes from sex. Responses to questions on current and previous places of residence were used to classify respondents into six groups: two non-migrant categories (rural and urban) and four migrant categories (rural-rural, rural-urban, urban-rural and urban-urban). Respondents also indicated whether they had ever had sex and, if so, their age at initiation. At the time of the survey, respondents had a mean age of 19. Most had a secondary or higher education (78 percent) and were not working (59 percent). Sixty-one percent lived in rural areas. Two-thirds had never migrated and had always lived in a rural area (45 percent) or an urban one (20 percent); 15 percent had moved between urban areas, 8 percent between rural areas, and the remainder from urban to rural regions (9 percent) or vice versa (3 percent). Slightly more than one-third (35 percent) of respondents had ever had sex; the proportion was higher among three of the migrant groups (urban-urban, urban-rural and rural-rural) than among the two non-migrant groups (41-46 percent vs. 30-32 percent).

ljadunola, K., Abiona, T., Balogun, J., \& Aderounmu, A. (2011). Provider-initiated (Opt-out) HIV testing and counselling in a group of university students in Ile-Ife, Nigeria. The European Journal of Contraception \& Reproductive Health Care, 16(5):387-396. Article available at: http://informahealthcare.com/doi/abs/10.3109/13625187.2011.593660

This study assessed the feasibility and uptake of provider-initiated (Opt-out) HIV testing and counselling among a sample of Nigerian university undergraduate students. The study was conducted at the health centre of the Obafemi Awolowo University (OAU), Ile-Ife, South-West, Nigeria. Two hundred and fifty-two Nigerian university students ranging in age from 16 to 36 years were offered rapid 'opt-out' HIV tests. The participants were also interviewed using a self-administered questionnaire and data were analysed using descriptive statistics. Almost all (251, 99.6 percent) students accepted testing and only one (0.4 percent) refused testing. More than half of the students were aged between 20 and 29 years (58 percent) while 39.3 percent were aged between 10 and 19 years old. The most common reason given for accepting rapid 'optout' testing was the desire to find out HIV status (93.2 percent). Only 24 (9.5 percent) students had previously ever been tested for HIV; among the 228 (90.5 percent) respondents who had not, the common reasons given for not testing were lack of knowledge of where to go to (25 percent), fear of testing positive (24 percent), and perception of being unlikely to have been exposed to HIV (18 percent).

\section{Mberu, B. U., \& White, M. J. (2011). Internal migration and sexual initiation among never married youths in Nigeria. Social Science \& Medicine, 72(8):1284-1293. Article available at: http://www.ncbi.nIm.nih.gov/pmc/articles/PMC4122216/pdf/nihms-518546.pdf}

This study examined patterns of internal migration and sexual initiation among Nigerian youth aged 15-24, using the 2003 Nigeria Demographic and Health Survey data, descriptive statistics, Kaplan-Meier survival curves, and discrete-time hazard regression models. Over a third (36.2 percent) of the 2,602 youths aged 15-24 had initiated premarital sex by the time of the survey. The data indicated a modest level of mobility, with 36 percent of all youths no longer residing in their places of birth. Migrants generally showed stronger association to early sexual initiation than non-migrants, and urban-urban migrants show the strongest independent association to early sexual initiation. These outcomes underscore that loss of social capital and exposure to sexually lenient urban environment increase youth's propensity to sexual engagement. Other significant covariates are age, gender, ethnic origin, education, independent living arrangement, and formal employment. 
Nwachukwu, C. E., \& Odimegwu, C. (2011). Regional patterns and correlates of HIV voluntary counselling and testing among youths in Nigeria. African Journal Reproductive Health, 15(2):131-146. Article available at: http://www.bioline.org.br/pdf?rh11026

Using data from the 2003 Nigerian National Demographic and Health Survey, the study examined the regional prevalence, pattern, and correlates of voluntary counselling and testing for HIV (VCT) among youth aged 15 to 24 in Nigeria. Analysis was based on 3573 (out of 11,050) observations using logistic regression model to estimate the effects of identified predictors of volunteering for HIV testing. Results show that national prevalence of VCT is low (2.6 percent) with regional variations. Generally, the critical factors associated with VCT uptake are age, sex, education, wealth index, and risk perception with North (sex, education, religion, occupation, and risk perception) and South (age and education) variance.

Nwoke, E. A., Okafor, J. O., Chukwuocha, U. M., \& Nworuh, B. O. (2011). Sociodemographic correlates of sexual behaviours: a cross-sectional survey of adolescents in Imo State secondary schools. East African Journal of Public Health, 8(1):13-16. Article available at: https://www.researchgate.net/publication/51782453_Sociodemographic_correlates_of_sexual_behaviours_a_cross_sectional_survey_of_adolescents in_Imo_State_secondary_schools

The study was designed to determine the socio-demographic correlates of sexual behaviours of the adolescents in Imo State secondary schools (South-East, Nigeria). Three objectives and three hypotheses were formulated to guide the study. A cross-sectional survey design was used and sample size was 3360 (2.2 percent) adolescents. A structured, validated and reliable questionnaire $(r=0.79)$ and focus group discussion were used as the instruments for data collection. Data analysis was done using mean and ANOVA statistics. The result generally, showed that the average sexual behaviours of the adolescents were below the decision mean of 2.50 and as such the adolescents were said to be sexually inactive. In Imo State secondary schools, various family sizes did not significantly influence the sexual behaviours of the adolescents (F-cal. 2.39, F-tab. $3.00 \& p>0.05$ ), family structure significantly influenced their sexual behaviours (F-cal. 17.78, F-tab. $3.00 \& p<0.05$ ) and different financial strengths influenced the adolescents sexual behaviours significantly (F-cal. 22.88, F-tab. $2.37 \& p<0.05$ ).

Okanlawon, F.A., \& Asuzu, M. C. (2011). Effect of peer education intervention on secondary school adolescents' reproductive health knowledge in Saki, Nigeria. African Journal of Medicine and Medical Sciences, 40(4):353-360. Article available at: http://www.ncbi.nlm.nih.gov/pubmed/22783685

This nurse-led concurrently controlled community interventional study utilized a pre and post intervention (quasi-experimental) design to examine the effect of peer education on school adolescents' reproductive health knowledge in Saki, South-western, Nigeria. The experimental group was exposed to the peer education programme for six months. Pre and post differential data in the experimental and control groups were compared and analysed using analysis of covariance. The intervention had a significant effect on adolescents in the experimental group compared with the control group in the area of knowledge of reproductive health issues $(\mathrm{F} 1,519)=37.117,(p<.05)$.

Oladepo 0., \& Fayemi, M. M. (2011). Perceptions about sexual abstinence and knowledge of HIV/AIDS prevention among in-school adolescents in a western Nigerian city. Biomed Central Public Health 11:304. Article available at: http://www.biomedcentral.com/14712458/11/304

The study was a descriptive cross-sectional survey of students aged 10-19 years old in Ibadan South-West Local Government Area, South-West, Nigeria. A total of 420 respondents (52 percent males and 48 percent females), selected through a multistage sampling technique, completed a semi-structured questionnaire. 
This was supplemented with 8 focus group discussions (FGDs) which had an average of 9 respondents within the 10 and 19 years age group. Twelve percent of the entire sample had ever had sex. Overall, knowledge of HIV transmission and prevention was high and most respondents favoured the promotion of abstinence as an HIV prevention strategy. A smaller proportion of male respondents (79 percent) abstained compared with the females (98 percent). Major predictors of sexual abstinence were being a female, not having a boyfriend or girlfriend, not using alcohol, and having a positive attitude towards abstinence $(p<$ 0.05). Sexual abstinence was also significantly associated with perceived self efficacy to refuse sex and negative perception of peers who engage in sexual behaviours $(p<0.05)$. Majority of the FGD discussants suggested the involvement of parents, media, schools, faith-based institutions, and non-governmental organizations in promoting the adoption of abstinence.

Onyeonoro, U. U., Oshi, D. C., Ndimele, E. C., Chuku, N. C., Onyemuchara, I. L., Ezekwere, S. C., \& Emelumadu, O. F. (2011). Sources of sex information and its effects on sexual practices among in-school female adolescents in Osisioma Ngwa LGA, south east Nigeria. Journal of Paediatric and Adolescent Gynaecology, 24(5):294-299. Article available at: http://www.jpagonline.org/article/S1083-3188(11)00230-0/abstract

This study is aimed at identifying adolescents' sources of sexuality information, and its likely effect on their sexual practices among in-school female adolescents in Osisioma LGA, in South-eastern Nigeria. A total of 304 girls selected by multi-stage sampling technique were studied. Responses were elicited from them using a pretested, semi-structured, self-administered questionnaire. Primary and subsequent sources of sexuality information were mainly the media and peers. Families and schools mostly were not involved in provision of early sex education. Media and peer influence were predominantly negative. Female adolescents' knowledge of issues of sex was low. Premarital sex, early sexual initiation, and unprotected sex was common among them. Consequently, adverse implication of negative sexual behaviour, such as unplanned pregnancies and induced abortion, was prevalent.

\section{Oyediran, K. A., Feyisetan, O. I., \& Akpan, T. (2011). Predictors of condom-use among young never-married males in Nigeria. Journal of Health, Population \& Nutrition, 29(3):273-285. Article available at: http://www.ncbi.nlm.nih.gov/pmc/articles/PMC3131128/}

This study examined the factors that influence condom-use among young never-married males in Nigeria. Data were derived from the 2003 Nigeria Demographic and Health Survey. Data analysis was restricted to 827 males aged 15-24 years, who had never married or lived with a woman. Both descriptive and analytical methods were used for assessing the net effects of socioeconomic factors on condom-use. The analysis used logistic regression models for determining the predictors of sexual behaviour and condom-use among young never-married males in Nigeria. About 43 percent of the study population was sexually experienced, and condom use was low. One in five reported the use of a condom at sexual debut. Level of education, place of residence in childhood, urban/rural region, religious affiliation, economic status index, and exposure to mass media were associated with sexual experience and use of protective measures. Economic status index and mass-media exposure were associated with the use of a condom by the respondents during their last sex encounter.

\section{Oyeyemi, Y. A., Abdulkarim, A., \& Oyeyemi, B. O. (2011). The influence of knowledge and sociodemographics on AIDS perception and sexual practices among secondary school students in Nigeria. African Health Sciences, 11(1):67-76. Article available at: http://www.ncbi.nlm.nih.gov/pmc/articles/PMC3220127/}

This study assessed secondary school students' perception of the AIDS epidemic, and the influence of sociodemographic variables and AIDS knowledge on their perception and sexual practices. Nigerian teenagers $(\mathrm{N}=1,143)$ were surveyed using a questionnaire that elicited information on their demographics, AIDS knowledge, perceptions and previous encounter with survivors, and sexual practices. Although the AIDS 
epidemic was not a serious issue of concern to a substantial number of the students, they were knowledgeable on AIDS, and their perceptions on the AIDS epidemic influenced their sexual practices. Female teenagers were more knowledgeable and concerned, and more frequently reported inexperience with sexual intercourse compared to their male counterparts.

\section{Uzochukwu, B., Uguru, N., Ezeoke, U., Onwujekwe, O., \& Sibeudu, T. (2011). Voluntary counselling and testing (VCT) for HIV/AIDS: a study of the knowledge, awareness and willingness to pay for VCT among students in tertiary institutions in Enugu State Nigeria. Health Policy, 99(3):277-84. Article available at: https://ideas.repec.org/a/eee/hepoli/v99y2011i3p277-284.html}

A cross-sectional study was carried out among undergraduate students of two tertiary institutions in Enugu, Southeastern, Nigeria using a pre-tested interviewer administered questionnaire. Information was collected from 250 respondents per institution. A majority of the students were aged 20-24 (67.6 percent) with 3.4 percent aged 15-19. Most of the respondents (64 percent) have heard about voluntary counselling and testing (VCT) and 70.6 percent of the students obtained their information from the mass media $(p<0.05)$ while a minority (3.8 percent) heard from families. About three-quarters (76.6 percent) of respondents believe VCT can provide useful information on HIV/AIDS and VCT is obtainable mainly in teaching hospitals (78.5 percent) and to a lesser extent in government hospitals (9.8 percent) and NGOs (8.8 percent), while being almost non-existent in private hospitals ( 2.9 percent). Over four-fifths ( 81 percent) of the respondents did not uptake VCT while only 19 percent had undergone VCT. The reasons for non-uptake were that the majority of the students (45.7 percent) were unaware of the services $(p<0.05)$, indifferent to VCT $(20.0$ percent), felt it was costly (12.8 percent), and were afraid of discovering their HIV status (13.3 percent). About 50 percent of the respondents were willing to pay for VCT and the mean willingness to pay was $\$ 3.2$ (N370). Out of those willing to pay, 46 percent of them were willing to pay (\$2.6) N300 while 34 percent and 20 percent were willing to pay $\$ 3.4$ (N400) and $\$ 4.3$ (N500), respectively ( $p<0.05$ ). Among those not willing to pay, 67.6 percent of them thought it should be free $(p<0.05)$. Males and people with higher knowledge of VCT stated higher willingness to pay values than females and those with less knowledge of VCT.

\section{Winskell, K., Hill, E., \& Obyerodhyambo, O. (2011). Comparing HIV-related symbolic stigma in six African countries: social representations in young people's narratives. Social Science \& Medicine, 73(8):1257-1265. Article available at: http://www.ncbi.nIm.nih.gov/pmc/articles/PMC3358781/}

This paper compares symbolic stigma in six African countries with contrasting HIV prevalence rates through the analysis of social representations in fictional narratives written by young people. The data provide access to the voices and imaginings of young Africans in a largely unmediated way, rather than through direct elicitation via survey, interview or focus group questions. In their creative writing about AIDS, young people draw on their own lived or imagined experience and on other culturally-determined sources of social understanding to create context, meaning, and values. The narratives thus provide unique insights into their appropriation and adaptation of dominant cultural scripts around sexuality, morality, and stigma. With the purpose of informing stigma reduction efforts within and across settings, investigators compared social representations of HIV in six African countries with estimated adult HIV prevalence rates ranging from 1 to 33 percent. This study used a unique data source, namely a stratified random sample ( $n=586, \sim 5$ percent) from 11,354 creative ideas contributed from six countries to a continent-wide HIV-related scriptwriting contest held between February and April 2005. The narratives were written by equal numbers of males and females aged 10-24 in urban and rural areas of Swaziland, Namibia, Kenya, South-East Nigeria, Burkina Faso, and Senegal. Investigators combined three analytical approaches: descriptive statistics on certain quantifiable characteristics of the narratives, thematic data analysis, and a narrative-based approach. The association of HIV with outsiders ("othering") and preoccupation with the circumstances of infection were more common in lower prevalence countries but varied substantially in tone depending on the sociocultural context. The highest proportion both of moralising narratives and of narratives with pessimistic outcomes 
came from South-East Nigeria and, to a lesser extent, from Kenya, countries with prevalence levels of 3.9 and 6.1 percent, respectively, in which evangelical Christian movements, including Pentecostalism, have sizeable followings. The data provide a rare cross-cultural overview of symbolic stigma, identify countryspecific needs, and point to strategies for future programming.

\section{Winskell, K., Beres, L. K., Hill, E., Mbakwem, B. C., \& Obyerodhyambo, O. (2011). Making sense of abstinence: social representations in young Africans' HIV-related narratives from six countries. Culture, Health \& Sexuality, 13(8):945-959. Article available at: http://www.ncbi.nlm.nih.gov/pmc/articles/PMC3358789/}

This paper presents an analysis of social representations of abstinence in a substantial corpus of qualitative data, comprising 586 fictional narratives written by young people aged 10-24 years from six African countries/regions with estimated adult HIV prevalence rates ranging from 1 to 33 percent. Narratives are a source of insight into how people make sense of the world, and how they communicate those understandings to others. In this study, they provided access to the voices and imaginings of young Africans in a largely unmediated way, revealing their spontaneous mentions of abstinence, rather than their responses to specific interview or focus group questions. With the purpose of informing programmatic practice, researchers examined how young Africans from six countries with contrasting HIV prevalence rates made sense of abstinence. 'Scenarios from Africa' scriptwriting contests invited young people to contribute ideas for short films about HIV. Using thematic narrative-based approaches, investigators analysed a stratified random sample of 586 ( 5 percent) of these narratives written in 2005 by young women and men aged 10-24 years from Senegal, Burkina Faso, South-East Nigeria, Kenya, Namibia, and Swaziland. Abstinence was considerably more prominent as a theme in the samples from South-East Nigeria, Kenya, and Swaziland. It was articulated in relation to conservative Christian sexual morality and in opposition to condom use with particular intensity in South-East Nigeria, with stigmatising implications for non-abstainers. However, cross-national commonalities were more striking than differences. Examples of non-stigmatising pro-abstinence messaging highlighted the appeal of discourses of romantic love and future plans across countries and demographic characteristics. The analysis yielded contextual understanding, youth-driven ideas, and recommendations to inform comprehensive HIV prevention efforts.

\section{Winskell, K., Obyerodhyambo, 0., \& Stephenson, R. (2011). Making sense of condoms: social representations in young people's HIV-related narratives from six African countries. Social Science \& Medicine, 72(6):953-961. Article available at: http://www.ncbi.nlm.nih.gov/pmc/articles/PMC3258095/}

In this study, access to young people's spontaneous mentions of condoms, rather than their responses to specific interview or focus group questions were explored. In order to inform education and communication efforts to increase condom use, investigators examined social representations of condoms among young people aged 10-24 in six African countries/regions with diverse HIV prevalence rates: Swaziland, Namibia, Kenya, South-East Nigeria, Burkina Faso, and Senegal. Researchers used a unique data source, namely 11,354 creative ideas contributed from these countries to a continent-wide scriptwriting contest, held from 1 February to 15 April 2005, on the theme of HIV/AIDS. They stratified each country sample by sex, age (10$14,15-19,20-24)$, and urban/rural location of the author and randomly selected up to 10 narratives for each of the 12 resulting strata, netting a total sample of 586 texts for the six countries. They analysed the narratives qualitatively using thematic data analysis and narrative-based methodologies. Differences were observed across settings in the prominence accorded to condoms, the assessment of their effectiveness, and certain barriers to and facilitators of their use. Moralization emerged as a key impediment to positive representations of condoms, while humour was an appealing means to normalize them. The social representations in the narratives identify communication needs in and across settings and provide youthfocused ideas and perspectives to inform future intervention efforts. 
Adegbenro, C. A, Fabiyi, A. K., Esimai, O. A., \& Aluko, M. O. (2010). Incidences of crossgeneration sexual activities in Nigeria: implications for HIV/AIDS control. International Quarterly of Community Health Education, 31(2):203-209. Article available at: http://qch.sagepub.com/content/31/2/203.long

A national baseline survey of mass media in Nigeria was carried out for 4 weeks in the month of July 2009. The objective was to design an intervention strategy to increase the knowledge of the country's population on the risk-factors associated with the practice of cross-generational sex (CGS) as well as changing perception toward the practice. The data were collected from three sources: (i) from major daily newspapers in the country; (ii) radio; and (iii) television news items. A total of 117 cases of CGS were reported by the media (i.e., newspapers, radio, and TV) in Nigeria during the period of our survey. The major source of data collection was from newspapers (38.5 percent) which were followed by radio (31.6 percent). The reported cases of CGS were almost constant throughout the 4 weeks of the survey, although higher cases were recorded in the fourth week (26.5 percent). Two zones from the six geo-political zones recorded nearly equal percentages that were slightly higher than the remaining zones. These were the South-South and South-West with 20.5 percent and 19.7 percent, respectively. From the list of reasons given by the perpetrators for engaging in CGS, "Advice that it can cure HIV/AIDS" topped the list with 48.7 percent.

\section{Ajuwon, A. J., Titiloye, M., Oshiname, F., \& Oyewole, O. (2010). Knowledge and use of HIV counselling and testing services among young persons in Ibadan, Nigeria. International Quarterly of Community Health Education, 31(1):33-50. Article available at: http://qch.sagepub.com/content/31/1/33.long}

This study assessed knowledge of HIV/AIDS and use of HIV counselling and testing (HCT) services among secondary school students and apprentices in Ibadan, Nigeria. Data were collected through 16 focus group discussions (FGDs) and administration of a 36-item questionnaire to 1,281 randomly selected male and female secondary school students and apprentices aged 15-25 years. The respondents consisted of 54 percent apprentices and 46 percent students. Although virtually all respondents were aware of AIDS, only 15.8 percent of the sample had heard about HCT. Of those who were aware of HCT, 30.1 percent knew where to access the service. Students had superior knowledge of HCT than apprentices. Only 7 percent of those aware of HCT had ever taken the test. The percentage of those who had reportedly taken the test: 11.3 percent of female apprentices, 6.3 percent of male students, 5.3 percent of female students, and 5.2 percent of male apprentices. The barriers identified by FGD participants to utilizing HCT services are fear of stigmatization, perceived exorbitant cost of testing, lack of knowledge of where HCT services are available, and belief that HCT is meant for only sexually active persons. However, 82.6 percent of the entire sample expressed the willingness to access HCT if it is provided free of charge, and there is a guarantee of confidentiality of results.

Akinyemi A., Banjo, O., Fadeyibi, O., Bamiwuye, O., Adewuyi, A., \& Aransiola, J. O. (2010). Influence of independent and proximate variables on condom use in selected states in Nigeria. African Journal of Reproductive Health, 14(4):51-60. Article available at: http://www.ncbi.nlm.nih.gov/pubmed/21812198

This study examined the influence of individual and proximate factors in determining condom use. Current condom use and condom use during last sex were used as proxies for consistent condom use. Data on 3,797 sexually active respondents of reproductive age were analysed from the 2007 USAID-COMPASS midline evaluation on basic family planning and reproductive health outcomes in five Nigerian states. About 9 percent of respondents were current users, while 11 percent used a condom during last sex. Younger and more educated respondents were more likely to report condom use. Of the 23 variables, 4 were statistically significant in predicting current use for females, 5 for males; 6 were statistically significant in predicting condom use during last sex for females and 7 for males. 
Arulogun, O. S., \& Adefioye, O. A. (2010). Attitude towards mandatory pre-marital HIV testing among unmarried youths in Ibadan northwest local government area, Nigeria. African Journal of Reproductive Health, 14(1):83-94. Article available at: http://www.bioline.org.br/pdf?rh10007

This study assessed the attitude of unmarried youth in Ibadan Northwest Local Government, Oyo State, South-West, Nigeria towards mandatory premarital HIV testing (MPHT). A three-stage sampling technique was used to select 571 unmarried youths from households. The mean age of respondents was $20.6+2.6$ years, 52.0 percent were males and 52.7 percent had completed their senior secondary education. Though 82.8 percent believed that MPHT could reduce the spread of HIV, 43.8 percent stated that it will increase the stigma associated with HIV infection. Attitude towards mandatory pre-marital HIV testing however was positive. Males were about two times more likely to have positive attitude towards mandatory pre-marital HIV testing $(\mathrm{OR}=1.507, \mathrm{Cl}=1.067-2.129)$.

Bamidele, J. O., Abodunrin, O. L., \& Adebimpe, W. O. (2010). Sexual behaviour and risk of HIV/AIDS among adolescents in public secondary schools in Osogbo, Osun State, Nigeria. International Journal of Adolescent Medicine and Health, 21(3):387-394. Article available at: http://www.ajol.info/index.php/ijhr/article/viewFile/47908/34276

A cross-sectional survey of 521 students aged between 10 and 19 years in 8 randomly selected public secondary schools (in Osogbo, Osun State, South-Western, Nigeria) sought to identify the sexual behaviours and risk of HIV among public secondary schools students in Nigeria. Respondents were selected by a multistage sampling technique from amongst the study population. Using a self-administered, semistructured, pre-tested questionnaire, data were obtained concerning their sexual behaviours and influencing factors. Most respondents ( $n=387,74.3$ percent) were in late adolescence (15-19 years). The study group comprised 279 (53.6 percent) males and 242 (46.4 percent) females. Many knew the consequences of premarital sex as unplanned pregnancy, STI/HIV/AIDS, incomplete schooling, and guilt feelings. About 40 percent of the respondents had been involved in sexual activities with partners who were classmates, neighbours, 'sugar daddies', teachers, or strangers (party-mates or sex workers). Heterosexual intercourse, oral sex, and anal sex, and homosexuality were practiced respectively by 78.1 percent, 13.3 percent, 12.4 percent and 11 percent of those who were sexually active. Sexual debut was $15.2+/-1.62$ years. About 36 percent of those who were sexually active had more than one partner, and about 14.8 percent were aware that their partners had other partners. Only 8.6 percent used a condom on a consistent basis, whereas 41.9 percent had never used a condom at all. More than half the sexual activities were not pre-planned. The reasons given for engaging in such practices were peer influence, financial reward, drug influence, fun, or experimentation.

Isikwenu, O. O., Omokiti, J., \& Nurudeen, D. (2010). A holistic approach to reproductive health interventions: Talk 2 Me case study. African Journal of Reproductive Health, 14(4):140-141. Article available at: http://www.bioline.org.br/pdf?rh10074

This article provides a case study of the Talk 2 Me project. The design of this project was based on knowledge shared by Straight Talk Foundation of Uganda during the 2008 "Investing in Young People's Health and Development: Research that Improves Policies and Programs" in Abuja, Nigeria. The idea was to use peer educators in secondary schools to facilitate discussions on sexuality, HIV/AIDS, sexually transmitted infections, and other reproductive health issues. The major tools used in gathering information were questionnaires and focus group discussions (FGDs). Trained peer educators facilitated 50 FGDs on different topics, 5 in each of 10 schools. The innovative strategy was to record the stories of students as they were discussed and to publish them in a monthly newsletter (Talk2Me). The newsletters were shared among young people in- and out-of-school, so they could learn from the discussions in the different school groups. Peer educators reported increased confidence and a better relationship with students who came for counselling and asked personal questions. The number of stories increased because everyone wanted to 
show their family and friends the newsletter. At the end of the project, a club (Champion's Forum) was formed which met once a month.

\section{Opara, P. I., Eke, G. K., \& Akani, N. A. (2010). Mothers' perception of sexuality education for children. Nigerian Journal of Medicine, 19(2):168-172. Article available at: http://www.ajol.info/index.php/njm/article/view/56513}

The objective of the study was to determine mothers' perception of sexuality education in children, in Port Harcourt, South-south, Nigeria. A structured, anonymous, and self-administered questionnaire was distributed amongst a convenient sample of women attending a Christian women's convention in Port Harcourt. Of the 158 women who participated in the study, most of them were married (80.4 percent), aged 30-49 years, and had a tertiary education (44.9 percent). Over 80 percent agreed that children needed sexuality education but only 15 women (9.5 percent) had a good knowledge of the concept of sexuality education. Over two-thirds (111, 70.2 percent) believed it was the responsibility of both parents to educate their children and over 70 percent acknowledged that the home was the best place for such education. 64 (40.5 percent) believed that 6-10 years was the ideal age for starting sex education while 49 percent thought that the ideal age was 11-15 years. Almost two-thirds (65 percent) of respondents discussed sexuality issues with their children at least occasionally; the content mostly involved describing body parts and reproductive organs. The average age of menarche amongst respondents was 14 years. One hundred (63 percent) of the women had prior knowledge of menstruation before menarche. About half of them had received information from their mothers.

\section{Oyekale, A. S., \& Oyekale, T. O. (2010). Application of health belief model for promoting behaviour change among Nigerian single youth. African Journal of Reproductive Health, 14 (2):63-75. Article available at: http://www.ncbi.nlm.nih.gov/pubmed/21243920}

The study analysed the factors influencing the uptake of HIV testing and risky behaviour change using the health belief model. The data were obtained from Nigeria's 2004 National Living Standard Survey data and analysed with descriptive statistics and Probit regression. Results show that 87.79 percent of the single youth (aged 14-30 years) were aware of HIV/AIDS, 3.34 percent had taken an HIV test, and 71.73 percent desisted from risky behaviour by having sex with one partner (24.35 percent), not starting sex (16.90 percent), and using condoms (14.29 percent). Also, the probability of HIV test uptake and changing risky behaviours significantly increased $(p<0.10)$ with age, access to radio, television, and per capita expenditure, while it significantly decreased with no formal education. Residence in an urban area significantly increased the probability of HIV test uptake, but significantly reduced probability of changing risky behaviours. The study recommends integration of health studies into Nigerian elementary school curriculums, provision of adequate facilities for free HIV test in rural areas, among others.

\section{Yahaya, L. A., Jimoh, A. A., \& Balogun, O. R. (2010). Factors hindering acceptance of HIV/AIDS voluntary counselling and testing (VCT) among youth in Kwara State, Nigeria. African Journal of Reproductive Health, 14(3):159-164. Article available at: http://www.bioline.org.br/pdf?rh10031}

This descriptive study examined the factors hindering the acceptance of voluntary counselling and testing (VCT) as expressed by youth in Kwara State, North central Nigeria. A total of 600 youth from the three Senatorial districts in the State were involved in the study. A survey instrument designed by the researchers was used to collect relevant information from the respondents. The age of the participants ranged between 15 and 24 years while the mean age was 19 years. 65 percent (390) of the respondents were males while 35 percent (210) were females. Among others, the study identified ignorance, poverty, inadequate number of VCT centres, stigma, and discrimination as major factors responsible for the low patronage of VCT centres in Kwara State. Gender and religion had no significant influence on the respondents' views while place of residence had significant influence. The implications of the findings to medical practice and counselling were identified and discussed. 


\section{Abdulraheem, I. S. \& Fawole, O. I. (2009). Young people's sexual risk behaviours in Nigeria. Journal of Adolescent Research, 24(4):505-527. Article available at: http://jar.sagepub.com/content/24/4/505}

A descriptive cross-sectional survey using a structured questionnaire and focus group discussions were used to determine the prevalence and correlates of HIV-related risk behaviours among adolescents and youth working in Nigeria. The study was carried out in Ilorin Metropolis, the capital of Kwara State, South West, Nigeria and conducted among 315 adolescents and youth who worked in organized apprenticeship programs and highly mobile unaffiliated groups (packed-water sellers, vendors of newspapers and other small items, shoe shine boys, and cassette sellers). A total of 40 adolescents and youth comprising 25 boys and 15 girls, aged between 15 and 19 years participated in the FGDs. The age range of the respondents was 13 to 24 years with a mean of 16.8 years $(S D=3.4)$ for boys and 17.6 years $(S D=4.1)$ for girls. Findings revealed that almost three-quarters (74.6 percent) of respondents were sexually active, of which 66.4 percent had multiple partners and only 38.1 percent always used condoms during sexual intercourse. "Decreased pleasure" (35.8 percent) was the main reason for not always using condoms. Positive attitude toward condom use was correlated with consistent use.

\section{Adebiyi, A. 0., \& Asuzu, M. C. (2009). Condom use amongst out of school youths in a local government area in Nigeria. African Health Sciences, 9(2):92-97. Article available at: http://www.ncbi.nlm.nih.gov/pmc/articles/PMC2707047/}

This article examined condom use amongst out-of-school youth in Ilero, a semi-rural town in Kajola Local Government Area of Oyo State in the south-western part of Nigeria. It was a cross-sectional study of 350 outof-school youth. The results revealed that about three-quarters (74.9 percent) had ever had sexual intercourse. Of these, 56.5 percent used no protection while 29.0 percent used condoms. Up to 78.6 percent had sex within the preceding 12 months of the study with 38.9 percent reporting condom use. The most common reason for non-condom use was that it reduces sexual enjoyment. Those who believed a single unprotected sexual exposure may result in HIV infection reported more condom use than those who believed otherwise (42 percent vs 27.2 percent, $p<0.05$ ). Those who had prior discussions with their partners on HIV/AIDS reported more condom use compared to those who had not (50 percent vs 25 percent, $p<0.05)$. Also, those who had sexual intercourse occurring as a spontaneous event reported less condom use compared to those who had previously discussed the possibility of having sex (68.0 percent vs 51.8 percent, $p<0.05)$.

\section{Adeokun, L. A., Ricketts. O. L., Ajuwon A. J. \& Ladipo, O. A. (2009). Sexual and reproductive health knowledge, behaviour and education needs of in-school adolescents in northern Nigeria. African Journal of Reproductive Health, 13(4):37-50. Article available at: http://www.jstor.org/stable/pdf/27802621.pdf?acceptTC=true}

A survey of 989 adolescents from 24 North-Eastern Nigerian secondary schools yielded information on sociodemographic characteristics, reproductive health knowledge, sexual activities, and sexuality education needs. Six secondary schools were purposively selected from rural, semi-urban, and urban areas in each of the 4 project states (Bauchi, Borno, Gombe and Yobe States) making a total number of 24 secondary schools. Of the interviewed respondents, 72 percent of females had experienced menstruation. Overall, 9 percent were sexually active, 3.1 percent knew when ovulation occurs, 47 percent knew pregnancy could result from first coitus, and 56 percent knew of contraception. Over four-fifths (84 percent) opined that adolescents should be given sexuality education but only 48.3 percent had received any. 
Akpabio, I. I., Asuzu, M. C., Fajemilehin, B. R, \& Ofi, A. B. (2009). Effects of school health nursing education interventions on HIV/AIDS-related attitudes of students in Akwa lbom State, Nigeria. Journal of Adolescent Health, 44(2):118-123. Article available at: http://www.jahonline.org/article/S1054-139X\%2808\%2900275-9/abstract

This study examined the effects of HIV preventive health education with parental involvement on students' attitude towards HIV prevention in Akwa Ibom State, South-South, Nigeria. The study population comprised students from three of nine secondary schools in the study area. The three schools were randomly assigned as intervention group 1 (IG1), involving nurses only; intervention group 2 (IG2), involving both nurses and parents (IG2); and a control group. Sampling involved multistage and stratified random technique to select 120 subjects from each of the 3 selected schools, with a total of 360 subjects representing 8.3 percent of the study population. From this number, 339 (94.2 percent) provided sufficient data for analysis. Results showed that the intervention had a significant effect on students' attitudes toward preventive measures $(F=$ 234.27, $\mathrm{p}<0.001$ ). IG1 was found to be a more potent strategy in obtaining favourable attitudes towards HIV prevention (IG1 mean, 20.59; IG2 mean, 19.20; control mean, 12.34). Attitudes were influenced by older age but not by gender.

Bakare, M. O., Agomoh, A. O., Ebigbo ,P. O., Onyeama, G. M., Eaton, J., Onwukwe, J. U., \& Okonkwo, K. O. (2009). Co-morbid disorders and sexual risk behaviour in Nigerian adolescents with bipolar disorder. International Archives of Medicine, 2(1):16. Article available at: http://www.ncbi.nIm.nih.gov/pmc/articles/PMC2695437/pdf/1755-7682-216.pdf

This study assessed the prevalence and pattern of co-morbid disorders and determined associated factors of sexual risk behaviour among adolescents with bipolar disorder. The participants were adolescents attending the outpatient unit of Federal Neuro-Psychiatric Hospital, New Haven, Enugu (FNHE), South East, Nigeria. A total of forty-six (46) adolescents with bipolar disorder were followed up over a one year period. There were 29 (63.0 percent) males and 17 (37.0 percent) females. The age range of the adolescents was between 15 and 18 years, the mean age was $16.90 \pm 1.07$. Twenty-two (47.8 percent) of the adolescents had co-morbid disorders with cannabis use disorders (23.9 percent), alcohol use disorders (8.7 percent), conduct disorder with or without other psychoactive substance use (13.0 percent) and HIV (2.2 percent). Twenty-one (45.7 percent) of the adolescents had a positive history of sexual risk behaviour, which was significantly associated with presence of co-morbid disorders, level of religious activities in the adolescents, and marital status of the parents.

DeSilva, M. B., Merry, S. P., Fischer, P. R., Rohrer, J. E., Isichei, C. O., \& Cha, S. S. (2009). Youth, unemployment, and male gender predict mortality in AIDS patients started on HAART in Nigeria. AIDS Care, 21(1):70-7. Article available at: http://www.ncbi.nlm.nih.gov/pmc/articles/PMC2849645/pdf/nihms-190701.pdf

This retrospective study identifies risk factors for mortality in a cohort of HIV-positive adult patients treated with highly active antiretroviral therapy (HAART) at the Faith Alive Foundation Hospital (FAFH) in Jos, Plateau State, North-Central, Nigeria. Investigators analysed clinical data from a cohort of 1,552 patients over the age of 18, who enrolled in a HIV/AIDS treatment program, and started on HAART between December 2004 and 30 April 2006. Death was the study endpoint. Patients were followed in the study until death, being lost to follow-up, or the end of data collection, 1 December 2006. Baseline patient characteristics were compared using Wilcoxon Rank Sum Test for continuous variables and Pearson Chi-Square test for categorical variables to determine if certain demographic factors were associated with more rapid progression to death. The Cox proportional hazard multivariate model analysis was used to find risk factors. As of 1 December 2006, a total of 104 cases progressed to death. In addition to the expected association of CD4 count less than 50 at initiation of therapy and active tuberculosis with mortality, the patient characteristics independently associated with a more rapid progression to death after initiation of HAART were male gender, aged less than 30 years old, and unemployment or unknown occupation status. 
Esiet, A. O., Esiet, U., Philliber, S., \& Philliber, W. W. (2009). Changes in knowledge and attitudes among junior secondary students exposed to the family life and HIV education curriculum in Lagos State, Nigeria. African Journal of Reproductive Health, 13(3):37-46. Article available at: http://www.bioline.org.br/pdf?rh09033

To address the needs of young people in Lagos State, South-West, Nigeria, for information about family life and HIV, the Lagos State Ministry of Education, in collaboration with Action Health Incorporated, began to offer the Family Life and HIV Education Curriculum in government junior secondary schools in 2003. Knowledge and attitudes were measured in a sample of 1,366 students in Lagos State, Nigeria, in November 2004, at the beginning of the school year, and again in July 2005 after receiving a year of the Family Life and HIV Education Curriculum. Students exposed to the curriculum reported significantly increased knowledge of sexuality and HIV, support for abstinence, and gender role equality.

Fatusi, A., \& Wang, W. (2009). Multiple sexual partnership mediates the association between early sexual debut and sexually transmitted infections among adolescents and young adult males in Nigeria. The European Journal of Contraception and Reproductive Health Care, 14(2):134-143. Article available at: http://informahealthcare.com/doi/abs/10.1080/13625180802601110

This cross-sectional survey was aimed at assessing the relationship between early sexual debut, risky sexual behaviours and sexually transmitted infections (STIs) among young males in Nigeria. The study used the sample of sexually experienced never married young males aged 15-24 years from the 2003 and 2005 National HIV/AIDS and Reproductive Health Surveys (NARHS) and involved 1,278 Nigerian males. Logistic regression was used in assessing the statistical relationship between early sexual debut ( $<16$ years) and self-reported STIs within the past 12 months, with demographic factors, sexual behaviours, and psychosocial measures controlled for. The results revealed that 6.8 percent had STI symptoms. At bivariate analysis, early sexual debut $(p=0.021)$, multiple partners $(p<0.001)$, concurrent partners $(p<0.002)$, and sex with casual/commercial partners $(p=0.013$ ) were associated with STIs. At multivariate analysis, early sexual debut (odds ratio $(\mathrm{OR})=2.12$, 95 percent confidence interval $(\mathrm{Cl})=1.17-3.84$ ) remained significantly associated with STIs. Multiple sexual partnerships $(\mathrm{OR}=2.00,95$ percent $\mathrm{Cl}=1.13-3.52)$ were also significantly associated with STIs, and is a mediator of the association between early sexual debut and STIs.

Nwagwu, W. E. (2009). Participatory gender-oriented study of the information needs of the youth in a rural community in South-Eastern Nigeria. African Journal of Library, Archives \& Information Science, 19 (2):129-140. Abstract available at: http://www.ajol.info/index.php/ajlais/article/view/48076 Article available at: http://www.highbeam.com/doc/1G1-212851173.html

The study investigates the information needs of the youth in Uzoagba, a rural community in South-Eastern Nigeria. Data were collected from the youth through focus group discussions involving 220 participants, and a questionnaire survey involving 250 respondents. One female, one male, and one mixed-gender focus groups for each of three age categories-7-12 years, 13-19 years, and 20-30 years-were used to generate data on the information needs of the youth. The questionnaire which consisted of closed and open questions was used to collect data on demographic characteristics, information needs, and current sources of information of the respondents. Two categories of the youth could be identified. The first comprised those aged 12 years or less who desired information concerning their education, health/HIV/AIDS, and income. The second group comprised those older than 12 years whose needs concerned income/employment and education. The youth wanted to develop their personal capacities through education in order to integrate themselves into productive activities in the community. 
Nwaorgu, O. C., Onyeneho, N. G., Onyegegbu, N., Okolo, M., Ebele, O., Ugochukwu, G., \& Mbaekwe, C. (2009). Family life and HIV/AIDS education (FLHE) in schools in Enugu State: baseline study of reproductive health issues among in-school adolescents in Enugu State. African Journal of Reproductive Health, 13(2):17-32. Article available at: http://www.bioline.org.br/pdf?rh09018

The study investigated the sexual and reproductive health (SRH) knowledge and practices among junior secondary school grades 1 and 3 students in Enugu State, South-East, Nigeria, preparatory to incorporating family life and HIV/AIDS education (FLHE) into the school curricula in the state. The study revealed that over 90 percent of the respondents were regularly involved in sexual activities. Almost one-fifth (17.5 percent) indicated that they would definitely have sex within the next two years, while 19.2 percent may have sex within the next two years. More than two-thirds (68.3 percent) of the respondents were females. The ages of the respondents ranged from 10 to 20 years with a mean age of 14.25 years and a standard deviation of +/1.841 years. The students lacked proper knowledge of protection and knowledge scores on SRH issues was low especially among the urban dwellers ( $p$ 0.001). Almost two-thirds $(64.4$ percent) did not know if condoms prevent pregnancy. Some indicated that charms and herbs are effective ways of preventing pregnancy.

Nwankwo, B. O. \& Nwoke, E. A., (2009). Risky sexual behaviours among adolescents in Owerri Municipal: predictors of unmet family health needs. African Journal of Reproductive Health, 13(1):135-145. Article available at: http://www.bioline.org.br/pdf?rh09012

The study examined the risky sexual behaviours of adolescents in Owerri Municipal in Imo State, South East, Nigeria. Adopting the descriptive survey research design, a stratified sampling technique was used to enrol 1,008 adolescents aged 10-19 years from 4 secondary schools into the study. A structured questionnaire was used for data collection. The study revealed that almost half of the adolescents ( 47.4 percent) have had sex and many have engaged in one form of risky sexual behaviours or another. Peer group seem to be major source of the sexuality information (55.6 percent) and influencing factor (52.3 percent). Significant association was found to exist between adolescents' risky sexual behaviours and age at first sexual experience or adolescent perception of parental rearing pattern $(p<.05)$.

Odeyemi, K., Onajole, A., \& Ogunowo, B. (2009). Sexual behaviour and the influencing factors among out of school female adolescents in Mushin market, Lagos, Nigeria. International Journal of Adolescent Medicine and Health, 21(1):101-109. Article available at:

http://www.degruyter.com/view/j/ijamh.2009.21.1/ijamh.2009.21.1.101/ijamh.2009.2 1.1.101.xml

This study examined the sexual behaviour of female out-of-school adolescents and identified factors that influence their sexual behaviour. The cross-sectional study was conducted among a representative sample of unmarried, out-of-school female adolescents ( $n=332$, mean age 17 years), selected using cluster sampling, who were working in a major market (Mushin) in Lagos, South-West, Nigeria. Data were collected using interviewer administered questionnaires. Many girls (43.7 percent) had had sexual intercourse. The mean age at initiation was 16 years. The main reason for initiation was curiosity. Risky sexual behaviour and transactional sex was common. Non-consensual sex was also reported. Sexual health knowledge was poor, and friends served as their main source of information on sexual health issues. Factors associated with the initiation of sexual activity were friends' sexual behaviour, the person adolescents resided with, parents' marital status, availability of funds to meet basic needs, and watching pornography. 
Owoaje, E. T., \& Uchendu, O. C. (2009). Sexual risk behaviour of street youths in south west Nigeria. East African Journal of Public Health, 6(3):274-279. Article available at: http://www.ncbi.nlm.nih.gov/pubmed/20803918

This survey was conducted to determine the sexual risk behaviours of young people on the streets of Ibadan, South-west, Nigeria. A cross-sectional survey was conducted among youth aged 15-24 years in the major markets, motor parks, and commercial areas in two local government areas in lbadan. Participants in the study areas were identified in groups based on their occupational activity and all consenting young people were interviewed. A semi-structured questionnaire was used to obtain information on sexual behaviours, condom use, and history of sexually transmitted infections. Most (68.8 percent) were males, 79.0 percent were sexually experienced, and the median age at sexual debut for males was 15 years and 16 years for females. More females (53.9 percent) compared to males (34.5 percent) reported that their first partners were five or more years older $(p<0.01)$. Condom use during the first sexual intercourse was reported by only 32.2 percent. Sex with a commercial sex worker or exchange of sex for money was reported by 18.2 percent (20.6 percent of males versus 12.2 percent of females, $p=0.01$ ). Factors significantly associated with history of transactional sex were male gender, older age (20-24 years), being out-of-school, and regular alcohol use. Multiple sexual partnerships were reported by 58.2 percent; significant predictors were male gender, early age at sexual debut, regular alcohol use, and history of transactional sex. Inconsistent condom use was reported by 44.8 percent; the predictors were female gender, regular alcohol use, and history of transactional sex in the previous year.

\section{Sangowawa, A. O., Owoaje, E. T., Faseru, B., Ebong, I. P., \& Adekunle, B. J. (2009).Sexual practices of deaf and hearing secondary school students in Ibadan, Nigeria. Annals of Ibadan Postgraduate Medicine, 7(1):26-30. Article available at: http://www.ncbi.nlm.nih.gov/pmc/articles/PMC4111003/}

The objective of the study was to compare the sexual practices of hearing impaired students with their nonhearing impaired counterparts. A cross-sectional survey was conducted. All consenting deaf students and an equal number of hearing students attending a halfway school in Ibadan, South-western Nigeria participated. A total of 78 deaf students and 74 hearing students with mean ages of 17.1 (S.D. \pm 3.0$)$ and 15.8 (S.D. \pm 1.9) years, respectively, participated. Twenty-six (33.3 percent) deaf and 36 (48.6 percent) hearing students had ever had sexual intercourse $(p=0.055)$. Median ages at sexual debut were 16 and 14 years for the deaf and hearing students, respectively. The number of sexual partners ever had ranged from 1 to 8 among the deaf and 1 to 6 among the hearing students. Four (15.4 percent) deaf and 23 (63.9 percent) hearing students reported that they had used a condom the last time they had sexual intercourse.

\section{Van der Maas, F., \& Otte, W. M. (2009). Evaluation of HIV/AIDS secondary school peer education in rural Nigeria. Health Education Research, 24(4):547-557. Article available at: http://her.oxfordjournals.org/content/24/4/547.long}

In this study, investigators assessed whether peer education was an effective method of HIV/AIDS awareness, in terms of knowledge, misconception, and behaviour, among adolescents in a rural area of Nigeria (Izzi, Ebonyi State, South eastern, Nigeria). A comparative case series ( $n=250$ ), cross-sectional structured survey $(n=135)$, and focus group discussions $(n=80)$ were undertaken among adolescents. In both the case series and structured survey, a questionnaire was used which addressed the following issues: socio-demography, knowledge on transmission and prevention of HIV, accessibility to different sources of HIV/AIDS information, stigmatization, and sexual behaviour. Binary logistic regression was applied to compare responses from the peer-educated and non peer-educated populations. The model was adjusted for confounders. Investigators demonstrated increased knowledge and decreased misconception and sexual risk behaviour in adolescents receiving peer education when compared to adolescents not receiving peer education. These differences were apparent both over time (2005-2007) and cross-sectionally (2007). 
Adedimeji, A. A., Heard, N. J., Odutolu, O., \& Omololu, F. O. (2008). Social factors, social support and condom use behaviour among young urban slum inhabitants in southwest Nigeria. East African Journal of Public Health, 5(3):215-222. Article available at: http://www.bioline.org.br/pdf?lp08040

This study used survey data to examine the effect of social factors and social support on condom use among economically disadvantaged adolescents living in urban slums in Ibadan, South-West, Nigeria. It examined the extent to which beliefs and self-efficacy about condoms, risk perception, and perceived social support act as predictors of use or non-use of condoms among sexually active young people aged 15-24 years. Data was obtained from sexually active boys (448) and girls (338) selected through multistage sampling techniques. Generally, there were low levels of condoms use, despite high levels of risky sexual behaviour. Although, half of boys and one third of girls reported ever using condoms, a considerably lower proportion of male and female adolescents regularly used condoms. Among those who reported ever using condoms, 61.7 percent of males aged 15-19 and 62.1 percent of males aged 20-24 did not use a condom during their last sexual activity. The proportion among females was 64.8 percent among those aged 15-19 and 70.1 percent among those aged 20-24 years. Logistic regression models showed that among girls, those who perceived social support from peers and non-parental figures were more likely to use condoms while among boys, earning an income, high risk perception, and self-efficacy were associated with higher odds of condom use.

\section{Aomreore, A. A., \& Alikor, E. A. (2008). Prevalence of major HIV- risk related behaviour among SSS3 students in Port Harcourt Metropolis, Nigeria. African Journal of Health Sciences, 15, 42-49. Article available at: http://www.bioline.org.br/pdf?jh08008}

This cross-sectional survey among 1,800 third year senior secondary school students examined their HIV infection risk-related behaviours. The participants were randomly selected from 13 secondary schools in Port Harcourt, South-South, Nigeria using a 2-stage sampling technique. Demographic data and information on the sexual behaviour of each student in the study group was obtained from a self-administered structured questionnaire. The prevalence of sexual intercourse was 61.1 percent. Males were more sexually active than

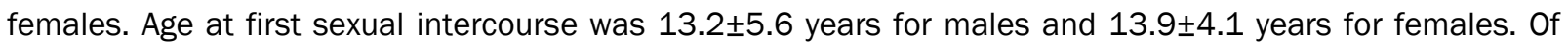
the sexually active students, 32.6 percent had multiple sexual partners. Sexual activity of the students did not increase with age. The prevalence of intravenous drug use was found to be 1.4 percent. The use of intravenous drugs was more among the males (80.8 percent) than among the females. Among the sexually active students only 437 (36.9 percent) used condoms. Sex of student, social class, and school were significant predictors of ever-had sexual activity.

Amoran, O. E., \& Fawole, O. (2008). Parental influence on reproductive health behaviour of youths in Ibadan, Nigeria. African Journal of Medicine and Medical Science, 37(1):21-27. Abstract available at: http://www.ncbi.nlm.nih.gov/pubmed/18756851 Article available at: https://www.researchgate.net/publication/23223210_Parental_influence_on_reproducti ve health behaviour of youths in Ibadan Nigeria

This cross-sectional study was carried out to document parental influence on the reproductive health behaviour of youth $(n=274)$ in Idikan community, Ibadan, South-Western, Nigeria. Information on the sociodemographic characteristics, parental communication, parental monitoring, and sexual practices of respondents were collected using a structured interviewer-administered questionnaire. Examples of liberal parental monitoring include parents allowing youth to go out at will on social outings or with parental consent while conservative parental monitoring examples include parents restricting the youth's movements and the youth only going out when parents were not at home or had to lie to go on social outings. The mean age of the respondents was $17.6+/-12.5$ years. One hundred and eleven (40.5 percent) were sexually active. The overall mean age at first sexual intercoursewas $15.2+/-3.0$ years (males $=15.4+/$ - 3.5 years, females 14.90 +/- 2.6 years). Fifty-two (19.0 percent) respondents used condoms regularly. More out-of-school youth (42.2 percent) were sexually active than those in-school (38.7 percent). More youth with a secondary school 
education (50.8 percent) used condoms regularly than those with a primary education (40.4 percent). Mothers were more involved in family life education than fathers ( 40.9 percent vs. 16.8 percent) and family life education was found to promote condom use. Predictors of regular condom use among the youth were comprehensive family life education by mothers (OR $=6.24, \mathrm{C} . \mathrm{I}=2.47-15.75, \mathrm{p}=0.001)$, respondents' level of education $(\mathrm{OR}=0.415, \mathrm{C} . \mathrm{I}=0.211-0.814 \mathrm{p}=0.011)$, and occupation $(\mathrm{OR}=0.48, \mathrm{C} . \mathrm{I}=0.24-0.95 \mathrm{p}=$ $0.034)$. While comprehensive family life education by mothers $(\mathrm{OR}=2.11, \mathrm{C} . \mathrm{I}=1.04-4.28, \mathrm{p}=0.038)$, female gender $(\mathrm{OR}=2.2, \mathrm{C} . \mathrm{I}=1.28-3.83 \mathrm{p}=0.005)$, and liberal monitoring pattern by mother $(\mathrm{OR}=2.16$, C.I $=1.03-4.53 p=0.04)$ were predictors of increased sexual activity.

\section{Akpabio, I. I., Asuzu, M. C., Fajemilehin, B. R, \& Ofi, A. B. (2008-2009). Effects of parental involvement in HIV/AIDS preventive education on secondary student knowledge about transmission and prevention in Akwa Ibom State, Nigeria. International Quarterly of Community Health Education, 29(1) 71-87. Article available at: http://qch.sagepub.com/content/29/1/71.full.pdf}

This intervention study used a pre-/post-test design with two intervention groups (IG1 and IG2) and a control group, selected from three urban secondary schools in Akwa Ibom State. This study investigated HIV preventive health education involving nurses alone (IG1) and another involving both nurses and trained parents/guardians (IG2) on students' knowledge of HIV transmission and prevention in Akwa Ibom State, South-South, Nigeria. Subjects included 339 students selected through a multistage and stratified random sampling technique. Data were obtained using a questionnaire, and analysis involved the use of analysis of covariance, multiple classification analysis, and Scheffe's post-hoc test. Results show that students exposed to parental involvement had significantly better mean scores on knowledge of prevention (IG2: $\mathrm{x}=7.51$; IG1: $x=6.96$ control: $x=3.82$ ). Furthermore, although the male students had a significantly higher mean score with the intervention involving only nurses, the females had a higher mean score with intervention involving both nurses and trained parents/guardians.

Borire, A. A., Oyekunle, O. A., Izekor, T., Akinlonu, A., Okanlawon, A. O., \& Noronha, C. C. (2008). Comparing the knowledge and attitude about HIV/AIDS and the sexual behaviour of secondary school students of a missionary school and a public school. Nigerian Quarterly Journal of Hospital Medicine, 18(4):206-210. Article available at: http://www.ncbi.nlm.nih.gov/pubmed/19391321

Investigators conducted a comparative cross-sectional study of secondary school students of a missionary school and a public school to determine their knowledge of HIV/AIDS and to compare their sexual behaviour. The schools were both located in Ipaja, semi-urban suburb in Alimosho Local Government Area of Lagos State, South-West, Nigeria. Most of the respondents were aged 11-15 in both schools. There was no significant statistical association between the type of school and the occurrence of sexual intercourse. However, only 4 percent of sexually active missionary school students used condoms compared to 37 percent of the public school students. Condom usage was associated with the type of school $(p=$ 0.000189). A quarter (25 percent) of sexually active public school students had multiple sexual partners, compared to 2 percent of their missionary school counterparts. There was a statistically significant relationship between the type of school and the number of sexual partners $(p=0.003390)$. There was also a statistically significant relationship between condom use and the age, sex, and class of sexually active students $(p=0.0000006 ; p=000000032 ; p=0.00497073$ respectively).

Daboer, J. C., Ogbonna, C., Jamda, M. A. (2008). Impact of health education on sexual risk behaviour of secondary school students in Jos, Nigeria. Nigerian Journal of Medicine, 17(3):324-9. Article available at: http://www.pubfacts.com/detail/18788261/Impact-ofhealth-education-on-sexual-risk-behaviour-of-secondary-school-students-in-Jos-Nigeria

The aim of this follow-up study was to find out the impact of a HIV/AIDS health education intervention on the sexual risk behaviours of senior secondary school students. Study controls were selected from similar 
schools. The students' sexual risk behaviour was assessed at baseline followed by a HIV/AIDS health education intervention. The risk behaviour was then re-assessed six months after the intervention. Students who lived in urban areas and those who lived with both parents were less likely to have experienced sexual intercourse at baseline than those who lived in the rural areas (but school in Jos, an urban area, during school sessions), and those who lived with single parents and other relations. Health education delayed sexual debut among students who were sexually naïve but had no effect on the sexual activity of those who were already sexually experienced.

\section{Esere, M. O. (2008). Effect of sex education programme on at-risk sexual behaviour of school-going adolescents in Ilorin, Nigeria. African Health Sciences, 8(2):120-125. Article available at: http://www.ncbi.nlm.nih.gov/pmc/articles/PMC2584331/pdf/AFHS0802- 0120.pdf}

The quasi-experimental study sought to determine whether a sex education intervention programme would reduce at-risk sexual behaviours of 24 school-going adolescents aged 13-19 years in llorin Metropolis, Kwara State, North-Central, Nigeria. The main outcome measures were self-reported exposure to sexually transmitted diseases, multiple sex partners, anal sex, oral sex, and non-use of condoms. When the treatment (intervention) group was compared with the control group in an intention to treat analysis, there were significant differences in at-risk sexual behaviours of the two groups. Those in the intervention group reported less at-risk sexual behaviours than their counterparts in the control group. The treatment group evaluated the intervention programme positively and their knowledge of sexual health improved.

\section{Fatusi, A. O., \& Blum, R. W. (2008). Predictors of early sexual initiation among a nationally representative sample of Nigerian adolescents. Biomed Central Public Health, 8. 136. Article available at: http://www.biomedcentral.com/content/pdf/1471-2458-8-136.pdf}

Interviewer-collected data of 2,070 never-married adolescents aged 15-19 years were analysed to determine association between age of sexual debut and demographic, psychosocial, and community factors. The data for this study was obtained as part of the 2005 National HIV/AIDS and Reproductive Health Survey (NARHS). Using Cox proportional hazards regression, multivariate analysis was carried out with two different models-one with and the other without psychosocial factors. The results showed that a fifth of respondents (18 percent males; 22 percent females) were sexually experienced. In the South 24.3 percent males and 28.7 percent females had initiated sex compared to 12.1 percent of males and 13.1 percent females in the North $(p<0.001)$. In the first model, only region was significantly associated with adolescent sexual initiation among both males and females; however, educational attainment and age were also significant among males. In the second (psychosocial) model factors associated with adolescent sexual debut for both genders included more positive attitudes regarding condom efficacy (males: $\mathrm{HR}=1.28$, 95 percent $\mathrm{Cl}=1.07-1.53$; females: $\mathrm{HR}=1.24,95$ percent $\mathrm{Cl}=1.05-1.46$ ) and more positive attitudes to family planning use (males: $\mathrm{HR}=1.19$, 95 percent $\mathrm{Cl}=1.09-1.31$; females: $\mathrm{HR}=1.18,95$ percent $\mathrm{Cl}=1.07-1.30)$. A greater perception of condom access $(\mathrm{HR}=1.42,95$ percent $\mathrm{Cl}=1.14-1.76)$ and alcohol use $(\mathrm{HR}=1.90,95$ percent $\mathrm{Cl}=1.38-2.62)$ among males and positive gender-related attitudes $(\mathrm{HR}=1.13,95$ percent $\mathrm{Cl}=$ 1.04-1.23) among females were also associated with increased likelihood of adolescent sexual initiation. Conversely, personal attitudes in favour of delayed sexual debut were associated with lower sexual debut among both males (males: $\mathrm{HR}=0.36,95$ percent $\mathrm{Cl}=0.25-0.52)$ and females $(\mathrm{HR}=0.38,95$ percent $\mathrm{Cl}=$ 0.25-0.57). Higher level of religiosity was associated with lower sexual debut rates only among females (HR $=0.59,95$ percent $\mathrm{Cl}=0.37-0.94)$. 
lyaniwura, C. A., \& Mautin, G. (2008). Sexual activity and other related practices among youth corpers in Nigeria. West African Journal of Medicine, 27(1):13-9. Article available at: http://connection.ebscohost.com/c/articles/34670987/sexual-activity-other-relatedpractices-among-youth-corpers-nigeria

The aim of the study was to assess the sexual practices of young graduates and examine their attitude to the abstinence only policy for youth. The study population consisted of 376 young graduates (197 males, 179 females) between the ages of 20 and 29 at the National Youth Service Corps (NYSC) Orientation Camp, Sagamu, Ogun State, South-West, Nigeria. Cluster sampling technique was used to choose the participants. Six hundred questionnaires were administered but only 376 completed questionnaires were returned and analysed. Results showed that 73.9 percent had ever had sex but only 54.8 percent had sex in the past year. A majority of those who had been sexually active had used condoms before ( 85.6 percent), 53 percent used them during their last sexual encounter, but only 34.5 percent used them regularly. Males were more likely to report their sexual activity history and multiple sexual partners, but more regular condom use $(p<0.05)$. One hundred and forty-three (38 percent) and 23 (6.1 percent) had used alcohol and cigarettes, respectively, in the previous year. Major behavioural changes made to avoid HIV included being faithful to a sexual partner (32.2 percent), abstaining from sex (27.1 percent), and using condoms during sex (20.6 percent). For both primary and secondary sexual abstainers, religious considerations and moral convictions were the major motivators.

Kafewo, S. A. (2008). Using drama for school-based adolescent sexuality education in Zaria, Nigeria. Reproductive Health Matters, 16(31):202-210. Article available at: http://www.jstor.org/stable/pdf/25475380.pdf

This paper describes the use of drama and participatory methods in a girls-only secondary school in Zaria, North-Central, Nigeria, as a means of sexuality education, carried out by the Nigerian Popular Theatre Alliance and the Second Chance Organization of Nigeria. The issues addressed had to come from the students to allow them to develop critical thinking and learn useful lessons. The group of girls (15) expressed concern with abortion, premarital sex and pregnancy, teacher-student relationships, and lesbianism. Participants developed a play about teacher-student relationships and presented it to the whole school. The presentation was stopped several times in order to involve the audience in discussing the choices available to the protagonist and what they would do in her place. This allowed all the students to explore the problem, generate and assess alternative solutions, and communicate their learning to others. It also started a process of change in how the school dealt with girls who were forced to drop out due to sexuality-related problems, including pregnancy.

\section{Mberu, B. U. (2008). Protection before the harm: The case of condom use at the onset of premarital sexual relationship among youths in Nigeria. African Population Studies, 22(2):57-83. Article available at: http://www.bioline.org.br/request?ep08004}

The study builds on the proposition that condom use at first intercourse is an immediate indicator of the risks associated with the encounter and the propensity of subsequent condom use consistently and regularly. Data from the 2003 Nigeria Demographic and Health Survey and binary logistic regression models were utilized to examine the predictors of condom use at premarital sexual debut among Nigerian youth aged 15-24. The analysis identified significant independent effects of age at sexual debut, living arrangements, level of education, and household economic status, with the strongest effect linked to ethnic origin. 
Morhason-Bello, I. O., Oladokun, A., Enakpene, C. A., Fabamwo, A.O., Obisesan, K. A., \& Ojengbede, O. A. (2008). Sexual behaviour of in-school adolescents in Ibadan, South-West Nigeria. African Journal of Reproductive Health, 12(2):89-97. Article available at: http://www.bioline.org.br/pdf?rh08025

This study was a cross-sectional survey conducted among 716 senior secondary school adolescents in Ibadan, South-West, Nigeria from March to August 2005. Out of the 716 students interviewed, the response of 695 students was suitable for analysis. Respondents were aged 12-24 years with a mean of $15 \pm 2.6$ years. Over a quarter (28.3 percent) of the respondents had previous sexual exposure with higher proportions being male $(p=0.00043)$. For a majority of the respondents, their first sexual exposure was unplanned. Family settings and educational level did not have a significant influence on the previous sexual exposure. The types of sexual practices were mainly vaginal while some had also practiced oral and anal sex. Most of those that have been sexually exposed had more than one partner. About half of the respondents learned about sex from their friends while others through their parents and media.

Nwaorgu, O. C., Onyeneho, N. G., Okolo, M., Obadike, E., \& Enibe, G. (2008). Reproductive health knowledge and practices among junior secondary school grade one students in Enugu State: threat to achieving millennium development goals in Nigeria. East African Journal of Public Health, 5(2):126-132. Article available at: http://www.bioline.org.br/pdf?lp08024

This study provided background information for the implementation of family life and HIV/AIDS education in post primary schools in Enugu State, South-East, Nigeria. A cross-sectional survey of the reproductive health knowledge and practices of 412 junior secondary school pupils from 12 schools in Enugu State, Nigeria was undertaken using a structured self-administered questionnaire. More than 60 percent (67.2 percent) of the respondents were female. The ages of respondents ranged from 10 to 20 years with a mean age of 13.5 years and a standard deviation of $+/-1.642$ years. The study revealed that while the pupils demonstrated fair knowledge of human biology, they lacked knowledge of self-protective mechanisms as it related to sexual health. About (50 percent) of participants reported that they have had sex, under the age of 11 years when they must have been in primary school, and most (89.3 percent) between the ages of 11 and 14 years. Half ( 50.9 percent) of the respondents held the belief that a girl would not get pregnant in her first sexual encounter.

Odu, 0. O., Asekun-Olarinmoye, E. O., Bamidele, J. O., Egbewale, B. E., Amusan, O. A., \& Olowu, A. O. (2008). Knowledge, attitudes to HIV/AIDS and sexual behaviour of students in a tertiary institution in south-western Nigeria. The European Journal of Contraception and Reproductive Health Care, 13(1):90-96. Article available at: http://informahealthcare.com/doi/abs/10.1080/13625180701617670

This study investigated the knowledge, attitude and sexual behaviour of students in tertiary institutions in South Western Nigeria with regard to HIV/AIDS. Using a cross-sectional survey, information was collected from 368 students of a tertiary institution in Ede, Osun State, Nigeria. Most (80.1 percent) students were aged between 18 and 24 years old. Most respondents (89.4 percent) were aware of the existence of HIV/AIDS and knew the aetiology, routes of transmission, signs, and symptoms, and preventive measures against the disease. While a little over half of respondents (59.8 percent) revealed that they could hug people with HIV/AIDS, one out of four (27.2 percent) stated that these persons should be isolated from the community. Less than a quarter (22.3 percent) of the respondents believed that they were vulnerable to HIV/AIDS. More than half (58.2 percent) had ever had sex; the mean age at their first sexual exposure (for all respondents) was $16.7 \pm 4.4$ years. Almost half (48.2 percent) of the 191 currently sexually active respondents had multiple sexual partners. Of the sexually active respondents, 75.9 percent claimed to have ever used condoms; among these, male respondents were more likely to have ever used condoms than their female peers $(p<0.05)$. 
Odu, B. K., \& Akanle, F. F. (2008). Knowledge of HIV/AIDS and sexual behaviour among the youths in South West Nigeria. International Journal of Tropical Medicine, 3(4):79-84. Article available at: http://www.idosi.org/hssj/hssj3\%281\%2908/10.pdf

This study examined the relationship between sexual behaviour and knowledge of HIV/AIDS among youth in South West Nigeria. The study also investigated the different types of sexual behaviour and whether youth have knowledge of key basic concepts of HIV/AIDS. Using the descriptive research design, a total number of 1,420 undergraduates aged 15-30 years who correctly filled the self-constructed questionnaire in 4 different universities in 4 different states of South West Nigeria were sampled. The result of the analysis revealed that most respondents were sexually active (72.5 percent). Respondents were also engaged in casual sex (55.1 percent), same sex (30.8 percent), multiple sex partners (59.2 percent), and sex in exchange for money or favour (37.7 percent).

\section{Sunmola, A. M., Adebayo, D. O., \& Ogungbemi, K. O. (2008). Patterns of condom acquisition and its association with consistent use among young men in Nigeria. AIDS Care, 20(7):791-795. Article available at: http://www.tandfonline.com/doi/abs/10.1080/09540120701513685?url_ver=Z39.88- 2003\&rfr_id=ori:rid:crossref.org\&rfr_dat=cr_pub\%3dpubmed\#.VQAHLOEYPLM}

This study analysed condom acquisition and sexual behaviour practices of 372 sexually active young men who were aged 19-30 years in Ibadan, South-western, Nigeria and logistic regression was utilised to determine whether condom acquisition practice was a predictor of consistent condom use. Results showed that most participants (41 percent) had mixed procurement of free and purchased condoms, 31 percent always bought condoms, while 28 percent always obtained free condoms. Almost three-quarters of individuals (71 percent) who always purchased condoms, 23 percent who had mixed procurement, and 12 percent who had free condoms consistently used condoms. The results also showed that having two or more partners and always purchased condoms increased the likelihood of consistent condom use.

Uthman, O. A. (2008). Geographical variations and contextual effects on age of initiation of sexual intercourse among women in Nigeria: a multilevel and spatial analysis. International Journal of Health Geographics, 7, 27. Article available at: http://www.ijhealthgeographics.com/content/7/1/27

A cross-sectional study was conducted to estimate prevalence of early sexual debut among ever or currently married women in six geographic regions of Nigeria using a large, nationally representative sample. The study also examined the extent of regional and state disparities in age of initiation of sexual intercourse. Multilevel logistic regression models were applied to data on 5,531 ever or currently married women who had participated in the 2003 Nigeria Demographic and Health Survey. Coital debut at 15 years or younger was used to define early sexual debut. Exploratory spatial data analysis methods were used to study geographic variation in age at first sexual intercourse. The median age at first sexual intercourse for all women included in the study was 15 years (range; 14-19). The North West and North East had the highest proportion of women who had reported early sexual debut (61 percent and 78 percent, respectively). The spatial distribution of age of initiation of sexual intercourse was non-random and clustered with a Moran's I = $0.635(p=.001)$. There was significant positive spatial relationship between median age of marriage and spatial lag of median age of sexual debut (Bivariate Moran's I $=0.646,(p=.001)$. The study found that individual-level and community contextual characteristics were independently associated with early sexual debut. 
Adedimeji, A. A., Omololu, F. O., \& Odutolu, 0. (2007). HIV risk perception and constraints to protective behaviour among young slum dwellers in Ibadan, Nigeria. Journal of Health, Population and Nutrition, 25(2):146-57. Article available at: http://www.ncbi.nlm.nih.gov/pmc/articles/PMC2753996/pdf/ihpn0025-0146.pdf

This study examined the relationship between HIV/AIDS risk perception and protective behaviour among sexually active urban young slum dwellers in Ibadan, South-West, Nigeria. Multistage sampling techniques were used for selecting 1,600 respondents aged 15-24 years. Of these, 1,042 (65 percent) respondents who reported unprotected sex in the last three months were selected for analysis. A self-administered questionnaire was used for obtaining information and focus-group discussions (FGDs), along with other participatory learning and action (PLA) activities, were conducted with male and female respondents in each community. Overall, 16 FGDs and PLA sessions were held in each community with males and females. Although the sexually active respondents demonstrated basic knowledge of HIV/AIDS and high risk perception, risky behaviour was common, and protective behaviour was poor. About 48 percent of 505 males and 12 percent of 537 females had multiple partners. Similarly, 29 percent of males and 38 percent of females were engaged in transactional sex. Only 14 percent of males and 5 percent of females used any form of protection, resulting in the high rates of sexually transmitted infections reported by 27 percent of males and 10 percent of females. Structural and environmental constraints were identified as barriers to adopting protective behaviour.

\section{Ajuwon, A. J., \& Brieger, W. R. (2007) Evaluation of a school-based reproductive health education program in rural South Western, Nigeria. African Journal Reproductive Health, 11(2):47-59. Article available at: http://www.bioline.org.br/pdf?rh07020}

This quasi-experimental study compared the relative efficacy of teacher instructions alone, peer education alone, and a combination of these two on reproductive health knowledge, attitude, perceived self-efficacy, and sexual practices among secondary schools students in the Ibarapa district, Oyo State, South-western Nigeria. A baseline questionnaire was administered to a systematic sample of students in four schools that were randomized into four treatment arms: teacher instructions alone (E1), peer education alone (E2), combination of teacher instruction and peer education (E3), and control (C). The results were used to design the contents of the interventions, which were implemented for one academic session. A follow-up survey using the same sampling procedures as baseline was conducted to measure the outcome of the intervention. The control group had superior reproductive health knowledge at baseline. By follow-up survey however, all three intervention schools showed significant knowledge gains, while the control school students' mean score increased slightly. Increase in knowledge was greatest among E3 (+5.0 points), followed by E2 (+3.4), E1 (+1.4), and C (0.3). The intervention schools showed a significant positive shift in attitude towards use of contraceptives with mean increase of $0.6,0.5$, and 0.9 points in E1, E2, and E3, respectively. Scores that measured the students' perceived self-efficacy for safe sex increased significantly among E1 (from 10.8 to 11.8) and E3 (from 10.4 to 12.6). Reported condom use was significantly higher among E2 (from 16.7 percent to 62.8 percent) ( $p<0.05$ ) and E3 (from 22.8 percent to 53 percent) ( $p<$ 0.05 ) compared to E1 (28.6 percent to 47.4 percent) ( $p>0.05$ ) and control (from 25 percent to 45.8 percent) $(p>0.05)$. Overall, the students from E3 showed more improvement in knowledge, attitude, and self-efficacy, than their counterparts from E2 and E3 and control.

\section{Babalola, S. (2007). Readiness for HIV testing among young people in northern Nigeria: the roles of social norm and perceived stigma. AIDS and Behaviour, 11(5):759-769. Article available at: $\mathrm{http}$ ://link.springer.com/article/10.1007\%2Fs10461-006-9189-0}

This study examined the predictors of readiness for testing among young people in northern Nigeria, paying attention to the role of stigma. Stigma was measured at two levels: individual and community (social norm). Study participants comprised 3,844 young people (1,924 males and 1,920 females) randomly selected from urban and semi-urban local government areas in two northern Nigeria states, Bauchi and Sokoto in the North East and North West geopolitical zones, respectively. The average age of the participants was 19.4 years for 
men and 18.8 years for women. There were commonalities and differences in the correlates of readiness among men and women. For men and women, knowledge about HIV prevention and a VCT source, discussion about condom use for HIV prevention, and perceived risk were strong predictors. Knowledge that an apparently healthy person can be HIV infected was only significant for women. Perceived stigma was a significant predictor for both men and women although the specific dimension of note differs between the sexes. Social norm was strongly and directly associated with readiness among men, but had no apparent influence among women. For both sexes, social norms appeared to have a strong mediating influence on the relationship between personal perceived stigma and readiness.

\section{Fatusi, A., Wang, W., \& Anyanti, J. (2007-2008). Multi-media campaign exposure and interpersonal communication on sexual abstinence among young people in Nigeria: $A$ propensity-matched study. International Quarterly of Community Health Education, 28(4):289-303. Article available at: http://qch.sagepub.com/content/28/4/289.long}

The study assessed the effect of a campaign exposure on interpersonal communication about abstinence among a nationally representative sample of never-married young people (15-24 years). The campaign assessed was a national multi-media campaign (Zip-Up!) which was initiated in Nigeria in 2004 to promote sexual abstinence among young people as part of comprehensive effort to reduce sexually transmitted infections and unwanted pregnancy. A propensity score matching technique was used to create a comparison group statistically equivalent to the group exposed to the campaign and the campaign effect. Of the 3,388 sampled, 29.1 percent had been exposed to the campaign. Factors significantly associated with campaign exposure included age $(O R=1.08 ; 95$ percent $C . I=1.04-1.66)$, and frequency of media use. Compared to the non-exposed group, campaign exposure was associated with a statistically significant adjusted increase of 10.9 percent in the proportion of young people who engaged in interpersonal communication about abstinence.

Groce, N. E., Yousafzai, A. K., \& Van der Maas, F. (2007). HIV/AIDS and disability: differences in HIV/AIDS knowledge between deaf and hearing people in Nigeria. Disability and Rehabilitation, 29(5):367-371. Article available at: http://informahealthcare.com/doi/abs/10.1080/09638280600834567

The study sought to compare HIV knowledge among deaf and hearing individuals in order to identify how effectively deaf members of the community are being reached by HIV/AIDS messages. A survey comparing knowledge about HIV/AIDS among deaf and hard of hearing adolescents $(n=50)$ and young adults $(n=50)$ was undertaken. The study population comprised deaf and hard of hearing participants $(n=50)$ recruited from two schools for the deaf located in Omorodu Iseke town in Ebonyi State and a town close by in Enugu State, South-East, Nigeria. Significant differences $(p<0.05)$ in levels of understanding about certain aspects of how HIV is spread were identified as well as differences in available resources for access to accurate information among deaf members of the population.

ljadunola, K. T., Abiona, T. C., Odu, O. O., \& ljadunola, M. Y. (2007). College students in Nigeria underestimate their risk of contracting HIV/AIDS infection. The European Journal of Contraception \& Reproductive Health Care, 12(2):131-137. Article available at: http://uaps2007.princeton.edu/papers/70483

The objectives of this study were to assess the perceptions of personal risk of acquiring HIV among students of selected tertiary institutions in Ile-Ife and Ilesa in Osun State, South-West, Nigeria and to determine the correlates of perceptions of personal risk of infection. The study employed a cross-sectional descriptive design. An interviewer-administered questionnaire was applied to the 405 study participants (252 men and 153 women aged 15-25 years) and correlates of perceptions of personal risk of HIV infection were evaluated using multiple logistic regression analysis, confidence intervals, and odd ratios. Only 15 percent of the students perceived themselves to be at moderate-to-high risk of acquiring HIV compared with 85 percent who perceived themselves to be at little or no risk. Investigators' assessment of risk status of the 
participants revealed that 77 percent of the participants were actually at high risk of infection and only 23 percent at low risk. The sensitivity, specificity, and negative predictive value of the students' self-perception of personal risk compared with their assessed risk were 7, 58, and 16 percent, respectively, with a Kappa statistic of 0.178 . The only significant correlate of self-perception of personal risk was a recent symptom of sexually transmitted infections. The findings revealed that college students exhibited an optimism bias' associating high rates of HIV risk indicators with low levels of perceived personal risk of infection. This has implications for HIV/AIDS control in Nigeria.

\section{Ike, S. O., Aniebue, P. N. (2007). HIV/AIDS perception and sexual behaviour among Nigerian university students. Nigerian Journal of Clinical Practice, 10(2):105-110. Article available at: http://www.ajol.info/index.php/njcp/article/download/11248/2407}

This cross-sectional study evaluated the HIV/AIDS knowledge and perceptions, and sexual behaviors of undergraduate students of the University of Nigeria (Enugu, South-East Nigeria). A pre-tested structured questionnaire was administered to collect relevant information on their socio-demographic characteristics, HIV/AIDS awareness, sexual behaviour, willingness to test for HIV, and attitude towards people living with HIV. Out of 600 students, 579 aged 16 to 40 years responded. Of these respondents, 283 (48.9 percent) were male while 296 (51.1 percent) were females. The mean age of the respondents was 22.2 years (SD \pm 3.1 ). Over half ( 55 percent) heard about HIV/AIDS through the media. Over two-thirds (72 percent) believed viruses cause HIV/AIDS, but 27 percent thought it was God's anger or witches. Less than half (44 percent) were sexually active or engaging in pre/extramarital sexual intercourse and only two-thirds of them used condoms during these sexual activities. Ninety-one percent of those not using condoms simply did not like it or admitted it was unavailable. More than 70 percent had never had a HIV screening test, mostly due to reluctance or fear. Ninety-two percent would lovingly care for a HIV/AIDS patient.

\section{Isiugo-Abanihe, I. M., \& Isiugo-Abanihe, U. C. (2007). Adolescent sexuality and reproductive health in two oil producing communities in Imo and Rivers States, Nigeria. African Population Studies, 22(2):47-77. Article available at: http://www.bioline.org.br/pdf?ep07010}

This study was conducted in two contiguous oil producing rural local government areas, Ohaji-Egbema in Imo State (South-East), and Onelga in Rivers State (South South) of Nigeria, to examine adolescent sexuality and the reproductive health situation in the area given its peculiarities. The study sought out to ascertain the level of sexual activity among in-school and out-of-school adolescents aged 13-24, determine the prevalence of unwanted pregnancy, childbearing, abortion, sexually transmitted infections (STIs) and other reproductive health problems, and assess the level and pattern of reproductive health (including HIV/AIDS), knowledge, attitude, and behaviour of young people. Data were collected through questionnaires administered among 725 students in secondary schools and 249 school drop-outs, comprising 483 females and 491 males. Supplementary qualitative data was collected through focus group discussions. The study found a high level of sexual activity among both in-school and out-of-school adolescents, low levels of knowledge of preventive measures, negotiation skills and STIs, and relatively high levels of premarital pregnancy, abortion, and incidence of STIs. There was a marked difference in the level of knowledge about sexual and reproductive behaviour by the in-school and out-of-school population.

\section{Lawoyin, 0. 0. (2007). Findings from an HIV/AIDS programme for young women in two Nigerian cities: a short report. African Journal of Reproductive Health, 11(2):99-106. Article available at: http://www.ncbi.nlm.nih.gov/pubmed/20690293 http://www.ajol.info/index.php/ajrh/article/view/7932}

This short report describes the findings from an HIV/AIDS programme for young women held in two Nigerian cities-Ibadan and Lagos in southwest Nigeri. It was attended by 68 young women-35 in Ibadan and 33 in Lagos-between the ages of 18 and 30 years. Responses were elicited from the programme participants through the use of pre-and post-test questionnaires to identify effective health education strategies for the 
prevention of sexually transmitted infections, including HIV/AIDS among young Nigerian women. Outcomes revealed low knowledge levels, poor attitudes, and misconceptions about HIV/AIDS, as well as widespread stigma. Overall, a significant reduction in the misconception about HIV and AIDS among programme participants and an increase in knowledge of HIV/AIDS and sexual health which helped to foster positive attitudes towards people living with HIV were observed.

\section{Mba, C. I., Obi, S. N., \& Ozumba, B. C. (2007). The impact of health education on reproductive health knowledge among adolescents in a rural Nigerian community. Journal of Obstetrics and Gynaecology, 27(5):513-517. Article available at: http://informahealthcare.com/doi/abs/10.1080/01443610701478991}

This intervention study was to evaluate the impact of reproductive health education on the knowledge and attitude of adolescents in a rural Nigerian community towards reproductive health issues. It compared adolescents in a secondary school (study group), which received health education on reproductive health with another secondary school (control group), which did not receive any. The impact of the programme was evaluated with a pre-/post-test questionnaire. One hundred eighty students were selected by systematic sampling from each of the two randomly selected schools in Item, a rural community in Abia State, SouthEast Nigeria participated in the programme. A total of 360 students participated both in the pre-test and post-test study. There were 87 females and 93 males in the control group, while the study group had 82 females and 98 males. The mean age of the students was 14.3 years (range 10-20years). While all the respondents had heard of reproductive health and could identify at least one of its components, their knowledge of it prior to the health education was insufficient and was obtained mainly from peers and the mass media. Such information was incomplete and often coloured with cultural and religious bias. However, there was a significant $(p<0.05)$ gain in correct knowledge following the health education. The students in the study group showed a positive and permissive attitude towards reproductive health education and there was a drop in risky sexual behaviour following the intervention. Pre-marital sex (94.3 percent), pregnancy prevention and abortion (88.5 percent), and sexually transmitted infections (82.8 percent) were common reproductive health problems raised by the students.

Moronkola, O. A., \& Oyebami, 0. (2007). Age at menarche, menstrual patterns, sexual health knowledge, attitudes and premarital sexual partners of female athletes in Ibadan, Nigeria. East African Journal of Public Health, 4(2):51-54. Article available at: http://www.bioline.org.br/pdf?lp07011

This study examined age at menarche, menstrual patterns, attitudes, and premarital sexual partners of female athletes in Ibadan, South-west Nigeria. The study adopted a descriptive cross-sectional survey design and involved 250 female athletes training or camping under Oyo State Sports Council, Ibadan, Nigeria. The data collection tool was a self-developed validated questionnaire. The age range of study participants was 14--36 years with 21 years of age accounting for the mode (16.8 percent) in age distribution. The study revealed that 44.0 percent had menarche between ages 12 and 13 years, 71.6 percent had regular menstrual periods, more than 50 percent of the study participants had correct knowledge of all sexual health knowledge items, and more than 50 percent of the responses to items on attitude suggested they were not favourably disposed to premarital sex. However, 72.4 percent had premarital sex with the person they wanted to marry, 44.0 percent with male athletes, 28.0 percent with coaches, and 23.1 percent with other staff of the sports council.

Moronkola, O. A., \& Fakeye, J. A. (2007-2008). Reproductive health knowledge, sexual partners, contraceptive use and motives for premarital sex among female sub-urban Nigerian secondary students. International Quarterly of Community Health Education, 28(3):229-238. Article available at: http://qch.sagepub.com/content/28/3/229.long

The study assessed the reproductive health knowledge, sexual partners, contraceptive use, and motives for premarital sex among female sub-urban Nigerian secondary students. The study was cross-sectional, 
involving 500 senior secondary female suburban students residing in Ido Local Government Area, Oyo State, South-West, Nigeria. The instrument used was a self-administered questionnaire. The majority (76.8 percent) were between 15 and 19 years of age and 59.8 percent lived with both parents, 52.6 percent were Christians, 45.4 percent Muslim, and 2.0 percent worshipped traditional gods. The study revealed that more than 70.0 percent of the respondents had knowledge of all reproductive health items; male and female condoms were popular contraceptives. At least 53.4 percent were sexually active and a majority (49.6 percent) had boyfriends as sex partners. Peer pressure (31.6 percent) and fun/pleasure (29.2 percent) were major motives for engaging in premarital sex. Two-fifths (40.3 percent) terminated pregnancies through selfmedication.

\section{Nwagwu, W. E. (2007). The internet as a source of reproductive health information among adolescent girls in an urban city in Nigeria. Biomed Central Public Health, 7, 354. Article available at: http://www.ncbi.nlm.nih.gov/pmc/articles/PMC2241614/pdf/1471-2458-7- 354.pdf}

The study investigated how in-school and out-of-school adolescent girls in Owerri, South-East, Nigeria use online resources to meet their reproductive health information needs. A questionnaire was used to collect data from 1,011 adolescent girls (aged 13-19 years) in selected secondary schools in the communities, and also from 134 out-of-school girls selected from the same communities. The study revealed that more than 73 percent of the girls reported having ever used the Internet; more than 74 percent and 68 percent of them being in-school and out-of-school, respectively. The in-school girls (43.9 percent) reported having home access more than the out-of-school (5.6 percent) although the out-of-school had used the Internet for finding reproductive and related information more than the in-school. While parents (66.22 percent) and teachers (56.15 percent) were the two sources most used by the in-school girls, friends (63.18 percent) and the Internet (55.19 percent) were reported by the out-of-school youth.

\section{Nweneka, C. V. (2007). Sexual practices of church youths in the era of HIV/AIDS: playing the ostrich. AIDS Care, 19(8):966-969. Article available at: http://www.tandfonline.com/doi/abs/10.1080/09540120701249512?journalCode=caic 20\#preview}

The study investigated the sexual practices of 341 youths in two churches (one Orthodox, one Pentecostal) in Port Harcourt, South-East, Nigeria. There were 176 males and 165 females, aged 12-35 years (mean age: 22.5 years; male: 23.4 years; female: 21.4 years). The Orthodox youth were significantly younger than the Pentecostal youth $\left(X^{2}=43.06 ; p<0.001\right)$. Nearly all the respondents were single (93 percent) while 73 percent had at least a secondary education. The study revealed that 65 percent were sexually experienced. In all, 3.2 percent of the sexually experienced respondents, initiated sexual activity before the age of 10 years and approximately 12 percent before 15 years of age. By 19 years of age, 42 percent of the females and 44 percent of the males had become sexually active. In the 12 months preceding the study, 19 percent of the sexually experienced youth abstained from sex, 30 percent had one sexual partner, and 28 percent had more than one sexual partner, and 60 percent had used condoms, of whom 24 percent used them always.

\section{Okonta, P. I., (2007). Adolescent sexual and reproductive health in the Niger Delta region of Nigeria-issues and challenges. African Journal of Reproductive Health, 11(1):113- 124.Article available at: http://www.bioline.org.br/request?rh07012}

This article reviews the sexual and reproductive health of adolescents in the Niger Delta region (NDR) of Nigeria using a desk review of print and electronic literature and national documents on adolescent reproductive health and policy. The author also used adolescent sexual and reproductive health information from the Nigeria Demographic and Health Survey as its data were disaggregated into the six geopolitical zones. The author found that adolescents in the NDR engaged in unhealthy sexual behaviour characterized by early age at sexual initiation, unsafe sex, and multiple sexual partners. 
Okonta, J. M., Momoh, M. A., Ekwunife, O. I., Mbagwu, I. S., \& Abali, S. O. (2007). Assessment of HIV/AIDS awareness and changes in sexual practices among secondary school students in Nsukka environment. Tropical Doctor, 37(4):269-71. Article available at: http://tdo.sagepub.com/content/37/4/269.long

This study assessed the awareness of HIV/AIDS and changes in sexual behaviour among Nigerian teens. Two hundred and fifty secondary school students from Nsukka, South Eastern, Nigeria were interviewed. The students' mean age was $15.45+/-3.62$ years. Only 5 percent of the respondents were able to state the full meaning of HIV or AIDS. A minority (28 percent) believed that HIV was real while the majority (72 percent) believed that HIV infects whites only. Under half (48 percent) of them had changed their sexual practices due to HIV. A small percentage, 2 percent, believed that HIV/AIDS could kill.

Sabitu, K., Iliyasu, Z., Baba, S. E. (2007). Sexual behaviour and predictors of condom use among students of a Nigerian tertiary institution. Nigerian Journal of Medicine, 16(4):33843. Article available at: $\mathrm{http}: / /$ www.ncbi.nlm.nih.gov/pubmed/18080592

The objective of the study was to describe sexual behaviour and identify predictors of condom use among students in a Nigerian university. A cross-sectional survey was conducted using self-administered questionnaires among 404 students of the Federal University of Technology, Minna in North Central Nigeria. A total of 328 (81.2 percent) questionnaires were completed and returned. There were 230 male and 98 female respondents giving a sex ratio of 1:2.3. The respondent's ages ranged from 16 to 38 years with an overall mean of 23.53 .51 years. A significantly higher proportion of males 184 (80.0 percent) reported being sexually experienced compared to $64(65.0$ percent $)$ females $\left(x^{2}=8.05 p<0.05\right)$. The mean age of first sexual experience was also significantly higher among male students [18.92.1 years] compared to female students [16.41.7 years] $(t=11.36, p<0.01)$. Similarly, a significantly higher proportion $(56.2$ percent $)$ of sexually active males had multiple partners compared to females (38.1 percent) $\left(x^{2}=11.9, p=0.001\right)$. In addition, the mean number of lifetime sexual partners was significantly higher (5.3) for males compared to females (2.6) $[t=12.0, p<0.001]$. Condoms were consistently used by 38.3 percent $(n=95)$ of sexually active students in both genders. A higher proportion (44.6 percent) $(n=82)$ of male students reported regular use of condoms compared to partners (20.3 percent) $(n=13)$ of sexually active female students $\left(x^{2}=11.8, p\right.$ $=0.001$ ). Significant predictors of regular condom use include (male) gender, (higher) level of study, and (single) marital status. Most students were sexually active and many practiced unsafe sex.

Sunmola, A. M., Olley, B. O., \& Oso, G. E. (2007). Predictors of condom use among sexually active persons involved in compulsory national service in Ibadan, Nigeria. Health

Education Research, 22(4):459-472. Article available at: http://her.oxfordjournals.org/content/22/4/459.long

The survey was conducted on sexually active men $(n=344)$ and women $(n=373)$ to investigate determinants of condom use during national service. It was conducted in Ibadan municipality, the capital of Oyo State, Southwest, Nigeria, among fresh graduates who were $\leq 30$ years. Over two-thirds (68 percent) of men and 41 percent of women reported condom use at last intercourse before the survey. For both men and women, condom use was common if they had one or more regular sex partners and if they were purchasing condoms. In addition, women's condom use was predicted by being single and having intention to use condoms in next intercourse. The findings further showed that there was high risk of HIV transmission in the sample population as consistent condom use was 15 percent for men and 4 percent for women. Twelve percent of men and 8 percent of women reported STI diagnoses in the last 12 months before the survey. Four percent of men and 2 percent of women reported they already had HIV diagnoses. Only 1 percent of men and 2 percent of women reported they would receive voluntary HIV test if offered free by the government. 
Tobin-West, C. I., Mezie-Okoye, M. M., \& Babatunde, S. (2007). Young people's sexual risk behaviour and vulnerability to HIV/AIDS in the Niger Delta region of Nigeria. Port Harcourt Medical Journal, 1, 161-166. Article available at: http://www.ajol.info/index.php/phmedj/article/view/38877

A cross-sectional design was used to study 533 subjects selected from 55 communities in 6 Local Government Areas (LGAs) in Bayelsa State, South-south, Nigeria by a 4-level, multi-stage sampling technique. A pre-tested, structured, interviewer-administered questionnaire was employed to collect information. The mean age of the subjects was $18.4( \pm 3.6)$ years. More than half ( 59.4 percent) were males and the majority had at least a secondary education (86.7 percent) and were single (95.1 percent). The study revealed that most of them (82.2 percent) were aware of sexually transmitted infections, and 77.9 percent were aware that condoms prevent transmission of HIV. Seventy-one percent of the young persons were sexually experienced (i.e., previously had sex), 12.9 percent admitted that they had previously had sex in exchange for money, and 63.4 percent reported ever using a condom. Median age of sexual debut (sexarche) was 15.7 years. Most (82.1 percent) of the sexually experienced were currently sexually active reporting sexual intercourse within the 6 months preceding survey. Nearly half (47.1 percent) of these had sex with a casual and/or commercial sex worker without a condom.

Uneke, C. J., Alo, M., \& Ogbu, O. (2007). Mandatory pre-marital HIV testing in Nigeria: the public health and social implications._AIDS Care, 19(1):116-121. Article available at: http://www.tandfonline.com/doi/abs/10.1080/09540120600872778?journalCode=caic 20\#preview

In this study, the prevalence of HIV infection among prospective couples referred for HIV testing by faith based organizations (FBOs) was determined. Also, an assessment of the public health and social implications of such mandatory premarital HIV screening in a typical heterogeneous and multi-ethnic society of the developing world was also done. This study was hospital-based and conducted at the Federal Medical Centre (FMC), Ebonyi State, South-eastern Nigeria. Of the total of 319 individuals (148 males, 171 females) screened, 25 (7.8 percent, 95 percentCl: 4.9-10.7 percent) were confirmed HIV-positive, comprising 13 (8.8 percent, 95 percent $\mathrm{Cl}$ : 4.2-13.4 percent) males and 12 (7 percent, 95 percentCl: 3.2-10.8 percent) females. No significant difference was observed in the association between HIV infection and gender $(\mathrm{X} 2=0.58, \mathrm{df}=1, \mathrm{p}<0.05)$. The highest prevalence of HIV infection (8.9 percent) was recorded among individuals in the 21-30 years age category, while the least HIV infection prevalence (5.3 percent) was observed among persons above 40 years old. There was no significant difference in the association between HIV infection and age $(x 2=0.68, d f=3, p<0.05)$. The authors concluded that mandatory pre-marital HIV screening could generate social stigmatization and infringement of the fundamental human rights of infected individuals. Voluntary counselling and confidential HIV testing and especially pre- and post-test counselling as the basis of pre-marital HIV testing are more desirable.

Akinwale, O. P., Omotola, B. D., Manafa, O. U., Adeneye, A. K., Idowu, E. T., Sulyman, M. A., \& Adewale, D. B. (2006). An assessment of parent-child communication on sexuality in Lagos, Nigeria. World Health \& Population, 8(1):58-61. Article available at: http://www.longwoods.com/content/17891

This study assessed parent-child communication among in-school adolescents $(n=300)$ in Lagos, SouthWest, Nigeria. The students' ages ranged between 10 and 16 years and they were made up of 149 (49.7 percent) males and 151 (50.3 percent) females. One hundred and eighty-one of them were Christians, 113 were Muslims, while 6 practiced the indigenous religion. Their parents' educational status ranged from no education to post education, while their occupations ranged from petty trading to civil service. Two hundred and forty-five (81.7 percent) of the parents were married, 26 (8.7 percent) separated, 13 (4.3 percent) divorced, while 16, (5.3 percent) were single parents with the average number of siblings in all the families was six. While 207 (69 percent) of the pupils lived with their parents, 33 (11 percent) lived with their mothers, 16 (5.3 percent) lived with their fathers, 27 (9 percent) lived with married guardians, and 17 (5.7 
percent) lived with unmarried guardians. One hundred and eight (36 percent) respondents disclosed that they were sexually active, while 62 (20.7 percent) of the sexually active ones stated that they have more than one sexual partner. The adolescents' main sources of information on sexuality were identified as follows: 121 (40.3 percent) from friends, 106 (35.3 percent) from the mass media, 68 (22.7 percent) from parents/guardian, and 5 (1.7 percent) from teachers.

Asim, A. E., Uwe, E. A., Ekuri, E. E., Asuquo, P. N., \& Ekpiken-Ekanem, R. S. (2006-2007). A path analytic model of socio-cultural indicators of in-school adolescents' response to HIV/AIDS preventive practices in Nigeria. International Quarterly of Community Health Education, 27(2):133-43. Article available at: http://qch.sagepub.com/content/27/2/133.long

This path modelling study examined the effect and magnitude of four socio-cultural indicators on adolescents' response to HIV preventive practices in a Nigerian setting. Questionnaire data were generated from 316 fifth year students (142 males and 174 females) in 15 secondary schools in Cross River State, South-South, Nigeria. The age range of the students was 13 to 18 with a mean age of 14.34. Data analysis results, using path analyses procedures, indicated that only three socio-cultural factors were effective in explaining adolescents' response to HIV preventive practices. Cultural indicators and sexuality attitudes had the most significant influence on adolescents' response to HIV preventive practices. In all, 56.5 percent of the total effect of the variables was direct, while 43.5 percent was indirect.

Bamgbala, A. O., Adebajo, S. B., Inem, V. A., Onajole, A. T., Ayankogbe, O. O., Roberts, A. A., \& Campbell, P. C. (2006). Perceptions and practices of private medical practitioners to adolescent reproductive health in Lagos State, Nigeria. Nigerian Postgraduate Medical Journal, 13(2):117-122. Article available at: http://www.ncbi.nlm.nih.gov/pubmed/16794648

Information was obtained from a random sample of 187 out of 352 (53 percent) registered private medical practitioners in 5 of the 20 Local Government Areas in Lagos State, South-West, Nigeria using a selfadministered structured questionnaire. Sixty-two percent of the doctors claimed they saw adolescents regularly, mainly for the treatment of sexually transmitted infections (STIs). Many (86 percent) believed that adolescents should use contraception and suggested that parents, teachers, and health workers provide sexuality information to adolescents. Sixty one percent of the practitioners believed that abortion should be legalized, though with restrictions. Many of them admitted to providing post abortion care to adolescents. The religious affiliation of the private medical practitioners influenced their perception and practices.

Ikechebelu, I. J., Udigwe, G. O., Ikechebelu, N., \& Imoh, L. C. (2006). The knowledge, attitude and practice of voluntary counselling and testing (VCT) for HIV/AIDS among undergraduates in a polytechnic in southeast, Nigeria. Nigerian Journal of Medicine, 15(3):245-249. Article available at: http://www.ncbi.nlm.nih.gov/pubmed/17111752

The objective of this cross-sectional study was to determine the level of knowledge, attitude, and practice of accessing voluntary counselling and testing (VCT) for HIV/AIDS among undergraduates in a Nigerian tertiary institution. Investigators utilized a multistage sampling method to enrol students from different levels of the national diploma programme into the study. A structured questionnaire was administered to 260 students of Federal Polytechnic, Oko in Anambra state, South-East, Nigeria, between the ages of 15 and 49 years. The mean age of respondents was $22.3 \pm 2.0$ years and the response rate was 70 percent. Only $115(63.2$ percent) of the students were aware of VCT with 68 (59.1 percent) having heard of it at least one year prior to the study. Mass media and churches were the highest sources of information on VCT. Most of the students did not know where VCT services could be obtained and knowledge of what VCT entails was also low. However, 127 (69.8 percent) students acknowledged the necessity of counselling prior to testing and 117 (64.3 percent) were ready to accept and manage a positive result in a healthy manner. At least one out of every four students (54 of 182) had been sexually active within the three months preceding the study. 
Only 48 (26.4 percent) students had taken an HIV test at one time or the other before the study. Majority of the respondents (74.2 percent) were willing to go for VCT. Among those who were not willing to go for VCT, the most common reason given was that they were certain they were not infected.

\section{Ilika, A. L., Emelumadu, O. F., \& Okonkwo, I. P. (2006). Religious leaders' perceptions and support of reproductive health of young people in Anambra State, Nigeria. Nigerian Postgraduate Medical Journal, 13(2):111-116. Article available at: http://www.ncbi.nlm.nih.gov/pubmed/16794647}

This study assesses religious leaders' perceptions of young people's reproductive health in Anambra State, South-East, Nigeria. Self-administered, semi-structured questionnaires and in-depth interviews were used to elicit religious leaders' perceptions of young people's reproductive health. Two hundred fifty religious leaders were selected by multistage random sampling. Over 85 percent of the religious leaders thought that young people are sexually active and are involved in high risk behaviours for unintended pregnancy, unsafe abortion, and sexually transmitted infections (STIs), including HIV. Over four-fifths (85 percent) felt that there is need for sexuality education in schools and that sexuality education will reduce unintended pregnancy, abortion, STIs, and HIV among young people. However 52.2 percent felt that sexuality education in school would increase promiscuity. Some religious leaders did not support teaching contraception and safe abortion in schools.

lyoke, C. A., Onah, H. E., \& Onwasigwe, C. N. (2006). Teachers' attitude is not an impediment to adolescent sexuality education in Enugu, Nigeria. African Journal Reproductive Health, 10(1):81-90. Article available at: http://www.ajol.info/index.php/ajrh/article/viewFile/7879/1506

This study was undertaken to determine the attitude of secondary school teachers in Enugu, South-eastern Nigeria, to adolescent sexuality education and to determine whether this depends on their sociodemographic characteristics. A cross-sectional study of the attitude of teachers to adolescent sexuality education was done. A total of 249 teachers were studied. Their mean age was 38.7 years +8.08 SD. Two hundred and ten teachers (84 percent) were females. Almost all teachers (224, 90 percent) were married and 168 (67.5 percent) were of the Roman Catholic faith. The awareness of reproductive health activities was high. There was a high proportion of respondents who approved of sexuality education for adolescents (77.5 percent) and an equally high proportion who believed that it was important (89 percent). One hundred and ninety-eight (79 percent) of the respondents were willing to teach sexuality education. The attitude to sexuality education was independent of religion, sex, or marital status ( $p>0.05)$. It was concluded that secondary school teachers in Enugu urban were willing to offer sexuality education to adolescents under their care irrespective of their religion, sex, or marital status.

\section{Momoh, S. O., Moses, A. I., \& Ugiomoh, M. M. (2006). Women and the HIV/AIDS epidemic: the issue of school age girls' awareness in Nigeria. Journal of International Women's Studies 8(1):212-218. Article available at: http://www.popline.org/node/193873}

This study had two main objectives. The first was to find out the level of HIV/AIDS awareness of female undergraduates students at a Nigerian university. The second was to identify other specific variables-age, marital status, and academic level of study-on knowledge of HIV/AIDS. Information was elicited from 1,222 randomly selected regular undergraduate female students from the 11 faculties of the University of Lagos, South-West, Nigeria with the use of a standardized structured questionnaire. Over four-fifths (85.7 percent) of the students were aged 16-25 years. Results revealed a moderate level of HIV/AIDS awareness among the undergraduate students with only those at the 600 level of study having a high level of awareness., . 
Okonta, P. I., \& Oseji, M. I. (2006). Relationship between knowledge of HIV/AIDS and sexual behaviour among in-school adolescents in Delta State, Nigeria. Nigerian Journal of Clinical Practice, 9(1):37-39. Article available at: http://ajol.info/index.php/njcp/article/viewFile/11232/14719

A questionnaire-based descriptive study of randomly selected secondary school students in Asaba, Delta state, South South Nigeria was conducted to determine if there was any correlation between the knowledge of HIV/AIDS among in-school adolescents in Delta state of Nigeria and their sexual behaviour. A total of 437 students were recruited for the study. There were 265 females and 172 males. The mean age of the females was 17.1 years while that of the males was 17.3 years. About 47 percent of respondents had good knowledge of HIV/AIDS. The electronic media were their main sources of information. Over half (58 percent) had ever had sex but only 10 percent were currently sexually active. About 73 percent of the males and 58 percent of the females reported condom use at their last sexual act. Just under three-quarters (73 percent) of the students that had poor knowledge of HIV/AIDS had ever had sex compared with 69.5 percent of students with good knowledge. Similarly 45.6 percent of students with poor knowledge used condoms compared with 58.8 percent who had good knowledge. However these observed differences were not statistically significant.

Okunlola, M. A., Morhason-Bello, I. O., Owonikoko, K. M., \& Adekunle, A. O. (2006). Female condom awareness, use and concerns among Nigerian female undergraduates. Journal of Obstetrics and Gynaecology, 26(4):353-356. Article available at: http://informahealthcare.com/doi/abs/10.1080/01443610600613516

A cross-sectional study of female condom awareness, usage, and concerns among the female undergraduates of the University of Ibadan was conducted in September 2004. The results of 850 out of the 879 female students interviewed were used for analysis (96.6 percent). A majority of the students were aged between 15 and 25 years (31.7 percent; 15-20: 44.9 percent; 21-25). Over 80 percent had knowledge of the female condom as a form of modern contraception and the majority of them learnt about it through the mass media (39.9 percent) and health workers (34.4 percent). However, only 11.3 percent had ever used the female condom with most (40 percent) using it to prevent both unwanted pregnancy and sexually transmitted infections, including HIV. The sexual partners' approval was appreciable, accounting for about 42.7 percent among those that had experience of the female condom usage. Major concerns mentioned such as difficulty of inserting it into the vagina and lack of sexual satisfaction, were not different from those in earlier studies.

Oladepo, O., Caleb, A., Adegbenro, J., \& Adeniyi, D. (2006). Effect of training programme on secondary schools teachers' knowledge and attitude towards reproductive health education in rural schools lle-lfe, Nigeria. African Journal of Reproductive Health, 10(3):98-105. Article available at:

http://www.ajol.info/index.php/ajrh/article/viewFile/7904/13891

This study assessed the effect of a training programme on teachers' knowledge of and attitude towards reproductive health education/sexuality education (RHE/SE) in five randomly selected rural secondary schools in Ife-North local government area (LGA), Osun State, Southwest, Nigeria. All 84 teachers in the selected schools in the LGA were recruited for the study. They [84 teachers] were all given training in RHE/SE for one month. Their knowledge and attitudes towards RHE/SE were assessed pre-and post-training. The results show a significant increase in the percentage of those who had good knowledge in general areas of RHE/SE at post-training assessment compared with pre-training assessment (from 14.3 percent to 53.6 percent, $p=0.0001$ ). Also, pre-post attitudinal disposition assessments show that there was an increase in the percentage of those who were favourably disposed to the teaching of RHE/SE in Nigerian schools at post-training assessment (from 17.9 percent to 45.2 percent, $p=0.0011$ ). 


\section{Omoigberale, A. l., Abiodun, P. O., \& Famodu, A. A. (2006). Knowledge and attitude of youth (ages 15-25 years) to HIV/AIDS and to routine HIV screening. Nigerian Journal of Clinical Practice, 9(1):11-13. Article available at: www.ajol.info/index.php/njcp/article/download/11261/63485}

The objective of this cross-sectional study was to determine the knowledge and attitudes of youth (aged 1525 years) to HIV/AIDS and to routine HIV screening. The study was carried out at the University of Benin Teaching Hospital, Benin City, Nigeria (Edo State, South-south) between January and December 2003. Among the 9,500 respondents (4,950 males and 4,550 females), 5,750 respondents were from the University of Benin with a population of 20,000 students while 3,750 were from some of the secondary schools (post primary school) randomly selected in Benin City, Nigeria. Subjects (56 percent) indicated that they have heard about HIV/AIDS, 4,180 (44 percent) had no knowledge of HIV/AIDS at all. Over two-thirds $(6,365,67$ percent) did not believe it exists and as a result they were not bothered by it. Eight hundred twenty-five of the 3,750 secondary school students had multiple sexual partners, while among the university students, 2,990 (52 percent) had multiple sexual partners. Only two-fiths of respondents (3,990, 42 percent) would agree to routine HIV screening.

Omoteso, B. A. (2006). A study of the sexual behaviour of university undergraduate students in South-western Nigeria. Journal of Social Sciences, 12(2):129-133. Article available at: http://www.krepublishers.com/02-Journals/JSS/JSS-12-0-000-000-2006Web/JSS-12-2-083-158-2006-Abst-Text/JSS-12-2-083-158-2006-Web/JSS-12-2-129133-2006-309-Omoteso-B-A/JSS-12-2-129-133-2006-309-Omoteso-B-A-Text.pdf

This study examined the sexual behaviour of university undergraduate students in South-western Nigeria. It investigated the influence of demographic variables such as age, gender, religion, and family background on student sexual behaviour. The population comprised the undergraduate students of three purposively selected universities in South-western Nigeria. From this a sample of 2,106 students was selected by stratified random sampling technique. Sexual Behaviour Inventory (SBI) was used to elicit information from the students. Data were analysed using percentages, ANOVA, and t-test. The results of the data analysis indicated that 54 percent of the students had steady boy/girlfriends, 63 percent had had sexual intercourse, 43 percent had sexual intercourse with their lovers, while 20 percent had sexual intercourse with "just somebody". Almost all (90 percent) often engaged in hand holding, 39.5 percent in kissing, 58 percent in hugging, and 52.5 percent in caressing. Student gender and family background had significant influences on the student sexual behaviour $(t=-3.46, p<.05)$ and $(F=2.44, p<.05)$ but student age and student religion had no significant influence on student sexual behaviour, $(F=.939, p>.05)$ and $(F=1.88>.05)$.

\section{Wagbatsoma, V. A., \& Okojie, O. H. (2006). Knowledge of HIV/AIDS and sexual practices among adolescents in Benin City, Nigeria._African Journal of Reproductive Health, 10(3):76-83. Article available at: http://www.jstor.org/stable/30032473?seq=1\#page_scan_tab_contents}

A cross-sectional study to determine the knowledge of HIV/AIDS and sexual practices of adolescents was undertaken in Benin City, South-south, Nigeria. The sample size for the survey was 920 while the total population for selected schools was 1,692 giving a sampling ratio of 1:2. Using the systematic sampling method and class register as a sampling frame every other child was selected for the study. However, only 852 students consented to participate giving a response rate of 92.6 percent. Of the 852 students studied 369 (43.3 percent) were males while 483 (56.7 percent) were females. Most 439 (51.4 percent) of the study population were in the age group 13-15 years followed by age group 16-18 years and the least were in age group 10-12 years. An overwhelming majority (99.8 percent) of the adolescents were aware of HIV/AIDS but only 16.2 percent knew the cause of the disease. The belief that kissing, living with infected persons, and sharing their utensils could lead to infection was an indication of ignorance. Sexual intercourse was the predominant route of transmission mentioned by 60 percent while multiple sexual partners were prevalent among the age group 13-15 years. Playing with sharps, frequent clean head shave with 
unsterilized instruments in the barber saloon, and promiscuity were some of the activities that adolescents were involved in that could lead to acquiring HIV.

\section{Ibe, S. N. (2005). HIV/AIDS awareness study of fresh students in tertiary institutions in Rivers State of Nigeria. Journal of Applied Sciences and Environmental Management, 9 (1):11 - 13. Article available at: http://www.bioline.org.br/request?ja05002}

This study examined the knowledge, attitude, and preventive practices (KAP) of 285 first year (140 males and 145 females) University of Port-Harcourt (Rivers State, South-South, Nigeria) students regarding HIV/AIDS in December 2002. The study participants were selected randomly from 18 departments of the University of Port-Harcourt and had an age range of 16-26 years. Data was collected using structured questionnaires administered by two trained interviewers. Students had partial knowledge of the definition of HIV/AIDS, the mode of transmission, prevention, and cure. Only 56.1 percent were concerned about contracting the virus, although 70.2 percent had had sex, 57.0 percent had had sex without a condom, and 42.1 percent had had multiple sex partners. Similarly, 82.5 percent believed HIV/AIDS was in their institution but a majority, 86.0 percent, had never tested for HIV

\section{Mabayoje, V. O., Akinwusi, P. O., Fadiora, S. O., Adeyeba, O. A., Aderounmu, A. O., \& Ebgewale, E. B. (2005). Sexual risk behaviour among young people in Osogbo, Osun state Nigeria. Tropical Doctor, 35(4):213-215. Abstract available at: http://www.ncbi.nlm.nih.gov/pubmed/16354471 Article available at: http://tdo.sagepub.com/content/35/4/213.long}

The study was carried out in August 2002 utilizing data from the survey of the sexual behaviour of 628 young people. Sampling was random, involving young people in post primary institutions, marketplaces, and the hospitals in Osogbo, Osun State, South-Western, Nigeria. The results of the questionnaire revealed that the mean age of first sexual encounter was 17.4 years for men and 16.5 years for women. Men tended to have multiple sexual partners more than the women (74.4 percent and 25.1 percent, respectively), while there was a highly significant relationship between sexually transmitted infections $(p<0.001)$ and multiple sexual partners among singles $(p=0.000)$.

Odimegwu, C. (2005). Influence of religion on adolescent sexual attitudes and behaviour among Nigerian university students: affiliation or commitment? African Journal of Reproductive Health, 9(2):125-140. Article available at: http://www.bioline.org.br/request?rh05032

This study examines the role of religion in adolescent sexual attitudes and behaviour in Nigeria. The study was conducted in two national universities in Nigeria with student populations of more than 40,000. The institutions are located in the South Eastern (University of Nigeria, Nsukka) and South Western (Obafemi Awolowo University, lle Ife) parts of the country. Data for the study were collected from a representative sample of students resident in the universities. A total of 1,870 students were successfully interviewed but because of the age restriction for adolescents, information from 1,153 campus-based adolescents was analysed. The average age of the students was 21 years, with an age range of 18-24years. There was a strong relationship between religiosity and adolescent sexual attitudes and behaviour, although religious commitment was more important than religious affiliation in affecting adolescent sexual attitudes and behaviours. 
Ogbuji, C. Q. (2005). Knowledge about HIV/AIDS and sexual practice among University of Ibadan Students. African Journal of Medicine and Medical Sciences, 34(1):25-31. Article available at:

https://www.researchgate.net/publication/7771068 Knowledge about HIVAIDS and se xual_practice_among_University_of_lbadan_Students

This study assessed the knowledge about HIV/AIDS and sexual practice of University students in lbadan, South-West, Nigeria. Two hundred and seventeen students from the University of Ibadan were randomly selected in 2001 from the College of Medicine, Faculties of Arts and Law and completed a questionnaire. The ages of the students ranged from 16 to 23 with a mean of 19.05 years; 98.2 percent of the students reported blood transfusion as a major route of transmission of HIV. This was followed by use of unsterilized needles (97.2 percent) and unprotected sexual intercourse (93.5 percent). The heterosexual route of transmission was rated third. Sexual practices of the students showed 29 percent were sexually active. Almost all (91.2 percent) considered HIV/AIDS a serious health problem. For prevention, 93 percent reported sticking to one uninfected partner as a means of prevention and 88 percent reported use of condoms as preventive measure. However, only 16.6 percent of the total respondents claimed to have used a condom with their partners within the last 3 months.

Okonkwo, P. I., Fatusi, A. O., \& llika, A. L. (2005). Perception of peers' behaviour regarding sexual health decision making among female undergraduates in Anambra State, Nigeria. African Health Science, 5(2):107-113. Article available at: http://www.ncbi.nlm.nih.gov/pmc/articles/PMC1831917/

Researchers conducted a cross-sectional study that aimed to assess the perception of Nigerian female undergraduate about sexual behaviours of their peers and the type of influence their peers tend to exert on them. The study involved 588 randomly selected unmarried female undergraduates in two tertiary institutions in Anambra State, South East, Nigeria. Three-quarters of respondents were between 15 and 24 years and the majority were from homes with formally educated parents (91.2 percent of mothers and 93.9 percent of fathers). Regarding sexual behaviour, 80.1 percent of respondents indicated that their peers were already sexually active, and 92 percent indicated that most of their friends had regular sexual partners. The use of condoms by sexually active friends was reported by 58.5 percent of respondents. Almost half (47.1 percent) of respondents indicated that they were under pressure by friends to engage in pre-marital sex, and 22.1 percent indicated that the pressure was moderate or severe in degree. However, 64.6 percent of respondents indicated that they would receive moderate or lots of support from their friends if they made the decision to abstain from sex.

\section{Onuoha, F. N., \& Munakata, T. (2005). Correlates of adolescent assertiveness with HIV avoidance in a four-nation sample._Adolescence, 40(159):525-532. Article available at: http://europepmc.org/abstract/med/16268131}

This cross-national study examined social and sexual assertiveness in four-country adolescent samples of Nigerian, Thai, Chinese, and Japanese college students. Results showed that Japanese students had the greatest sexual agency followed by Thai, Nigerian, and Chinese in that order. Expectedly, female students in all four cultures showed higher sexual assertiveness and risk avoidance than their male counterparts who showed higher social assertiveness, cross-culturally. Whereas the combination of social and sexual assertiveness may be required for adolescent risk reduction, as shown in this study, sexual assertiveness is a necessary condition cross-nationally. 
Oshi, D. C., Nakalema, S., \& Oshi, L. L. (2005). Cultural and social aspects of HIV/AIDS sex education in secondary schools in Nigeria. Journal of Biosocial Science, 37(2):175-183. Article available at: http://journals.cambridge.org/action/displayAbstract?fromPage=online\&aid $=282256$

This qualitative study examined the social and cultural determinants of the teaching of HIV/AIDS sex education among secondary school teachers in Eastern Nigeria. The research analysed how teachers perceived passing their knowledge of HIV prevention measures to their students in the context of their cultural and social norms, which restrict open discussion of sex. In-depth interviews were conducted with 60 teachers, supplemented with 5 focus group discussions, and content analysis of teachers' lesson preparatory notes. The findings showed a high level knowledge of HIV/AIDS preventive measures among teachers. However, teachers were not passing on this knowledge because of cultural and social inhibitions. In addition, teachers had not been receiving adequate training and motivation on information, education and communication for HIV/AIDS sex education.

Oshi, D. C., \& Nakalema, S. (2005). The role of teachers in sex education and the prevention and control of HIV/AIDS in Nigeria. Journal of Sex Education, 5(1):93-104. Article available at: http://www.tandfonline.com/doi/abs/10.1080/1468181042000301911\#.VP8NsPnF9N M

Research was undertaken to assess the role of primary school teachers with regard to the prevention and control of HIV/AIDS in Nigeria. Structured and semi-structured questionnaires were responded to by 210 teachers drawn from primary schools in Eastern Nigeria (with pupils aged 6-15 years). These were supplemented by focus group discussions and key informant interviews with head teachers. The findings showed that the teachers had a reasonably high knowledge of the HIV transmission modes, the behavioural risk factors, and modes of prevention. The teachers, however, were reluctant to teach this subject matter because of socio-cultural and religious factors, lack of teacher training in delivery of sex education, as well as poor motivation.

Owolabi, A. T., Onayade, A. A., Ogunlola, I. O., Ogunniyi, S. O., \& Kuti, O. (2005). Sexual behaviour of secondary school adolescents in llesa, Nigeria: implications for the spread of STIs including HIV/AIDS. Journal of Obstetrics and Gynaecology, 25(2):174-178. Article available at: http://informahealthcare.com/doi/abs/10.1080/01443610500051460

This study examined the sexual behaviour and perception of the risk of HIV/AIDS and other sexually transmitted infections (STIs) among adolescents in Nigerian secondary schools. Quantitative data was collected from 450 senior secondary school 1 and 2 students who were selected from 5 of the 22 coeducational secondary schools in Ilesa, South-west, Nigeria using a multistage sampling technique. In addition qualitative data was collected by focus group discussions (FGDs) with eight groups (four for each of the sexes) of ten randomly selected respondents from four other secondary schools. The age range of respondents was from 10 to 19 years and the mean age was 16.26 years. Less than two-thirds (63 percent) had had sexual intercourse. There was no statistically significant $(p>0.05)$ difference between the genders [females (52.3 percent), males (77.8 percent)], although males appeared to be more sexually active. The median age at first intercourse was 12 years with a range of 6-19 years. Many of the respondents had multiple sexual partners. There was poor perception of the risk of sexually transmitted infections, including HIV. 
Oyo-Ita, A. E., Ikpeme, B. M., Etokidem, A. J., Offor, J. B., Okokon, E. O., \& Etuk, S. J. (2005). Knowledge of HIV/AIDS among secondary school adolescents in Calabar - Nigeria. Annals of African Medicine, 4(1):2-6. Article available at:

http://www.researchgate.net/publication/27788921 Knowledge of HIVAIDS Among Se condary_School_Adolescents_in_Calabar_-Nigeria

The aim of this study was to establish the impact of HIV/AIDS awareness programmes on students in Calabar, South-south, Nigeria. The mean age of participants was 14.69 years (SD 4.18 years). About 181 (31.2 percent) of the adolescents did not know the aetiological agents of HIV/AIDS. A majority, 522 (90 percent) knew HIV was transmitted through sexual intercourse. This level of knowledge was related to sex and class of study. Only 78 (13.4 percent) of them knew that HIV-positive individuals might look normal. Majority, 519 (89.5 percent) did not know the features of AIDS. Only a few, of the adolescents knew that avoidance of sex (281;48.4 percent), keeping one sexual partner (15; 2.6 percent), use of condom (101; 17.4 percent), and screening blood before transfusion (31;5.3 percent) could prevent HIV transmission. Mass media was the main source of information on HIV/AIDS to these adolescents. About 191 (32.9 percent) of them believed HIV cannot be prevented, 228 (39.3 percent) felt HIV/AIDS is common among the uneducated, 127 (21.9 percent) thought it is not common in Nigeria, and 143 (24.7 percent) believed it is not common among the youth.

Adewole, D. A., \& Lawoyin, T. O. (2004). Characteristics of volunteers and non-volunteers for voluntary counselling and testing among unmarried male undergraduates. African Journal of Medicine and Medical Sciences, 33(2). 162-170. Article available at: http://www.ncbi.nlm.nih.gov/pubmed/15565937

This descriptive cross-sectional survey was aimed at collecting information on sexual behaviour of unmarried male undergraduate students at the University of Ibadan, Oyo State, South West Nigeria. Of the 609 randomly selected and enrolled undergraduated males, 51 (8.3 percent) volunteered to have their blood screened for HIV. All volunteers who received pre-test counselling went for the HIV test. Volunteers were significantly older than the non-volunteers $(p<0.0001)$, and were more likely to be sexually experienced $(p=0.002)$. Among the sexually experienced, the volunteers were older at first sexual intercourse $(F S I)(p<$ $0.0001)$, and were more likely to have used a condom at FSI $(p=0.001)$. Volunteers had significantly higher knowledge scores for HIV/AIDS ( $p=0.006$ ), and the attitude to HIV/AIDS in both groups was positive. The marriage pattern of their parents with regard to polygyamy was similar, and fewer volunteers had fathers in the higher socio-economic class and mothers who had completed secondary education. Among the 51 volunteers, 8 (15.7 percent) tested positive. Those who tested positive were less likely to have lived with parents, and were all sexually experienced. Those who screened positive were also more likely to be currently sexually active and to have fathers with low level of education. Three (5.9 percent) of the volunteers did not return for results and post-test counselling. One of the three was positive for HIV. Of those who tested positive, 3 (37.5 percent) reported not using condoms at all, while the rest were using a condom only occasionally.

\section{Aomreore, A. A., Alikor, E. A., \& Nkanginieme, K. E. (2004). Survey of knowledge of HIV infection among senior secondary school 3 (SSS3) students in Port Harcourt. Nigerian Journal of Medicine, 13(4):398-404. Abstract available at: http://www.ncbi.nlm.nih.gov/pubmed/15523869 Article available at: https://www.researchgate.net/publication/8196451_Survey_of_knowledge_of_HIV_infect ion_among_senior_secondary_school_3_\%28SSS3\%29_students_in_Port_Harcourt}

The objective of this study was to examine the HIV/AIDS knowledge among third year senior secondary school (SSS3) students in Port Harcourt, Rivers State, South-South, Nigeria. It was a cross-sectional survey involving 1,800 SSS3 students from 13 secondary schools selected by a 2-stage stratified sampling technique, using a self-administered structured questionnaire. Students identified sexual intercourse (31 
percent), blood transfusion (14.4 percent), mother to child (vertical) transmission (9.1 percent), and intravenous drug use ( 8 percent) as modes of transmission of HIV infection. Only 7.1 percent identified all the listed four modes of transmission of HIV whilst 0.7 percent of the students identified all the listed preventive methods. The level of HIV/AIDS knowledge of the students did not significantly increase with age. Students from federal schools demonstrated more knowledge than students from state and private schools. Similarly, students from all-male schools had more knowledge than students from all-female and coeducational schools. Students from a high social class demonstrated more knowledge than those from middle and low social classes

\section{Asuquo, P. N., Ekuri, E. E., Asuquo, A. E., \& Bassey D. A. (2004-2005). Adolescents' perception of HIV/AIDS and their attitude to its prevention in Calabar, Nigeria. International Quarterly of Community Health Education, 23(1):63-72.Article available at:http://baywood.metapress.com/app/home/contribution.asp?referrer=parent\&backto=i ssue,5,6;journal,48,133;linkingpublicationresults,1:300315,1}

This study investigated adolescents' perception of HIV/AIDS and their attitudes to prevention programs. Subjects were 500 students (220 males and 280 females), aged 13 to 16 years, drawn from 10 secondary schools in Calabar, Cross Rivers State, South-South, Nigeria. Data analysis indicated that significant gender difference exist in terms of perception of HIV/AIDS in favour of the males. This study has shown that adolescents tend to demonstrate an optimistic perception of the HIV prevention programs. They are aware of the modes of transmission and prevention of HIV.

\section{Etuk, S. J., Ihejiamaizu, E. C., \& Etuk, I. S. (2004). Female adolescent sexual behaviour in Calabar, Nigeria. Nigerian Postgraduate Medical Journal, 11(4):269-273. Article available at: http://www.ncbi.nlm.nih.gov/pubmed/15627155 https://www.researchgate.net/publication/8104111_Female_adolescent_sexual_behavio ur_in_Calabar_Nigeria}

Female senior secondary school adolescents in Calabar, Cross River State, South-South, Nigeria, were studied with the help of a pre-tested, self-administered questionnaire to explore their age at menarche and their sexual behaviour. The average age at menarche was 12.86 years. About 37.4 percent of senior secondary school female adolescents were sexually active with an average age at initiation of 13.7 years. About 22.6 percent of them had more than one sexual partner. Most of them (51.2 percent) learned about sexual intercourse from their peers. They engaged in sexual intercourse for fun, intimacy, and friendship (84 percent). Only 6.0 percent of the sexually active adolescents ever used family planning methods. About 18.4 percent of them have been pregnant at least once, 15.1 percent have had genital tract infection, and 31.9 percent had sustained genital tract injury during sexual intercourse.

\section{Fatiregun, A. A., \& Bamgboye, E. A. (2004). Sexually transmitted diseases seen in a Nigerian tertiary institution. West African Journal of Medicine, 23(3):236-239. Article available at: http://www.ajol.info/index.php/njcp/article/download/11248/2407}

The study was carried out via a retrospective review of records of all new patients presenting at the Special Treatment Clinic (STC) of the University College Hospital, Ibadan, South-West, Nigeria, between $1^{\text {st }}$ January 2000 and 31st December 2000. The objective of the study was to provide a descriptive epidemiology of the pattern of STIs among clinic attendees at the STC of the University College Hospital (UCH), Ibadan. Clinic records were available for 336 new patients who visited the clinic in the year under review. The clinic was open to all age groups but about half of the attendees (53.7 percent) were between the ages of 10-29 years old. More than half (57.4 percent) of the attendees in the year under review were males. The results showed that non-gonococcal urethritis (45.2 percent) and gonococcal urethritis (15.9 percent) were the most common sexually transmitted infections in men, while candidiasis ( 37.2 percent) and gardnerella vaginitis (31.8 percent) were the most common in women. Three (1.1 percent) of the patients had HIV. 
Isiugo-Abanihe, U. C., \& Oyediran, K. A. (2004). Household socioeconomic status and sexual behaviour among Nigerian female youth. African Population Studies, 19(1):81-98. Article available at: http://www.bioline.org.br/abstract?id=ep04005

This paper examines the determinants of sexual behaviour with special reference to the effect of household socio-economic status as a proxy for poverty. The data were derived from the 1999 Nigeria Demographic and Health Survey and the analysis was restricted to 1,831 never married females aged 15-24. Both descriptive and analytical methods are used to assess the effects of each poverty-related factor when the effects of other demographic and socio-cultural factors are controlled statistically. The results showed that 31.5 percent of the respondents have had sexual intercourse, and more than half of these had an affair in the month preceding the survey. The median age of sexual debut was 17 years, and there was little variation among socio-demographic and poverty-related indices, indicating a generally early initiation of sexual activity. Condom use was low among the youth; only 15 percent have ever used condoms, and about 22 percent of the sexually experienced used condoms the last time they had an affair.

\section{Odusanya, O. O., \& Alakija, W. (2004). HIV: knowledge and sexual practices amongst students of a school of community health in Lagos, Nigeria. African Journal of Medicine and Medical Sciences, 33(1):45-49. Abstract available at: http://www.ncbi.nlm.nih.gov/pubmed/15490794 Article available at: https://www.researchgate.net/publication/8225815_HIV_knowledge_and_sexual_practic es_amongst_students_of_a_school_of_communnity_health_in_Lagos_Nigeria}

A cross-sectional study was conducted amongst students of a school of health technology in Yaba, Lagos State, South-West, Nigeria to determine their knowledge about HIV/AIDS and their sexual practices. A selfadministered questionnaire was used to collect data. Two hundred and thirty-six students out of 250 participated in the study (94 percent response rate). The mean age was 24.7+5.2 years, 167 (71 percent) respondents were females while 69 (29 percent) were males. One hundred and seventy-seven (75 percent) students were single and 59 (25 percent) were married. Knowledge on HIV was graded using 29 items on the questionnaire, each scored one mark. A maximum score of 29 was obtainable and respondents with scores greater than 50 percent were classified as having a satisfactory level of knowledge. Almost all (99 percent) had heard about HIV/AIDS through several sources. Knowledge of symptoms, methods of transmission, and prevention were generally satisfactory. One hundred and seventy one (72 percent) students were sexually active, 48 percent engaged in casual sex, and 9 percent had multiple partners. Of the 171 who were in a sexual relationship with a primary partner, 49 (29 percent) used condoms all the time. One hundred and fourteen (48 percent) admitted to having casual sex but 60 (53 percent) used condoms all the time during casual sex. Partner and personal dislike as well as reduction in sexual pleasure were reasons for non-use of condoms. A significantly higher proportion of students in the higher classes (74/94, 79 percent) possessed a higher level of knowledge than those in the lower class (78/142, 55 percent, $\mathrm{p}=0.0003$ ). One hundred and fifty-two (64 percent) students possessed a satisfactory level of knowledge on the subject, but many engaged in risky behaviour.

Omigbodun, 0. O., \& Omigbodun, A. O. (2004). Unmet need for sexuality education among adolescent girls in southwest Nigeria: a qualitative analysis. African Journal of Reproductive Health, 8(3):27-37. Article available at: https://tspace.library.utoronto.ca/bitstream/1807/4940/1/rh04040.pdf

This study utilised a qualitative approach to elicit the reproductive health concerns of girls at a Christian summer camp with a view to making recommendations on how to improve the content and process of future sessions. The girls asked questions anonymously about various aspects of their sexuality, which were analysed to identify emergent themes. There were 75 participants with ages ranging from childhood to late adolescence (7-21 years). The mean age of participants was 13.59 years (SD 3.39). The different levels of cognitive development were clearly illustrated in the types of questions asked. The late adolescents focused on coping with relationships and demands for sex. The early and middle adolescents focused on their 
feelings, relationships, menstruation and breast size. Those aged 7-11 years appeared totally ignorant about parts of their body. Myths and misconceptions were identified in all age groups.

\section{Onah, H. E., Mbah, A. U., Chukwuka, J. C., \& Ikeme, A. C. (2004). HIV/AIDS awareness and sexual practices among undergraduates in Enugu, Nigeria. Nigerian Journal of Medicine, 11(2):121-125. Article available at: http://europepmc.org/abstract/med/15300274}

The purpose of this study was to assess the knowledge of HIV/AIDS among Nigeria undergraduates and to determine how the knowledge has influenced their sexual behaviour. All the 505 respondents had heard of HIV/AIDS. The respondents exhibited a high knowledge of HIV/AIDS. For the 348 (68.9 percent ) respondents who had ever had sexual intercourse, the mean number of sexual partners, which they had before and after they became aware of HIV/AIDS did not differ significantly 93.2+1.7 versus $2.9+1.5 ; p=$ 0.3). However, there was a significant tendency towards a more consistent condom use after the respondents became aware of HIV/AIDS. On univariate logistic regression, being married $(\mathrm{OR}=2.8,<0.001)$, previous risky sexual behaviour $(\mathrm{OR}=2.5,<0.0001)$ and being more than 20 years old $(\mathrm{OR}=1.4, \mathrm{p}<0.02)$ (but not respondents' level of knowledge of HIV/AIDS etc.) were significant predictors of risky sexual behaviour after the respondents became aware of HIV/AIDS. On multivariate logistic regression - previous risky sexual behaviour ( $O R=2.5,<0.00001)$ and being married $(O R=2.1, p<0.001$ ) remained significant. High knowledge of HIV/AIDS has no correlation with subsequent sexual behaviour among Nigerian undergraduates.

\section{Peltzer, K., \& Oladimeji, Y. (2004). Some factors in condom use amongst first-year Nigerian University students and black and white South Africans. Psychological Reports, 94(2):583-586. Article available at: http://www.amsciepub.com/doi/abs/10.2466/pr0.94.2.583-586?url_ver=Z39.88- 2003\&rfr_id=ori:rid:crossref.org\&rfr_dat=cr_pub\%3dpubmed}

A questionnaire was administered to 213 sexually active first-year Nigerian university students and 150 black and 150 white South African adults. Nigerian students gave 90 percent correct answers on 6 of the 10 items of a measure of condom knowledge $(M=6.1)$. The most common mistakes with respect to condom use were ignorance about putting a condom on just before ejaculation (37 percent), the use of an oil-based lubricant with a condom (29 percent), and when to take off a condom (28 percent). For the South African sample utility of the Health Belief Model and Theory of Reasoned Action for HIV prevention could be confirmed by intention to use condoms. Race and preventive benefits were predictive for current condom use.

\section{Smith, D. J. (2004).Youth, sin and sex in Nigeria: Christianity and HIV/AIDS-related beliefs} and behaviour among rural-urban migrants. Culture, Health \& Sexuality, 6( 5):425-437. Article available at: http://www.jstor.org/stable/4005308?seq=1\#page_scan_tab_contents

This paper reports results from a two-year study of HIV/AIDS-related beliefs and behaviour among adolescent and young adult rural-urban migrants in two Nigerian cities, Aba and Kano. Criteria for inclusion in the survey were that respondents were between the ages of 15 and 24, had migrated to the city after age 12, had lived in the city at least three months, were of Igbo ethnicity, and had never married. Respondents were selected randomly, using a grid to divide the study areas into zones from which interviewers identified eligible migrants. The young people in the study originated from south-eastern Nigeria; they almost uniformly identified themselves as Christian; and they commonly situated their understandings and explained their behaviours in response to the HIV/AIDS epidemic in terms of religion, especially in relation to the increasingly popular and dominant religious discourses of evangelical and Pentecostal Christianity. Findings suggest that popular religious interpretations of HIV risk pose real dangers, leading many young migrants to imagine themselves as at little or no risk, and contributing to inconsistent protective practices. 
Smith, D. J. (2004). Premarital sex, procreation, and HIV risk in Nigeria. Studies in Family

Planning, 35(4):223-235. Article available at:

http://paa2004.princeton.edu/papers/40163

Data from two sample surveys of 863 adolescent and unmarried young adults, in-depth interviews, and participants' observations were combined in this study to explain some of the discrepancies between people's knowledge of HIV/AIDS and the extent to which they protect themselves. The study population were migrants aged 15-24 years in Kano, Kano state (Northwest) and Aba, Abia state (Southeast). Young migrants appeared to make sexual and contraceptive decisions in relation to gender norms and attitudes concerning procreation at least as much as in relation to fear of disease. There were assessments of current and potential partners, choices about whether or not to have sex, and decisions about whether or not to use condoms were influenced by shared cultural values regarding the importance of parenthood. These cultural conceptions of parenthood were gender-specific and put men and women in different negotiating positions with regard to sex and contraception.

\title{
Okonkwo, I. P., \& Ilika, A. I. (2003). Maternal attitudes and values to youth sexuality- related activities in Delta State, Nigeria. Nigerian Postgraduate Medical Journal, 10(3):177-181. Article available at: http://www.ncbi.nlm.nih.gov/pubmed/14692062
}

This descriptive study assessed maternal attitudes to youth sexuality-related activities in Delta State, South South Nigeria. Using an adapted questionnaire, 300 women with adolescent children were chosen through a multistage sampling technique and relevant data obtained regarding their socio-economic status, perceptions and values as well as their knowledge of basic reproductive health concerns. Sixty-seven percent of mothers studied, discussed sexuality issues regularly with their adolescent children, though only 46.4 percent of them were comfortable discussing these issues and about 50 percent admitted having enough information in such discussions. Another 76 percent of the women would approve of their children receiving reproductive health information and services including condoms. The mothers studied believed that guided reproductive health information and services should be routinely provided for young people.

\section{Okonofua, F. E., Coplan, P., Collins, S., Oronsaye, F., Ogunsakin, D., Ogonor, J. T., Kaufman, J.A., \& Heggenhougen, K. (2003). Impact of an intervention to improve treatment-seeking behaviour and prevent sexually transmitted diseases among Nigerian youths. International Journal of Infectious Diseases, 7(1):61-73. Article available at: http://www.ncbi.nlm.nih.gov/pubmed/12718812}

\begin{abstract}
A randomized controlled trial was conducted in 12 schools in Edo State, South South, Nigeria, to evaluate an intervention to improve sexually transmitted infection (STI) treatment-seeking and STI treatment provision. 1,866 and 1,858 youth aged 14-20 years were enrolled in the pre and post intervention survey. The intervention based on formative research consisted of community participation, peer education, public lectures, health clubs in schools, and training STI treatment providers including those with no formal training. Youth in the intervention schools, compared to control schools, reported statistically significant improvements in knowledge of STIs, condom use, partner awareness that the youth had an STI, and STI treatment-seeking behaviour. Treatment by private physicians increased ( $\mathrm{OR}=2.1,95$ percent $\mathrm{Cl}=1.1-4.0)$, and treatment by patent medicine dealers or pharmacists decreased ( $\mathrm{OR}=0.44,95$ percent $\mathrm{Cl}=0.22-0.88)$. The reported prevalence of STI symptoms in the past six months was significantly reduced in the intervention compared to control.
\end{abstract}


Orji, E. O., \& Esimai, O. A. (2003). Introduction of sex education into Nigerian schools: the parents', teachers' and students' perspectives. Journal of Obstetrics and Gynaecology, 23(2):185-188. Article available at: http://informahealthcare.com/doi/abs/10.1080/0744361031000074772

The purpose of the study was to assess parents', teachers', and students' knowledge of sex education and their level of acceptance of its introduction into the school curriculum in Nigeria. Questionnaires were sent to teachers, students, and parents of eight secondary schools located within Ile-lfe town, South-western, Nigeria. The responses of individual groups were collated, analysed, and compared. A total of 1,000 respondents (400 students, 400 parents, and 200 teachers) returned the completed questionnaires. All the teachers and parents and 60 percent of the students had heard of sex education. A majority of the parents (92 percent), teachers (90 percent), and students (78 percent) supported its introduction into the school curriculum and believed that it would prevent unwanted pregnancies, enhance healthy relationships between opposite sex, prevent sexually transmitted infections, including HIV, provide the knowledge of sexual interactions, consequences and responsibilities and to educate the students on the basic processes of human reproduction. One hundred and fifty-four (15.4 percent) of the respondents opposed the introduction of sex education, because they believed that it would corrupt the students, might lead to experimentation, and that it should be the responsibility of the parents at home.

\section{Slap, G. B., Lot, L., Huang, B., Daniyam, C. A., Zink, T. M., \& Succop, P. A. (2003). Sexual behaviour of adolescents in Nigeria: cross-sectional survey of secondary school students. BMJ, 326(7379):15. Article available at: http://www.ncbi.nIm.nih.gov/pmc/articles/PMC139494/}

This study was a cross-sectional school survey with a two-stage, clustered sampling design. The objective of the survey was to determine whether family structure (polygamous or monogamous) is associated with sexual activity among school students in Nigeria. Study participants included 4,218 students aged 12-21 years attending 39 schools in Plateau state, North Central Nigeria. Responses from 2,705 students were included in the analysis. Overall 909 students (34 percent) reported ever having had sexual intercourse, and 1,119 (41 percent) reported a polygamous family structure. Sexual activity was more common among students from polygamous families (42 percent of students) than monogamous families (28 percent) $\left(X^{2}\right.$ =64.23; $\mathrm{p}$ < 0.0001). Variables independently associated with sexual activity were male gender [adjusted odds ratio 2.52 (95 percent confidence interval 2.05 to 3.12)], older age [1.62 (1.24 to 2.14)], lower sense of connectedness with parents [1.87 (1.48 to 2.38)], having a dead parent [1.59 (1.27 to 2.00)], family polygamy [1.58 (1.29 to 1.92)], lower sense of connectedness with school [1.25 (1.09 to 1.44)], and lower educational level of parents [1.14 (1.05 to 1.24)].

\section{Sunmola, A.M., Dipeolu, M., Babalola, S., \& Adebayo, O. D. (2003). Reproductive knowledge, sexual behaviour and contraceptive use among adolescents in Niger State of Nigeria._African Journal of Reproductive Health, 7(1):37-48. Article available at: http://www.jstor.org/stable/3583344?seq=1\#page_scan_tab_contents}

Study investigators recruited 896 adolescents aged 11-25 years into this study using a multi-stage random sampling method. Overall, about 33 percent of them had already had their first sexual experience, but more males than females reported having had experienced their first sexual encounter. Only 3.6 percent of the respondents were married. One half of the sexually experienced adolescents had more than one sexual partner at the time of the study. Majority of the respondents (91.9 percent) had heard about HIV/AIDS and at least one sexually transmitted infection. A wide disparity was found in knowledge and use of the contraceptive methods studied, ranging from 41.9 percent to 63.8 percent for knowledge and from 0.7 percent to 12.5 percent for use. Knowledge and use of condom was highest. For prevention of HIV, more males than females thought condoms were useful. More Gwari and Hausa respondents claimed that they did not use any family planning method during their first sexual experiencethan Yoruba and Igbo respondents. 
Ajuwon, A.J., McFarland, W., Hudes, E.S., Adedapo, S., Okikiolu, T., \& Lurie P. (2002). HIV risk-related behaviour, sexual coercion, and implications for prevention strategies among female apprentice tailors in Ibadan, Nigeria. AIDS and Behaviour, 6(3):229-235. Article available at: http://link.springer.com/article/10.1023/A\%3A1019839824312\#page-1

Investigators conducted a survey of 300 young female apprentice tailors in a peri-urban community in Ibadan, South-western Nigeria. The objectives were to assess HIV risk-related behaviour in order to plan appropriate prevention interventions. Most apprentice tailors were 18-21 years old (68 percent), single (95 percent), and had not completed secondary school (98 percent). A history of sexual intercourse was reported by 53 percent; 42 percent had ever experienced unwanted touching of the breast, backside, shoulder, or waist; 4 percent reported being raped in the last 6 months. Of the sexually active women, 57 percent reported sexual debut with an instructor; 21 percent had exchanged sex for money or gifts; and only 27 percent had used a condom during their most recent sexual intercourse. Instability of employment and lack of instructor support were primary barriers to implementing a pilot peer-education HIV prevention project.

Akpede, G.O., Lawal, R.S., \& Momoh, S.O. (2002). Perception of voluntary screening for paediatric HIV and response to post-test counselling by Nigerian parents. AIDS Care, 14(5):683-97. Article available at: http://www.tandfonline.com/doi/abs/10.1080/0954012021000005515?url_ver=Z39.8 8-2003\&rfr_id=ori:rid:crossref.org\&rfr_dat=cr_pub\%3dpubmed

Two hundred and fifty-eight parents of hospitalized children ( $>1$ month to 15 years of age) were interviewed using a structured questionnaire. In addition, to complement the data, four examples of seropositive mother's responses during post-test counselling were presented and analysed. In the survey, 223 (86 percent) parents were aware of HIV/AIDS, but only 88 (39 percent) of these parents could describe one or more route(s) of transmission and none described vertical transmission. Among the respondents, 153 (62 percent) of 248 would consent to screening of themselves, and 195 (85 percent) of 230 to screening a hospitalized child if based on his/her clinical condition. Perceptions of good health, lack of exposure, and despair owing to lack of a specific treatment were the common reasons for refusing consent. These represent some of the issues which would need to be addressed to increase the acceptance of voluntary testing. The fear of a break up of families with seropositive mothers but seronegative fathers was a major concern expressed during post-test counselling.

Atulomah, N. O., \& Oladepo, O. (2002). Knowledge, perception and practice with regards to occupational risks of HIV/AIDS among nursing and midwifery students in lbadan, Nigeria._African Journal of Medicine and Medical Science, 31(3):223-227. Abstract available at: http://www.ncbi.nlm.nih.gov/pubmed/12751561 Article available at: https://www.researchgate.net/publication/10755143 Knowledge perception and practi ce_with_regards_to_occupational_risks_of_HIVAIDS_among_nursing_and_midwifery_stud ents_in_lbadan_Nigeria

This study was carried out to provide important baseline data about knowledge, perception and practice with regards to occupational risks of HIV/AIDS among 359 nursing and 120 midwifery students $(N=479)$ in Ibadan, Oyo State, South-West, Nigeria. The study utilized both qualitative and quantitative methods to gather information from nursing and midwifery students. The results revealed a poor knowledge of World Health Organization recommended universal precaution for preventing HIV transmission among students in all the schools. Students of the schools of midwifery performed more high risk occupational practices compared to those in the nursing schools, but received less supervision. 
Nwokocha, A. R., \& Nwakoby, B. A. (2002). Knowledge, attitude, and behaviour of secondary (high) school students concerning HIV/AIDS in Enugu, Nigeria, in the year 2000. Journal of Pediatric and Adolescent Gynaecology, 15(2):93-96. Article available at: http://www.jpagonline.org/article/S1083-3188\%2801\%2900150-4/abstract

The study investigates the knowledge, attitude, and behaviour of secondary (high) school students concerning HIV/AIDS as a way of assessing the need for inclusion of reproductive health education in the school curriculum. Questionnaires were administered to 360 students who were randomly selected from 5 secondary (high) schools in Enugu, South-East, Nigeria. The study revealed that the students had poor knowledge of the disease. They were aware and afraid of the disease as being deadly but not sure of the cause, nature, or modes of transmission and prevention, except that illicit sexual activity should be avoided. Their attitude and behaviour were consequently defective. Their main source of information was the media.

Obiechina, N. J., Diwe, K., \& Ikpeze, O. C. (2002). Knowledge, awareness and perception of sexually transmitted diseases (STDs) among Nigerian adolescent girls. Journal of Obstetrics and Gynaecology, 22(3):302-305. Article available at: http://informahealthcare.com/doi/abs/10.1080/01443610220130634

The study investigated the knowledge, awareness, and perception of the common sexually transmitted infections (STIs), such as HIV, gonorrhoea, and syphilis among high school adolescent girls. The study targeted post-primary school female adolescents, aged 11-19 years, in Onitsha, South-East, Nigeria. Two schools out of the nine female post-primary schools in Onitsha were selected randomly and studied. Questionnaires were distributed to the students $(n=983)$ with instructions and explanations on the completion of the questionnaire. The study revealed that the most important sources of information for both schools were the school, television, and radio. Students from both schools were most aware of HIV/AIDS followed by gonorrhoea. The awareness of chlamydia was very low for both schools. A high number (202) of students from school 1 identified herbs/native medicines as treatment for STIs; 282 and 234 identified antiviral and antibacterial drugs, respectively, as treatment for STIs. Also, 136 and 162 students in the respective schools identified prayer houses as a source of remedy for these conditions.

Odimegwu, C. O., Solanke, L. B., \& Adedokun, A. (2002). Parental characteristics and adolescent sexual behaviour in Bida Local Government Area of Niger State, Nigeria. African Journal of Reproductive Health, 6(1):95-106. Article available at: http://www.bioline.org.br/request?rh02013

This study was conducted in Bida Local Government Area of Niger State, North Central Nigeria to examine how parental attributes influence adolescent sexual activity. Data were gathered through structured interview with 400 adolescents aged 12-24 years using a 3-stage random sampling procedure. Findings show that more than one-third of adolescents interviewed had sexual intercourse in the month preceding the survey. Less than one-fifth of sexually active adolescent were using a method of contraception to either prevent infections or avoid unwanted pregnancy. Further analysis confirmed that adolescents with whom parents had discussed family life issues were less likely to be sexually active than those with whom parents had never discussed family life issues. The study also found a negative effect of family instability on adolescent sexuality.

Sunmola, A. M., Dipeolu, M., Babalola, S., \& Otu, A. D. (2002). Reproductive, sexual and contraceptive behaviour of adolescents in Niger State, Nigeria._African Journal of Reproductive Health, 6(3):82-92. Article available at: http://www.jstor.org/stable/3583260?seq=1\#page_scan_tab_contents

This was a multi-stage random sampling study involving 896 male and female adolescents in Chanchanga, Mariga, Shiroro, Agwara, Gurara and Agaie Local Government Areas in Niger State of North Central Nigeria. The purpose of the study was to obtain in-depth information about sexual activities, beliefs, perceptions, 
knowledge, and experience of adolescents in Niger State of Nigeria. There were 439 (48.9 percent) male respondents and 459 (50.9 percent) female respondents. Over half (52.9 percent) were from the urban areas while the remaining 47.1 percent were from the rural areas. The respondents ranged in age from 11 to 25 years (mean age $=16.8$ years, $S D=2.1$ ); 85 percent of them were aged between 14 and 20 years. Onethird (33 percent) of the respondents had already had their first sexual experience. Only 3.6 percent were married. Most of the Gwari and Hausa respondents acknowledged that they married at an earlier age than the Yoruba respondents. One half of those who were sexually experienced had more than one sexual partner. Majority of the respondents were informed about HIV/AIDS and STIs. More Gwari and Hausa respondents felt that acquiring HIV could be prevented by not having multiple sexual partners than Yoruba and lgbo respondents. A wide disparity between contraceptive knowledge and use was found. Knowledge rate was between 41.9 percent and 63.8 percent, while use rate was between 0.7 percent and 12.5 percent for the contraceptive methods studied. Condom knowledge and use rate was the highest. For prevention of HIV, more males than females thought condoms were useful. Most Gwari and Hausa respondents did not use any family planning method during their first sexual relationships.

\section{Uwalaka, E., \& Matsuo, H. (2002). Impact Of knowledge, attitude, and beliefs About AIDS on sexual behavioural change among college students in Nigeria: the case of the University Of Nigeria Nsukka. West Africa Review. Article available at: http://www.africaknowledgeproject.org/index.php/war/article/view/329}

This study explored the degree of sexual behavioural change resulting from the threat of AIDS, and the factors which impacted behavioural change among college students in Nigeria. AIDS-related knowledge, attitudes, beliefs of susceptibility, and self-efficacy regarding performance of safe sexual practices of college students will provide valuable information for assessing the level of HIV risk in the college age population and targeting particular behaviours for prevention. Data were collected from a disproportionate stratified sample of 505 undergraduate students enrolled at the Nsukka campus of the University of Nigeria, October 1997 to January 1998. Four faculties (colleges)-the Faculty of Education, Biological Sciences, Social Sciences, and Physical Sciences were chosen through a stratified random method. The sample consists of 246 males (49.1 percent) and 255 females (50.9 percent), with a mean age 23.47 and a standard deviation of 3.84. In this sample, 425 people (85.7 percent) reported that they attend religious services once a week or more, which indicated the high degree of these respondents' religiosity. Surprisingly, 266 people (55 percent) personally knew someone who had tested positive for HIV, had contracted HIV, or had died from AIDS. Furthermore, 53 people (10.9 percent) had had a sexually transmitted infection, and 66 people (13.3 percent) had tested positive for HIV. Mean number of sexual partners in lifetime of this sample was 4.26 with a standard deviation of 8.68. Furthermore, people who were not married were more likely to have changed sexual behaviours. Bivariate analysis indicated that those who have accurate knowledge about AIDS were more likely to have changed sexual behaviours and to have confidence in sexual practice.

\section{Alubo, 0. (2001). Adolescent reproductive health practices in Nigeria. African Journal of Reproductive Health, 5(3):109-119. Article available at: http://www.jstor.org/stable/pdf/3583329.pdf}

This study of 2,510 respondents from 4 tertiary educational institutions in Plateau State, North-Central Nigeria, utilized in-depth interviews and focus group discussions to examine various forms of reproductive health practices, their origins, reproductive health services available in the institutions, and the role of gender relations in reproductive health concerns. The findings show that respondents engaged in a wide range of folk practices and do-it-yourself procedures to maintain personal hygiene, prevent and treat sexually transmitted infections, as well as prevent and terminate unwanted pregnancies. These practices, which involved the use of everyday commodities such as lime, antacids, and other drugs in particular ways, were learnt from and passed on through peers. The practices were considered more confidential and were preferred to the reproductive health services in the institutions' clinics. 
Anochie, I.C., \& Ikpeme, E.E. (2001). Prevalence of sexual activity and outcome among female secondary school students in Port Harcourt, Nigeria. African Journal of Reproductive Health, 5(2):63-7. Article available at: http://www.ajol.info/index.php/ajrh/article/viewFile/7681/13873

Sexual activity among 534 Nigerian female secondary school students in Port Harcourt (South-south) was studied using a self-administered questionnaire. The age range of the students was 8 to 23 years. The prevalence of sexual intercourse was 25.7 percent. There was no significant difference between the junior (48.2 percent) and senior (51.8 percent) students $(p>0.05)$. Seventeen (12.4 percent) students had initiated sexual intercourse before the age of 11 . The frequency of sexual exposure was high, with 34.3 percent of the students having intercourse more than once a week. Pregnancy rate among sexually active females was 27.0 percent, with 24.8 percent rate of induced abortion.

Brieger, W. R., Delano, G. E., Lane, C. G., Oladepo, O., \& Oyediran, K. A. (2001). West African Youth Initiative: outcome of a reproductive health education program. Journal of Adolescent Health, 29(6):436-446. Article available at: http://www.jahonline.org/article/S1054-139X\%2801\%2900264-6/abstract

To describe the implementation and evaluation of an adolescent reproductive health peer education program in West Africa. The program, known as the West African Youth Initiative (WAYI), was developed to improve knowledge of sexuality and reproductive health, and promote safer sex behaviours and contraceptive use among sexually active adolescents in Nigeria and Ghana. Between November 1994 and April 1997, two organizations, the Association for Reproductive and Family Health (ARFH), based in Nigeria, and Advocates for Youth, based in Washington D.C., supported community-based youth-serving organizations in the two countries to implement peer education projects. Consultants from the African Regional Health Education Centre (ARHEC) in Nigeria provided technical assistance in designing and conducting a quasiexperimental process and outcome evaluation of the projects. There were significant differences over time and between intervention and control groups concerning reproductive health knowledge, use of contraceptives in the previous three months, willingness to buy contraceptives, and self-efficacy in contraceptive use. Overall, the project provided evidence that peer education is most effective at improving knowledge and promoting attitudinal and behaviour change among young people in school settings.

Dare, O. O., Oladepo, O., Cleland, J. G., \& Badru, O. B. (2001). Reproductive health needs of young persons in markets and motor parks in south west Nigeria. African Journal of Medicine and Medical Science, 30(3):199-205. Article available at: http://www.ncbi.nlm.nih.gov/pubmed/14510129 https://www.researchgate.net/publication/9080212_Reproductive_health_needs_of_you ng_persons in markets and_motor_parks in_south_west_Nigeria

The aim of the study was to assess the reproductive health needs of out-of-school males and females aged 12-26 years working in markets and motor parks in Ibadan, Oyo State, South-West, Nigeria, using focus group discussions (FGDs) and a survey questionnaire. Results revealed that sexual experience was higher among males ( 80 percent) compared to females (66 percent). Multiple concurrent sexual partnerships were found to be common among unmarried young men (71 percent) than women (51 percent), but means of preventing pregnancy or sexually transmitted infections (STIs) were rarely employed. The knowledge of HIV was high (70 percent), though very few (12 percent) were aware that an infected individual would remain asymptomatic. Moreover, 36.5 percent thought that condoms make sex less enjoyable. Between 6 and 9 percent used a method for disease prevention within marriage or regular partnerships compared to 16 percent in casual contacts. Despite high exposure to risk, the prevalence of sexually transmitted infections was low as only 4 percent of the sexually experienced males and 9 percent of females were infected with candida albicans, chlamydia trachomatis, and trichomonas vaginitis or neisseria gonorrhoea. 
Izugbara, C. 0. (2001). Tasting the forbidden fruit: the social context of debut sexual encounters among young persons in a rural Nigerian community. African Journal of Reproductive Health, 5(2):22-29. Article available at: http://www.jstor.org/stable/pdf/3583427.pdf

The study attempts to use the circumstances surrounding the debut sexual encounters of young persons in a rural Nigerian community as an entry point to understanding their vulnerability to sexual and reproductive health problems. This study took place in Abala, a large rural community located in the southeast of Obingwa Local Government Area of Abia State. Data for the study were gathered using in-depth interviews of 180 persons aged 11-25 years. Emerging evidence shows that first sexual encounter took place under conditions that exposed young people to infections, disability, and even death. The study recommends that there is need to build on the clear evidence that good sex and reproductive health education for young persons delay the onset of sexual activity and makes it safer when it eventually commences.

Ajuwon, A.J., Fawole ,0.I., \& Osungbade, K.0. (2000-2001). Knowledge about AIDS and sexual practices of young female hawkers in trucks and bus stations in Ibadan, Nigeria. International Quarterly of Community Health Education, 20(2):133-143. Article available at: http://qch.sagepub.com/content/20/2/133.full.pdf+html

This study explored HIV/AIDS knowledge and sexual practices of 228 young female hawkers in four bus and truck stations in Ibadan, South-western, Nigeria. The mean age of the hawkers was 17.1 years. Over half (51 percent) did not know that a girl could become pregnant during her first sexual encounter; 71.7 percent and 65.6 percent knew of the sexual and perinatal routes of transmission of HIV infection, respectively. However a large proportion held misconceptions. They believed that HIV could be spread through sharing utensils (60.4 percent) and toilets (59 percent) with infected persons. Less than half (42 percent) had ever had sex; only 16.1 percent used a condom during the first episode of sex. Forty five percent of the sexually experienced had ever been pregnant with more than half (55 percent) of these pregnancies aborted.

\section{Brieger, W. R., \& Oladepo, O. (2000). Sexual attitudes and behaviour of male secondary school students in rural and urban areas of Oyo State, Nigeria. African Journal of Reproductive Health, 4(2):21-34. Article available at: http://www.jstor.org/stable/pdf/3583445.pdf}

The study was carried out among male adolescents in eight selected secondary schools to obtain information on male students' sexual behaviour, attitude to contraceptives, and reproductive health knowledge and formed the baseline for designing an intervention. A randomly selected sample of 1,527 male students in rural (Ibadan) and urban high schools (Idere) Ifeloju LGA of Oyo State, South-West, Nigeria, was studied. Respondents' ages ranged from 8 to 23 years old. Mean age at first sexual intercourse was 13.5 years among the 19.9 percent who had ever had sex. Having had sex before was associated with increasing age and number of father's wives. A positive male dominance attitude was common among rural, older, and sexually experienced youth. Only 26.2 percent of sexually experienced youth had used condom. Perceived self-efficacy was the only factor associated with condom use.

Iwuagwu, S. C., Ajuwon, A. J., \& Olaseha, I. O. (2000). Sexual behaviour and negotiation of the male condom by female students of the University of Ibadan, Nigeria. Journal of Obstetrics \& Gynaecology, 20(5):507-513. Article available at: http://informahealthcare.com/doi/abs/10.1080/014436100434712

This study explored the sexual behaviour of unmarried female students of the University of Ibadan, SouthWest, Nigeria, and assessed the extent to which those who were sexually active negotiated and used the male condom. Four focus group discussions were conducted followed by a survey of 354 students. The ages of the students ranged from 15 to 39 years with a mean age of 22.5 years. The result showed that 55.1 percent had had sexual intercourse; the mean age at first intercourse was 16.5 years. The number of 
lifetime sexual partners ranged from 1 to 20 with a mean of 3.4; 75 percent of those who had had sex reported ever using condom; 16.9 percent and 39 percent used it during their first and last sexual episodes respectively; only 34.3 percent used it consistently. Seventy-three percent had ever negotiated condom use with a partner, but only 41 percent did so during their last sexual encounter. A significant association was found between condom negotiation and number of sexual partners: Students with fewer life time partners (3.2) had less frequently negotiated condom use than those with more partners (4.3) $(p<0.05)$. Condom negotiators also scored significantly higher (4.6) on a 6-point AIDS Knowledge Score than those who had never done so $(4.0)(p<0.05)$. About a quarter $(26.7$ percent) had ever bought a condom, while 38.5 percent had ever carried it.

\section{Oladimeji, O., \& Oyedunni, S. O. (2000). Effect of peer education on deaf secondary school students' HIV/AIDS knowledge, attitudes and sexual behaviour. African Journal of Reproductive Health, 4(2):93-103. Article available at: http://www.ajol.info/index.php/ajrh/article/view/7714}

This study evaluated the effect of an HIV/AIDS education program on deaf secondary school students' knowledge, attitude, and perceived susceptibility to AIDS using peer education. Two secondary schools matched for ownership (government), composition (mixture of hearing and deaf), and teaching arrangement (separate teaching of deaf students using sign language) were used, and each school was randomly allocated the intervention or control status. The ages of respondents ranged from 10 to 22 years in both schools. A higher proportion falls within the 16 to 22 years age group with mean ages of 17 and 18 years in both schools. All students completed a questionnaire on HIV/AIDS at baseline and post-intervention. Following the baseline, volunteers from the intervention group received four weeks training as peer educators, after which they provided HIV/AIDS information to their peers on a one-to-one basis and in groups, using a variety of approaches for a period of eight months, while the control subjects did not. Prepost group differential scores for knowledge of the causes, modes of transmission and methods of prevention of AIDS among intervention group compared with the control group were significant $(p<$ $0.0000001)$ but not to perceived personal susceptibility $(p=0.64217)$.

\section{Raufu, A. (2000). The rising toll of HIV infection among Nigerian children. AIDS Analysis Africa, 10(4):11. Article available at: http://www.ncbi.nlm.nih.gov/pubmed/12349434}

This is an article discussing the burden of HIV infection among Nigerian children.

\section{Smith, D. J. (2000)."These girls today Na War-0": premarital sexuality and modern identity in Southeastern Nigeria.Africa Today, 47(3/4):99-120. Article available at: http://www.jstor.org/stable/4187370?seq=1\#page_scan_tab_contents}

This article examined the social context of premarital sexual relations among young people in lgbo-speaking South-eastern Nigeria. In particular, the paper explored conflicts between contemporary sexual identities and traditional models of gender and family as these tensions unfold in premarital sexual and reproductive decision making. This paper was based on 20 months of research, from 1995 to 1997, in Ubakala, a Southeastern Nigerian community located about 10 miles outside Umuahia, the capital of Abia State. The principal research methods included participant observation, semi-structured interviewing, and case studies. A written questionnaire was administered to 775 secondary school students selected randomly at each of the nineteen state-run secondary schools in Umuahia Local Government Area. At each school samples of between 20 and 50 students were also interviewed. The students ranged in age from 14 to 21 . A similar, but more detailed questionnaire was administered to 406 undergraduate students at Abia State University. A series of group discussions and more extensive individual interviews with male and female students, respectively, was also conducted. 


\title{
Prevention and Management of the Complications of Abortion
}

\author{
Ikeako, L., Onoh, R., Ezegwu, I.H., \& Ezeonu, P. (2014). Pattern and outcome of induced \\ abortion in Abakaliki, southeast of Nigeria. Annals of Medical and Health Science \\ Research, 4 (3):442-6. Article available at: \\ http://www.ncbi.nIm.nih.gov/pmc/articles/PMC4071748/
}

Investigators aimed to determine the pattern of unsafe abortion and the extent to which unsafe abortion contributes to maternal morbidity and mortality in their setting as well as assess the impact of post-abortion care. To achieve this, investigators conducted a descriptive study of patients who were admitted for complications following induced abortions between 1 January 2001 and 31 December 2008 at the Federal Medical Centre, Abakaliki South East of Nigeria with data obtained from case records. Out of the 1,562 gynaecological admissions, a total of 83 patients presented with the complications arising from induced abortion. The age group 20-24 years was mostly affected and adolescents constituted 32.5 percent $(27 / 83)$. Nearly 15.7 percent $(13 / 83)$ of these patients died while the remaining 84.3 percent $(70 / 83)$ had various complications, which were mainly septicaemia 59.0 percent (49/83), anaemia 47.0 percent (39/83), peritonitis 41.0 percent (34/83), haemorrhage 34.9 percent (29/83), and uterine perforation 30.1 percent (25/83). During the study, there were 38 gynaecological deaths and abortion-related death accounted for 34.2 percent (13/38) of these gynaecological deaths. Over four-fifths (84.3 percent; 70/83) of the patients had no documented evidence of counselling on family planning and 59.0 percent (49/83) were not aware of the different methods of contraception.

Ikeanyi, M.E., Okonkwo C.A. (2014). Complicated illegal induced abortions at a tertiary health institution in Nigeria. Pakistan Journal of Medical Sciences, 30(6):1398-402. Article available at: http://www.ncbi.nlm.nih.gov/pmc/articles/PMC4320738/

This was a retrospective descriptive study carried out at the University of Benin Teaching Hospital in Southsouth, Nigeria. Investigators' objective was to define the characteristics of those admitted with complications of induced abortions over a five year period. The medical records of patients managed for induced abortion complications between 1 January 2009 and 31 December 2013 were reviewed. Relevant data relating to the socio-demographic profile of the patients, clinical presentation, abortion service providers and facilities, and mode of termination of pregnancy were extracted. One hundred and nineteen patients, constituting 3.4 percent of gynaecological admissions were studied. The mean age of the patients was $23.5 \pm 6.6$ years with over 80 percent single. The mean gestational age at abortion was $12.8 \pm 4.1$ weeks. Incomplete abortion and postabortal sepsis formed the major indication for admission. About a fifth of the cases had abdominal visceral involvement. Twenty (18 percent) had laparotomy and 10(9 percent) had renal dialysis. Over 75 percent of patients were discharged in stable state.

\section{Abiodun, O.M., Balogun, O.R., Adeleke, N.A., \& Farinloye, E.O. (2013). Complications of unsafe abortion in South West Nigeria: a review of 96 cases. African Journal of Medicine and Medical Sciences, 42(1):111-5. Abstract available at: http://www.ncbi.nlm.nih.gov/pubmed/23909102}

The objective of this study was to determine the sociodemographic characteristics and pattern of complications present in patients managed for unsafe abortion. The patients studied were treated in Federal Medical Centre, Ido Ekiti, a tertiary health institution located in a rural town and a main referral hospital in Ekiti State, South West Nigeria. The records of patients admitted for complications of unsafe abortion over a 5-year period were analysed with regard to sociodemographic characteristics, gestational age at termination 
of pregnancy, the providers, methods used, and the complications they develop. A total of 102 patients were treated for complications of unsafe abortion during the period under review constituting 7.4 percent of total gynaecological admission. Majority (60.4 percent) of the patients were less than 25 years old, 74.0 percent were students, while 81.3 percent were unmarried. Only 9.4 percent of the women had ever used contraceptives. Of all the cases, 21 (21.9 percent) were performed within 8 weeks of gestation while 47.9 percent were performed in the second trimester. Surgical uterine evacuation was the method used in 67.7 percent of the patients and 65.6 percent of the abortions were performed by non-physicians. Sepsis was the commonest complication in the patients (79.2 percent) while uterine perforation was present in 12.5 percent of the women. The case fatality rate was 16.6 percent and unsafe abortion accounted for 30.8 percent of all maternal mortality during the period.

\section{Ibrahim, I.A., \& Onwudiegwu, U. (2012). Sociodemographic determinants of complicated unsafe abortions in a semi-urban Nigerian town: a four-year review. West Indian Medical Journal,61(2):163-7. Article available at: http://caribbean.scielo.org/pdf/wimj/v61n2/a12v61n2.pdf}

This four-year retrospective study aimed to determine the socio-demographic factors involved in complicated unsafe abortions. Investigators conducted an evaluation of all cases of complicated unsafe abortions managed at the Niger Delta University Teaching Hospital, Okolobiri, Bayelsa state, South-south Nigeria between 1 January 2007 and 31 December 2010. The incidence of unsafe complicated abortions over the study period was 4.1 percent of total deliveries and contributed 14 percent of gynaecological admissions: 34.92 percent occurred in adolescents less than 20 years of age, of which the majority (55.55 percent) were secondary school students. There were 55.45 percent of patients who were nulliparae, 60.32 percent were unemployed, and 69.8 percent were unmarried. A total of 87.3 percent had never used any form of contraceptive. Abortion mortality rate was $256 / 100,000$ deliveries and the case fatality was 4.76 percent. It constituted 30 percent of all gynaecological deaths and 17.64 percent of maternal deaths during the study period. The commonest cause of death was septicaemia (66.66 percent).

\section{Ochiogu, I. N., Miettola, J., llika, A.L., Vaskilampi, T. (2011). Impact of timing of sex education on teenage pregnancy in Nigeria: cross-sectional survey of secondary school students. Journal of Community Health, 36(3):375-80. Article available at: http://link.springer.com/article/10.1007\%2Fs10900-010-9318-6}

The objective of this study was to explore whether the time at which sex education was provided had any impact on reported cases of unintended pregnancies. A cross-sectional survey of secondary school students and their teachers was conducted using self-administered questionnaires. The participants were 1,234 students aged 14-17 years and 46 teachers in 5 secondary schools in South Eastern Nigeria. The outcome measures were reported pregnancies within the last three years by type of school and class level; class level at the time of receiving sex education at school; and age at the time of receiving sex education at home. In all schools, sex education was provided at all the junior and senior secondary school levels (JSS and SSS, respectively). Overall, reported cases of unintended pregnancies were highest among the junior students. In the private schools, four in ten teachers reported pregnancies among JSS 3 students. Almost four in ten teachers in public schools reported pregnancies among JSS 2 students. Of all the students, about three in ten reported pregnancies among JSS 2 and 3 students respectively. At home, sex education was provided at the mean age of 16 years (SD \pm 2.2 ). All participants cited financial need and marital promise as major predisposing factors. About four in ten students did not use contraceptives during their first sexual experience. 
Oriji, V.K., Jeremiah, I., \& Kasso, T. (2009). Induced abortion amongst undergraduate students of University of Port Harcourt. Nigerian Journal of Medicine. 18(2):199-202. Article available at: http://www.ncbi.nlm.nih.gov/pubmed/19630330

To determine the proportion of the undergraduate students who support the restrictive abortion laws in Nigeria, a cross-sectional questionnaire survey of undergraduate students of the University of Port Harcourt, South-south Nigeria, was done through a cluster sampling method along with focus group discussions with some of the respondents. 451 out of 500 administered questionnaires were retrieved and analysed. The incidence of induced abortion amongst the respondents was 47.2 percent. About 40 percent had never used an effective form of contraception in the past and 13 percent were unaware of contraception. Over threequarters (77.9 percent) of the induced abortion was by dilation and curettage and 1 percent by manual vacuum aspiration. Up to two-thirds of the respondents were against legalization of abortion.

\section{Osazuwa, H., \& Aziken, M. (2007). Septic abortion: a review of social and demographic characteristics. Archive of Gynaecology and Obstetrics, 275(2):117-119. Article available at: http://link.springer.com/article/10.1007\%2Fs00404-006-0233-0}

The objectives of this study were to determine the population at risk for septic abortion, define abortion providers, and evaluate the pattern of contraceptive usage. The study was carried out at the University of Benin Teaching Hospital, Edo State, South South, Nigeria. Medical records of patients admitted and managed for septic abortions, over a 4-year period, extending from June 2001 to May 2005, were reviewed. The total number of patients admitted and managed for septic abortion was 288, out of which 264 case notes were available for analysis with a retrieval rate of 91.7 percent. Two hundred and four (77.3 percent) and 60 (22.7 percent) had induced and spontaneous abortion, respectively, preceding the sepsis. The majority of patients were nulliparous, 216 (81.8 percent) and 191 (72.7 percent) were single. One hundred and forty-four (54.5 percent) had a history of previous induced abortion. Most of the patients had secondary education 129 (72.7 percent). Patients who had primary and tertiary education were 18.2 percent and 9.1 percent, respectively. One hundred and fifty-six (59.1 percent) were between the ages of 16 and 19 years while 13.6 percent aged $20-24$ years. In 33 (16.2 percent) cases, the status of the abortion provider was not mentioned. Medical doctors and nurses accounted for 102 (50.0 percent) and 69 (33.8 percent), respectively. The majority, 204 (77.3 percent), used no contraceptive method. Forty-eight (18.2 percent) post-coital pill, while 12 (4.5 percent) were practicing the rhythm method.

\section{Chatterji, M., Murray, N., Dougherty, L., Winfrey, W., Okonofua, F., \& Moreland, S. (2006). Factors related to induced abortion among young women in Edo State, Nigeria. Studies in Family Planning, 37(4):251-268. Article available at: http://www.ncbi.nlm.nih.gov/pubmed/17209283}

This study assessed the prevalence of and factors associated with induced abortion among 602 young women aged 15-24 who were surveyed in Edo State, Nigeria, in 2002. Investigators found that 41 percent of all pregnancies reported by the young women surveyed were terminated, and estimated that the agespecific abortion rate for 15-19-year-olds in Edo State to be at 49 abortions per 1,000 women, which was slightly higher than previous local estimates and nearly double the countrywide estimate for women aged 15-49. They constructed explanatory multivariate models to predict the likelihood that a young woman has experienced sexual intercourse, has become pregnant, and has undergone an induced abortion, controlling for important demographic, and risk-behaviour factors. Young women unmarried at the time of the study were found to be significantly more likely than married women to have had an abortion. Young women who had experienced transactional or forced sex were also significantly more likely to report ever having had an abortion, as were young women who had experienced more than one pregnancy. 
Igwegbe, A., \& Amobi, I. (2004). Unintended pregnancy among unmarried adolescents and young women in Anambra State, South East Nigeria. African Journal of Reproductive Health, 8(3):92-102. Article available at: http://www.bioline.org.br/pdf?rh04045

This study identified the characteristics and factors influencing unintended pregnancy among unmarried young women in a rural community in south-east Nigeria. One hundred and thirty-six unmarried teens with unintended pregnancy attending a Christian hospital in Ozubulu, a rural community in Anambra state, from January 1998 to December 2001 were included in the study. Information was obtained using a semistructured questionnaire and in-depth interview. Almost half of the subjects (43.4 percent) were between the ages of 17 and 19 years. Three out of four (75 percent) of the girls had their first sexual intercourse by 19 years, and over 69 percent had multiple partners. Over 95 percent had sex for economic reasons and exchanged sex for money or gifts. Only 13.5 percent ever used condoms. Almost all (97 percent) suffered violence such as beating and verbal abuse from family members because of the pregnancy. Most of the adolescents or young women experienced major stressors, most importantly school and job termination, partner's negative attitude, religious sanction, discrimination and stigmatization as a result of the unintended pregnancy.

\section{Oye-Adeniran, B. A., Adewole, I. F., Umoh, A. V., Fapohunda, O. R., \& Iwere, N. (2004). Characteristics of abortion care seekers in south-western Nigeria. African Journal Reproductive Health, 8(3):81-91. Article available at: http://www.bioline.org.br/pdf?rh04044}

This prospective hospital-based study was carried out to understand the characteristics of abortion care seekers in South-western Nigeria. Information was obtained from a total of 1,876 women seeking abortion at hospitals (100 in Lagos and 50 in Edo State, South-south, Nigeria) using a questionnaire. The results show that majority (60 percent) were between the ages of 15 and 24 years, of which adolescents between the ages of 15 and 19 years constituted 23.7 percent. Most (63.2 percent) of the respondents were unmarried, but married women also constituted a significant proportion (30.2 percent) of the abortion care seekers. Students were the single highest group (32.6 percent), while the predominant economic activity was trading (26.7 percent). Respondents terminated their pregnancies mainly because they were students or because they did not desire to have children. Most (35.5 percent) of the women were introduced to providers by friends. Average contraceptive prevalence among the abortion care seekers was 27.4 percent.

Orji, E. O., Adeyemi, A. B., \& Esimai, O. A. (2003). Liberalisation of abortion laws in Nigeria: the undergraduates' perspective. Journal of Obstetrics and Gynaecology, 23(1):63-66.

Article available at: http://informahealthcare.com/doi/pdf/10.1080/0144361021000043281

The views of 396 undergraduates of Obafemi Awolowo University, Ile-Ife, South-west, Nigeria concerning the liberalisation of abortion laws were investigated in May 2001. About a quarter (24.7 percent) of the respondents were aged between 18 and 21 years, while 34. 9 percent were aged 22-25 years and 9.1 percent were 17 years or younger. The percentage of male (49 percent) and female (51 percent) respondents were about the same. Ninety respondents (22.7 percent) supported the liberalisation of abortion laws in Nigeria because they believed that it would lead to reduction in associated morbidity and mortality, encourage more qualified personnel to perform it, encourage women to request abortion openly and encourage accurate statistics on abortion. However, the majority of the respondents (59.6 percent) opposed the liberalisation of abortion laws due to the fear that it would increase promiscuity, sexually transmitted infections, and abortion rates. Religious opposition and the belief that liberalisation would not reduce the level of poverty, ignorance, and lack of reproductive health facilities were the common factors leading to unwanted pregnancy and unsafe abortion in Nigeria. Support for the liberalisation of abortion laws shows significant relationship with increasing age $(p=0.001)$, male sex $(p=0.001)$ and a science-orientated faculty $(p<0.001)$, but not religion $(p>0.05)$. 
Oyediran, K.A., Ishola, G.P., \& Adewuyi, A.A. (2002). Knowledge of possible pregnancy at first coitus: a study of in-school adolescents in Ibadan, Nigeria. Journal of Biosocial Science, 34(2):233-48. Article available at: http://journals.cambridge.org/action/displayAbstract?fromPage=online\&aid=99809

This paper discusses the reproductive health knowledge of Nigerian in-school adolescents, with special reference to pregnancy occurrence at first coitus. The data were derived from an Association for Reproductive and Family Health (ARFH) survey carried out in four secondary schools in Ibadan, Southwest Nigeria, between August and October 1995. A total of 828 students were interviewed. The results revealed that the majority of sexually active adolescents were not aware of the consequences of their actions. Religious affiliation and number of wives in a male adolescent's family, and religion and marital status of a female adolescent's parents, were found to influence adolescents' knowledge of pregnancy probability at first coitus.

Otoide, V.O., Okonofua, F. E., \& Oronsaye, F. (2001). Why Nigerian adolescents seek abortion rather than contraception: evidence from focus-group discussions. International Family Planning Perspectives, 27(2):77-81. Article available at: http://www.guttmacher.org/pubs/journals/2707701.html

Investigators examined adolescents' perceptions concerning the risks of contraceptive use versus those of induced abortion. Data were collected through focus group discussions held with adolescents of diverse educational and socioeconomic backgrounds residing in Benin-City, Edo State, South-south, Nigeria. All were asked what they knew about abortion and contraception, and each method of contraception was discussed in detail. In particular, youth were asked about contraceptive availability, perceived advantages of method use, side effects, and young people's reasons for using or not using contraceptives. Fear of future infertility was an overriding factor in adolescents' decisions to rely on induced abortion rather than contraception. Many focus group participants perceived the adverse effects of modern contraceptives on fertility to be continuous and prolonged, while they saw abortion as an immediate solution to an unplanned pregnancyand, therefore, one that would have a limited negative impact on future fertility. This appears to be the major reason why adolescents prefer to seek induced abortion rather than practice effective contraception. 


\title{
Elimination of Harmful Customary Practices
}

\author{
Ashimi, A.O., Amole, T.G. (2015). Perception and attitude of pregnant women in a rural \\ community north-west Nigeria to female genital mutilation. Archives of Gynecology and \\ Obstetrics, 291(3):695-700. Article available at: \\ http://link.springer.com/article/10.1007\%2Fs00404-014-3478-z
}

This descriptive cross-sectional study utilized a pretested structured interviewer administered questionnaire to assess the types of female genital mutilation (FGM) known, reasons for performing it, and willingness to support or perform FGM among 323 pregnant women attending antenatal care in two different health facilities. The ages of the respondents ranged from 15 to 40 years with a mean of $23.7 \pm 5.33$ years while the parity ranged from 0 to 11 . One hundred and sixty seven (51.7 percent) were housewives, 94 (29.1 percent) were petty traders, 40 (12.4 percent) were seamstresses, 15 (4.6 percent) teachers, and $7(2.2$ percent) were hairdressers. Of the 323 respondents, 256 (79.3 percent) were aware of the practice and the common varieties of FGM known to them were Gishiri cut in 137 (53.5 percent) and Angurya cut 113 (44.1). The notable reasons for carrying out FGM in the community were tradition 88 (34.4 percent), to ease difficulty in childbirth 69 (26.9 percent), and better marriage prospect in 55 (21.5 percent). Of the respondents that were aware of FGM; 100 (39.1 percent) had experienced it and 55 (21.5 percent) of those aware of it would subject their daughters to the procedure. There was statistically significant association between willingness to mutilate daughters by the respondents type of education $(p=0.014)$ and the type of facility they were receiving antenatal care $(p=0.001)$.

\section{Ahanonu, E.L., Victor, O. (2014). Mothers' perceptions of female genital mutilation. Health Education Research, 29(4):683-9. Article available at: http://her.oxfordjournals.org/content/29/4/683.long}

This study was conducted to assess the perceptions of female genital mutilation (FGM) among mothers at a primary healthcare centre in Lagos, South-west Nigeria. A convenience sample of 95 mothers completed the pre-tested, semi-structured questionnaires. Just over a third (36.8 percent) were between the ages of 25 and 29 years with 8.4 percent between the ages of 20 and 24 years. The majority of the mothers (67.4 percent) were Christians and only 7.4 percent were single. Most of them were from the Yoruba (61.1 percent) and lbo (32.6 percent) ethnic groups of Nigeria. Just over half (52.6 percent) had secondary level education and 55.8 percent said they were self-employed. Findings showed that the mothers held ambivalent beliefs about the practice. Although over half of the respondents (56.8 percent) perceived the practice of FGM as not being beneficial, and 44.2 percent thought that uncircumcised girls will become promiscuous. Nearly a third (30.5 percent) believed that FGM promotes a woman's faithfulness to her husband. About a quarter (26.3 percent) reported that women who have undergone FGM are not at any risk of gynaecological complications. There was a significant relationship between the educational background of the mothers and the perception that uncircumcised girls will be promiscuous.

\section{Ashimi, A., Aliyu, L., Shittu, M., Amole, T. (2014). A multicentre study on knowledge and attitude of nurses in northern Nigeria concerning female genital mutilation. European Journal of Contraception and Reproductive Health Care, 19(2):134-40. Article available at: http://informahealthcare.com/doi/abs/10.3109/13625187.2014.885940}

To determine the knowledge and attitude of nurses in northern Nigeria concerning female genital mutilation (FGM), a cross-sectional study was conducted in which 350 nurses working in three tertiary health institutions in northern Nigeria ( 2 in the northwest and one in the northeast) were assessed, using a self- 
administered questionnaire, with regard to their knowledge of, and attitude to, FGM. Two hundred and sixtyfive respondents (76 percent) were female, and 190 (54 percent) were married. Most (249; 71 percent) were Muslims, and 228 (65 percent), of Hausa/Fulani ethnicity. Their ages ranged from 18 to 60 years with a mean of $29.3 \pm 8.9$. Among the respondents, 318 (91 percent) had heard of FGM; of these 127 (40 percent) knew no particular type of FGM. Only 155 (49 percent) could identify 'Angurya' and 'Gishiri' cuts as forms of FGM. Two hundred and forty-five (77 percent), 231 (73 percent) and 200 (63 percent), respectively, identified haemorrhage; risk of HIV, hepatitis, and tetanus; and painful sexual intercourse as possible complications of FGM. Thirteen (4 percent) would perform it and also would have it done on their daughters.

\section{Lawani, L.O., Onyebuchi, A.K., lyoke, C.A., Okeke N.E. (2014). Female genital mutilation and efforts to achieve Millennium Development Goals 3, 4, and 5 in southeast Nigeria. International Journal of Gynaecology and Obstetrics, 125(2):125-8. Article available at: http://www.ijgo.org/article/S0020-7292\%2814\%2900067-8/abstract}

A prospective descriptive study of parturients in southeast Nigeria was conducted from January to December 2012 to determine the prevalence of female genital mutilation (FGM), the common forms of FGM, reasons for the practice, associated obstetric outcomes, and how these have affected efforts to achieve Millennium Development Goals (MDGs) 3, 4, and 5 in southeast Nigeria. All primigravid women attending delivery services at 2 health institutions during the study period were recruited, examined, and classified using the 2008 WHO classification for FGM. The mean age of the 516 participants was $27.24 \pm 4.80$ years and most (66.3 percent) had undergone FGM. Type II FGM was the most common form, accounting for 59.6 percent of cases. Most FGM procedures were performed in infancy (97.1 percent) and for cultural reasons (60.8 percent). Women who had undergone FGM had significantly higher risk for episiotomy, perineal tear, haemorrhage, caesarean delivery, neonatal resuscitation, fresh stillbirth/early neonatal death, and longer hospitalization, with higher risk ratios associated with higher degrees of FGM.

Adebowale, S. A., Fagbamigbe, F. A., Okareh, T. O., \& Lawal, G. 0. (2012). Survival analysis of timing of first marriage among women of reproductive age in Nigeria: regional differences. African Journal of Reproductive Health, 16(4):95-107. Article available at: http://www.ncbi.nIm.nih.gov/pubmed/23444547

A retrospective cross-sectional study that sought to examine age at first marriage through analysing data extracted from the Nigeria Demographic and Health Survey, 2008. Findings revealed that the mean age at first marriage was $17.8 \pm 4.8$ years and significant difference existed between the mean age at first marriage of women in the North $(16.0 \pm 3.6)$ and South (20.4 \pm 5.0$)$. Majority of the women married between ages 15 and 19 years (43.1 percent), while very few married at age 30 or later (2.3 percent), and about 27.0 percent married earlier at less than 15 years. Region, education, religion, residence, nutritional status, age at first sexual intercourse, and children ever born were significantly associated with timing of first marriage. Early marriage was more common in all the regions in the North than the South, and it was highest in the North West and North East. Women who resided in rural areas married earlier than their counterparts in the urban areas. Age at first marriage was directly related to levels of education. Muslim women married earlier than Christians.

\section{Amu, O.C., Udeh, E.I., Ugochukwu, A.I., Madu, C., Nzegwu, M.A. (2012). A case of vulvar swelling secondary to female circumcision posing a diagnostic dilemma. International Journal of Surgery Case Reports, 3(9):431-4. Article available at: http://www.ncbi.nIm.nih.gov/pmc/articles/PMC3397301/}

The aim of this paper was to highlight the diagnostic dilemma associated with this type of case and the psychological trauma of a patient following her genital mutilations. Authors presented the case of epidermal inclusion dermoid cyst in an 18-year-old woman referred to them (at Enugu State University Teaching Hospital, South-east, Nigeria) from the gynaecologist as a case of hydrocele of the canal of Nuck involving the left labia majora. The patient had been previously seen by a general practitioner who diagnosed a left 
Bartholin's cyst. Excision of the mass, revealed a well encapsulated cystic mass containing serous fluid with no extension to the inguinal area, measured $10 \mathrm{~cm} \times 8 \mathrm{~cm}$. Histology showed epidermoid inclusion dermoid cyst probably related to female genital mutilation.

\section{Garba, I.D., Muhammed, Z., Abubakar, I.S., Yakasai, I. A. (2012). Prevalence of female genital mutilation among female infants in Kano, Northern Nigeria. Archives of Gynecology and Obstetrics, 286(2):423-8. Article available at: http://link.springer.com/article/10.1007\%2Fs00404-012-2312-8}

To determine the prevalence and type of female genital mutilation (FGM) among female infants, reasons and attitude of the mothers to the practice, a cross-sectional descriptive study was conducted at tertiary centre in Kano, Northwestern Nigeria (Aminu Kano Teaching Hospital). A pre-tested questionnaire was administered for mothers of female infants presenting for routine immunization. A total of 250 questionnaires were administered, but only 200 were properly filled and this was used for the analysis. Twenty-six infants had FGM during the period of study, giving a prevalence rate of 13 percent. The mean age at cutting was 8 days \pm 7.3 . The commonest type of FGM was type I accounting for 96.2 percent of the cases. Tradition/culture was the commonest reason for mutilation accounting for 73.1 percent, other reasons included; religious in 11.5 percent, hygienic in 11.5 percent, and to preserve virginity in 3.8 percent. Traditional barbers were the most common operators in 80.8 percent of cases, followed by the nurse/midwife in 15.4 percent of cases. The fathers were the main decision makers in 46.2 percent, followed by both parents in 26.9 percent and grandparents in 15.4 percent of the cases. 84 percent of mothers were not in support of the practice. Thirteen percent of the clients would have FGM done on all their daughters. Forty-eight percent of the clients were of the opinion that FGM causes harm to the victims. Four percent of those whose daughters were yet to have FGM done would do so later.

Iliyasu, Z., Abubakar, I.S., Galadanci, H.S., Haruna, F., Aliyu, M.H. (2012). Predictors of female genital cutting among university students in northern Nigeria. Journal of Obstetrics and Gynaecology, 32(4):387-92. Article available at: http://informahealthcare.com/doi/abs/10.3109/01443615.2012.666582

Using self-administered questionnaires, investigators studied the prevalence and determinants of female genital cutting $(F G C)$ among female university students in Kano, Nigeria $(n=359)$. Respondents' age ranged from 17 to 40 years (mean $\pm S D=22.8 \pm 3.3$ years). The majority of respondents were of Hausa-Fulani ethnicity ( $n=222,61.8$ percent), Muslim ( $n=275,76.5$ percent), and single ( $n=261,73.1$ percent). The prevalence of FGC was 12.1 percent (95 percent confidence interval $=8.8-15.8$ percent). Awareness and disapproval of FGC among the study population was very high (96 percent and 91 percent, respectively). In multivariate regression models, ethnicity and geographic origin were significant predictors of female circumcision.

Johnson, O.E., Okon, R.D. (2012). Perception and practice of female genital cutting in a rural community in southern Nigeria. African Journal of Reproductive Health, 16 (4):1329. Article available at: http://www.ncbi.nlm.nih.gov/pubmed/23444550

This study was carried out to determine the awareness and practice of female genital cutting (FGC) in a rural community in southern Nigeria. A cross-sectional study was carried out among Ayadehe women in Itu, LGA Akwa Ibom State, South-south Nigeria using a semi-structured, interviewer-administered questionnaire. A total of 218 respondents participated in the study. Most of the respondents, 138 (63.3 percent) were above 30 years of age. More than half, 129 (59.2 percent) were married, while 45 (20.6 percent) were single. A total of 83(38.1 percent) had no formal education, 79 (36.2 percent) had primary and 49 (22.5 percent) secondary education. One hundred and twenty one (55.5 percent) were farmers, while civil servants constituted the least group of 7 (3.2 percent). Majority, 215 (98.6 percent) were aware of the practice of FGC. Type 2 FGC was the commonest type reported by 71.2 percent of respondents. Prevalence of FGC was 92.7 percent. A total of 69.8 percent were circumcised between the ages of 6 and 12 years. Health 
complications experienced included excruciating pains, (36.6 percent), severe bleeding, (15.8 percent), and painful urination, (26.7 percent). Up to 53.5 percent were circumcised by traditional birth attendants. The belief that FGM should be discontinued increased with educational level.

Okeke, T., Anyaehie, U., Ezenyeaku, C. (2012). An overview of female genital mutilation in Nigeria. Annals of Medical and Health Sciences Research, 2(1):70-3. Article available at: http://www.ajol.info/index.php/amhsr/article/view/87793/774445

The objective of this review was to ascertain the current status of female genital mutilation (FGM) in Nigeria. Pertinent literature on FGM retrieved from internet services [Google search on FGM in Nigeria, www.online Nigeria, PubMed of the national library of medicine www.medconsumer. Info/tropics/fgm.htm, Biomed central and African Journal Online (AJOL) (FGM)] and textbooks, journals, and selected references for proper understanding of the topic was included in this review. The national prevalence rate of FGM was found to be 41 percent among adult women. Evidence abounded that the prevalence of FGM was declining. The ongoing drive to eradicate FGM was being tackled by World Health Organization, United Nations International Children Emergency Fund, Federation of International Obstetrics and Gynecology (FIGO), African Union, The economic commission for Africa, and many women organizations. However, there was no federal law banning FGM in Nigeria. The reviewers concluded that there was a need to eradicate FGM in Nigeria and that education of the general public at all levels with emphasis on the dangers and undesirability of FGM was paramount.

Okwudili, O.A., Chukwudi, O.R. (2012). Urinary and genital tract obstruction as a complication of female genital mutilation: case report and literature review. Journal of Surgical Technique and Case Report, 4(1):64-6. Article available at: http://www.ncbi.nIm.nih.gov/pmc/articles/PMC3461785/

This paper presents the case of a 23-year-old undergraduate, with urinary and genital tract obstruction following female genital mutilation (infibulation) who presented to the authors' urology service at the Federal Teaching Hospital, Abakiliki in South-east Nigeria. She was managed by elective defibulation, with a satisfactory outcome.

Alo, O.A., \& Gbadebo, B. (2011). Intergenerational attitude changes regarding female genital cutting in Nigeria. Journal of Women's Health, 20 (11):1655-61. Article available at: http://online.liebertpub.com/doi/abs/10.1089/jwh.2010.2610

This study used data from 420 women aged 15-49 years who had at least one surviving daughter to investigate changes in female genital cutting (FGC) prevalence among mothers and daughters. The sample was systematically selected through stratified random sampling across the six states of southwest Nigeria. Focus group discussion, and an in-depth interviews with fourteen women considered to be specialist in FGC were also held to compliment data generated from the interview. The analysis indicated an FGC prevalence rate of 75 percent and 71 percent for mothers and daughters, respectively. It further indicated that the practice is rooted in tradition despite the fact that 52 percent of the respondents were aware of the health hazards of FGC. Educated mothers were found to be less likely to favour the cutting of their daughters.

Ezenyeaku, C., Okeke, T., Chigbu, C., Ikeako, L. (2011). Survey of women's opinions on female genital mutilation (FGM) in Southeast Nigeria: study of patients attending antenatal clinic. Annals of Medical and Health Science Research, 1(1):15-20. Article available at: http://www.ncbi.nIm.nih.gov/pmc/articles/PMC3507097/

To determine women's views on aspects of female genital mutilation and the prevalence among the study population, women attending the antenatal clinics of two university teaching hospitals in Southeast Nigeria were interviewed by means of structured pre-tested interviewer-administered questionnaires. There were 342 respondents. The mean age of the respondents was 31.5 \pm 9.7 (Range: $14-50$ ) years. One hundred and 
thirteen (33.0 percent) of the respondents were nulliparous, 46 (13.5 percent) were primiparous, 88 (25.7 percent) were multiparous, and 95 (27.8 percent) were grand multiparous. Sixteen (4.6 percent) of the respondents had no formal education, 40 (11.7 percent) had primary education, while 102 (29.8 percent) had secondary education. One hundred and eighty four (53.8 percent) had tertiary education. The prevalence of FGM was 42.1 percent. However, only 14.3 percent of the respondents had FGM done on their own daughters or showed willingness to have FGM done on their daughters indicating considerable reduction in uptake of the practice. A larger proportion (63.7 percent) would support legislation against FGM.

\section{Dattijo, L.M., Nyango, D.D., Osagie, O.E. (2010). Awareness, perception and practice of female genital mutilation among expectant mothers in Jos University Teaching Hospital Jos, north-central Nigeria. Nigerian Journal of Medicine, 19 (3):311-5. Article available at: http://svriforum2009.svri.org/presentations/Osagie.pdf}

Semi-structured questionnaires were administered to 260 expectant mothers at the antenatal clinic of Jos University Teaching Hospital from 1 to 31 July 2007. Majority of the respondents (94.6 percent) were aware of female genital mutilation (FGM). Mass media was the main source of information. Majority (83.8 percent) wanted the practice to be discontinued, 31.3 percent reported having had FGM, most done by traditional healers. About 14.6 percent had a plan to have FGM done on their daughters citing tradition, marriage prospects, and faithfulness to husband as their reasons. Only 16.2 percent wanted the practice to continue.

\section{Ekwueme, O.C., Ezegwui, H.U., Ezeoke, U. (2010). Dispelling the myths and beliefs toward female genital cutting of woman: assessing general outpatient services at a tertiary health institution in Enugu state, Nigeria. East African Journal of Public Health, 7(1):64-7. Article available at: http://www.ncbi.nlm.nih.gov/pubmed/21413575}

This study aimed at using accurate information to dispel the traditional myths and beliefs about female genital mutilation (FGM) among women. Using a before and after intervention evaluation research design, interviewer administered questionnaires were administered to a sample of 100 women drawn by systematic sampling from the General Outpatient Department of University of Nigeria Teaching Hospital, Southeastern, Nigeria. Information on their knowledge, attitude, and behaviour towards FGM were elicited pre-and-post intervention. Pre-intervention, knowledge of the respondents on the true meaning of FGM was 54 percent and that of the 6 complications enlisted on average was 22.2 percent. Seventy (70.0 percent) believed that FGM is good and should be continued based mainly on culture and tradition (85.7 percent). Among the 29 (29.0 percent) respondents against FGM, 26 (89.7 percent) and 24(82.8 percent) said it increases risk of HIV and pregnancy complications, respectively. Respondents displayed a high negative and stigmatizing attitude toward the uncircumcised women. Seventy-four (74.0 percent) said they are promiscuous. Additionally, 49 percent said they are shameful, 14 percent cursed/outcast while 66 percent would not recommend them for marriage. Post-intervention, 85 percent of the respondents understood full meaning of FGM and 71.3 percent on the average knew the complications. While only 11 percent supported FGM and 83 percent were against the practice. The stigmatizing attitudes held against uncircumcised women decreased significantly from baseline to post-intervention as follows: promiscuous 74 percent to 22 percent, shameful 49 percent to 12 percent, outcast/cursed 14 percent to 2 percent, and not good for marriage from 66 percent to 19 percent. The differences in the baseline and post-intervention data on knowledge, beliefs, and attitudes of the respondents toward FGM were statistically significant $(p<0.001)$.

\section{Osifo, O.D. (2010). Post genital mutilation giant clitoral epidermoid inclusion cyst in Benin City, Nigeria. Journal of Pediatric and Adolescent Gynecology, 23 (6):336-40. Article available at: http://www.sciencedirect.com/science/article/pii/S108331881000080X}

To report overall occurrence, and the mode of presentation and management of girls with post genital mutilation giant clitoral epidermoid inclusion cyst in an African subregion, investigators documented the prospective experience with female patients who presented at two centres in Benin City, South-south Nigeria, between January 2005 and December 2009 with clitoral epidermoid inclusion cyst following underground 
traditional female genital mutilation performed on neonates. In total, 37 patients were seen with clitoral epidermoid inclusion cyst, 15 (40.5 percent) were post pubertal girls who could no longer cope with the giant cyst that measured more than $3.5 \times 6.5 \mathrm{~cm}$ in size at an average age of 17 (range 14-21) years. Ignorance, financial constraints, and the fear of possible prosecution by anti-female genital mutilation agencies were reasons for late presentation. Consequently, rapid increase in size of all cysts (100 percent), mass effect producing dragging discomfort in the vulva of 14 (93.3 percent) girls, social stigmatization of 12 (80 percent) girls by peers and spouses, sexual difficulty experienced by 10 (66.7 percent), and irritating bulge in the perineum of 10 (66.7 percent) girls, were the most common indications for surgical consultation. Outcomes of cystectomy that included total clitoridectomy performed on an outpatient basis mainly with local anaesthesia were encouraging with no incidence of recurrence recorded on 1-4 years postoperative followup.

\section{Kandala, N.B., Nwakeze, N., Kandala, S.N. (2009). Spatial distribution of female genital mutilation in Nigeria. American Journal of Tropical Medicine and Hygiene, 81(5):784-92. Article available at: http://www.ajtmh.org/content/81/5/784.long}

The aim of this study was to use the 2003 Nigeria Demographic and Health Survey data to determine the spatial distribution of the prevalence of FGM and associated risk factors. Data were available for 7,620 women; 1,673 (22.0 percent) interviewed had had FGM and 2,168 women had living children, of whom 485 (22.4 percent) daughters had undergone FGM. Unmarried women were more likely to report a lower prevalence of FGM.

\section{Osifo, D.O., \& Evbuomwan .I. (2009). Female genital mutilation among Edo people: the complications and pattern of presentation at a pediatric surgery unit, Benin City. African Journal of Reproductive Health, 13(1):17-25. Article available at: http://www.bioline.org.br/pdf?rh09003}

This prospective study on female genital mutilation among Edo people was based on female children and parents who presented on account of female genital mutilation at the University of Benin Teaching Hospital, Benin City, South-south Nigeria, between January 2002 and December 2007. During the period, 51 female children aged between 10 days and 18 years presented with complications following genital mutilation. Twenty-nine were brought by their parents for mutilation while 67 parents interviewed believed strongly in female genital mutilation with 47 mothers mutilated. Religio-cultural and superstitious beliefs were the main indications and the type of mutilation ranged from excision of clitoridal tip in 10 (19.6 percent) children to complete excision of the clitoris, labia minora, and inner layer of majora in 7 (13.7 percent). Complications ranged from clitoridal cyst formation in 21 (41.2 percent) to life threatening infections with one mortality due to tetanus infection.

\section{Asekun-Olarinmoye, E.O., Amusan, O.A. (2008). The impact of health education on attitudes towards female genital mutilation (FGM) in a rural Nigerian community. European Journal of Contraception and Reproductive Health Care, 13 (3):289-97. Article available at: http://informahealthcare.com/doi/abs/10.1080/13625180802075174}

To determine the level of practice of female genital mutilation (FGM) and the impact of a health education intervention in Shao community (Kwara state, north-central, Nigeria), an intervention study using a multistage sampling technique was conducted. The instrument was a pre-tested, structured questionnaire. The survey was supplemented by an in-depth interview of the traditional excisors. Most respondents were females (pre-intervention stage: 60.2 percent; post-intervention stage: 56.1 percent). The modal age group was 30-39 and 20-29 years in the pre- and post-intervention groups, respectively. The vast majority of respondents were of Yoruba ethnic origin (97.0 percent and 97.3 percent in the pre-and post-intervention stages, respectively), with formal education (71.0 percent and 72.1 percent),and Christians (67.8 percent and 63.8 percent); 28.8 percent and 31.8 percent were Muslims and 3.0 percent and 4.4 percent were traditionalists in the pre- and post-intervention stages, respectively. Most respondents (88.0 percent) cited 
traditional excisors as operators of the procedure, while 7.8 percent mentioned health workers. Factors found to be statistically significantly associated with the practice of FGM are age, gender and educational status of respondents $(p<0.05)$. The age at which FGM is usually performed was put at under one year old by 60.3 percent of respondents. All respondents cited type II FGM as the type practised in the community. Most (88.0 percent) of the female respondents were excised. A greater proportion of men than women did not want the practice of FGM stopped in the pre-intervention stage; however, there was a statistically significant decrease in the proportion of males who did not want the practice of FGM stopped in the postintervention stage. Also, there was a statistically significant increase in the proportion of respondents who had no intention to excise future female children in the post-intervention stage $(p<0.05)$. Legislation, female literacy and empowerment, educating men, and provision of alternative vocation for excisors were means suggested by respondents for stopping the practice.

\section{Ekenze, S.O., Ezegwui, H.U., Adiri, C.O. (2007). Genital lesions complicating female genital cutting in infancy: a hospital-based study in south-east Nigeria. Annals of Tropical Paediatrics, 27(4):285-90. Article available at: http://www.ncbi.nlm.nih.gov/pubmed/18053345}

A prospective evaluation of girls with genital complications of female genital cutting (FGC) between January 2003 and June 2005 at the Federal Medical Centre, Owerri, south-east Nigeria was conducted to determine the genital lesions complicating childhood FGC and the underlying factors that sustain this practice among the Igbos in south-east Nigeria. The girls' mothers were interviewed at presentation and subsequent visits to determine their perception and attitudes towards FGC. The average age at presentation was 3.5 years (range 1-5) and the genital cutting procedures were performed 8-90 days after birth. The procedure was undertaken by traditional practitioners in 14 ( 66.7 percent) girls and by nurses in 7 (33.3 percent) girls. Twelve girls (57.1 percent) had type I genital cutting and nine (42.9 percent) type II. Inclusion clitoral dermoid cyst and labial fusion were the complications in 13 (61.9 percent) and 8 (38.1 percent), respectively. Treatment involved complete excision of the cysts and operative division of the labial fusion. Post-operative complications were wound infection (5) and labial adhesion (2). With duration of admission ranging from 3 to 5 days, the average cost of managing each child was \$120. Of the girls' mothers, 15 (71.4 percent) had been educated to secondary level and 17 (80.1 percent) were aware of the campaign against FGC. All the mothers had genital cutting themselves during childhood and 13 (61.9 percent) stated that they would like to perpetuate the practice for socio-cultural reasons. Despite this, they all volunteered that FGC is enforced by the child's paternal relatives.

Ezem, B.U. (2007). Delayed presentation of clitoridal cyst: a case report. Nigerian Journal of Medicine, 16(3):272-3. Article available at: http://www.ncbi.nlm.nih.gov/pubmed/17937169

The case presented by this paper is that of a large clitoridal cyst which presented in the post-menopausal period 28 years after its onset. The aetiology, types, and complications of genital mutilation are discussed.

Adeokun, L.A., Oduwole, M., Oronsaye, F., Gbogboade, A.O., Aliyu, N., Wumi, A., Sadiq, G., Sutton, l., Taiwo, M. (2006). Trends in female circumcision between 1933 and 2003 in Osun and Ogun States, Nigeria (a cohort analysis). African Journal of Reproductive Health, 10(2):48-56. Article available at: http://www.bioline.org.br/pdf?rh06026

Changes in female circumcision occurring in two south-western States of Nigeria between 1933 and 2003 were tracked in a cross-sectional survey using cohort analysis. The analysis included 1,174 female live births to 413 women. About 53 percent of all females were circumcised. The prevalence dropped from 64.9 percent during the period 1933-60 to 25.7 percent for the period 2000-2003. For first order births, the corresponding rates were 58.8 percent and 25.0 percent. The decline for first-born females came a decade before other birth orders. Age and education of mother were two main factors of the decline. 
Amusan, O.A., Asekun-Olarinmoye, E.O. (2006-2007). Knowledge, beliefs, and attitudes to female genital mutilation (FGM) in Shao community of Kwara State, Nigeria. International Quarterly of Community Health Education, 27 (4):337-49. Article available at: http://qch.sagepub.com/content/27/4/337.long

To determine the level of knowledge, belief, and assess the attitude to FGM and its complications in Shao community, north-central Nigeria, a cross-sectional descriptive study with a health education intervention was conducted. The results showed that the majority of respondents were females in pre- and postintervention stages, 60.2 percent and 56.1 percent, respectively. The modal age group was 30-39 and 2029 years in the pre- and post-intervention groups respectively. The vast majority of respondents were of the Yoruba ethnic origin, Christians, and with formal education, 97.0 percent, 67.8 percent, and 71.0 percent vs. 97.3 percent, 63.8 percent, and 72.1 percent, respectively, in the pre-and post-intervention stages. A majority of respondents (99.5 percent) understood female circumcision to mean cutting off parts of the female genitals. There was a high level of knowledge regarding most of the complications of FGM as more than 50 percent of respondents knew at least four complications of FGM. Awareness of the global anti-FGM campaign was also high (78.8 percent). The most common reasons proffered for the practice of FGM were based on tradition or religion. Paternal grandfathers ( 50.0 percent) and fathers ( 21.0 percent) were cited as decision makers in the family most often responsible for requesting FGM. Post-intervention results showed that there was a statistically significant increase in the proportion of respondents who knew more complications of FGM and who had no intention of circumcising future female children.

Heading 2 Babalola, S., Brasington, A., Agbasimalo, A., Helland, A., Nwanguma, E., Onah, N. (2006). Impact of a communication programme on female genital cutting in eastern Nigeria. Tropical Medicine and International Health, 11(10):1594-603. Article available at: http://onlinelibrary.wiley.com/doi/10.1111/j.13653156.2006.01701.x/abstract,jsessionid=401AF3B69D078B22FC796037ADFF70EF.f01t $\underline{04}$

This study describes a female genital cutting (FGC) elimination communication programme in Enugu State, southeastern Nigeria, and assesses its impact in changing relevant knowledge, attitudes, and behavioural intentions. The FGC programme combined a community mobilization component with targeted advocacy and mass media activities. Data for assessing the impact of the programme derived from baseline and follow-up surveys in three intervention local government areas (LGA) in Enugu State and three comparison LGAs in Ebonyi State. An ideation model of behaviour change guided the analyses of the impact of the programme on personal advocacy for FGC, perceived self-efficacy to refuse pressure to perform FGC, perceived social support for FGC discontinuation, perceived benefits of FGC, perceived health complications of FGC, and intention not to perform FGC on daughters. The analytical methods included comparing change in pertinent outcome variables from baseline to follow-up in the two study states and using logistic regression on followup data for the intervention state to assess the link between programme exposure and the relevant outcome indicators. The data showed that while the pertinent ideational factors and the intention not to perform FGC either worsened or remained stagnant in Ebonyi State, they improved significantly in Enugu State. The logistic regression results showed that programme exposure is associated with the expected improvements in all the pertinent indicators.

Onuh, S.O., Igberase, G.O., Umeora, J.O., Okogbenin, S.A., Otoide, V.O., Gharoro, E.P. (2006). Female genital mutilation: knowledge, attitude and practice among nurses. Journal of the National Medical Association, 98 (3):409-14. Article available at: http://www.ncbi.nIm.nih.gov/pmc/articles/PMC2576104/

To determine the knowledge, attitude, and practice of female genital mutilation (FGM) among nurses in Benin City, Edo state, South-south Nigeria, where FGM is illegal. One-hundred-ninety-three nurses in the study hospital were recruited in the study out of which 182 (94.3 percent) appropriately filled and returned 
the questionnaires. The average age of respondents was 37 years, and the average duration of postgraduation experience was 14.5 years. Most respondents are of Bini (36.8 percent) and Esan (34.1 percent) ethnic origin. All respondents identified at least one form of FGM, but only 12 respondents (6.6 percent) could correctly identify the four types of FGM. The harmful effects of FGM identified by the majority of respondents include haemorrhage, difficult labour/childbirth, genital tears, infections, and scar/keloid formation. Forty-four (24.2 percent) of respondents were of the opinion that some forms of FGM are harmless. Eighty nurses admitted to having undergone FGM, for a prevalence of 44 percent. Five respondents (2.8 percent) viewed FGM as a good practice and would encourage the practice. Twelve respondents ( 6.6 percent) routinely performed FGM out of which seven ( 58.3 percent) viewed FGM as a bad practice. Nurses performing FGM routinely were those who had spent $>20$ years (59 percent) and 11-20 years (41 percent) in the profession. Another 26 (14.3 percent) had performed FGM before, though not on a routine basis. Of this latter group, 15 will perform FGM in the future when faced with certain circumstances. Reasons for FGM practice were mainly cultural. Eight of the respondents would have their daughters circumcised.

\section{WHO study group on female genital mutilation and obstetric outcome, Banks, E., Meirik, 0., Farley, T., Akande, O., Bathija, H., Ali, M.( 2006). Female genital mutilation and obstetric outcome: WHO collaborative prospective study in six African countries. Lancet. 3;367(9525):1835-41. Article available at: http://www.thelancet.com/journals/lancet/article/PIIS0140-6736\%2806\%2968805- 3/abstract}

This study examined the effect of different types of female genital mutiliation (FGM) on obstetric outcome among 28.393 women attending for singleton delivery between November 2001 and March 2003 at 28 obstetric centres in Burkina Faso, Ghana, Kenya, Nigeria, Senegal, and Sudan. The women were examined before delivery to ascertain whether or not they had undergone FGM, and were classified according to the WHO system: FGM I, removal of the prepuce or clitoris, or both; FGM II, removal of clitoris and labia minora; and FGM III, removal of part or all of the external genitalia with stitching or narrowing of the vaginal opening. Prospective information on demographic, health, and reproductive factors was gathered. Participants and their infants were followed up until maternal discharge from hospital. Compared with women without FGM, the adjusted relative risks of certain obstetric complications were, in women with FGM I, II, and III, respectively: caesarean section 1.03 (95 percent $\mathrm{Cl}$ 0.88-1.21), 1.29 (1.09-1.52), 1.31 (1.01-1.70); postpartum haemorrhage 1.03 (0.87-1.21), 1.21 (1.01-1.43), 1.69 (1.34-2.12); extended maternal hospital stay 1.15 (0.97-1.35), 1.51 (1.29-1.76), 1.98 (1.54-2.54); infant resuscitation 1.11 (0.95-1.28), 1.28 (1.101.49), 1.66 (1.31-2.10), stillbirth or early neonatal death 1.15 (0.94-1.41), 1.32 (1.08-1.62), 1.55 (1.122.16), and low birth weight 0.94 (0.82-1.07), 1.03 (0.89-1.18), 0.91 (0.74-1.11). Parity did not significantly affect these relative risks. FGM is estimated to lead to an extra one to two perinatal deaths per 100 deliveries.

\section{Abubakar, I., Iliyasu, Z., Kabir, M., Uzoho, C.C., Abdulkadir, M.B. (2004). Knowledge, attitude and practice of female genital cutting among antenatal patients in Aminu Kano Teaching Hospital, Kano. Nigerian Journal of Medicine, 13 (3):254-8. Article available at: http://www.ncbi.nlm.nih.gov/pubmed/15532227}

To assess knowledge, attitude, and practice of female genital cutting (FGC) among antenatal patients in Aminu Kano Teaching hospital in northern Nigeria, a cross-sectional study was conducted on 210 antenatal patients seen at Aminu Kano Teaching Hospital from February to March 2003. A structured intervieweradministered questionnaire was used to collect information about socio-demographic characteristics, knowledge, attitude and practice of FGC. Majority (91.4 percent) of the respondents had heard about FGC. Clitoridectomy and infibulation were known by 36.2 percent and 5.2 percent of the respondents respectively. Sixty and 5.2 percent of respondents knew that HIV and hepatitis could be transmitted by methods used in FGC. Other complications mentioned include sexual dissatisfaction (25.7 percent) and difficult delivery (8.6 percent). Furthermore, 16 percent of respondents wished FGC would continue mainly due to cultural or 
religious reasons, this opinion was associated with low (20.5 percent) level of education. Opponents of FGC gave medical complications as their main reason. Prevalence of circumcision was 23.3 percent and the most common type (36.7 percent) was clitoridectomy.

Anuforo, P.O., Oyedele, L., Pacquiao, D.F. (2004). Comparative study of meanings, beliefs, and practices of female circumcision among three Nigerian tribes in the United States and Nigeria. Journal of Transcultural Nursing, 15(2):103-13. Article available at: http://tcn.sagepub.com/content/15/2/103.long

This study was conducted to gain insight into the meanings, beliefs, and practices of female circumcision among three Nigerian tribes in the United States and Nigeria. Participant-observations occurred in three sites in Nigeria (Ibadan, Lagos, and Owerri) and in Essex County, New Jersey (Newark, Irvington, and East Orange). A total of 50 informants included adult males and females from the three main Nigerian ethnic tribes: Igbo, Yoruba, and Hausa. Leininger's culture care theory of diversity and universality was the study framework. Findings revealed existence of similarities and differences in the cultural meanings, beliefs, and practices among the tribes. Religion, education, and occupation were significant factors influencing informants' attitudes toward continuation of the practice. Government-sponsored public education and influence by the media were found to increase informants' awareness of complications of female circumcision. Changes in attitudes toward the practice and use of alternative practices were evident.

Dare, F.O., Oboro, V.O., Fadiora, S.O., Orji, E.O., Sule-Odu, A.O., Olabode, T.O. (2004). Female genital mutilation: an analysis of 522 cases in South-Western Nigeria. Journal of Obstetrics and Gynaecology, 24(3):281-3. Article available at: http://informahealthcare.com/doi/abs/10.1080/01443610410001660850

This study was conducted at three teaching hospitals (Obafemi Awolowo University Teaching Hospitals Complex, Ile-Ife, Lautech Teaching Hospital, Osogbo, and Ogun State University Teaching Hospital, Sagamu) in South-Western Nigeria. Parturients were examined to find out if they had had female genital mutilation. Those who did were given a self-administered questionnaire. The majority of the patients were in their twenties. The mean age (+standard deviation) was $26(+5.1)$ years. Results show that all the patients had either Type I (69 percent) or Type II (31 percent) mutilation (using WHO classification). The average age at which the procedure was performed was $6.9+/-2.9$ years, with 4 percent of women having the procedure performed in pregnancy. The majority of the procedures were performed by medically untrained personnel (89 percent). Up to 67 percent of the women reported complications following the procedure. Severe pain and bleeding were the most common (69 percent) of the complications reported. The most common reason given for the procedure is cultural/traditional (63 percent). About a fifth of the women wanted their female child to undergo female genital mutilation.

Ibekwe, P. C. (2004). Physical and psychological sequelae of female genital mutilation: a case report. Nigerian Journal of Medicine, 13(3):293-294. Article available at: http://www.ncbi.nIm.nih.gov/pubmed/15532236

This article provides a review of the relevant literature on female genital mutilation and provides a case-note of a 17 year old patient managed for complications of female genital mutilation.

\section{Mandara, M.U. (2004). Female genital mutilation in Nigeria. International Journal of Gynaecology and Obstetrics, 84 (3):291-8. Article available at: http://www.ijgo.org/article/S0020-7292\%2803\%2900277-7/abstract}

To determine the prevalence and distribution of female genital mutilation (FGM) procedures in a Nigerian population, five hundred consecutive women were evaluated for evidence of FGM. The World Health Organization classification system was utilized. Demographic and sociocultural information was collected. Thirty-four percent of women were found to have some type of FGM. Type I and Type II procedures were the 
most common. Fifty-five percent of women were unaware they had FGM and 62 percent with FGM did not know the reason. Twenty-one percent of women said they were going to have FGM on their daughters.

\section{Ugboma, H.A., Akani, C.I., Babatunde, S. (2004). Prevalence and medicalization of female genital mutilation. Nigerian Journal of Medicine. Vol,13(3):250-3. Article available at: http://www.ncbi.nlm.nih.gov/pubmed/15532226}

To ascertain the prevalence and operators of female genital mutilation (FGM), a cross-sectional study was carried out in a semi-urban town in Rivers State of Nigeria between January and April 1988, utilizing structured questionnaires which were randomly distributed. The response of 600 respondents was analysed. Prevalence of FGM amongst the study population was 53.2 percent. Medical doctors were the most mentioned operators (34.5 percent) followed by traditional birth attendants (33.8 percent). Control of excess female sexual desires (58.2 percent) and promotion of culture (39.5 percent) were the major reasons adduced for this practice.

\section{Akpan, E. (2003). Early marriage in eastern Nigeria and the health consequences of vesico-vaginal fistulae (VVF) among young mothers. Gender and Development, 11 (2):70- 76. Article available at: http://www.jstor.org/stable/4030642?seq=1\#page_scan_tab_contents}

This paper deals with the problem of early marriage and childbirth in eastern Nigeria, particularly among the Ibibio ethnic group. The author intended the paper to be a tool to help both human-rights activists and policy makers to effect positive change for girl children affected by early marriage. First, the paper examines the challenges posed to early marriage by the Nigerian Constitution, and human rights law. The article then focuses on the health risks involved in early pregnancies and, specifically, the fate of young women who are affected by VVF. The author visited a VVF Centre in Mbribit Itam, Akwa Ibom State (South-south, Nigeria), and shares some of the experiences of the interviewees. The paper concludes with some suggestions for reform to address the interests and needs of women.

Ogunlola, I.O., Orji, E.O., Owolabi, A.T. (2003). Female genital mutilation and the unborn female child in southwest Nigeria. Journal of Obstetrics and Gynaecology, 23(2):143-5. Article available at: http://informahealthcare.com/doi/abs/10.1080/0144361031000074655

The risk of female genital mutilation to a female child in southwest Nigeria was investigated by interviewing 430 consecutive pregnant women attending the antenatal clinic of Wesley Guild Hospital Ilesa, Nigeria from July to October 2001 . The results show that 60 percent of the pregnant women studied had a type of genital mutilation. The decision to mutilate a female child was taken before she was born. Seventy-four (17.2 percent) of the women and 146 (34 percent) of their husbands would circumcise their female child. The decision to circumcise a female child was made between the husband and wife but the final decision came mainly from the husband. Because the majority of the women (58.4 percent) were yet to decide whether or not to circumcise their female children, they could sway the decision either way before the husband made up his mind.

\section{Briggs, L.A. (2002). Male and female viewpoints on female circumcision in Ekpeye, Rivers State, Nigeria. African Journal of Reproductive Health, 6(3):44-52. Article available at: http://www.bioline.org.br/pdf?rh02034}

One hundred and ninety five male and female volunteers (in Ekpeye, South-south Nigeria) across the social strata were interviewed using a structured questionnaire. The mean age of male and female respondents was 34.8 and 31.0 years respectively with 59.5 percent males between 30 and 44 years and 50.5 percent of females between 15 and 29 years. With regard to education, a greater proportion of the males (43.0 percent) than females (42.1 percent) had higher education. such as National Certificate of Education, 
diplomas and university degree. Also, 30.0 percent and 33.7 percent of males and females, respectively, had secondary education, while 13.0 percent of males and 7.4 percent of females had elementary education. However, 14.0 percent of males and 16.8 percent of females did not attend any formal school. The occupation of respondents differed, 31.0 percent of males were civil servants while 36.8 percent of females were traders. A higher proportion of females (31.6 percent) were farmers compared to 15.0 percent of males. The study revealed that 74.7 percent of female respondents were circumcised. They believed that the practice would help prevent sexual promiscuity, curb sexual desires, and a custom they could not do without. Most of the men would not marry an uncircumcised female, while a substantial number of the respondents would like to circumcise their daughters. Community effort to eradicate the practice was very minimal.

\section{Larsen, U., Okonofua, F.E. (2002). Female circumcision and obstetric complications. International Journal of Gynaecology Obstetrics, 77 (3):255-65. Article available at: http://www.ijgo.org/article/S0020-7292\%2802\%2900028-0/abstract}

One thousand eight hundred and fifty-one women seeking family planning or antenatal care in three southwest Nigerian hospitals were interviewed and had a medical exam. The prevalence of complications at delivery for uncircumcised women and circumcised women with type 1 (partial or total removal of the clitoris) or type 2 (partial or total removal of the clitoris and part or all of the labia minora) were determined. Associations between self-reported complications at delivery and clinic-reported type of circumcision were analysed using bivariate and multivariate logistic regression. Almost half (45 percent) were circumcised; 71 percent had type 1 and 24 percent had type 2. Circumcised women had significantly higher risks of tearing and stillbirths when all pregnancies were analysed.

\section{Okonofua, F.E., Larsen, U., Oronsaye, F., Snow, R.C., Slanger, T.E. (2002). The association between female genital cutting and correlates of sexual and gynaecological morbidity in Edo State, Nigeria. BJOG,109(10):1089-96. Article available at: http://onlinelibrary.wiley.com/doi/10.1111/j.1471- 0528.2002.01550.x/abstract;jsessionid=B394F37C3191FB0C00077B2057BD1B27.fO $\underline{2 \mathrm{t} 04}$}

To examine the association between female genital cutting and frequency of sexual and gynaecological symptoms among a cohort of cut versus uncut women in Edo State of Nigeria, a cross-sectional study among women attending family planning and antenatal clinics at three hospitals in Edo State, South-south Nigeria was conducted. The sample included 1,836 healthy premenopausal women. Information about type of female genital cutting was based on medical exams while a structured questionnaire was used to elicit information on the women's sociodemographic characteristics, their ages of first menstruation (menarche), first intercourse, marriage and pregnancy, sexual history and experiences of symptoms of reproductive tract infections. Associations between female genital cutting and these correlates of sexual and gynaecologic morbidity were analysed using univariate and multivariate logistic regression and Cox models. The main study outcome measures were frequency of self-reported orgasm achieved during sexual intercourse and symptoms of reproductive tract infections. Results revealed that forty-five percent were circumcised and 71 percent had type 1, while 24 percent had type 2 female genital cutting. No significant differences between cut and uncut women were observed in the frequency of reports of sexual intercourse in the preceding week or month, the frequency of reports of early arousal during intercourse, and the proportions reporting experience of orgasm during intercourse. There was also no difference between cut and uncut women in their reported ages of menarche, first intercourse or first marriage in the multivariate models controlling for the effects of socio-economic factors. In contrast, cut women were 1.25 times more likely to get pregnant at a given age than uncut women. Uncut women were significantly more likely to report that the clitoris is the most sexually sensitive part of their body $(\mathrm{OR}=0.35,95$ percent $\mathrm{Cl}=0.26-0.47)$, while cut women were more likely to report that their breasts are their most sexually sensitive body parts $(\mathrm{OR}=1.91 ; 95$ percent $\mathrm{Cl}$ $=1.51-2.42)$. Cut women were significantly more likely than uncut women to report having lower abdominal pain $(\mathrm{OR}=1.54,95$ percent $\mathrm{Cl}=1.11-2.14)$, yellow bad-smelling vaginal discharge $(\mathrm{OR}=2.81$, 95 percent 
$\mathrm{Cl}=1.54-5.09)$, white vaginal discharge $(\mathrm{OR}=1.65,95$ percent $\mathrm{Cl}=1.09-2.49)$, and genital ulcers $(\mathrm{OR}=$ 4.38, 95 percent $\mathrm{Cl}$ 1.13-17.00).

\author{
Slanger, T.E., Snow, R.C., Okonofua, F.E. (2002). The impact of female genital cutting on \\ first delivery in southwest Nigeria. Studies in Family Planning, 33 (2):173-84. Article \\ available at: http://www.jstor.org/stable/3181171?seq=1\#page_scan_tab_contents
}

In this cross-sectional study, 1,107 women at three hospitals in Edo State, South-south, Nigeria, reported on their first-delivery experiences. Over half (56 percent) of the sample had undergone genital cutting. Although univariate analyses suggest that genital cutting is associated with delivery complications and procedures, multivariate analyses controlling for socio-demographic factors and delivery setting show no difference between cut and non-cut women's likelihood of reporting first-delivery complications or procedures. In this setting, apparent associations between cutting and obstetric morbidity appeared to reflect confounding by social class and by the conditions under which delivery takes place.

\title{
Snow, R.C., Slanger, T.E., Okonofua, F.E., Oronsaye, F., Wacker, J. (2002). Female genital cutting in southern urban and peri-urban Nigeria: self-reported validity, social determinants and secular decline. Tropical Medicine and International Health, 7(1):91- 100. Article available at: http://onlinelibrary.wiley.com/doi/10.1046/j.1365- 3156.2002.00829.x/abstract;jsessionid=DF4701AB9DB854F82AAF59228EBCEDA5.f03 $\underline{\mathrm{t} 02}$
}

In three antenatal and three family planning clinics in South-west Nigeria investigators studied the prevalence, social determinants, and validity of self-reporting for female genital cutting (FGC) among 1,709 women. Women were interviewed on social and demographic history, and whether or not they had undergone FGC. Interviews were followed by clinical examination to affirm the occurrence and extent of circumcision. In total, 45.9 percent had undergone some form of cutting. Based on WHO classifications by type, 32.6 percent had Type I cuts, 11.5 percent Type II, and 1.9 percent Type III or IV. Self-reported FGC status was valid in 79 percent of women; 14 percent were unsure of their status, and 7 percent reported their status incorrectly. Women are more likely to be unsure of their status if they were not cut, or come from social groups with a lower prevalence of cutting. Ethnicity was the most significant social predictor of FGC, followed by age, religious affiliation, and education. Prevalence of FGC was highest among the Bini and Urhobo, among those with the least education, and particularly high among adherents to Pentecostal churches; this was independent of related social factors. There is evidence of a steady and steep secular decline in the prevalence of FGC in this region over the past 25 years, with age-specific prevalence rates of 75.4 percent among women aged 45-49 years, 48.6 percent among 30-34-year-olds, and 14.5 percent among girls aged 15-19.

Igwegbe, A.O., Egbuonu, I. (2000). The prevalence and practice of female genital mutilation in Nnewi, Nigeria: the impact of female education. Journal of Obstetrics and Gynaecology, 20 (5):520-2. Article available at: http://informahealthcare.com/doi/abs/10.1080/014436100434749

Three hundred and twenty-five consecutive live female deliveries at Nnamdi Azikiwe University Teaching Hospital, Nnewi were followed up for nine months for evidence of any genital mutilation. Their mothers were examined for genital mutilation and a questionnaire based on face-to-face interview of the mothers was also administered. There was no genital mutilation observed among the 200 female babies whose mothers completed the 9 months follow up. The prevalence of genital mutilation among the mothers was 48 percent. The prevalence of female genital mutilation among the mothers increased with age. The circumcision index C.I. was zero and 3.0 at 16-20 years and 31-35 years age groups, respectively. Also, the prevalence decreased with increasing level of education. The circumcision index was 1.0 for mothers at primary level education and least 0.33 at tertiary level of education. There was no relationship with parity. None of the mothers was willing to allow genital mutilation to be performed on her baby but 36 percent applied local 
treatment to the clitoris especially powder (28 percent). Dystocia was the most common complication in the mothers and the knowledge about female genital mutilation was acquired informally from fellow women. 


\section{Screening for Reproductive Tract Cancers-Prostate, Breast and Cervix}

Arowolo, O. A., Akinkuolie, A. A., Adisa, A.O., Obonna, G.C., \& Olasode, B.J. (2013). Giant fibroadenoma presenting like fungating breast cancer in a Nigerian teenager. African Health Sciences, 13 (1):162-5. Article available at: http://www.ncbi.nlm.nih.gov/pmc/articles/PMC3645107/pdf/AFHS1301-0162.pdf

This is a case report of a 14-year-old pre-menarchal girl with a massive ulcerating and fungating left breast mass that was initially thought to be a fungating locally advanced breast carcinoma on clinical examination. Further examination of the morphology of the resected surgical specimen and histological examination confirmed it to be giant fibroadenoma of the breast. It was successfully managed by partial mastectomy and breast reconstruction with an excellent result and a high degree of patient satisfaction was achieved.

Nwachokor, F., lgbe, A.P., \& Forae, G.D. (2013). Histopathological review of breast tumours in children and adolescents in Delta State Nigeria. African Journal of Paediatric Surgery, 10 (2):65-7. Article available at: http://www.afrjpaedsurg.org/article.asp?issn=01896725;year=2013; volume=10;issue=2; spage $=65$; epage $=67$; aulast=Nwachokor

This study highlighted the spectrum of tumours in children and adolescents. Investigators conducted a 7 year retrospective analysis of all histologically diagnosed breast tumours in people aged 0-19 years presenting at Central Hospital, Warri, South-south Nigeria. There were 134 breast tumour diagnoses occurring in 133 females and 1 male (gynecomastia). One hundred and nineteen cases, (88.8 percent) were recorded in the 10-14 year age group and 15 cases (11.2 percent) in the 15-19 year age group. No case was found in children aged less than 10 years. The most common tumour was fibroadenoma accounting for 75.4 percent $(n=101)$ of all tumours followed by tubular adenoma $(n=11 ; 8.2$ percent), and adenosis $(n=$ $10 ; 7.4$ percent). No case of malignancy was recorded in this study.

Arowolo, O.A., Akinkuolie, A.A., Adisa, A.O., Obonna, G.C., \& Olasode, B.J. (2012). Neglected giant fibroadenoma of the breast presenting like a fungating breast cancer in a premenarchal Nigerian teenager. West African Journal of Medicine, 31 (3):211-3. Article available at: http://www.researchgate.net/profile/Adewale_Adisa/publication/236118039_Neglected Giant_Fibroadenoma_of the Breast_presenting_like_a_Fungating_Breast_Cancer_in_a Premenarchal_Nigerian_Teenager_Fibroadnome_gant_neglig_du_sein_simulant_un_canc er_fungode_du_sein_chez_une_adolescente_Nigeriane_en_pr_mnarche/links/00463516 1d4d64691c000000.pdf

This is a case presentation of a 14-year-old premenarchal girl presenting with a massive ulcerating and fungating left breast mass that was initially thought to be a fungating locally advanced breast carcinoma on clinical examination. Further examination of the morphology of the resected surgical specimen and histological examination confirmed it to be giant fibroadenoma of the breast. The giant fungating breast tumour was successfully managed by partial mastectomy and breast reconstruction with an excellent result and a high degree of patient satisfaction was achieved. 
Makwe, C.C., Anorlu, R.I., \& Odeyemi, K.A. (2012). Human papillomavirus (HPV) infection and vaccines: knowledge, attitude and perception among female students at the University of Lagos, Lagos, Nigeria. Journal of Epidemiology and Global Health, 2(4):199206. Article available at: http://www.jegh.org/article/S2210-6006\%2812\%29000597/abstract

This study sought to determine knowledge of and attitude towards HPV infection, HPV-related diseases, and HPV vaccines among female undergraduate students at the University of Lagos, South-west Nigeria. A selfadministered questionnaire was administered between May and July 2010 to 368 female students aged 16-29 years, who were selected from two faculties of the University of Lagos using two-stage sampling method. Data collected included: socio-demographic characteristics, sexual history, awareness and knowledge of HPV infection, cervical cancer and genital warts, and HPV vaccine; the perceived risk of acquiring genital HPV infection and developing cervical cancer or genital warts, and the willingness to receive an HPV vaccine. Only 64 (17.7 percent) and 52 (14.4 percent) of the students had ever heard of HPV infection and HPV vaccines, respectively. The median HPV knowledge on a 15-item score was 2. Overall, only 11.1 percent knew that genital HPV infection can cause cervical cancer. Fourteen (6.9 percent) of those who were aware of cervical cancer agreed they were at risk of developing the disease. Of the 52 students who had heard of the HPV vaccine, 24 (46.2 percent) knew it was given for cervical cancer prevention and 30 (57.7 percent) expressed their willingness to receive the vaccine.

Isara, A.R., \& Ojedokun, C.I. (2011). Knowledge of breast cancer and practice of breast self-examination among female senior secondary school students in Abuja, Nigeria. Journal Preventive Medicine and Hygiene, 52(4):186-90. Article available at: http://youth.org.ng/wp-content/uploads/2013/03/Isara-Ojedokun-2011-Knowledge-ofbreast-cancer-and-practice.pdf

This descriptive cross-sectional study was carried out among female senior secondary school students from selected schools in the municipal area council of Abuja, North-central Nigeria. The tool for data collection was a structured self-administered questionnaire. Two hundred and eighty-seven students participated in the study. Their mean age was $16.5+/-1.4$ years. A greater proportion of respondents 163 (56.8 percent) had poor knowledge of breast cancer while 217 (75.6 percent) had poor knowledge of breast self-examination (BSE). Only 114 (39.7 percent) of the respondents knew that being a female was a risk factor for breast cancer and the least known risk factors were obesity and aging. The major source of information for breast cancer and BSE among the respondents was the mass media. Only 29 (10.1 percent) of respondents had practiced BSE. Knowledge of BSE was significantly associated with BSE practice.

Olugbenga-Bello, A., Oladele, E. A., Bello, T. O., Ojo, J. O., \& Oguntola, A. S. (2011). Awareness and breast cancer risk factors: perception and screening practices among females in a tertiary institution in Southwest Nigeria. Nigerian Postgraduate Medical Journal, 18(1):8-15. Article available at: http://europepmc.org/abstract/med/21445107

This descriptive, cross-sectional study assessed the practices of breast cancer screening and risk perception of women of reproductive age group in a tertiary institution in Osun state, South West Nigeria (Federal Polytechnic, Ede). A total of 393 eligible respondents recruited using a stratified random sampling technique, were interviewed using semi-structured questionnaire after obtaining a verbal consent from them. About twothirds (67.9 percent) of those who had heard of breast cancer knew that there were screening methods available. Of these 91.6 percent knew breast self-examination, 93.2 percent knew clinical breast examination, and only a third 32.8 percent knew mammography as a screening method. About half of respondents who were aware of breast cancer practiced breast self-examination. Only 28 (7.6 percent) of the respondents had ever visited any clinic for breast cancer screening, and 85.7 percent (24) of the visit was for clinical breast examination while mammography was rarely done (14.3 percent). Eighty one percent of those who were aware of breast cancer believed that screening had a role to play. 
Aniebue, P.N., \& Aniebue, U.U. (2010). Awareness and practice of cervical cancer screening among female undergraduate students in a Nigerian university. Journal of Cancer Education, 25(1):106-8. Article available at: http://link.springer.com/article/10.1007\%2Fs13187-009-0023-z

The objective of this study was to assess awareness and practice of cervical cancer screening amongst female students in a Nigerian university. A cross-sectional survey of 394 female students at the Enugu campus of the University of Nigeria (South-east, Nigeria) was done. The age range of respondents was 1638 years with a mean 23.8 years and SD \pm 3.8 years. Most (55.1 percent) of the respondents were 21-24 years and 360 (91.4 percent) were single. One hundred and ninety respondents ( 48.2 percent) were sexually active. The majority (54.2 percent) had their first sexual exposure at 20-24 years. One hundred and sixty two (85.3 percent) respondents reported one current partner and 14.7 percent had multiple partners. The rate of condom use in their last sexual encounter was 54.7 percent. About 23.1 percent identified the Pap smear as a screening test. Only 5.2 percent of respondents had ever been screened and 52.8 percent reported willingness to be screened. The major reason for unwillingness to get a Pap smear was absence of symptoms (31.7 percent).

Iliyasu, Z., Abubakar, I.S., Aliyu, M.H., Galadanci, H.S. (2010). Cervical cancer risk perception and predictors of human papilloma virus vaccine acceptance among female university students in northern Nigeria. Journal of Obstetrics and Gynaecology, 30 (8):857-62. Article available at: http://informahealthcare.com/doi/abs/10.3109/01443615.2010.511724

Investigators studied cervical cancer awareness and HPV vaccine acceptance among 375 female university students in Kano state, Northwestern Nigeria. Respondents' age ranged from 16 to 35 years (mean+SD, 22.7+3.1 years). At the time of the study, 79 participants (21.1 percent) were sexually experienced. Of these, 59 (74.7 percent) were sexually active in the preceding 6 months. The average age of sexual debut was $17.5+4.6$ years. The majority of sexually experienced students (67.1 percent) had only one partner. The mean number of sexual partners was $2.5+1.6$ for all respondents, with 6.4 percentadmitting to having had an STI in the past (gonorrhoea, syphilis, chlamydia, or HIV). A total of 133 participants knew of HPV (35.5 percent), 202 (53.9 percent) had heard of cervical carcinoma, and 277 (74.0 percent) were willing to accept HPV vaccination. After adjusting for potential confounders, age (adjusted odds ratio $(A O R)=2.3,95$ percent confidence interval $(\mathrm{Cl}), 1.47-6.53)$; medical education $(\mathrm{AOR}=3.4,95$ percent $\mathrm{Cl}$, 1.74-6.93); $\mathrm{HPV}$ knowledge $(A O R=1.8,95$ percent $\mathrm{Cl}, 1.38-5.41)$; and awareness of cervical cancer $(\mathrm{AOR}=2.3,95$ percent $\mathrm{Cl}, 1.52-5.06)$ were significant predictors of readiness to accept HPV vaccine.

\section{Umanah, I.N., Akhiwu, W., Ojo, O.S. (2010). Breast tumours of adolescents in an African population. African Journal of Paediatric Surgery, 7(2):78-80. Article available at: http://www.afrjpaedsurg.org/downloadpdf.asp?issn=0189- 6725; year $=2010$; volume $=7$;issue $=2 ;$ spage $=78$; epage $=80$; aulast $=$ Umanah;type}

The purpose of this study was to highlight the clinicopathologic features of breast tumours in adolescents in a Nigerian city. Eighty-four breast tumour materials from patients aged 10-19 years were analysed over a 10-year period at the Department of Pathology, University of Benin Teaching Hospital (UBTH), Benin City, Edo State, South-south Nigeria. A majority of the breast tumours were benign. Fibroadenoma was the most common tumour with 46 cases (54.8 percent), followed by fibrocystic changes with 15 cases (17 percent). Malignancy was extremely rare in this group, with only one case (1.2 percent) of an invasive ductal carcinoma. Histologically, most tumours were indistinguishable from the adult types. 
Gwarzo, U.M., Sabitu, K., \& Idris S.H. (2009). Knowledge and practice of breast-selfexamination among female undergraduate students of Ahmadu Bello University Zaria, north-western Nigeria. Annals of African Medicine, 8 (1):55-8. Article available at: http://www.bioline.org.br/request?am09011

Researchers assessed knowledge and practice of breast self-examination (BSE) among female undergraduate students of Ahmadu Bello University Zaria, North-central Nigeria. In this study, knowledge and practice of BSE were examined among 221 female students aged 16-28 years old studying at Ahmadu Bello University Zaria using self-administered questionnaires. It was found that although nearly three-quarters of the respondents (87.7 percent) had heard of BSE, only 19.0 percent of them were performing this examination monthly. Regarding the sources of information about BSE among respondents, media was found to be most common followed by health workers accounting for 45.5 percent and 32.2 percent respectively. Regular performance of BSE was significantly correlated with duration of stay in the University $\left(X^{2}=81.9, \mathrm{df}=3, \mathrm{p}<.05\right)$ and family history of breast cancer $\left(X^{2}=17.4, \mathrm{df}=2, \mathrm{p}<.05\right)$.

Akujobi C.N., Ikechebelu, J.I., Onunkwo, I., \& Onyiaorah, I.V. (2008). Knowledge, attitude and practice of screening for cervical cancer among female students of a tertiary institution in South Eastern Nigeria. Nigerian Journal of Clinical Practice, 11 (3):216-9. Article available at: http://www.ajol.info/index.php/njcp/article/view/11407/63586

The objective of this study was to determine the knowledge, attitude, and practice of cervical cancer screening among female undergraduates. A pre-tested questionnaire was administered to third and fourth year female students of the Faculty of Natural Sciences, Nnamdi Azikiwe University Awka, South-east Nigeria. Out of the 220 students involved in the study, 134 (60.9) had knowledge of cervical cancer and 118 (53.6 percent) were sexually active with the average age at sexual debut being 21.2 years. The mean age of the students was 23.8 years and the age range was 17 to 39 years with 175 (80 percent) in the age range of 20-29 years. About 2/3 of the students did not know about Pap smear and none of them had undergone a Pap screening test before. This low participation in screening for cervical cancer was attributed to several reasons including ignorance of the existence of such a test, lack of awareness of centres where such services are obtainable, ignorance of the importance of screening, and the risk factors to the development of cervical cancer.

Nzegwu, M.A., Adanna, A., Daniel, O., Ugochukwu, A., Agu, K. (2008). An unusually early age of presentation of Phylloides tumour in Eastern Nigeria. European Journal of Cancer Care (Engl), 17(3):312-3. Article available at: http://onlinelibrary.wiley.com/doi/10.1111/j.1365-2354.2007.00845.x/abstract

To show that Phylloides tumour presents in South-eastern Nigeria at an unusually early average age, departmental records for biopsied breast lesions (University of Nigeria Teaching Hospital) were used to collate data on Phylloides tumour seen from 1 January 2000 to 31 December 2004. The mean age of presentation of Phylloides tumour was 24 years with a standard deviation of 7 years, giving an average age range of 17-31 years. The masses ranged in size from $5 \mathrm{~cm}$ to $25 \mathrm{~cm}$. They were all benign and were found exclusively in females. Treatment modalities used were mostly wide excisions, but a few had mastectomy especially where the tumour had grown so large as to cause pressure necrosis of the ipsilateral breast. Post mastectomy, four patients had a recurrence and had a second surgery. They all did well, thereafter without subsequent morbidity and mortality. 


\section{Ayinde, O.A., Omigbodun, A.O., llesanmi, A.0. (2004). Awareness of cervical cancer, Papanicolaou's smear and its utilisation among female undergraduates in Ibadan. African Journal of Reproductive Health, 8(3):68-80. Article available at: https://tspace.library.utoronto.ca/bitstream/1807/4943/1/rh04043.pdf}

A survey was conducted among 421 undergraduates of the University of Ibadan, South-west Nigeria using self-administered questionnaires probing into their risk factors for neoplastic cervical lesions, awareness of cervical cancer, and Papanicolaou's smear and its utilisation. The percentage of sexually active respondents was 81.5 percent. The age range of respondents was $16-36$ years with a mean age of 23.6 years ( \pm 3.6 ). Sexual exposure before the age of 20 years occurred in 51.7 percent. The mean age at sexual debut was 18.8 years while the modal age was 18 years. Over half (57 percent) had multiple sexual partners, but only 38.1 percent used condoms. Almost three-quarters (71 percent) were aware of cervical cancer, while only 33.5 percent were aware of Papanicolaou's smear. Awareness was found to be more among medical students and the married ones. On the other hand, only 8.3 percent of them had ever done a Papanicolaou's smear.

\section{Onuigbo, W. (2003). Breast fibroadenoma in teenage females. Turkish Journal of Pediatrics, 45(4):326-8. Article available at: http://www.turkishjournalpediatrics.org/?fullTextld=99\&lang=eng}

Over a period of 30 years, the researcher received surgical specimens of fibroadenoma from doctors who had operated on 530 teenage females of the Igbo ethnic group of southeastern Nigeria. The peak age was 18 years. The right breast (51.3 percent) was involved more often than the left (48.7 percent). There were 58 bilateral cases (10.9 percent of the entire series). Seven teenagers had undergone previous operations for fibroadenoma and five growths were infarcted. The teenagers showed awareness of breast disease as manifested by (a) rising incidence trend during the 1970s, 1980s, and 1990s (43, 186, and 301), (b) little delay in presenting for treatment and (c) smallness of the excised tumours. 


\section{Sexual Abuse, Coercion, and Violence}

Folayan, M. O., Odetoyinbo, M., Harrison, A., \& Brown, B. (2014). Rape in Nigeria: a silent epidemic among adolescents with implications for HIV infection. Global Health Action, 7 , 25583. Article available at: http://www.globalhealthaction.net/index.php/gha/article/view/25583

This letter to the editor highlights the rape epidemic among adolescents in Nigeria and discusses the implications for adolescents' health and the current legal and societal response.

Olatunya, O. S., Akintayo, A. A., Olofinbiyi, B., Isinkaye, A. O., Ogundare, E. O., \& Akinboboye, 0. (2013). Pattern and medical care of child victims of sexual abuse in Ekiti, south-western Nigeria. Paediatrics and International Child Health, 33(4):247-252. Article available at: http://www.maneyonline.com/doi/abs/10.1179/2046905513Y.0000000089

A retrospective, descriptive study aimed at reviewing the pattern and medical care of victims of child sexual abuse (CSA) in a tertiary hospital over a 39-month period. Case files of 28 cases of CSA were retrieved from those of 6,535 patients seen in the paediatric out-patient department of Ekiti State University Teaching Hospital, South-West Nigeria between 1 January 2010 and 31 March 2013. Victims of CSA accounted for 0.43 percent of new patients seen during the period under review with a yearly increase over that time. Victims were all female with a median age of 11.5 years and the age range was 4-17 years. They all had genito-urinary findings and 3.6 percent had an anal tear. The assailants were all male, mostly adults. A school teacher and school friends were the perpetrators in 3.6 percent and 10.8 percent of cases, respectively. All were screened for HIV, but only 60.7 percent were screened for hepatitis $\mathrm{B}$ and $\mathrm{C}$. Only 60.7 percent received HIV post-exposure prophylaxis and none was given prophylaxis against viral hepatitis $B$ and C. Of those eligible for post-exposure emergency contraception, only 43.8 percent received it. Antibiotics and analgesics were routinely given in 89.3 percent cases. Only one of the patients attended for follow-up. None had repeat serological screening tests. The police were involved in 60.7 percent of cases but there was no prosecution.

Oshiname, F.O., Ogunwale, A.O., \& Ajuwon A.J. (2013). Knowledge and perceptions of date rape among female undergraduate of a Nigerian university. African Journal of Reproductive Health, 17(3):137-148. Article available at: http://reference.sabinet.co.za/sa_epublication_article/ajrh_v17_n3_a14

This study focused on knowledge and perceptions of Date Rape (DR) among female undergraduates of the University of Ibadan, Southwest Nigeria. The cross-sectional survey was conducted among 651 unmarried female undergraduates selected using a four-stage random sampling technique. A semi-structured questionnaire which included a 6-point knowledge scale and a 21-points perceptions scale was used to collect data. Knowledge scores of $0-2,3-4$ and 5-6 were rated as poor, fair and good respectively. Perception scores of 0-10 and 11-21 were categorized as supportive and non-supportive perception of DR respectively. Data were analysed using descriptive statistics and Chi-square at $p<0.05$. Mean knowledge score was 2.3 +/- 2.1 and 50.0 percent participants had poor knowledge of DR. Knowledge of DR increased significantly by level of study. Participants' had a mean perception score of $9.1+/-2.8$ and 66.9 percent had perceptions supportive of DR. 
Ige, 0., \& Fawole, O. I. (2012). Evaluating the medical care of child sexual abuse victims in a general hospital in Ibadan, Nigeria. Ghana Medical Journal, 46(1):22-26. Article available at: http://www.ncbi.nIm.nih.gov/pmc/articles/PMC3353498/

A retrospective cross-sectional study was carried out aimed at evaluating the medical care provided to victims of Child Sexual Abuse (CSA). The study participants were children $<18$ years who were treated as victims of sexual assault at the general outpatient clinic of a secondary health care facility in Ibadan, SouthWest, Nigeria. The median age of victims was 12 years (range 3-17 years). All were females and 33.3 percent had attained menarche. A familiar person was the perpetrator of CSA in 45 (62.5 percent) of the cases. Many (68.1 percent) had torn hymen; of these, 16.3 percent also had vaginal lacerations and bleeding. Children $>10$ years more often had torn hymen $(p<0.001)$. Vaginal swab microscopy was done in 84.0 percent of those with torn hymen. About 60 percent of victims had retroviral screening done (all were non-reactive). None of the patients received post exposure prophylaxis for HIV. Of those with signs of vaginal penetration who had also attained menarche, 12.2 percent had emergency contraceptives prescribed. Treatment of victims consisted mostly of antibiotics ( 47.2 percent) and analgesics ( 37.5 percent) with only 15.3 percent of patients proffered any form of counselling.

\section{John, C., Okolo, S. N., \& Isichei, C. (2012). Nonconsensual sexual relationship and prevalence of HIV infection in adolescent in Jos, Nigeria. Nigerian Medical Journal, 53(4):210-212. Article available at: http://www.ncbi.nlm.nih.gov/pmc/articles/PMC3640241/}

This study was designed to determine the prevalence of non-consensual sex (NCS) and HIV in adolescents. The study took place in Jos, the capital city of Plateau state in North-central Nigeria. Eight hundred and eighty-three adolescents (883) aged 10-19 years from 10 secondary schools were randomly selected and given a questionnaire to fill. All had group pre-test counselling and had HIV screening. Of the 883 students, 169 (19.2 percent) were sexually experienced. Of which 101/169 (59.8 percent) were males and 40.2 percent females. Mean age at first sexual debut was $14.4 \pm 2.6$ years; males $13.3 \pm 2.7$ years and females 14.6 \pm 3.2 years, $p=0.006$. Seventy-three of 127 respondents ( 57.5 percent) indicated consensual sex and 42.5 percent (54/127) indicated NCS. Of the 54 subjects, 74 percent were females and 22 percent males. Mean age at first sex in NCS was $13.5+3.4$ years; males, $12.5 \pm 2.9$ years in NCS and $14 \pm 2.6$ in consensual, $p=0.045$; females $14 \pm 3.5$ in NCS and $16.5 \pm 1.2$ in consensual $p=0.02$. Circumstances of sex showed 59.3 percent were forced sex or rape, 7.4 percent was following gifts. Over 70 percent of NCS group use no form of protection. In the population studied 9/883 (1.02 percent) were HIV positive. Among the sexually experienced HIV prevalence was 2.4 percent (4/169), and 3.7 percent (2/54) among NCS.

\section{Ogunfowokan, A. A., \& Fajemilehin, R. B. (2012). Impact of a school-based sexual abuse prevention education program on the knowledge and attitude of high school girls. Journal of School Nursing, 28(6):459-68. Article available at: http://isn.sagepub.com/content/28/6/459.long}

This study was conducted to develop a sexual abuse prevention education package (SAPEP) which was tested among high school girls to determine its effectiveness in improving their knowledge and attitude. The study was conducted in two public, mixed sex secondary schools in Ife Central and Ife East Local Government Areas of Osun State, South-West, Nigeria, using a quasi-experimental study design (PretestPosttest non-equivalent group design).The sample comprised 200 high school girls who were in senior secondary I and II and were between the ages of 13 and 24 years. This study adopted a quasi-experimental design in which a sexual abuse prevention education package was developed and used to educate high school girls in a selected school in Nigeria. Evaluation of the impact of the package revealed a significant increase in the knowledge mean scores of the girls at first post-intervention stage and this increase was maintained at second post-intervention stage. No significant shift was observed for the attitude of the girls. 
Ogunwale, A.O., Oshiname, F.O., \& Ajuwon, A.J. (2012). Date rape experiences and helpseeking behaviour among female university students in Ibadan, Nigeria. International Journal of Collaborative Research on Internal Medicine and Public Health, 4(8):15451559. Article available at: http://www.iomcworld.com/ijcrimph/files/v04-n08-06.pdf

The study was designed to determine the prevalence of date rape, context of its occurrence and helpseeking behaviour among female undergraduates of the University of Ibadan, Southwest, Nigeria. The crosssectional survey was conducted among 610 female undergraduates selected using a multi-stage random sampling technique. A semi-structured questionnaire was used for data collection. Data were analysed using descriptive statistics, Chi-square and logistic regression. Respondents' mean age was 21.0-2.5 years, 50.5 percent were sexually experienced and prevalence of date rape was 11.8 percent. The forms of date rape ever experienced included forced vaginal sex (80.3 percent), forced anal sex (10.5 percent), forced oral sex (15.8 percent), and forced insertion of fingers into the vagina (32.9 percent). Date rape was experienced by majority (73.6 percent) of the victims when they became undergraduates. Respondents aged 17-19 were at higher risk of date rape (OR: 4.69, 95 percent $\mathrm{Cl}$ : 1.99-11.04, $\mathrm{p}=0.001$ ) than other age groups. Date rape was experienced by 73.3 percent in perpetrators' residence outside the campus. Most (91.5 percent) survivors of date rape never sought any medical help, legal redress, or counselling services. Reasons adduced for not seeking medical services included lack of serious physical injury (53.0 percent) and fear of stigmatization (12.1 percent). Many (57.3 percent) felt it was not necessary to seek for counselling services

Olaleye, O.S., \& Ajuwon, A.J. (2012). Prevalence and factors associated with perpetration of non-consensual sex among students of a tertiary institution in Ibadan, Nigeria. African Journal of Reproductive Health, 16(4):108-118. Article available at: http://www.jstor.org/stable/23485780

This cross-sectional survey explored the extent to which students of the Polytechnic, Ibadan (Southwest Nigeria) had perpetrated non-consensual sex (NCS). A total of 594 randomly selected students completed a questionnaire and three perpetrators (male) were interviewed in-depth. Mean age of the survey respondents was $22.7+/-2.9$ years. Over one-fifth (22 percent) had ever perpetrated at least a form of NCS, out of which 75.9 percent reported involvement in this behaviour in the six months preceding the study. Forms of NCS perpetrated included unwanted touch of breast/back side (14.6 percent), unwanted kiss (9.4 percent), attempted rape (2.7 percent), and rape (1.7 percent). The predictors of perpetration of NCS were alcohol use (OR: 2.2; $\mathrm{Cl}: 1.41-3.33$ ) and cigarette smoking (OR: 2.5, Cl: 1.13-5.56). In-depth interviews revealed that peer group influence and alcohol consumption contributed to perpetration of NCS.

\section{Ajuwon, A.J., Fawole, F.O., \& Osungbade, K.O. (2011). Experience and perpetration of violent behaviours among secondary school students in Ibadan, Nigeria. Sierra Leone Journal of Biomedical Research, 3(1):27-35. Article available at: http://www.ajol.info/index.php/sljbr/article/view/66648}

This cross-sectional survey assessed experience and perpetration of physical, sexual and psychological violent behaviours among school-based adolescents. A total of 1,366 students (50.4 percent females and 49.6 percent males) randomly selected from six public secondary schools in Ibadan, Southwest, Nigeria were interviewed using a 36-item questionnaire. Respondents answered questions regarding demographic profile, sexual behaviour, and the extent to which they had experienced or perpetrated physical, sexual, and psychological violent behaviours. Respondents' age ranged from 9 to 24 years with a median age of 14 years. The lifetime experience of at least one of the three forms of violence was 97.9 percent: physical violence ranked first (94.4 percent), followed by psychological (77.6 percent), and sexual violence (34.9 percent). The most common types of these forms of violent behaviours experienced were slaps (84.5 percent), unwanted touch of breast and backside (22.7 percent), and being belittled (63.2 percent). Approximately 8 percent of the study group had had sex and 25 percent of sexually active respondents claimed that their first sexual encounter occurred in coercive circumstances. The predictors of experience of violence among males were use of alcohol, witnessing domestic violence, involvement in work, and parental 
use of alcohol. Among females parental use of alcohol and being young were predictors of violence. Reports of perpetration of physical, sexual and psychological violence among males were 75.3 percent, 44.9 percent and 13.3 percent respectively.

\section{Gharoro, E. P., Enabudoso, E. J., \& Sodje, D. K. (2011). Non-consensual sex in Benin. Nigerian Journal of Clinical Practice, 14(2):190-194. Article available at: http://www.njcponline.com/article.asp?issn=1119- 3077;year=2011;volume=14;issue=2;spage=190;epage=194; aulast=Gharoro}

The objective of the study was to investigate the prevalence and risk factors of non-consensual sex/rape in Benin. The respondents were between 17 and 56 years of age, with a mean of $25.37 \pm 6.05$ years. Five hundred and eighty (580) females in the University Community of Benin, Edo State, South-South, Nigeria, were surveyed; 414 questionnaires were sufficiently completed for analysis. Seventy-six (18.4 percent) respondents reported that they had been victims of non-consensual sex (NCS), 36 (47.1 percent) out of the 76 was in their current relationship. The unmarried single respondents had the lowest mean age at NCS experience of 18 years, while the divorced victims had the highest mean age of $32.5(p=0.000)$. The majority of sex offenders were their present partners-boyfriends (61.1 percent) and next the husbands (22.2 percent). The father was the perpetrator on one (2.78 percent) occasion, while armed robbers raped two of the victims. Eighteen of the seventy-six respondents made a formal report. Cumulatively, 95.4 percent of the respondents felt it was futile reporting, 4 (5.3 percent) felt it was not all a bad experience. The risk of being infected with the HIV/AIDS virus was the worst fear. Allmost a quarter $(95,22.9$ percent) wanted the public and parents to be educated, 84 (20.3 percent) desired better sex education in the schools, 64 (15.5 percent) wanted the penal code to be tougher and better implemented, while 64 (14.0 percent) craved for a dress code for the University Community. There was a major exposure peak age at 19 with a smaller peak at 25 years.

\section{Olaleye, O.S., \& Ajuwon, A.J. (2011). Experience of non-consensual sex among students of a tertiary institution in Ibadan, Nigeria. Sierra Leone Journal of Biomedical Research, 3(3):175-183. Article available at: http://www.ajol.info/index.php/sljbr/article/view/74051}

This study explored experiences of non-consensual sex (NCS) among students of a polytechnic in Ibadan, Southwest Nigeria. A total of 594 randomly selected students completed questionnaires which explored experience of NCS and help-seeking behaviour. The mean age of the respondents was $22.7 \pm 2.9$ years and 58.9 percent were females. Over half (56 percent) of respondents had experienced sexual intercourse; of these, 9.0 percent reported that their first sexual intercourse was due to rape. A little less than half (47 percent) of the entire sample had ever experienced at least a form of NCS out of which 70.5 percent were affected during the six months preceding the study. Forms of NCS experienced included unwanted touch of breast or back side (26.4 percent), attempted rape (14.0 percent) and rape (5.7 percent). Rape victims consisted of 5.3 percent of males and 6.0 percent of females. Predictors of the experience of NCS were alcohol consumption (Odd Ratio $[\mathrm{OR}]=1.7, \mathrm{Cl}=1.17-2.52)$, being a female $(\mathrm{OR}=1.9, \mathrm{Cl}=1.34-2.72$ ), and having a friend of the opposite $\operatorname{sex}(\mathrm{OR}=2.4, \mathrm{Cl}=1.04-5.52, \mathrm{p}=0.04)$. Well known friends of the victims were the major perpetrators of all forms of NCS. Most (86.6 percent) of those who reported experience of NCS did not seek redress or medical care.

Ikechebelu, J. I., Udigwe, G. O., Ezechukwu, C. C., Ndinechi, A. G., \& Joe-lkechebelu, N. N. (2008). Sexual abuse among juvenile female street hawkers in Anambra State, Nigeria. African Journal of Reproductive Health, 12(2):111-119. Article available at: http://www.ajol.info/index.php/ajrh/article/view/7864/30526

This was a descriptive study carried out among juvenile female hawkers in two urban settlements (Awka and Nnewi) in Anambra State, Southeastern Nigeria. Based on the Nigeria Labour Act's definition of a child, only hawkers who were aged 16 years and below were eligible for inclusion into the study. Data was collected 
over a period of six weeks between August and September 2004. The hawkers were recruited into the study while hawking on the streets between 3 and $6 \mathrm{pm}$ from Monday to Saturday. Semi-structured questionnaires which took about 15-20 minutes to administer were used in interviewing the girls. The mean age of the female hawkers was $13.0+2.2$ years. Out of 186 respondents, 130 (69.9 percent) had been sexually abused with 32 (17.2 percent) having had penetrative sexual intercourse (28.1 percent were forced and 56.3 percent submitted willingly) while hawking. Majority (59.4 percent) of the sexual partners were adults. Other types of sexual abuse experienced include inappropriate touches (106 cases; 81.5 percent) and verbal abuse (121 cases; 93.1 percent). There was low awareness of the twin risks of pregnancy (43.1 percent) and sexually transmitted infections (54.3 percent) following sexual abuse among the respondents.

\section{Olley, B. O. (2008). Child sexual abuse, harmful alcohol use and age as determinants of sexual risk behaviours among freshmen in a Nigerian University. African Journal of Reproductive Health, 12(2):75-88. Article available at: http://www.bioline.org.br/pdf?rh08024}

The aims of this study were to: (1) establish the prevalence of sexual risk behaviours among entering freshmen in a Nigerian university (University of Ibadan, Oyo State, South-West) and (2) identify to what extent the above stated factors and some others are associated with sexual risk behaviours. Eight hundred and forty-one, freshmen who attended a routine orientation program were asked to respond to a questionnaire. Their mean age was 20.4 years (SD 1.33), 64 percent were male and 36 percent female. Results showed that 30.8 percent were sexually active and 47 percent did not use a condom in their last sexual episode. Factors associated with sexual risk behaviours, included being a male freshman, increasing age, lower tendency for violence, increase sexual compulsivity, alcohol abuse, history of rape, and a history of child sexual abuse (CSA). Three variables: alcohol abuse; history of CSA, and increasing age remained significant in a multiple regression analysis.

\section{Ajuwon, A. J., Olaleye, A., Faromoju, B., \& Ladipo, O. (2006). Sexual behaviour and experience of sexual coercion among secondary school students in three states in North Eastern Nigeria. Biomed Central Public Health, 6, 310. Article available at: http://www.biomedcentral.com/1471-2458/6/310}

The objective of this descriptive survey was to collect data to plan appropriate interventions that meet the reproductive health knowledge, service and skills needs of secondary school students in three Nigerian states, Bauchi, Borno and Gombe in North-eastern Nigeria. Face-to-face interviews were conducted for 624 consenting students who were randomly selected from eighteen secondary schools using an 83-item structured questionnaire. The mean age of the respondents was 16.5 years. There were slightly more males (52 percent) than females (48 percent). Students' knowledge about reproductive health was generally low even though girls had better knowledge than boys. Thirteen percent of the entire students had had sexual experience; significantly more males (19 percent) than females (6 percent) had done so. Among boys the age at sexual debut ranged from 10 to 26 with a mean of 15.7 and median of 16 . By contrast, the age at first sex among girls ranged from 10 to 18 years with a mean and median of 16.1 and 17 years, respectively. Only 24 percent of those who were sexually active used a condom during their last sexual encounter. Overall 11 percent of the students reported that they had been tricked into having sex, 9 percent had experienced unwanted touch of breast and backside, and 5 percent reported rape.

\section{Okoro, F. I., \& Obozokhai, O. (2005). Sexual harassment: the experience of out-of-school teenagers in Benin City, Nigeria. African Journal of Reproductive Health, 9(3):118-127. Article available at: http://www.bioline.org.br/pdf?rh05046}

This study sought to investigate the experiences of out-of-school teenagers with regards to sexual harassment in Benin City, Edo State, South South, Nigeria. 650 teenagers (293 males and 357 females) participated in the study. They were all aged between 13 and 16 years with an average age of 14 years for the females and 15 years for males. The findings indicated that sexual harassment was common to the 
extent that it was viewed as the norm in the society by the adolescents. For example, 296 (83 percent) of all females and 152 (62 percent) of all males had experienced one or more forms of sexual harassment. It was also found that more females ( 82 percent) compared to 48 percent males experienced harassment and that anger was the most common response to the experience. The majority of the victims considered their assailants abnormal and for the most part did not know how to handle the situation.

\section{Ajuwon, A.J., Olley, B.O., Akintola, O., \& Akin-Jimoh, I. (2004). Sexual coercion in adolescents: exploring the experiences of rape victims in Ibadan, Nigeria. Health Education, 104(1):8-17. Article available at: http://www.emeraldinsight.com/doi/pdfplus/10.1108/09654280410511743}

In-depth interviews with eight female victims of rape in Ibadan, Southwest Nigeria were used to explore the context in which the coercive incident occurred, the health-seeking behaviours that followed and the consequences of this experience in victims' lives. The mean age of the women was 17 years. In all cases, perpetrators of rape were persons with whom the women were acquainted. Rape occurred mainly in familiar and private settings. Rarely did victims communicate the incident to family or friends or report the incident to the enforcement authorities. The stigma associated with rape was a primary barrier to seeking care. Interventions are proposed to address these problems.

Olley, B.O., Ajuwon, A.J., Akin-Jimoh, l., \& Akintola, O. (2003). Skills training for safe sex practice and coercive behaviour prevention among adolescents in Ibadan, Nigeria. Ife Psychologia, An International Journal of Psychology in Africa, 11(2):34-51. Article available at: http://www.ajol.info/index.php/ifep/article/view/23485

This study examined the effect of a didactic skills training program for in-school adolescents in Ibadan (Southwest, Nigeria) on knowledge concerning prevention of sexual coercion, knowledge about HIV/AIDS, sexual role/responsibility, and assertiveness/communication skills. A total of 73 in-school adolescents ages 15-19 years $(X=18.2, S D 2.1)$ who were recruited from four secondary schools in a local government area took part in the study. Results showed a significant $(p<0.05)$ increase in knowledge about prevention of sexual coercion, HIV/AIDS, sexual role/responsibility, and assertiveness/communication skills at postintervention testing. Also, being male, having good general self-efficacy, greater age, and greater number of years of education significantly predicted a greater increase in skill acquisition. At six months follow-up, an appreciable number of adolescents were educated concerning various forms of topics.

\section{Ajuwon, A. J., Akin-Jimoh, I., Olley, B. 0., \& Akintola, 0. (2001). Perceptions of sexual coercion: learning from young people in Ibadan, Nigeria. Reproductive Health Matters, 9(17):128-136. Article available at: http://www.sciencedirect.com/science/article/pii/S0968808001900163}

This study explored sexual coercion from the perspectives of 77 young people aged 14-21 in Ibadan Northwest Local Government in South-western, Nigeria, the behaviours they perceive to be sexually coercive and the contexts in which these occur through four narrative workshops. Participants were drawn from 2 secondary schools and 15 apprentice workshops. All four groups identified similar coercive behaviours and developed narratives of the events that typically lead up to them. Behaviours included rape, unwanted touching, incest, assault, verbal abuse, threats, unwanted kissing, forced exposure to pornographic films, use of drugs for sedation and traditional charms for seduction, and insistence on abortion if unwanted pregnancy occurs. Men were typically the perpetrators and young women the victims. Perpetrators included acquaintances, boyfriends, neighbours, parents, and relatives. All the narratives revealed the inability of young people to communicate effectively with each other and resolve differences. 


\section{Ajuwon, A. J., Olley, B. O., Akin-Jimoh, I., \& Akintola, O. (2001). Experience of sexual coercion among adolescents in Ibadan, Nigeria. African Journal Reproductive Health, 5(3):120-131. Article available at: \\ http://www.jstor.org/stable/3583330?seq=1\#page scan tab contents}

This study surveyed 1,025 adolescent male and female students and apprentices in Ibadan, North West Local Government Area (LGA) of Oyo State, Nigeria, to document their sexual behaviour and experience of sexual coercion including verbal threats, unwanted touch, unwanted kiss, assault, deception, drugging, attempted rape, and rape. The study population comprised adolescents aged 15-19 years. Almost twothirds (65 percent) of male and 48 percent of female apprentices were sexually experienced, compared to 32 percent of male and 24 percent of female students. More males than females reported sex with multiple partners and contact with a sex worker while females had exchanged sex for money and gifts. Over half (55 percent) of all the subjects had been victims of at least one type of sexual coercion, the most common being unwanted kiss and touch of breasts (47 percent). Although both males and females were victims of coercion, females were disproportionately affected; 68 percent of female students and 70 percent of female apprentices had experienced one coercive behaviour, compared to 42 percent of male students and 40 percent of male apprentices. Female apprentices fared worst, with 19 percent of them raped. The main perpetrators of the coercion were persons well known to the victims including neighbours, peers, and boy/girlfriends.

\section{Ogunyemi, B. (2000). Knowledge and perception of child sexual abuse in urban Nigeria: some evidence from a community-based project. African Journal of Reproductive Health, 4(2):44-52. Article available at: http://www.jstor.org/stable/3583447?seq=1\#page_scan_tab_contents}

This study reports some baseline findings from a community-based project on the incidence of child sexual abuse (CSA) in two Nigerian urban centres. Data were generated through in-depth-interviews (IDIs), focus group discussions (FGDs), and survey questionnaires (SQs) involving 958 respondents. About 38 percent and 28 percent of female and male respondents, respectively, reported being initiated to sex before the age of 18 years. Majority of the respondents condemned CSA acts like rape, date rape, child prostitution, and incest. However, evidence of gender-role stereotyping, which puts girl-children at reproductive health risks of these and related acts, seems widespread. 


\title{
Other Sexual and Reproductive Health and Rights Related Topics
}

\author{
Amu, E.O., \& Bamidele, J.O. (2014). Prevalence of menstrual disorders among adolescent \\ girls in Osogbo, South Western Nigeria. International Journal of Adolescent Medicine and \\ Health, 26(1):101-6. Article available at: \\ http://www.degruyter.com/view/j/ijamh.2014.26.issue-1/ijamh-2013-0500/ijamh-2013- \\ 0500.xml
}

\begin{abstract}
This study aimed to determine the patterns of menstruation as well as the prevalence of menstrual disorders and their consequences among adolescent girls in Osogbo, South Western Nigeria. The study employed a descriptive cross-sectional design. Adolescent school girls aged 10-19 years comprised the sample. A pretested, self-administered, semi-structured questionnaire was used to elicit information from 402 adolescents selected from private secondary schools in the Osogbo Local Government Area (LGA) of Osun State, using a multistage sampling technique. A total of 391 (97.8 percent) respondents had heard about menstruation before, with the three most important sources of information being their mothers ( 81.8 percent), teachers (7.4 percent), and peer groups (6.1 percent). The mean age at menarche was $12.5 \pm 1.0$ years. Menstrual bleeding lasted between 2 and 7 days in 81.1 percent and cycle length lasted for 21-35 days in 81.6 percent of the respondents. The three most important menstrual disorders they experienced were dysmenorrhea (77.8 percent), menorrhagia (57.4 percent), and metrorrhagia (18.6 percent), among others. Menstrual disorders, especially dysmenorrhea, interfered with the daily activities of the respondents.
\end{abstract}

Folayan, M. O., Haire, B., Harrison, A., Odetoyingbo, M., Fatusi, O., \& Brown, B. (2014). Ethical Issues in Adolescents' Sexual and Reproductive Health Research in Nigeria, Developing World Bioethics. Article available at: http://onlinelibrary.wiley.com/doi/10.1111/dewb.12061/abstract

This paper examined the various ethical issues that may impact stakeholders' decision making when considering engaging adolescents in SRH research in Nigeria. It makes a case for lowering the age of consent for adolescents. While some experts believe it is possible to extrapolate relevant information from adult research, studies on ethical aspects of adolescents' participation in research are still needed, especially in the field of sexual and reproductive health where there are often differences in adolescents' knowledge, attitudes and practices compared to adults. The paper concluded that ethical guidelines in Nigeria should consider the feasibility of engaging adolescents aged 14 years and above (rather than the current consideration of 16 years and above) in research without the need for parental consent.

Ekpenyong, C.E., \& Etukumana, E.A. (2013). Ethnicity, family socioeconomic inequalities, and prevalence of vaginal douching among college students: the implication for health. Journal of American College Health. 61(4):222-30. Article available at: http://www.tandfonline.com/doi/pdf/10.1080/07448481.2013.787620\#.VRAzO-EYPLM

This study assessed the association between ethnicity and family socioeconomic status (SES) as it relates to the prevalence of vaginal douching among female undergraduates in a university community. This was a cross-sectional survey conducted between September 2011 and February 2012 among 1,535 female undergraduates using a semi-structured behavioural questionnaire adapted by the authors from previous research related to vaginal douching practice. The overall prevalence of vaginal douching was 79.35 percent and the practice was significantly associated with the mother's age, ethnicity, low SES (educational level, occupation, and monthly income), and area of residence. The father's age and SES were statistically nonsignificant. 
Obianwu, 0. (2012). Getting real with youth-friendly services in Africa: report of a satellite session at the 2012 International HIV/AIDS Conference. African Journal of Reproductive Health, 16(4):180-184. Article available at: http://www.popcouncil.org/uploads/pdfs/2012HIV YouthHIV-Vulnerability.pdf

The report gives insight into the Ford Foundation and Population Council co-sponsored satellite session at the XIX International AIDS Society Conference (AIDS 2012) in Washington D.C. The satellite session titled "Getting Real with Youth-Friendly Services in Africa", stimulated young people to engage with and react to a study that provides a comprehensive evidence based picture of the HIV related issues facing young people in the six study countries and the prevailing legal, policy, and programmatic responses, and in the light of the findings, discuss and share their perspectives, experiences and concerns about how responsive existing policies, programs and services are to the HIV prevention and impact mitigation needs of young Africans. The session consisted of a presentation of the research findings, panellists' reactions to the study findings, and a discussion with the audience about the issues that were raised. The session was moderated by Humphrey Nabimanya of Reach a Hand Uganda (RAHU) and the panellists included Babatunde Ahonsi (Population Council), Chris Castle (UNESCO-United Nations Educational, Scientific and Cultural Organization), Phindile Sithole-Spong (AIDS Consortium; Rebranding HIV), Kikelomo Taiwo (Youth Advocate Group, Education as a Vaccine) and Eka Esu Williams (Ford Foundation).

\section{Sangowawa, A., \& Owoaje, E. T. (2011). Economic problems of youth with HIV/AIDS in Ibadan, Nigeria. Annals of Ibadan Postgraduate Medicine, 9(2):105-110. Article available at: http://www.ncbi.nlm.nih.gov/pmc/articles/PMC4111030/pdf/AIPM-9-105.pdf}

This paper describes the economic problems of youth with HIV in Ibadan, South-western Nigeria. A crosssectional survey of people living with HIV/AIDS (PLWHA) attending two HIV/AIDS support groups in Ibadan and the University College Hospital (UCH) antiretroviral (ARV) clinic was carried out. Information was obtained on socio-demographic characteristics and economic problems. One hundred and seventy youth aged 18-35 years were interviewed; 140 (82.4 percent) were female. One hundred and eight (63.5 percent) respondents were currently employed, 57 (52.8 percent) of whom were traders. Reasons for unemployment were that respondent's business capital had been used up to pay for healthcare (38.3 percent) and ill health (23.4 percent); while 38.3 percent were currently schooling. Common economic problems experienced by the respondents were significant increase in healthcare expenses (38.8 percent) and loss of employment (22.0 percent). Coping strategies employed to mitigate these problems included depletion of savings (61.1 percent), borrowing (18.8 percent), and sale of property (9.4 percent). Loss of employment was significantly higher among respondents who were symptomatic prior to diagnosis and among those who had a health complaint at the time of the study. Female respondents were also more likely to have lost their jobs compared to male.

\section{Lawan, U. M., Yusuf, N. W., \& Musa, A. B (2010). Menstruation and menstrual hygiene amongst adolescent school girls in Kano, Northwestern Nigeria. African Journal of Reproductive Health, 14(3):201-207. Article available at: http://reference.sabinet.co.za/sa_epublication_article/ajrh_v14_n3_a9}

This study examined the knowledge and practices of adolescent school girls in Kano, North-Western Nigeria around menstruation and menstrual hygiene. A cross-sectional design was used to study a sample of 400 adolescent female secondary school students aged 10-19 years; the mean age of the students was $14.4 \pm$ 1.2 years. The students attained menarche at $12.9 \pm 0.8$ years. Majority had fair knowledge of menstruation, although they were deficient in specific knowledge areas. Most of them used sanitary pads as absorbent during their last menses; changed menstrual dressings about 1-5 times per day; and three-quarter increased the frequency of bathing. 
Ogunfowokan, A.A., \& Babatunde O.A. (2010). Management of primary dysmenorrhea by school adolescents in ILE-IFE, Nigeria. Journal of School Nursing, 26(2):131-6. Article available at: http://isn.sagepub.com/content/26/2/131.full.pdf+html

A cross-sectional, descriptive study was conducted among adolescents with dysmenorrhea $(N=150)$ in lleIfe, Southwest Nigeria. The aims of the study were to determine their knowledge of menstruation and primary dysmenorrhea, assess the severity of pain they experienced during an episode of primary dysmenorrhea, and determine the management strategies they adopted. A pre-tested, semi-structured questionnaire was used to collect data. Findings revealed that the adolescents had a knowledge deficit regarding menstruation and dysmenorrhea, 58 percent of respondents reported pain between face 4 and face 10 on the Faces Pain Scale, and the majority used inappropriate methods to manage primary dysmenorrhea.

\section{Adinma, E.D., \& Adinma, J.I. (2009). Menstrual characteristics amongst south-eastern Nigerian adolescent school girls. West African Journal of Medicine, 28(2):110-3. Article available at: http://europepmc.org/abstract/med/19761174}

Researchers examined the characteristics of menstruation amongst adolescent lgbo school girls with respect to the biosocial characteristics, the pattern of menstruation, associated complications, and the source of information on menstruation. They conducted a descriptive cross-sectional study of 550 students recruited from a multi-sampling of 50 secondary schools in Onitsha, Anambra State, Nigeria, using pre-tested, semistructured, and interviewer-administered questionnaires. Four hundred and sixteen (75.6 percent) respondents were aged 15-17 years; 338 (61.4 percent) of whom were Catholics. Menarcheal age range of respondents was 11-16 years, with a mean age of $13.40+/-1.15$ years. Menstruation was regular in 410 (74.5 percent), and irregular in 124 (22.5 percent) of respondents. Duration of menstrual flow ranged between 2 and 8 days, although a 4-day flow occurred most commonly, 268 (53.6 percent). Abdominal pain, (66.2 percent) and waist pain, (38.5 percent) constituted the major problems associated with menstruation, followed by depression (24.4 percent), vomiting ( 6.9 percent), school absenteeism (4.5 percent), anorexia (1.8 percent), weakness (1.5 percent), and increased appetite (1.1 percent). The most common source of information on menstruation (prior to menarche) amongst respondents was from the mother (48.4 percent), followed by elder sister (14.2 percent) and friends ( 8.7 percent), while the teacher constituted the least source (1.1 percent).

Fawole, A. O., Babarinsa, I. A., Fawole, O. I., Obisesan, K. A., \& Ojengbede, O. A. (2009). Menstrual characteristics of secondary school girls in Ibadan, Nigeria. West African Journal of Medicine, 28(2):92-96. Article available at:

http://www.ncbi.nlm.nih.gov/pubmed/19761170

The aim of the study was to assess the menstrual patterns of school girls in Ibadan, Oyo State, Southwestern Nigeria. The study method used was cross-sectional descriptive study in which 1,213 apparently healthy girls aged 9-23 were selected by multi-stage sampling technique in 15 secondary schools in 5 local governments within the metropolis. Information about details of menstruation was obtained with a selfadministered questionnaire. Majority of the respondents 768 (63.3 percent) experienced normal cycle length, 391 (32.2 percent) had short cycles, and 55 (5.4 percent) had a cycle length greater than 35 days. Prevalence of normal cycle increased with increasing age; abnormalities of cycle length tended to decrease with increasing age $(p<p<0.01)$. The majority, 1,152 (95 percent) had a normal menstrual cycle. Almost three-quarters (882, 72.7 percent) experienced dysmenorrhea; severe dysmenorrhea was reported by 154 (12.7 percent). Cycle length was not associated with presence of dysmenorrhea ( $p>0.05$ ); 695 (57.3 percent) had symptoms of pre-menstrual syndrome. 
Omorodion, F. I. (2009). Vulnerability of Nigerian secondary school to human sex trafficking in Nigeria. African Journal of Reproductive Health, 13(2):33-48. Article available at: http://www.bioline.org.br/pdf?rh09019

This paper is based on a cross-sectional survey conducted in two urban and two rural schools located in Delta and Edo states of South-South, Nigeria. The aim was to assess in-school students' (aged 15-25 years) knowledge and awareness of, and attitude towards sex trafficking as a way to understanding their personal vulnerability to trafficking. A semi-structured questionnaire was administered in 2004-2005 to a classroom random sample of 689 adolescents in the age range of 16-20 years. The results show that in-school adolescents are vulnerable to sex trafficking due to poverty (77.2 percent), unemployment (68.4 percent), illiteracy (56.1 percent), and low social status (44.5 percent). Students in co-ed schools showed higher knowledge and awareness of the serious health consequences of trafficking.

Titilayo, A., Agunbiade, O. M., Banjo, O., \&Lawani, A. (2009). Menstrual discomfort and its influence on daily academic activities and psychosocial relationship among undergraduate female students in Nigeria._Tanzania Journal of Health Research, 11(4):181-188. Article available at: http://www.bioline.org.br/request?th09032

This study combined quantitative and qualitative approaches in investigating the prevalence of dysmenorrhoea and menorrhagia and their psychosocial effects by focusing on the daily activities of female undergraduates at the Obafemi Awolowo University, Ile-Ife, Southwestern, Nigeria. A multi-stage sampling technique was employed to select 415 female undergraduates at the University. A snowball sampling technique was used in selecting 37 informants for the in-depth interviews. The age range of all the in-depth interview informants was 18-31 years. Majority (63.5 percent) of the respondents that satisfactorily completed the questionnaires were in their early twenties (20-24 years). Less than 9 percent were teenagers. Results showed a high prevalence of dysmenorrhoea (64 percent) among respondents within 3 months prior to this study. Dysmenorrhoea was significant among female students who reported dizziness, headache, depression and irritation; and those whose menstrual disorder ever called for medical attention ( $p$ $<0.05$ ). Similarly, menorrhagia was less frequent (21 percent) than dysmenorrhoea (64 percent), but occurred more significantly with dizziness, headaches, and depression, and those whose menstrual disorderliness ever called for medical attention or even surgical intervention $(p<0.05)$. Both dysmenorrhoea and menorrhagia were significant predictors of psychosocial relationship of the female students $(p<0.05)$. Those with dysmenorrhoea reported one and a half times of depression than those without. However, menorrhagia appeared as the principal factor affecting their daily school activities and relationship with colleagues.

Adinma, E. D., \& Adinma, J. I. (2008). Perceptions and practices on menstruation amongst Nigerian secondary school girls. African Journal of Reproductive Health, 12(1):74-83. Article available at: http://www.bioline.org.br/pdf?rh08011

This cross-sectional descriptive study was undertaken amongst 550 adolescent secondary school girls in Onitsha, southeastern Nigeria to determine their perceptions on, medical problems associated with and key practices during, menstruation with a view to identifying information and practice gaps, and misconceptions on menstruation requiring address. Majority of the students, (75.6 percent), were aged $15-17$ years. Only 39.3 percent perceived menstruation to be physiological. Abdominal pain/discomfort, (66.2 percent), was the commonest medical problem encountered by the respondents, although 45.8 percent had multiple problems. Medical problems were most commonly discussed with the mother, ( 47.1 percent), and least commonly discussed with the teachers ( 0.4 percent). Analgesics, ( 75.6 percent), were most commonly used to relieve menstrual pain. Only 10 percent of respondents used non-pharmacologic remedies. Unsanitary menstrual absorbents were used by 55.7 percent of the respondents. 
Umeora, 0., \& Egwuatu, V. (2008). Age at menarche and the menstrual pattern of Igbo women of southeast Nigeria. African Journal of Reproductive Health, 12(1):90-95. Article available at: http://www.ajol.info/index.php/ajrh/article/view/7958/30516

A retrospective cross-sectional survey of Igbo women living in 12 randomly selected rural communities within Ebonyi State, South eastern Nigeria, was carried out over a ten-week period, 2 March to 11 May 2005 . This study determined the age at menarche and menstrual pattern of an Igbo population in the randomly selected communities. Information on recalled ages at menarche, menstrual flow duration, and cycle length was collected using a semi-structured questionnaire over three months. Study investigators interviewed 1,209 women of reproductive age. The mean age at menarche was 15.0 years and this declined over the years. The mean menstrual flow duration and cycle lengths were 3.3 days and 29.7 days, respectively. Only 10.2 percent had a menstrual cycle length of 28 days.

\section{Ogunlayi, M. A. (2005). An assessment of the awareness of sexual and reproductive rights among adolescents in south western Nigeria. African Journal of Reproductive Health, 9(1):99-112. Article available at: \\ http://www.jstor.org/stable/3583164?seq=1\#page_scan_tab_contents}

This assessment, conducted in Ikeja and Ikorodu Local Government Areas of Lagos State, examined the awareness of sexual and reproductive rights among adolescents in south-western Nigeria. A total of 600 inschool and out-of-school adolescents were interviewed using quantitative and qualitative methods. The study population included both male and female in-school adolescents aged 10-19 years and out-of-school adolescents aged 15-19 years. The study revealed that majority of the adolescents were aware of sexual and reproductive health rights (60.3 percent in Ikeja LGA and 62.3 percent in Ikorodu LGA), but lacked knowledge of contents of the rights. Majority of them in various categories (by school condition and type of settlement) were not aware of sexual and reproductive health programmes being implemented for adolescents. In addition, those who were aware of such intervention programmes could not access or use the services due to certain sociocultural barriers.

Anukam, K. C., Osazuwa, E. O., Reid, G., \& Katsivo, M. N. (2004). Receptivity for probiotic products among premenopausal female students in an African university. Sexually Transmitted Diseases, 31(8):460-464. Article available at: http://journals.Iww.com/stdjournal/Fulltext/2004/08000/Receptivity_for_Probiotic_Prod ucts Among.3.aspx\#

The objective of this study was to examine the receptivity for probiotic products among premenopausal female students at the University of Benin, Edo State, South-South, Nigeria. Closed-ended questionnaires were administered to a sample of 280 participants and these addressed age, marital status, perceived risk of HIV infection for the next three years, and history of urogenital infections. Approximately 14 percent were aged 16-20 years and 29 percent were 21-25 years. Of the 280 participants, 55.3 percent indicated that they believed they were at risk of acquiring HIV within the next 3 years. Over four-fifths ( 82 percent) of the subjects stated they would welcome probiotic products in capsular form for vaginal instillation or to be taken orally to improve vaginal health. Over one-third (36 percent) of women indicated they would be willing to use the probiotic products as part of their daily self-care. One hundred and nine (39.6 percent) respondents were willing to purchase the probiotic products at a reasonable price of 0.08 US dollars per dose, whereas 71.5 percent were willing to pay up to 0.38 US dollars. Some subjects ( 25 percent) raised some concern over safety of probiotics. 
Brabin, L., Roberts, C., Barr, F., Agbaje, S., Harper, G., \& Briggs, N. (2004). Sex hormone patterns and serum retinol concentrations in adolescent girls. Journal of Reproductive Medicine, 49(1):41-51. Article available at: http://europepmc.org/abstract/med/14976795

The objective of this study was to describe the pattern and relation of sex serum hormones and retinol concentrations over 1 menstrual cycle in adolescent girls living in a resource-poor setting. The hormonal study was undertaken in 1997 in K'Dere, a rural Ogini farming/fishing village in Gokana District, 60km from Port Harcourt, in Rivers State, South-South, Nigeria, and assessed adolescents over one menstrual cycle. Venous blood samples were collected on alternate days of the cycle, and oestrogen, progesterone, luteinizing hormone (LH), follicle stimulating hormone and serum retinol were measured. A linear random effects model was used to examine the relationship between sex hormones and serum retinol. Twenty-eight girls were studied. During the follicular phase, serum retinol was associated negatively with progesterone and positively with LH. In the luteal phase, serum retinol was positively associated with oestrogen. Serum retinol increased in the follicular phase but not the luteal phase. Sex hormone and serum retinol concentrations showed marked individual and day-to-day variability. Two girls maintained serum retinol concentrations $>0.7$ mumol/L throughout the cycle. Six remained at $<0.7$ mumol/L, which indicated subclinical deficiency. This study indicated that in adolescent girls, sex hormone patterns correlate significantly with serum retinol, and in vitamin A-deficient girls this could be important for reproductive function.

Oye-Adeniran, B. A., Adewole, I. F., Iwere, N., Mahmoud, P. (2004). Promoting sexual and reproductive health and rights in Nigeria through change in medical school curriculum. African Journal of Reproductive Health, 8(1):85-91. Article available at: http://www.jstor.org/stable/3583311

This article describes the processes leading to the adoption of the Nigerian medical schools' sexual and reproductive health and rights curriculum. The exercise culminated in the identification of internal and external stakeholders and needs of the Nigerian medical schools in teaching reproductive health. The participation of lecturers (bottom-up approach) brought about a sense of ownership of the document and promoted the broad consultation and participation of all participants. It also identified capacity building and the need for evaluation as a basis for further review. 


\section{Appendix I: List of Contributors}

Adline Chiamaka Uzomba

Akinola Olusegun Alalade

Babatunde Ahonsi

Otibho Obianwu

Segun Sangowawa

Sherry Hutchinson

Sylvia Adebajo 
Population Council No. 16 Mafemi Crescent Abuja, Nigeria

Ideas. Evidence. Impact. 